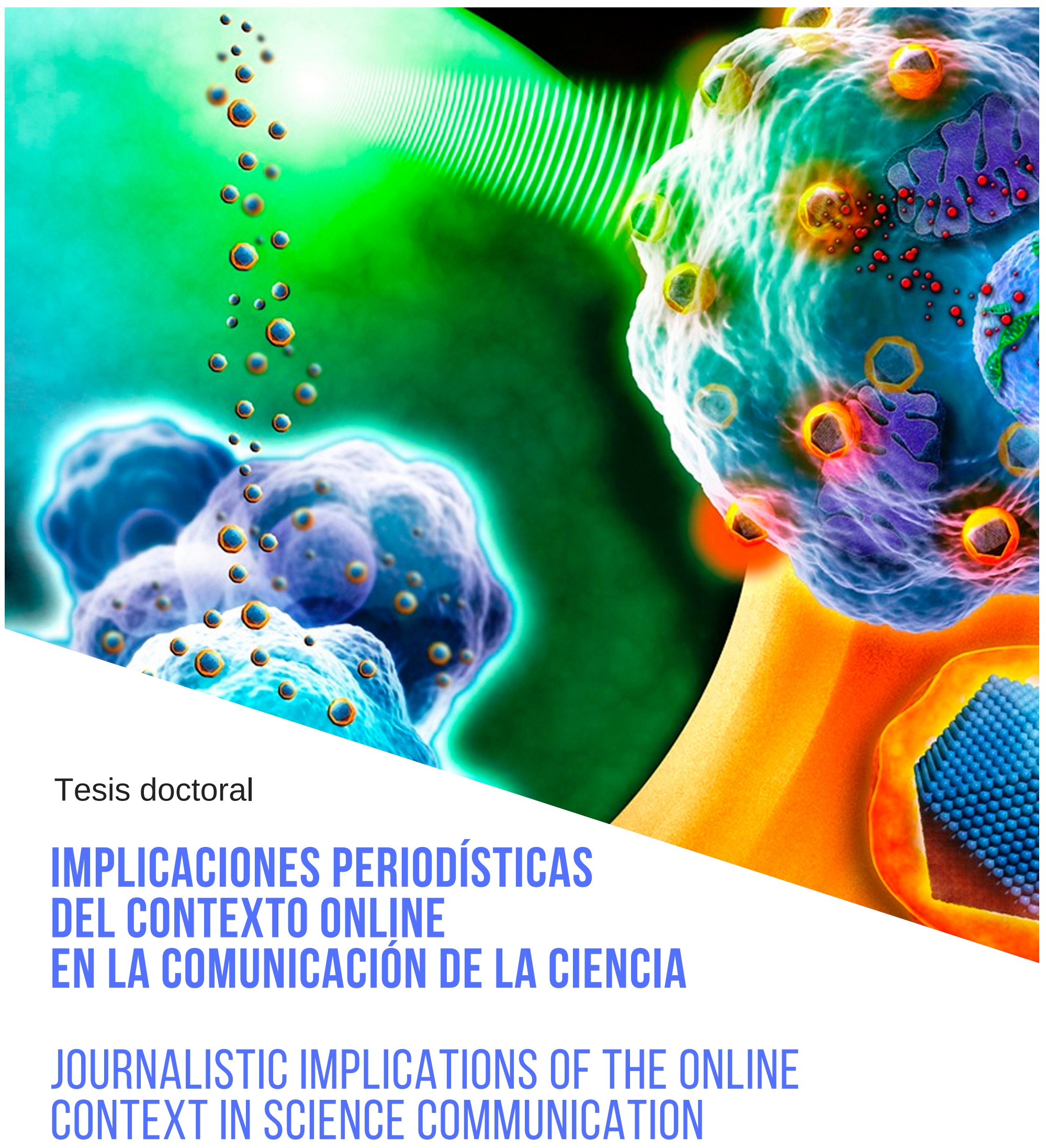

Presentada por Cristina González Pedraz

Dirigida por la Dra. Eva Campos Domínguez

UNIVERSIDAD DE VALLADOLID, 2018 
Universidad deValladolid

PROGRAMA DE DOCTORADO EN ESPAÑOL:

LINGÜÍSTICA, LITERATURA Y COMUNICACIÓN.

ELLCom.

TESIS DOCTORAL:

\section{IMPLICACIONES PERIODÍSTICAS DEL CONTEXTO ONLINE EN LA COMUNICACIÓN DE LA CIENCIA}

Presentada por Cristina González Pedraz para

optar al grado de

Doctora por la Universidad de Valladolid

Dirigida por:

Dra. Eva Campos Domínguez 
A Laura y José Miguel 


\section{Agradecimientos}

A lo largo de este amplio, complejo y apasionante camino que emprendí hace 6 años me han acompañado grandes profesionales, compañeros, familiares y amigos, con los que he compartido conocimientos y experiencias, y también sufrimientos y desahogos. Sin su apoyo, en todos estos aspectos, no hubiera sido posible llegar hasta la meta final.

Gracias a Eva Campos Domínguez, mi directora, mi amiga. Sin sus magníficos conocimientos, su experiencia impagable, sus sabios consejos, su buen hacer, su tenacidad, su compromiso y sobre todo su soporte en todos los sentidos, profesional y anímico, esta tesis doctoral no hubiera salido adelante. Y gracias también al Grupo de Reflexión y Estudio GRECO de la Universidad de Valladolid. A María, a Dafne y a Cristina. Un gran hallazgo en lo académico y en lo personal.

Gracias a todo el equipo de la Fundación $3 \mathrm{CIN}$, mi segunda familia. Trabajar con ellos no es una obligación, es un placer. Gracias a Ana Victoria, quien me animó a emprender este camino. Es un honor para mí tenerla a mi lado. Muchas gracias también a Pablo, a Teresa y a Jose, por su soporte técnico.

Gracias a la Fundación Española para la Ciencia y la Tecnología (FECYT) del Ministerio de Economía, Industria, y Competitividad del Gobierno de España por financiar el Estudio de Caso dentro del proyecto FCT-15-10271 de la Convocatoria pública de ayudas para el fomento de la cultura científica, tecnológica y de la innovación de 2015.

Y por último gracias a toda mi familia. En especial a Laura, que vino al mundo durante este camino y se ha convertido en el centro de nuestras vidas. Hija mía, siento si, en algún momento de esta travesía, no te presté toda la atención que necesitabas. Gracias a José Miguel, mi amor, mi compañero de fatigas, quien ha intentado comprenderme y ayudarme en todo momento. $Y$ gracias también a mi padre y a mi madre, que estaría muy orgullosa. Siempre confiaron en mí. Gracias a mis hermanas, María y Beatriz, mis almas gemelas, mi soporte. $Y$ gracias a mis cuñados, mis sobrinos, mis suegros y mis amigas -María, Arancha-. Todos ellos han puesto su granito de arena para ayudarme en lo posible.

A todos ellos, GRACIAS. 


\section{Resumen}

En la historia reciente, ningún otro avance tecnológico ha supuesto un cambio tan importante para la comunicación de la ciencia como Internet. Esta tecnología se encuentra ya consolidada y parece haber alcanzado una madurez suficiente como para estudiar, con cierta perspectiva, las implicaciones que ha supuesto para la comunicación de la ciencia, en general, y para el periodismo científico, en particular.

Esta tesis doctoral se propone, como objetivos específicos, profundizar en la situación del periodista científico en un entorno online abierto y complejo, determinar si otros actores están desplazando a este profesional en su papel de mediador entre la ciencia y el público, conocer cómo afectan los cibermedios y sus particularidades a la práctica profesional, extraer qué problemas afrontan y, en último término, valorar si sigue siendo necesaria la figura del periodista científico en un entorno en el que el público puede acceder directamente a las fuentes y conformarse como emisor.

Con este hilo conductor se han desarrollado dos estudios diferenciados en cuanto a metodología, resultados y conclusiones, pero complementarios para obtener una visión profunda e integral del objeto de estudio.

Tras un primer bloque de carácter introductorio, que sitúa el objeto de investigación en perspectiva y justifica la relevancia y el interés del trabajo expuesto, se desarrolla, el segundo bloque, el primer estudio, un estado de la cuestión sobre comunicación de la ciencia en Internet que incluye una revisión sistemática cuantitativa y cualitativa. Se realiza un análisis bibliométrico y de contenido de 205 artículos en inglés, portugués y español, publicados entre el 01/01/1996 y el 31/12/2016. Posteriormente, se compendian y sintetizan los datos de esta colección de estudios y de otras referencias localizadas, en un estado de la cuestión sobre la comunicación de la ciencia en Internet que, hasta este momento, no había sido realizado.

De este primer estudio se concluye que una de las principales implicaciones del nuevo contexto online de la comunicación de la ciencia para el periodismo es la influencia creciente de la comunicación institucional y la dependencia informativa de estas fuentes en la prensa digital, lo que podría estar modulado por el tamaño y el alcance geográfico del cibermedio, según lo sugerido en un estudio previo enmarcado en el proyecto de investigación Impacto de las UCC+i en la visibilidad pública de la Ciencia española: prensa digital y Twitter (FCT-15-10271). ${ }^{1}$

\footnotetext{
${ }^{1}$ Proyecto titulado 'Impacto de las UCC+i en la visibilidad pública de la Ciencia española: prensa digital y Twitter', participado por la Fundación $3 \mathrm{CIN}$-donde desempeña su actividad profesional la autora de esta
} 
Para confirmar esta hipótesis, dentro de este mismo proyecto, se ha llevado a cabo un estudio de caso, presentado en el tercer bloque, en el que se han analizado las diferencias en la información relativa a las universidades españolas que publica la prensa digital nacional y la regional/local. Se ha aplicado una metodología mixta, un análisis de contenido cuantitativo y una observación cualitativa, sobre una muestra de 3.137 piezas periodísticas publicadas entre 01/01/2016 y el 01/09/2016 en dos periódicos digitales de alcance nacional y 13 regionales y locales, acerca de 23 universidades públicas españolas. Los resultados apuntan a esa dependencia informativa y a una menor calidad de los contenidos científicos en los cibermedios locales y regionales, más modestos; mientras que los cibermedios nacionales, con mayores recursos, están eludiendo ese "control" institucional y realizando un periodismo científico independiente.

Cuando un cibermedio tiene una estructura y unos recursos personales y materiales suficientes, los periodistas científicos siguen llevando a cabo las tradicionales funciones de selección de información, búsqueda de diversos puntos de vista, vigilancia y contraste de las fuentes. Estos roles son primordiales en el contexto online de la comunicación de la ciencia reportado en este trabajo, en el que los ciudadanos tienen acceso a más información científica que nunca antes en la historia, pero en el que la multiplicidad de emisores interesados y la posibilidad de comunicarse directamente con el público podrían estar obstaculizando enormemente el acceso a información científica veraz, contrastada y de calidad.

tesis-, la Universidad de Valladolid y la Universidad de Salamanca. El proyecto ha sido financiado por el Ministerio de Economía, Industria y Competitividad del Gobierno de España a través de la FECYT (referencia del proyecto FCT-15-10271). Dicha entidad financiadora no ha participado, de ningún modo, en el diseño del estudio, la recopilación y el análisis de los datos y la redacción del presente documento. 


\section{ÍNDICE}

\section{BLOQUE I. INTRODUCCIÓN}

1. Introducción general

1.1. Un breve recorrido por la historia de la comunicación de la ciencia............... 14

1.2. La irrupción de Internet en la comunicación de la ciencia.............................. 19

1.3. Internet para informarse sobre ciencia y tecnología ................................... 22

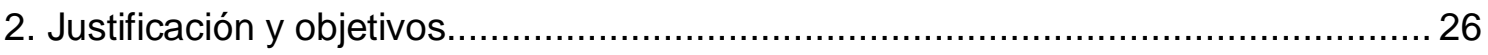

\section{BLOQUE II. ESTADO DE LA CUESTIÓN}

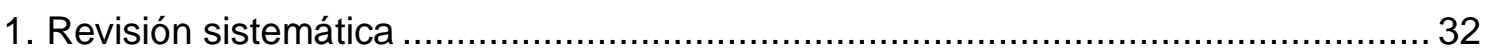

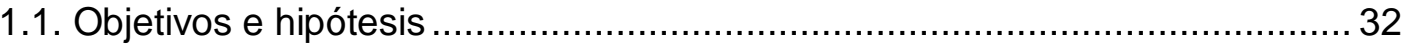

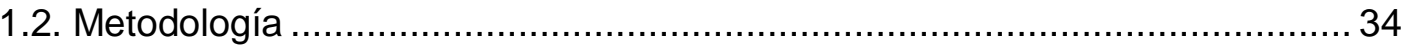

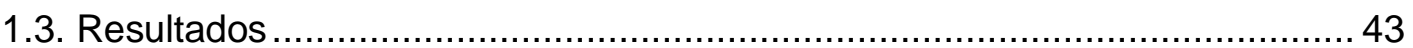

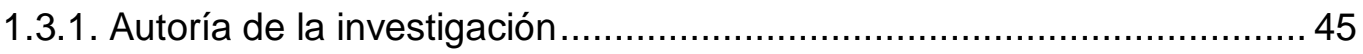

1.3.2. Estructura y contenido de la investigación .........................................56

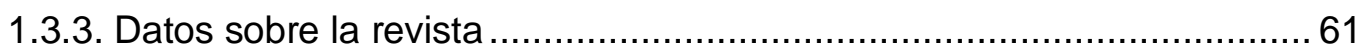

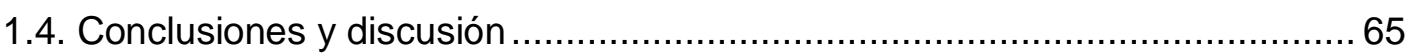

2. Internet como canal: un nuevo espacio para la comunicación de la ciencia .............70

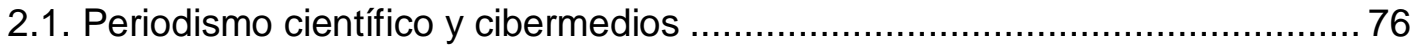

2.2. Blogs, redes sociales y comunicación científica ...................................... 78

2.2.1. El impacto de los blogs en la comunicación de la ciencia y el periodismo científico 79

2.2.2. La ciencia en las redes sociales ....................................................... 94

2.2.3. Emisión audiovisual online, dispositivos móviles y ciencia.....................98

3. El mensaje periodístico sobre ciencia en Internet ......................................... 101

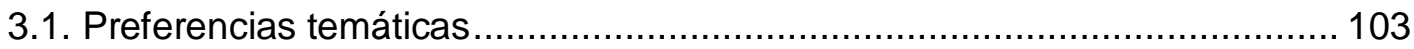

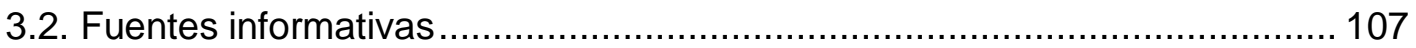

3.3. Las fuentes de información científica en los cibermedios ............................ 109

3.4. La autoría de la información científica publicada en los cibermedios............ 113

4. El acceso a la red de las audiencias interesadas en ciencia .................................117

4.1. El receptor de contenidos científicos en la web: datos y perfil ..................... 119 
4.2. Alfabetización científica y mediática 122

4.3. La búsqueda de información científica online: modos y tendencias 126

4.4. Interactividad y participación en contenidos científicos. 131

5. Los efectos de los cibermedios en la comunicación de la ciencia 136

5.1. Efectos de la fuente en la credibilidad de la información científica en Internet.. 138

5.2. Estudio de los efectos a partir de las teorías de la Agenda Setting y el Framing 140

6. La multiplicidad de emisores en el contexto online. 144

6.1. Los científicos como emisores en Internet. 146

6.1.1. Comunicación externa o informal en Internet. 148

6.1.2. Las relaciones entre científicos y periodistas científicos 152

6.2. Los periodistas científicos ciudadanos 154

6.3. Revistas, agencias y otros agentes. 157

6.4. Emisores emergentes: universidades y centros de investigación 163

6.4.1. Las estrategias de comunicación online..... 165

6.5. El emisor tradicional: el periodista científico 170

6.5.1. Roles cambiantes del periodista científico en el entorno digital. 186

6.5.2. La formación del periodista científico en competencias digitales 175

6.5.3. La dependencia informativa de fuentes organizadas 181

7. Discusión 180

\section{BLOQUE III. ESTUDIO DE CASO}

1. Presentación 190

2. Objetivos, preguntas de investigación e hipótesis ............................................ 192

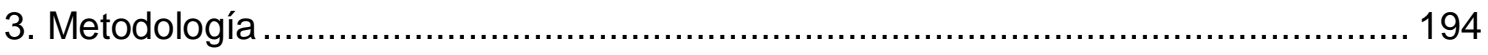

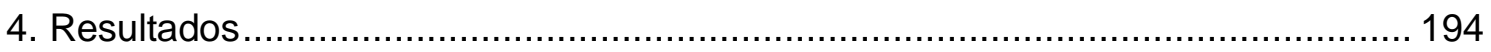

5.1. Análisis comparativo respecto al tratamiento periodístico ........................... 196

5.2. Análisis comparativo respecto al marco mediático ................................... 200

5.3. Análisis comparativo respecto a la cobertura temática ............................... 203

5.4. Análisis comparativo respecto tratamiento ciberperiodístico.........................204

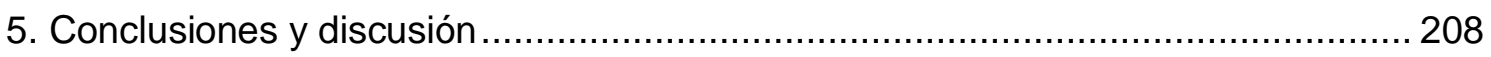




\section{BLOQUE IV. CONSIDERACIONES FINALES}

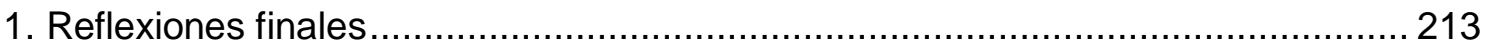

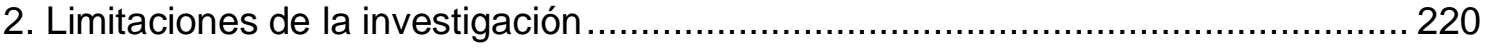

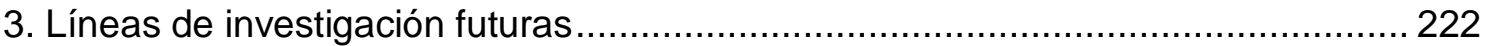

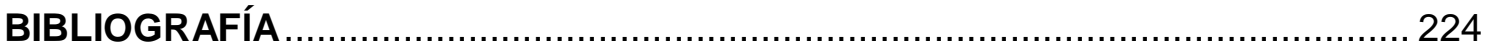

ANEXOS




\section{BLOQUE I}

INTRODUCCIÓN 


\section{INTRODUCCIÓN GENERAL}

La ciencia y la tecnología ocupan un lugar fundamental en la sociedad actual. Están presentes en todos los ámbitos de la vida cotidiana, hasta el punto de que es difícil comprender el mundo moderno y la mejora de la calidad de vida del ser humano sin entender el papel que cumplen (Sagan, 1989; Nieda y Macedo, 1998; Ziman, 2003). Por ello, ya no es posible reservar la cultura científica y tecnológica a una élite: tener nociones básicas es clave para adquirir las habilidades necesarias que permitan al ciudadano desenvolverse en el día a día (Nieda y Macedo, 1998). La salud, la alimentación, el medio ambiente, la energía, las telecomunicaciones o el transporte son solo algunos ejemplos de asuntos de naturaleza científica y tecnológica con los que convivimos.

Poner a disposición de los ciudadanos el conocimiento científico y tecnológico, así como dotarlos de las herramientas necesarias para el cuestionamiento, el reconocimiento de las limitaciones de la ciencia y el juicio crítico y razonado debe ser uno de los principales objetivos políticos, educativos y sociales (Lewenstein, 1992). En este contexto, la comunicación de la ciencia juega un papel decisivo. Para Nelkin (1995) no solo permite mejorar la capacidad de los ciudadanos para evaluar cuestiones de política científica, sino que ayuda a las personas a tomar mejores decisiones sobre sus propias vidas. Burns et al. (2003) definen la comunicación de la ciencia como el uso de las habilidades, medios, actividades y diálogo apropiados para producir una o más de las siguientes respuestas personales sobre la ciencia: conciencia, disfrute, interés, formación de opinión y comprensión.

En la literatura, la comunicación de la ciencia se utiliza como expresión genérica que engloba un conjunto de planteamientos y procesos comunicativos entre los cuales se encuentran la diseminación, la difusión, la divulgación o la popularización (Martín Sempere y Rey Rocha, 2007). Estos procesos comunicativos se diferencian unos de otros, fundamentalmente, en la naturaleza del emisor -ya sea el propio científico, periodistas, gabinetes de comunicación, divulgadores, educadores, etc.-, en el lenguaje utilizado en el mensaje -especializado o sencillo y comprensible- y en el tipo de público receptor -los propios científicos, público interesado en ciencia, público en general, etc.-.

Pese a los matices, parece existir consenso entre los expertos en algunos puntos. La comunidad científica coincide, en general, en señalar que la diseminación hace referencia al proceso de comunicación de la ciencia entre los propios científicos, es 
decir, entre pares, a través de un lenguaje especializado; en que en la difusión los científicos tratan de transmitir información especializada a audiencias instruidas, aunque no por qué expertas en la materia; en que el proceso de divulgación de la ciencia participan otros emisores, además de los científicos, periodistas, educadores o divulgadores, intermediarios encargados de trasladar, en un lenguaje sencillo y comprensible para todos, la ciencia a un público general; y la popularización, muy cercana a la divulgación, centrada en la transmisión de contenidos científicos básicos y dirigida a públicos sin conocimientos previos, como los jóvenes. La siguiente figura ilustra las diferencias entre estos cuatro conceptos.

Figura 1. Comunicación de la ciencia: diferencias entre diseminación, difusión, divulgación y popularización.

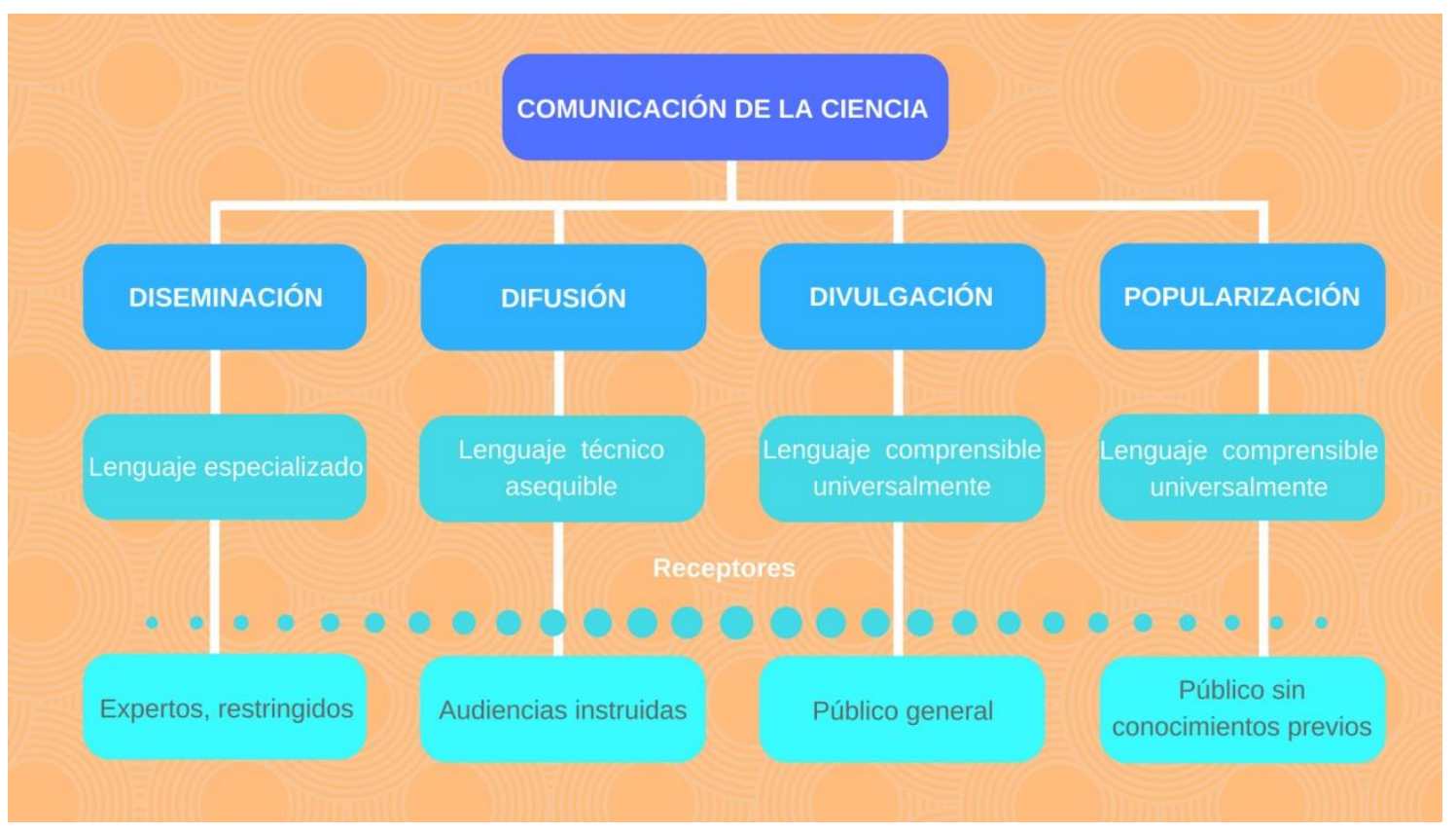

Fuente: Elaboración propia a partir de Martín Sempere y Rey Rocha (2007).

Diversas ramas integran, complementan y profundizan en las tareas de diseminación, difusión, divulgación y popularización de la ciencia. En la literatura disponible sobre la materia aparecen junto a ellos, indistintamente, otros conceptos y disciplinas cercanas como la alfabetización científica, la cultura científica, el periodismo científico o la comprensión pública de la ciencia. La definición de estos planteamientos y procesos es compleja y los límites entre unos y otros son, en ocasiones, difusos, hasta el punto que a menudo son empleados como sinónimos (Bolet, 2015). 
La comunidad científica ha discutido de forma recurrente en torno a estos temas tratando de definir y delimitar cada concepto y cada disciplina. Teóricos de distintos ámbitos como la filosofía, la sociología o la comunicación han aportado sus propias definiciones y teorías con connotaciones ajustadas a sus especialidades (Calvo Hernando, 1997; Elías, 2008; Ferrer y León, 2008; Quintanilla, 2010; Mazzaro, 2010; Martínez Mendoza, 2011; López-Pérez y Olvera-Lobo, 2015, entre otros).

En las últimas décadas, los académicos han recurrido a lemas como la alfabetización científica y tecnológica, la comprensión pública de la ciencia, la cultura científica y tecnológica o la educación CTS (Ciencia Tecnología y Sociedad) para llamar la atención sobre las urgencias detectadas en la enseñanza de las ciencias (Membiela Iglesia, 2002).

La alfabetización científica es un movimiento educativo que tiene su origen en los años 50 y que considera este tipo de enseñanza como elemento clave para el desarrollo de las personas y de los pueblos (Fourez, 1997; Gil-Pérez y Vilches, 2001). El movimiento CTS en la enseñanza de las ciencias da un paso más, buscando promover la alfabetización en ciencia y tecnología para que los ciudadanos puedan participar en el proceso democrático de toma de decisiones y promover la acción ciudadana en la resolución de problemas relacionados con la ciencia y la tecnología en la sociedad (Membiela Iglesia, 2002).

Para Gil-Pérez y Vilches (2004), la participación ciudadana en la toma de decisiones precisa, más que de un nivel elevado de conocimientos, un mínimo de conocimientos específicos, accesibles para todos, así como planteamientos globales y consideraciones éticas que permitan a los ciudadanos ser críticos. Es decir, precisa un nivel básico de cultura científica, tal y como la entiende Quintanilla (2010). Para este autor, la cultura científica es la parte de la cultura de un grupo social relacionada con la actividad científica. Pero a diferencia de otras acepciones, no solo se refiere a la ciencia que comparten todos o la mayoría de los miembros de una sociedad, sino también a las representaciones, prácticas y valores que los mismos tienen sobre la ciencia.

En el último medio siglo, los medios de comunicación y otras formas de aprendizaje informal han cumplido un papel fundamental en el sostenimiento de la cultura científica en adultos. La necesidad de la población adulta de instruirse sobre ciencia después de las etapas escolares es evidente (Miller, 2010), ya que asuntos como las células madre, la nanotecnología o el calentamiento global no estaban incluidos en los libros de texto hace tres décadas porque eran objetos de investigación nuevos, de forma que 
los adultos de 40 años o más no han podido aprender sobre ellos a través de la educación reglada. Para el mismo autor, el ritmo acelerado del desarrollo científico significa que la mayoría de personas ajenas a la comunidad científica aprenderá más sobre ciencia tras salir de la escuela formal que en ella. Y cuando la educación formal termina, los medios de comunicación se convierten en las herramientas más accesibles para adquirir información sobre los nuevos descubrimientos científicos, controversias, eventos o el trabajo investigador (Nisbet et al., 2002).

Es aquí donde reside la importancia del periodismo científico o periodismo de ciencia -según la terminología anglosajona-, como especialidad periodística que aborda los asuntos concernientes a la ciencia y la tecnología (Calvo Hernando, 1997). Y, más allá de informar sobre dichos asuntos, una de las principales diferencias entre el periodismo y la divulgación científica es que el periodismo debe contextualizar política, social y culturalmente los nuevos conocimientos y sus posibles repercusiones, así como contribuir al pensamiento crítico de los ciudadanos (Elías, 2008). A esa labor de "intérprete" de los progresos en la ciencia y la tecnología, Calvo Hernando (1997) agrega una tercera función, la de control público, para favorecer que se tomen decisiones de política científica acordes a las necesidades e intereses de los ciudadanos, a la mejora de su calidad de vida y a su enriquecimiento cultural.

\subsection{UN BREVE RECORRIDO POR LA HISTORIA DE LA COMUNICACIÓN DE LA CIENCIA}

La comunicación de la ciencia ha ido, históricamente, de la mano de los avances y descubrimientos científicos y tecnológicos. Ha vivido periodos dorados, como el de la antigua Grecia, donde la transmisión del conocimiento tenía lugar y era debatido en las plazas públicas y en el que la democratización del conocimiento condujo a importantes avances en la filosofía y la ciencia; y etapas más oscuras, como la Alta Edad Media, en la que el conocimiento fue alejado de unas masas analfabetas, y transferido solo por escrito a unos pocos privilegiados (Illingworth, 2015). La invención de la imprenta de Johannes Gutenberg en 1456 supuso un punto de inflexión, ya que propició que la palabra impresa y, por ende, el conocimiento, fuese mucho más accesible y fácil de difundir (Eisestein, 1980; Burke y Briggs, 2002).

Sin embargo, el saber científico siguió fundamentalmente restringido a los eruditos. A principios del siglo XVII surgen las primeras sociedades científicas en Inglaterra y en Francia y, primero por correspondencia y después a través de las primeras revistas científicas -Journal des Sçavans y Philosophical Transactions of the Royal Society-, los 
intelectuales empezaron a comunicar formalmente sus trabajos a otros pares. En las décadas posteriores se crearon nuevas publicaciones en diversas ramas de conocimiento y en otros países, extendiéndose esta forma de comunicación y erigiendo el sistema de revisión por pares que pervive en la actualidad (Mendoza y Paravic, 2006).

El siglo XVIII podría considerarse otro periodo de auge en la comunicación pública de la ciencia, tal y como sugieren los innumerables libros de popularización escritos para satisfacer el creciente interés público, especialmente de las mujeres -como los libros Algarotti's Newtonianism for Ladies o Lalande's L'Astronomie des Dames-, la cantidad de artículos recogidos en la prensa sobre descubrimientos científicos, o la organización de las primeras ferias y exposiciones públicas para mostrar los avances más significativos de la ciencia y la tecnología (Bucchi, 2008).

Ya en el siglo XIX, las sociedades científicas empezaron también a tomar conciencia de la importancia de transmitir su trabajo a la sociedad. En 1831 se celebra en York (Inglaterra) la primera reunión de la British Science Association (BSA), que declara entre sus objetivos fundacionales "obtener un mayor grado de atención nacional hacia los objetos de la ciencia" (Illingworth, 2015:sp). No obstante, las prácticas, los modos y los canales de comunicación formal de la ciencia no variaron sustancialmente hasta el siglo XX, vehiculadas fundamentalmente por las revistas científicas y el sistema de revisión por pares restringido a la propia comunidad académica.

Volviendo a la comunicación pública de la ciencia, se puede estipular que ha vivido tres fases en los tiempos recientes (Trench, 2006). Son los avances en física alcanzados en las primeras décadas del siglo XX los que instauran de nuevo la idea de que la ciencia es "demasiado complicada" para que el público en general pueda entenderla (Bucchi, 2008). Esta premisa se refuerza con las primeras encuestas para medir el interés, los conocimientos y las actitudes del público hacia la ciencia. La pionera, llevada a cabo por R. Davis en 1957, recogía una serie de variables que siguen constituyendo el núcleo fundamental de las actuales encuestas (Cortassa, 2010). Y, al igual que las siguientes, como las conducidas por el National Science Board de Estados Unidos desde los años 70, los resultados fueron poco alentadores. Preguntas sobre la definición del concepto de "molécula" -contestada correctamente solo por 1 de cada 10 encuestados- o en torno a la convivencia entre humanos y dinosaurios -más de la mitad apuntaba a una coexistencia- advirtieron de una falta grave de conocimientos entre la población, una brecha cultural que requería acciones externas de alfabetización científica (Lewenstein, 2003). Este enfoque, conocido como 
Modelo del Déficit, presume que existe un déficit cognitivo en el público que debe ser paliado con iniciativas de comunicación -como documentales, revistas divulgativas, artículos de prensa, etc. -, lo que permitiría evitar, por ejemplo, la oposición social y/o una opinión pública negativa en momentos de controversia científica y tecnológica o en la formulación de determinadas políticas (Bubela et al., 2009).

Esta concepción deriva en otros planteamientos que detalla Bucchi (2008): la necesidad de una mediación entre científicos y público en general, la irrupción de nuevos perfiles profesionales e instituciones encargadas de cubrir esa necesidad periodistas científicos, divulgadores, museos de ciencia, etc. -, y el uso de la metáfora como herramienta lingüística para "traducir" la complejidad y ejercer de forma efectiva esa mediación.

Sin embargo, el Modelo del Déficit obvia que, más allá de una falta de conocimiento, las personas pueden estar influenciadas por otros factores que modulan su percepción y sus actitudes hacia la ciencia. Asimismo, pasa por alto que las acciones de comunicación dirigidas a reducir la brecha cognitiva llegan a una audiencia pequeña y compuesta por lo general por entusiastas de la ciencia, bien informados (Bubela et al., 2009). Es decir, se estaría únicamente "predicando a los ya convertidos", lo que no solucionaría el problema.

Con la llegada del nuevo siglo y, pese a los esfuerzos en comunicación, se observa una preocupación pública en aumento sobre ciertos temas relacionados con la ciencia y la tecnología, como el cambio climático o las células madre. También se percibe una creciente demanda ciudadana de participación en estos temas y a una proliferación de no expertos tratando de influir en la agenda de la investigación en campos como la biomedicina, lo que lleva a reconsiderar el significado de la comunicación pública de la ciencia (Bucchi, 2008). En el 2000, un informe de la Cámara de los Lores del Reino Unido pone de manifiesto los límites de una comunicación de la ciencia basada en una relación paternalista y unidireccional -de arriba abajo- entre científicos y público, y reconoce un "nuevo ánimo para el diálogo".

Es el origen de un nuevo modelo de comunicación de la ciencia interactivo -el Modelo de Diálogo- que concibe la comunicación como un flujo bidireccional entre científicos y público (Alcíbar, 2015). Al igual que el Modelo del Déficit, este nuevo enfoque propone una serie de acciones de comunicación para hacer efectivo ese flujo bidireccional entre ciencia y sociedad. Conferencias de consenso o cafés científicos emergen como nuevos espacios dialógicos. La prioridad de educar a un público científicamente analfabeto es sustituida por la legitimidad del público a participar en la 
discusión, con el supuesto de que los legos tienen conocimientos y competencias que mejoran y completan las de los académicos (Bucchi, 2008). Además, los científicos se comprometen a dar a conocer el impacto de sus trabajos a la sociedad para que esta muestre un respaldo activo hacia la ciencia y no un consentimiento pasivo como hasta la fecha (López-Pérez y Olvera-Lobo, 2015). Esta nueva prioridad se ve reflejada en la terminología recogida en los programas de financiación y en las políticas de muchos países, fundamentalmente de los Estados Unidos y Europa: se empieza a hablar de "diálogo" en lugar de "comunicación", y de "ciencia en sociedad" frente a "ciencia y sociedad" (Bucchi, 2008).

Sin embargo, tanto el Modelo del Déficit - de forma más tajante-, como el Modelo de Diálogo -de manera más sutil-, niegan a los legos cualquier capacidad para participar en la producción del conocimiento, que para estos enfoques sigue siendo competencia únicamente de los expertos. Las voces críticas exigen una mayor participación de los ciudadanos en los asuntos científicos y tecnológicos, en base a que estas materias les afectan directamente en su día a día y que parte de sus impuestos son dirigidos a financiar una investigación que no eligen. Emerge así una nueva visión de la comunicación de la ciencia, el Modelo de Participación.

Este enfoque respeta la participación de los ciudadanos en el sistema científico como agentes autorizados, asumiendo como legítimas sus aportaciones (PérezRodríguez, 2016). Surgen de esta perspectiva participativa iniciativas como las agendas ciudadanas -consultas públicas en las que los ciudadanos eligen, de entre varios problemas y retos que pueden afrontarse con la ciencia y la tecnología, aquellos que más les convengan, información que se utiliza en la construcción de agendas de investigación e innovación que guían las políticas científicas gubernamentales- o la ciencia ciudadana -aquella que involucra al público general en actividades científicas y fomenta la contribución activa de los ciudadanos a la investigación a través de su esfuerzo intelectual, su conocimiento general, o sus herramientas y recursos-. ${ }^{2}$

Mientras que los Modelos del Déficit y de Diálogo se caracterizan por una comunicación lineal -unidireccional y bidireccional, respectivamente-, el Modelo de Participación es multidireccional porque considera e integra la comunicación entre expertos y públicos, y entre los distintos públicos -no solo ciudadanos, también otros agentes interesados, como asociaciones de pacientes, entidades ambientalistas, empresas, instituciones públicas, etc.- (Trench, 2006).

\footnotetext{
${ }^{2}$ Concepto recogido en el Libro verde de la ciencia ciudadana elaborado por el CSIC en el marco del proyecto europeo Socientize: http://ow.ly/iodm30jZxjK (última consulta 07/03/2018)
} 
Los medios de comunicación, como canal, y los periodistas científicos, como mediadores entre la ciencia y el público, tienen un papel protagonista dentro de estos modelos que, si bien se han sucedido en la historia reciente de la comunicación de la ciencia, en la actualidad coexisten y son reconocibles en las diversas formas que puede adoptar dicha comunicación.

En el marco del Modelo del Déficit, el conocimiento científico obtenido de la fuente experta es "traducido" por los mediadores periodistas en un texto asequible para el público lego. Es decir, en este modelo el periodismo científico se concibe como una forma de alfabetización científica. La II Guerra Mundial supuso un punto de inflexión en este sentido. Desde la televisión en color a los antibióticos, los ordenadores o la carrera espacial, los avances científicos y tecnológicos empezaron a hacerse hueco en las páginas de los periódicos, sobre todo en los estadounidenses, con el periodista especializado en ciencia como profesional en auge (Franklin, 1998). En los años 70, las páginas de ciencia de los periódicos se habían convertido en un güeto de noticias que el lector podía saltarse fácilmente. Además, una cierta hostilidad hacia la ciencia era bien vista, según el mismo autor, por los editores de la época, con activistas ecologistas, antinucleares o anti experimentación con animales pisando los talones de los reporteros. También el propio periodismo fue cambiando, y las dificultades para encontrar tiempo y espacio para publicar sobre temas de ciencia y tecnología se fueron haciendo mayores.

Por ello, para los modelos dialógico y participativo, el periodismo científico debe dar un paso más allá de la mediación y comprometerse activamente en los procesos de consulta ciudadana y de toma de decisiones en la agenda de la investigación. Es decir, el periodismo científico es concebido en estos modelos como una herramienta para fomentar el diálogo y la participación. Para los defensores de las iniciativas de participación pública en la ciencia, las consultas ciudadanas deben realizarse cuando el proceso científico y/o tecnológico se encuentra en su etapa inicial, de manera que los ciudadanos puedan tomar decisiones determinantes en materia de propiedad, regulación, usos, beneficios y riesgos de dichos productos de la ciencia y la tecnología (Bubela et al., 2009). En ese momento, apuntan los mismos autores, los medios deben cumplir un papel sustancial para generar conciencia y compromiso público: informar sobre las líneas y los procesos de la investigación, poner sobre la mesa de debate las distintas perspectivas de la ciencia, sopesando riesgos y beneficios, y detallar las posibles vías de participación. Todo ello teniendo en cuenta que: "son pocas las decisiones que toman los políticos y las partes interesadas sin tener a los medios de comunicación en mente" (Bubela et al., 2009:515-516). 


\subsection{LA IRRUPCIÓN DE INTERNET EN LA COMUNICACIÓN DE LA CIENCIA}

Como se ha esbozado en el apartado precedente, a lo largo de la historia, la ciencia ha tratado de aproximarse al ciudadano de a pie y ha encontrado en los avances tecnológicos un canal aliado para llegar a ellos. Según apuntan Meso-Ayerdi y DíazNoci (2002), la comunicación, la información y el periodismo han sido siempre un "campo abonado" para las nuevas tecnologías. Desde la imprenta al telégrafo, pasando por la radio y la televisión, la tecnología ha contribuido enormemente a mejorar la transmisión de información sobre ciencia y sobre muchos otros temas a los ciudadanos.

De entre todas las tecnologías de la comunicación que se han desarrollado y generalizado en las últimas décadas Internet es, sin duda, la más importante. Multitud de autores destacan la trascendencia que ha tenido la red en la comunicación, concretamente, de la ciencia (Trench, 2007; Holliman, 2010; Shanahan, 2010; Brossard, 2013; Peters et al., 2014; Dunwoody, 2014). Para algunos de ellos, el cambio que ha traído Internet a la comunicación de la ciencia, tanto en su vertiente formal como informal, ha sido radical (Magalhães y Almeida, 2009; Ribas, 2012).

Fernández de Lis (2013) considera que la ciencia ha encontrado por fin una herramienta lo suficientemente poderosa como para comunicarse de manera eficaz con la sociedad. La posibilidad de ampliar información de forma prácticamente ilimitada gracias al hipertexto (Díaz-Noci, 2018), de modificarla o actualizarla si es necesario, el potencial de los recursos multimedia o la interacción entre emisores y receptores a través de las múltiples herramientas que facilita la web -como los comentarios o las redes sociales-; unido a su bajo coste, su inmediatez, su amplio alcance o su simplicidad de uso (Holliman, 2010; Oliveira Fagundes, 2014), otorgan grandes posibilidades a la comunicación pública de la ciencia en todos los modelos posibles: Déficit, Diálogo y Participación.

López-Pérez y Olvera-Lobo (2015) apuntan que fue precisamente la Web 2.0 la que trajo consigo el Modelo de Participación. Desde la aparición de Internet hasta aproximadamente el año 2001, la Web fue de solo lectura. Es decir, el usuario no podía interactuar con el contenido y se limitaba a consultar lo que el webmaster subía a la página web. En 2004, Tim O’Reilly acuña el término Web 2.0 para referirse a una segunda generación en la historia del desarrollo de tecnología web, más dinámica y 
participativa. ${ }^{3}$ Los usuarios dejan de ser sujetos pasivos para convertirse en usuarios activos que participan y contribuyen en el contenido de la red (Nafría, 2007). También llamada Web Social, la Web 2.0 está basada en comunidades de usuarios y en una gama de servicios que fomentan la colaboración y el intercambio ágil de información entre ellos, lo que se ve reflejado en el auge de los blogs y de las redes sociales, las webs creadas por los usuarios usando plataformas de autoedición, el contenido agregado por los usuarios o el etiquetado.

El Modelo de Participación, fundamentado en la integración total de los ciudadanos en el proceso de comunicación de la ciencia, encuentra en las herramientas de la Web social y participativa un aliado perfecto para llevar a cabo los tres procesos en los que se fundamenta: la comunicación, la consulta y la participación pública (López-Pérez y Olvera-Lobo, 2015).

\footnotetext{
${ }^{3}$ El término se emplea por primera vez en el artículo de O`Reilly "What Is Web 2.0: Design Patterns and Business Models for the Next Generation of Software" que puede consultarse en el siguiente enlace: http://ow.ly/lSew30jZx0V (última consulta 07/03/2018)
} 
llustración 1. Representación de las relaciones entre ciencia y sociedad en los modelos de comunicación pública de la ciencia.

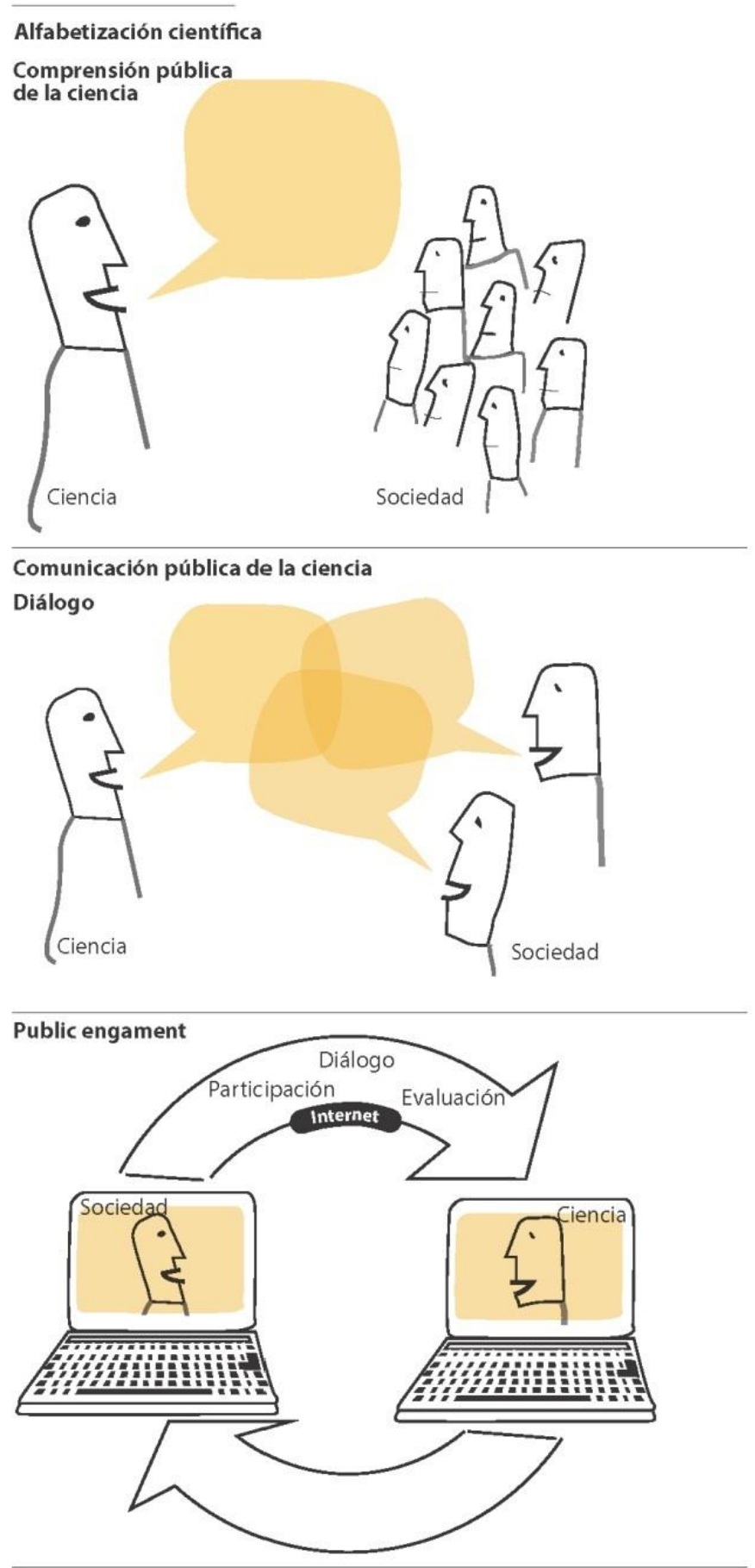

Fuente: López-Pérez y Olvera-Lobo (2015)

En la red confluyen formas tradicionales de divulgación científica -como museos de ciencia online, conferencias y cafés científicos retransmitidos en directo o en diferido, revistas divulgativas digitales, etc.- con nuevas actividades e iniciativas que han surgido en la propia red -como los blogs de ciencia o las redes sociales-. De esta 
forma, multitud de emisores representativos de la sociedad -no solo ciudadanos, también sociedades profesionales, centros de investigación, instituciones de educación superior, grupos que promueven la ciencia, empresas o grupos que cuestionan la ciencia, entre otros perfiles interesados-, son activos en la creación, la difusión y la discusión de contenidos científicos y tecnológicos a través de Internet (Trench, 2009; Asensi, 2013). Así, la red posibilita la coexistencia de ambientes informacionales múltiples y heterogéneos (Porto, 2009)

El ciberperiodismo científico (González-Pedraz, 2013) es una de las múltiples vertientes que adopta la comunicación pública de la ciencia en Internet (Seabra, 2012). Según Hermida (2010), la red ha tenido un impacto indiscutible en la forma de hacer periodismo, ya que los canales digitales han roto las barreras técnicas y económicas que separaban a los comunicadores profesionales de una audiencia en buena parte pasiva, la de los medios de comunicación impresos y audiovisuales tradicionales (Peters et al., 2014). Respecto a las barreras técnicas, la red marca un cambio importante en los procesos de producción, vehiculación, y consumo de noticias, alterando de forma radical el dinamismo y la velocidad en la elaboración y puesta en circulación de la información (Porto, 2009). También permite que cuestiones complejas y controvertidas de la ciencia puedan ser presentadas de forma atractiva e innovadora (Hermida, 2010), gracias a los elementos de hipertextualidad, multimedialidad, interactividad y actualización que caracterizan a la web (Díaz Noci y Salaverría, 2003; Salaverría, 2016).

Asimismo, los cibermedios permiten a los usuarios hacer búsquedas sobre determinados temas científicos de su interés, frente a los contenidos preseleccionados que llegan a ellos a través de los medios de comunicación tradicionales (Anderson et al., 2010). Además, posibilitan encontrar una amplia gama de antecedentes con relación a un asunto científico (Koolstra et al., 2006).

\subsection{INTERNET PARA INFORMARSE SOBRE CIENCIA Y TECNOLOGÍA}

La importancia que ha adquirido Internet en la comunicación pública de la ciencia se refleja claramente en las encuestas. En la actualidad, Internet y la televisión son los principales medios que utilizan los ciudadanos para informarse sobre ciencia y tecnología, tal y como indican los principales sondeos específicos a nivel nacional e internacional en los últimos años (National Science Board, 2014; Eurobarómetro 
Especial 401, 2013; VIII Encuesta de Percepción Social de la Ciencia de FECYT, 2016).

Aunque la televisión ha sido, históricamente, el principal medio de información, desde que la red empezara a generalizarse en los hogares su influencia ha crecido de manera exponencial, hasta situarse como primera fuente a la que recurren los ciudadanos en países como Estados Unidos, tal y como recogen los Science and Engineering Indicators que elabora bianualmente la National Science Foundation, a través de su National Science Board. Según los últimos datos disponibles, correspondientes a 2016, la red es la principal fuente de información sobre ciencia y tecnología para el $47 \%$ de los nortamericanos. Este porcentaje ha crecido drásticamente desde 2001, cuando solo el 9\% nombraba Internet como primer medio de información. ${ }^{4}$

Gráfico 1. Evolución (\%) de los tres principales medios nombrados por los norteamericanos para informarse sobre ciencia y tecnología.

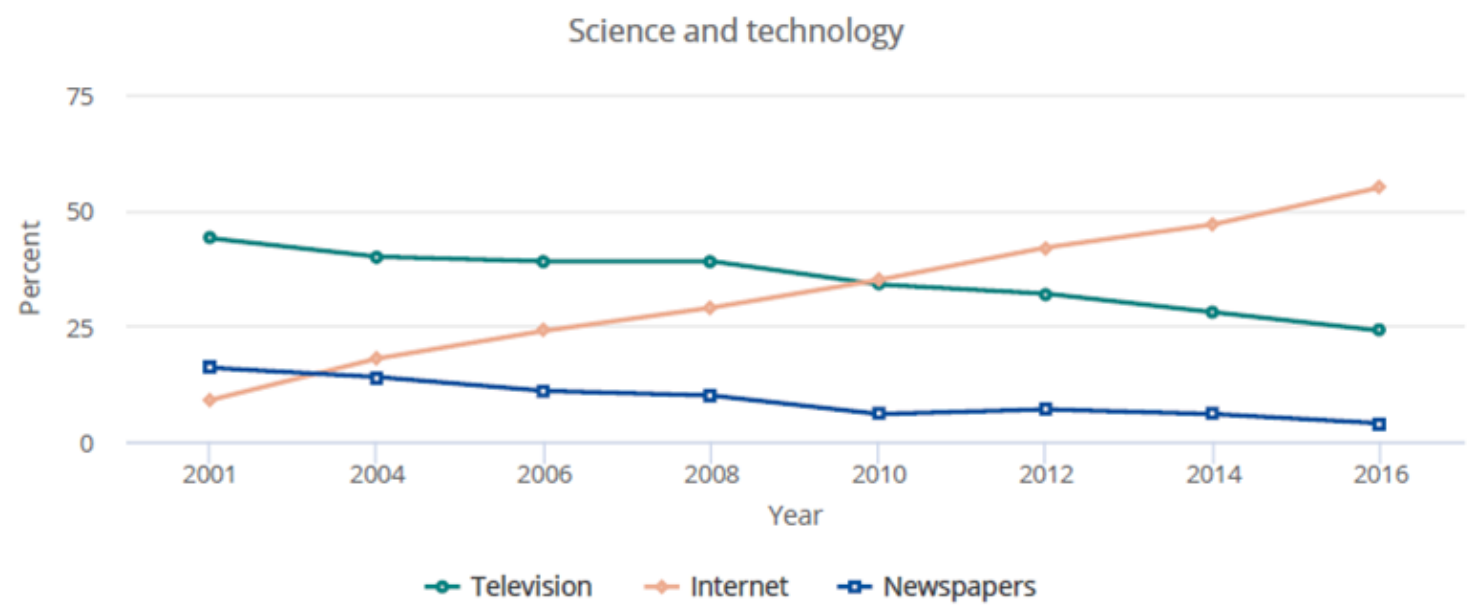

Fuente: National Science Board (2014)

Estos datos se invierten a nivel europeo, según el Eurobarómetro Especial 401: Responsible Research and Innovation (RRI), Science and Technology de 2013, en el que la televisión (65\%) se sitúa por delante de Internet (35\%) como principal medio para informarse sobre ciencia y tecnología. No obstante, los datos difieren en gran medida en el desglose por países. ${ }^{5}$

${ }^{4}$ Los resultados de la encuesta referida pueden consultarse en el siguiente enlace: http://ow.ly/WKsK30iZ1c9 (última consulta 07/03/2018)

${ }^{5}$ Los resultados de dicho Eurobarómetro se escuentran disponibles en el siguiente enlace: http://ow.ly/3HXd30iZ1fL (última consulta 07/03/2018) 
Son los ciudadanos de los países nórdicos, junto con los holandeses, los que acceden en mayor medida a Internet para obtener información sobre ciencia y tecnología, mientras que la mayor parte de los estados del centro y el sur de Europa se decantan, primero, por la televisión.

Las encuestas referenciadas estiman también la confianza que suscitan los distintos medios de comunicación a los ciudadanos en relación con la ciencia y la tecnología. Variables como la edad o el nivel educativo influyen de forma determinante en la confianza percibida, de manera que, en general, los más formados confían más en Internet y en la prensa, mientras que los menos formados recurren más a la televisión. Asimismo, los más jóvenes otorgan una mayor confianza a Internet y los de edad más avanzada a la prensa.

En España, desde 2004, la Fundación Española para la Ciencia y la Tecnología (FECYT) se encarga de analizar el panorama relativo a la ciencia y la tecnología y los medios de comunicación dentro de la Encuesta de Percepción Social de la Ciencia y la Tecnología, de carácter bianual. Específicamente, las ampliaciones realizadas en el cuestionario en 2010 y 2014 están permitiendo obtener la instantánea más completa, de las estudiadas, sobre los medios utilizados por la población para informarse sobre ciencia y tecnología.

Los datos relativos a la última Encuesta, la de $2016,{ }^{6}$ ponen de manifiesto que la televisión es, efectivamente, el medio de comunicación más nombrado por los españoles cuando se les pregunta a través de qué medios se informan sobre ciencia y tecnología en respuesta múltiple $(71,2 \%)$, por delante de Internet $(57,8 \%)$. No obstante, Internet es ligeramente el más citado en primer lugar $(37,7 \%)$, frente a la televisión $(36,4 \%)$.

En la serie histórica, se aprecia cómo Internet ha ido ganando terreno a la televisión como medio preferente para acceder a información sobre ciencia y tecnología entre los españoles. La distancia entre ambos medios se ha ido reduciendo progresivamente desde los 40 puntos en 2004, a los 13 en 2016.

Asimismo, la web es el medio preferido por los más jóvenes (82,1\%, 9 puntos por encima de la televisión) y por las personas con formación universitaria (79,0\%, 13 puntos por encima de la televisión). También Internet es el principal medio de

\footnotetext{
${ }^{6}$ La VIII Encuesta de Percepción Social de la Ciencia de FECYT se llevó a cabo en 2016 y los datos fueron presetados en abril de 2017. Los datos correspondientes a 2018 aún no están disponibles. Mäs información disponible en: http://ow.ly/1HIN30jWOW6 (última consulta 09/03/2018)
} 
información para las personas que declaran explícitamente interés por la ciencia y la tecnología.

A diferencia de las otras encuestas referidas, desde 2010, la de FECYT profundiza en los medios concretos que utilizan los encuestados que se informan sobre ciencia y tecnología en la red, lo que ofrece una visión más detallada de la situación. Según datos de 2016, estos ciudadanos recurren fundamentalmente a las redes sociales $(75,4 \%)$, a los vídeos $(62,3 \%)$, a los medios digitales generalistas $(58,9 \%)$ y a Wikipedia (57,0\%). Mientras que las redes sociales y los vídeos son más utilizados a medida que desciende la edad, los medios digitales generalistas lo son más a medida que se incrementa la edad y el nivel formativo.

En general, todos los medios digitales se utilizan de forma más intensiva y extensiva que en años precedentes. No obstante, respecto a 2014, se observa un aumento estadísticamente significativo en el uso de redes sociales y de vídeos. También, aunque la recurrencia a estos medios sea menor, crece significativamente el uso de podcast y radio por Internet y retrocede el acceso a medios digitales especializados en ciencia y tecnología.

Gráfico 2. Evolución histórica del uso de distintos medios digitales para informarse sobre ciencia y tecnología.
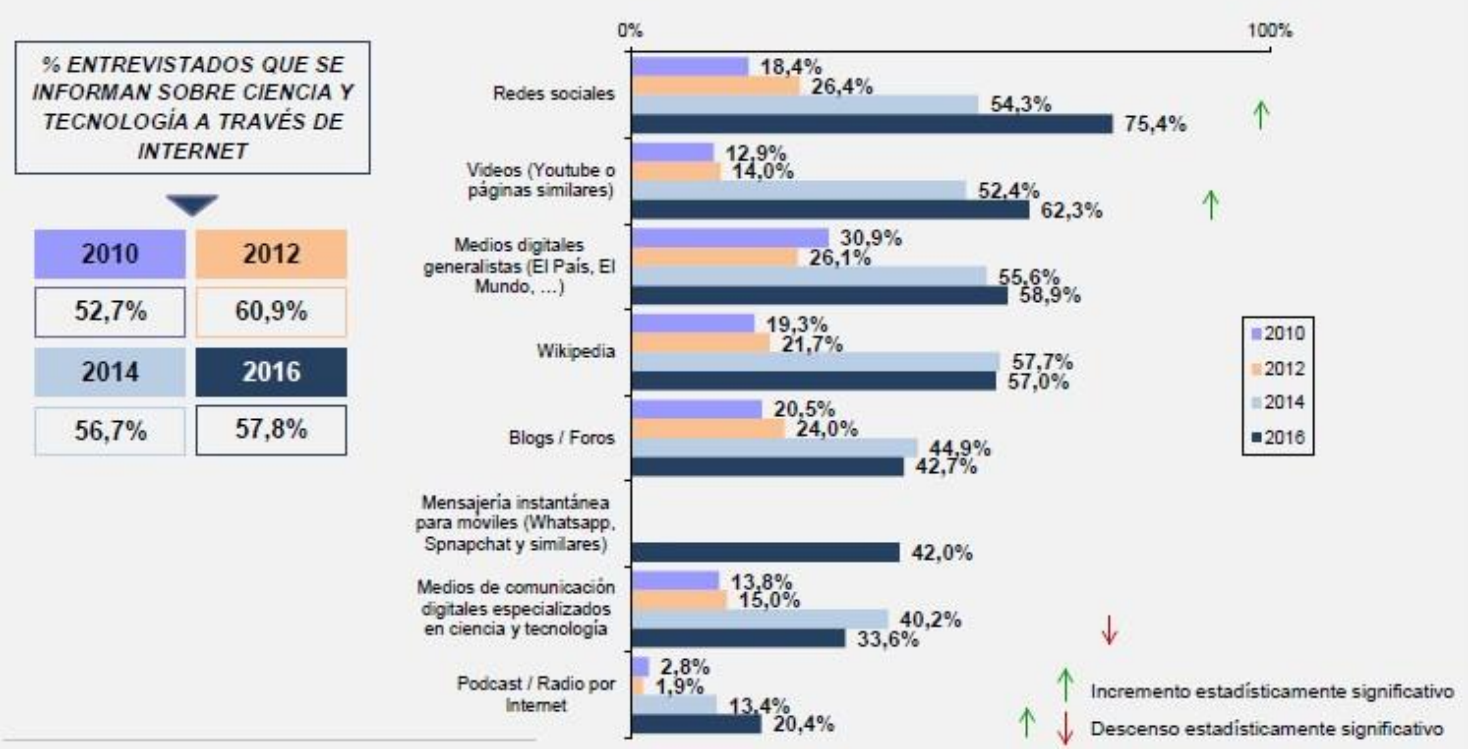

Fuente: VIII EPSCT (2016)/FECYT

En solo dos años, el porcentaje de encuestados que se informa a través de redes sociales ha aumentado en más de 21 puntos. La encuesta profundiza además en qué redes sociales utilizan los ciudadanos que dicen informarse por esta vía. El 93,8\% lo 
hace a través de Facebook, el 37,3\% de Twitter, el 30,7\% de Instagram y el 13,9\% de Linkedln. Todas las redes sociales, salvo Twitter -que cae 10 puntos-, crecen respecto a la anterior encuesta. La que más aumenta es Instagram -9 puntos-, que prácticamente empata con Twitter en el segmento de 15 a 24 años.

\subsection{JUSTIFICACIÓN Y OBJETIVOS}

El contexto presentado pone de relieve cómo, en la historia reciente, ningún otro avance tecnológico ha supuesto un cambio tan relevante para la comunicación de la ciencia como Internet. Su amplio alcance como fuente de información en ciencia y tecnología, convierten a la red en uno de los objetos de estudio fundamentales en la investigación en este campo.

Así, las oportunidades que ofrecen características como la hipertextualidad, la multimedialidad, la interactividad o la actualización para elaborar contenidos más atractivos; las poderosas herramientas surgidas de la web, como los blogs y sobre todo en la actualidad las redes sociales; la aparición de nuevos actores en este entorno comunicativo abierto, o el actual rol activo de un público tradicionalmente pasivo, se han convertido en objetos de estudio preferentes en el emergente campo de la comunicación de la ciencia en Internet, en general, y del periodismo científico, en particular.

Sin embargo, quizás debido a los problemas que entraña el análisis de fenómenos contemporáneos o a las dificultades para acotar un campo tan vasto, complejo y cambiante, no se ha localizado a día de hoy ningún estado de la cuestión y/o revisión sistemática sobre la materia, un estudio de carácter descriptivo, pormenorizado y transversal que aglutine y ponga en perspectiva todas las aportaciones realizadas hasta la fecha por la comunidad académica internacional en relación a la comunicación de la ciencia a través de Internet y las implicaciones que tiene para el periodismo científico. Una situación que ha sido ya advertida en algunas revisiones específicas sobre comunicación de la ciencia (Elías, 2009; Brossard y Schefeule, 2013; Olvera-Lobo y López-Pérez, 2015).

“La Web, un recurso indispensable para la ciencia contemporánea, no es solo un instrumento tecnológico, sino también un campo en el que los diferentes puntos de vista sobre lo que la ciencia es y cuáles son sus fines sociales se chocan. Un campo que vive en la comunicación y que necesita ser estudiado de forma detallada, sin dejar de lado sus contradicciones y sus puntos débiles" Delfanti (2009:1). 
Como indican Martínez Nicolás y Saperas Lapiedra, "el interés por conocer el estado de la investigación en cualquier campo de los saberes científicos debe ser tenido por un indicador de la madurez del mismo" (2011:105). En un momento como el actual, en el que Internet es ya una tecnología consolidada y en el que la investigación sobre la materia es extensa y variada, se considera que se ha alcanzado la madurez suficiente para estudiar el fenónemo con cierta perspectiva y emitir una valoración crítica sustentada en una metodología sólida (Humanes, 2007; Martínez Nicolás y Saperas Lapiedra, 2011).

Por ello, el objeto último de esta tesis doctoral es profundizar en las implicaciones que ha supuesto para el periodismo científico el nuevo panorama de la comunicación de la ciencia en Internet, realizando una revisión sistemática de carácter cuantitativo y cualitativo, para aglutinar y evaluar las aportaciones académicas realizadas hasta el momento en esta línea y ponerlas a disposición de la comunidad científica. Asimismo, se pretende contribuir a un mayor conocimiento y comprensión del fenómeno mediante la realización, posteriormente, de un estudio de caso en torno a uno de los aspectos que se ha detectado como clave en dicho trabajo de revisión, la dependencia informativa de los cibermedios españoles de las fuentes organizadas, en concreto, de los gabinetes de comunicación de las universidades.

El interés en este objeto de estudio tiene su origen en el desempeño profesional de esta autora, que trabaja desde hace una década en el ámbito de la comunicación de la ciencia dentro de la Fundación Centro de Estudios para la Ciencia, la Tecnología y la Innovación ( $3 \mathrm{CIN})$, entidad que coordina y mantiene la Agencia Iberoamericana para la Difusión de la Ciencia y la Tecnología (DiCYT), una agencia online de noticias especializada en ciencia, tecnología e innovación. También en su colaboración en proyectos de investigación e innovación docente sobre comunicación online llevados a cabo en la Universidad de Valladolid, donde ha sido profesora asociada impartiendo docencia en innovaciones tecnológicas aplicadas al periodismo y metodologías de investigación en comunicación.

La presente tesis doctoral supone la continuación de un Trabajo Fin de Máster presentado en la Universidad de Valladolid en el curso 2012/2013 bajo la dirección de Eva Campos-Domínguez, un estudio de caso sobre las diferencias en el tratamiento periodístico del descubrimiento del Bosón de Higgs en las ediciones impresa y online del diario El Mundo que sirvió como primera aproximación a este campo (GonzálezPedraz, 2014a; González-Pedraz, 2014b). 
No obstante, tras una exhaustiva revisión previa de la literatura, en esta ocasión se ha determinado que el objeto de estudio sea la comunicación de la ciencia en Internet y no solo el ciberperiodismo científico, ya que en Internet se diluyen las fronteras entre periodismo -como actividad profesional ejercida por periodistas, con sus códigos y prácticas propias- y comunicación de la ciencia en general -que incluye también la comunicación llevada a cabo por otros emisores emergentes gracias a las facilidades que precisamente ofrece Internet-, y el interés que existe por estudiar, en concreto, esta paradigmática situación.

En este escenario surgen diversos interrogantes en relación con el periodismo científico y la profesión periodística que guiarán esta investigación: ¿Cuál es la situación del periodista científico en el nuevo entorno online? ¿Qué papel desempeña el periodista científico en este nuevo panorama? ¿Cómo afectan las características de los cibermedios a su práctica profesional? ¿Qué problemas afrontan estos profesionales? ¿Están otros actores desplazando al periodista en su papel de "mediador" entre la ciencia y el público? ¿Sigue siendo necesaria la figura del profesional periodista? ¿Qué valor añadido aporta en el actual contexto de la comunicación de la ciencia online?

Como se ha señalado, el trabajo se ha iniciado con una primera búsqueda de bibliografía, un paso previo fundamental para centrar el objeto de estudio. Esta lectura previa ha permitido obtener una visión general de los aspectos que han sido analizados en la literatura, desde qué perspectiva, con qué enfoques metodológicos y qué líneas de investigación necesitan ser estudiadas con una mayor profundidad.

Se ha observado, de forma preliminar, que existe una vasta investigación en este campo, teórica y empírica, aunque se encuentra aislada, sin un aparente hilo conductor, trabajos que se llevan a cabo no solo por comunicadores sino por investigadores de otras ramas de conocimiento y que parecen realizarse de forma independiente sin que exista contacto y lectura entre los distintos autores, y objetos de estudio que generalmente no tienen continuidad en el tiempo.

Por ello, se ha determinado que una de las principales necesidades de investigación en este campo se encuentra a nivel de revisión sistemática, es decir, en cuantificar y describir de manera empírica dicha situación. De este modo, como primer objetivo específico se plantea desarrollar un análisis cuantitativo y cualitativo de los distintos estudios localizados, para profundizar de forma práctica en la investigación realizada hasta el momento en la materia. Como indican Marín Martínez et al. (2009), cuando los estudios se acumulan en un campo determinado, como sucede en este caso, este 
tipo de trabajos adquieren una gran relevancia, ya que permiten establecer el estado del conocimiento. Las revisiones sistemáticas y metanálisis son estudios consolidados y valorados en campos como las ciencias de la salud, pero no son tan frecuentes en otras áreas, como las ciencias sociales y la comunicación en particular, donde este tipo de trabajos son ciertamente escasos.

Por otro lado, se ha detectado la necesidad de sintetizar y compendiar los datos de la colección de estudios sobre comunicación de la ciencia en Internet, con la recopilación, organización y valoración de todos esos conocimientos y aportaciones sobre el objeto de estudio que actualmente se encuentran dispersos. De este modo, se plantea la realización de un estado de la cuestión, un trabajo teórico cualitativo que permita aunar, en un solo documento y con una visión selectiva y de conjunto, la bibliografía publicada hasta la fecha y situarla en perspectiva (Day, 1994; Ramos Miguel, 2003; Vera Carrasco, 2009).

Las revisiones de la literatura son de suma importancia hoy día debido al incremento en el número de las publicaciones científicas, la falta de tiempo de los investigadores y su excesivo costo (Cué Brugueras et al. 1999). De este modo, según el mismo autor, las revisiones son una solución que tienen los investigadores y profesionales para mantenerse actualizados acerca de los últimos conocimientos y tendencias sobre una determinada materia, en este caso, la situación del periodismo en el marco de la comunicación de la ciencia en Internet. Del mismo modo, las revisiones son necesarias para consolidar la información existente y dar una respuesta clara y actualizada sobre un tema.

De los resultados obtenidos en la revisión sistemática se han detectado los asuntos estudiados en mayor medida y las necesidades de investigación en el campo de la comunicación de la ciencia en Internet. Con esta información se ha seleccionado un objeto de estudio de especial interés para la realización de un trabajo de campo. De esta forma, el segundo objetivo específico de esta tesis es llevar a cabo dicho estudio de caso que permita contribuir a un mayor conocimiento del fenómeno.

Teniendo en cuenta que se trata de una tesis enmarcada en la rama del periodismo y que su autora se dedica profesionalmente al periodismo científico en un cibermedio, el objetivo transversal de las dos partes de la tesis, el estado de la cuestión y el estudio de caso, es profundizar en este tipo de periodismo y en los cibermedios, así como valorizar la figura del periodista científico en el nuevo contexto de la comunicación de la ciencia en Internet, y discutir los retos y oportunidades a los que se enfrenta este profesional. 
Asimismo, esta investigación pretende integrar la perspectiva RRI (Responsible Research and Innovation), un concepto amplio que aglutina diferentes dimensiones dentro de la relación entre investigación, innovación y sociedad: participación ciudadana, acceso abierto, igualdad de género, educación científica, ética y gobernanza. Aunque su aplicación práctica es aún un asunto en desarrollo (Osset Hernández, 2014), es recomendable tener en cuenta estas dimensiones relacionadas con la responsabilidad social y la transparencia a la hora de llevar a cabo cualquier tipo de investigación (Owen et al., 2012; Stahl, 2013). Por ello, la RRI es una recomendación integrada en los programas europeos de investigación e innovación desde 2014. Este trabajo tendrá en cuenta las distintas dimensiones contempladas por la $R R I$ y se medirán, en los casos posibles, variables relacionadas con el acceso abierto, la igualdad de oportunidades, la ética y la transparencia. 


\section{BLOQUE II}

\section{ESTADO DE LA CUESTIÓN}




\section{REVISIÓN SISTEMÁTICA}

En los siguientes epígrafes se exponen los objetivos y las hipótesis de partida del presente estudio de revisión, así como la metodología aplicada. Posteriormente, se presentan los resultados correspondientes a las cuatro dimensiones analizadas y las conclusiones extraídas. Por último, se discute el estudio.

\subsection{OBJETIVOS E HIPÓTESIS}

Los objetivos de la revisión sistemática se exponen a continuación en tres grandes apartados.

a) Profundizar en el estado de la investigación sobre comunicación de la ciencia en Internet y establecer si se trata o no de un objeto de estudio consolidado, con unas bases teóricas y metodológicas sólidas. Se trata de conocer en qué medida esta investigación se realiza desde de la comunicación, si desde otros campos se están realizando aportaciones y si existen diferencias en los enfoques de investigación adoptados. Determinar qué evolución ha tenido dicha investigación a lo largo de los últimos años. Localizar qué grupos de investigación son los más activos a nivel internacional. Describir el perfil de los investigadores, su filiación y su área de procedencia. Dentro de la perspectiva RRI, se busca analizar si existe desigualdad en el género de los autores principales, si existe equilibrio entre hombres y mujeres en los equipos de investigación, en qué grado estos trabajos se publican en acceso abierto, y la participación existente entre grupos de investigación de distintos campos y procedencias.

b) Ahondar en la estructura y contenido científico del artículo y estimar la calidad de la investigación desarrollada. Estudiar aspectos de la estructura del artículo -como la presencia de abstract, palabras clave, el formato de redacción IMRyD- y de su contenido -la descripción metodológica, la profundidad de la bibliografía, la autocitación, la financiación, la declaración de conflictos de interés, etc.- como indicadores de la calidad de la investigación. Estos aspectos están estrechamente relacionados con otra de las dimensiones de la RRI, la ética en la investigación. También recoger qué áreas temáticas son las más estudiadas, el enfoque de los trabajos y el tipo de metodología aplicada.

c) Determinar el impacto y la visibilidad de dicha investigación. Registrar las revistas donde se publica la investigación localizada y considerar su impacto y visibilidad a partir del factor de impacto y del cuartil. Establecer en qué grado la 
investigación sobre comunicación de la ciencia en Internet se difunde en revistas del ámbito de la comunicación o si es transversal a todos los campos.

Para esta investigación se formulan las siguientes hipótesis:

H1. La investigación de la comunicación de la ciencia en Internet es todavía incipiente: a pesar de que hay variedad temática en su objeto, no existe una tradicción teórica ni metodológica uniforme ni consensuada en los estudios analizados.

H2. La comunicación de la ciencia en Internet no es un objeto de estudio propio de la Comunicación o de las Ciencias Sociales en general, sino que es transversal a todas las áreas de conocimiento, lo que se observa tanto en el campo de especialización de los autores como en la temática de las revistas donde se publican los estudios. Predominan los estudios relativos al propio canal y a sus herramientas asociadas, como los blogs o las redes sociales.

H3. Los equipos de investigación que estudian la comunicación de la ciencia en Internet son reducidos y desequilibrados en cuanto a paridad de género. Las redes internacionales de colaboración internacional e interdisciplinar son prácticamente inexistentes en este objeto.

Para guiar la investigación se plantean las siguientes preguntas:

¿La investigación en Comunicación de la Ciencia en Internet se circunscribe únicamente a la Subárea de Periodismo o, de forma más genérica, a las Áreas de la Comunicación o de las Ciencias Sociales?

¿Se pueden identificar grupos que tengan varios artículos en esta línea de investigación? ¿Cuál es el tamaño de los equipos de investigación? ¿Hay investigadores de diversos campos? ¿Existe colaboración entre grupos de investigación? ¿Cuál es su alcance?

¿Qué perfil tienen los autores que investigan en esta línea? ¿Cuál es su género, país de origen, filiación e idioma en el que escriben? ¿El número de investigadores e investigadoras presente en los equipos es equilibrado? ¿Son todos investigadores académicos o se pueden identificar otros perfiles?

¿Los artículos se publican en abierto o en plataformas de pago? ¿Los artículos de pago se difunden a través de las redes sociales académicas?

¿En qué aspectos de la comunicación se centran los trabajos? ¿Predominan los trabajos de carácter teórico, empírico o mixto? ¿Cuál es la perspectiva metodológica dominante? ¿Con qué profundidad se detalla la metodología aplicada? ¿Es común el uso de software para registrar y procesar los datos? 
¿Cuál es la estructura del artículo? ¿Los artículos en idiomas ajenos al inglés traducen el título, el resumen y las palabras clave para obtener mayor difusión? ¿El apartado bibliográfico es solvente?

¿En qué revistas se publican estos trabajos? ¿De dónde proceden? ¿Se trata de revistas bien situadas en SCImago Journal Rank -SJR?

\subsection{METODOLOGÍA}

Se plantea un estudio descriptivo transversal que se apoya en la metodología del análisis de contenido de carácter mixto, cuantitativo y cualitativo, en una muestra que engloba los artículos publicados en revistas académicas indexadas con relación al objeto de estudio entre el 01/01/1996 y el 31/12/2016. En total, la muestra la conforman 261 artículos. La selección de la muestra se ha llevado a cabo a partir de una búsqueda sistemática en bases de datos (Scopus, WOS, ProQuest, Teseo, Dialnet, ISOC y Google Scholar) utilizando los siguientes descriptores: "Science Journalism"+Internet; "Periodismo Científico"+Internet, "Jornalismo Científico"+Internet; "Science Communication"+Internet; "Comunicación Científica"+Internet y "comunicação científica"+Internet. No obstante, para garantizar la representatividad de cada artículo, siguiendo la metodología de Schäfer (2012), se realizó una comprobación manual previa a la inclusión final en la muestra, consistente en la revisión del título y resumen del artículo. En los casos en los que la representatividad del artículo no estaba claro tras estos pasos, se procedió a la lectura del mismo.

La búsqueda y selección sistematizada se realizó entre el 1/11/2014 y el 31/12/2016. Se localizaron 316 referencias que englobaron artículos científicos, capítulos de libro, monografías, comunicaciones en congresos, trabajos académicos y entradas de blog en torno al objeto de estudio. De ellas, 205 se correspondieron con artículos científicos y se incorporaron a la muestra final objeto de análisis cuantitativo. Las restantes, se revisaron igualmente para la elaboración del estado de la cuestión.

Una vez conformada la muestra, se aplicó una ficha de análisis para acopiar información sobre 37 variables (Anexo I) y se elaboró un libro de códigos (Anexo II). Para recoger las variables cuantitativas y cualitativas se ha diseñado una aplicación ad hoc con el software FileMaker Pro 14. 
Imágenes 1 y 2. Capturas de pantalla de la aplicación propia diseñada con el software Filemaker para la recogida de datos.

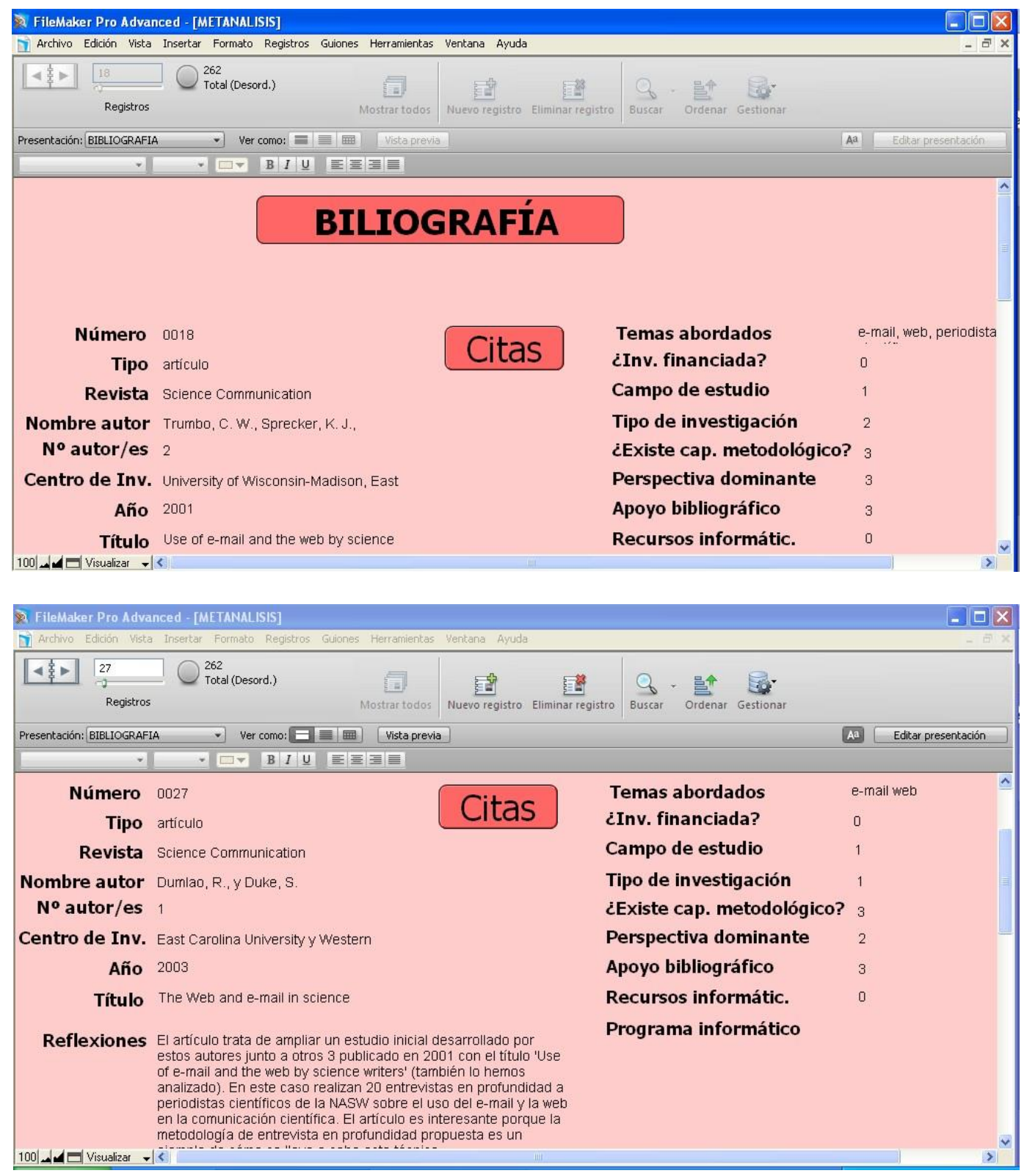

Las variables registradas se han agrupado en torno a cuatro dimensiones: datos identificativos, autoría del artículo, contenido del artículo y datos de la revista. Estas dimensiones han sido recogidas en otras revisiones sistemáticas y metanálisis previos, tal y como se desgrana a continuación:

D1. Datos generales. Se incluyen en esta dimensión cinco variables. Primero, tres variables relativas a la identificación del texto: año de publicación del artículo, título e idioma del texto. Se han seleccionado como idiomas de referencia el inglés, el lenguaje que impera en la actualidad en la investigación 
académica a nivel global (Ammon, 2001; Enrique Hamel, 2007); el castellano, por ser la segunda lengua del mundo en número de hablantes y por el peso de la cultura hispana en el mundo (Fernández Vítores, 2016), así como por ser el idioma del país en el que se desarrolla la presente tesis doctoral; y el portugués, cuarta lengua más hablada del mundo, por sus vínculos históricos y culturales con España e Iberoamérica y por su importante proyección (Albuquerque y Esperança, 2010). En segundo lugar, se recogen dos variables relacionadas con el acceso al artículo. Se señala primero si el acceso a la revista es abierto o si es de pago, teniendo en cuenta que la corriente Open Access (OA) en la investigación está tomando ventaja en los últimos años, respaldada el programa de investigación europeo H2020 y por los estudios que apuntan a un impacto de citación significativamente más alto en estos artículos (Antelman, 2004; Harnad y Brody, 2004). En el caso de los artículos de pago, se recoge en otra variable si pueden requerirse a sus autores a través de otros medios, en concreto, de sus perfiles en las dos principales redes sociales de corte académico, Academia.edu y ResearchGate (Quintas Froufe, 2016; Meishar-Tal y Pieterse, 2018). De esta forma, se puede estimar el impacto que están teniendo estos canales alternativos en la difusión de la investigación, en general, y de la comunicación de la ciencia, en particular; y también contrastar los resultados obtenidos en otros estudios en los que se señala, por ejemplo, que el número de miembros españoles en estas redes sociales es muy escaso (González Díaz et al., 2015).

D2. Autoría del artículo. En esta segunda dimensión se miden 16 variables en torno al autor principal y a los autores secundarios del trabajo, en relación con cuatro aspectos concretos: coautoría, género, pluridisciplinariedad y plurinacionalidad. En primer lugar, se trata de dilucidar si la coautoría es o no frecuente en el campo de investigación seleccionado (Newman, 2004). También se pretende cuantificar el tamaño de la coautoría. La investigación de las redes de colaboración científica es frecuente en campos de conocimiento relacionados con la Medicina y la Salud (González-Alcaide et al., 2006; González-Alcaide et al., 2009; Belinchón Carmona, 2010; Aleixandre Benavent, 2013; Ávila-Toscano, 2014) pero no tanto en el de las Ciencias sociales y, específicamente, en las áreas de Comunicación, donde solo se han localizado algunos estudios (Escribà y Cortiñas, 2013). En esta misma línea, se analiza el perfil de sus autores ya que, durante la búsqueda y selección de los artículos para el metanálisis se detectó que a veces el perfil no es estrictamente académico, sino que también otros actores relacionados con la comunicación de la ciencia, como periodistas y 
divulgadores, contribuyen en su investigación. Se busca así cuantificar esta situación y determinar la frecuencia de estos perfiles.

En segundo lugar, se incluyen algunas variables relacionadas con el género. Se mide el sexo del autor principal y de los autores secundarios. La integración de las mujeres en la Ciencia es objetivo de las políticas europeas desde finales de la década de los 90 . Según la comunicación de la Comisión 'Mujeres y ciencia' celebrada en 1999, las mujeres están subrepresentadas en todos los sectores científicos pese a que se considera que su participación plena en todas las disciplinas y a todos los niveles permitirá consolidar el progreso y la excelencia de la ciencia europea. Sin embargo, la variable de género está presente en solo algunos estudios bibliométricos y de metanálisis (González-Alcaide, 2009). Se pretende así conocer, primero, en qué grado la mujer es autora principal en esta línea de investigación y, segundo, si hay mujeres en coautoría y si su proporción es equilibrada, o si por el contrario los equipos y redes de investigación están constituidas por hombres.

En tercer lugar, se estudia la internacionalidad de los autores, para conocer qué países son los predominantes en esta línea de investigación y determinar si son los mismos que se sitúan en los primeros lugares en los ránkings internacionales de producción científica. Se estima si los autores de los artículos proceden de más de un país diferente, con el fin de conocer si existen redes de colaboración internacionales en este campo (Newman, 2001). También el alcance de las colaboraciones y redes científicas (regionales, nacionales o internacionales). A lo largo del siglo $\mathrm{XX}$ se produjo un aumento significativo en la colaboración científica entre países (Sancho et al., 2006; Russell et al., 2007). De este modo, se trata de cuantificar la colaboración científica en la investigación de la comunicación de la Ciencia a través de medios digitales y de establecer el alcance de esta cooperación, siguiendo la metodología de Sancho (2006).

En cuarto y último lugar, se indaga en la pluridisciplinariedad de los autores. El incremento en la colaboración científica ha sido motivado por la especialización temática y la necesidad de abordar cuestiones cada vez más complejas (Sancho et al., 2006). También por las políticas de financiación para fomentar la cooperación entre grupos pluridisciplinares, por acuerdos de cooperación regionales y por el desarrollo de tecnologías que facilitan el trabajo colaborativo a distancia (Russell et al., 2009). Se investiga si existe esta pluridisciplinariedad en la investigación de la comunicación de la Ciencia a través de medios 
digitales. En función de la coordinación establecida es posible predecir el éxito de los equipos investigadores (Cummings y Kiesler, 2005).

Se recoge así la universidad, centro de investigación u otro tipo de entidad a la que se adscribe el autor principal y los autores secundarios del artículo y sus áreas de conocimiento. Para responder a esta variable se utilizan las áreas de conocimiento definidas por la Agencia Nacional de Evaluación y Prospectiva (ANEP) como entidad de referencia a nivel español en materia de calidad científico-técnica. La ANEP comprende 26 áreas temáticas. La clasificación de las áreas refleja la situación de las actividades de I+D que se llevan a cabo en los centros de investigación y universidades españolas. En cada una se ha incluido un descriptor de su contenido (por ejemplo, Área de Ciencias SocialesCS) que es el que se emplea en la presente codificación. ${ }^{7}$ Para realizar un análisis más detallado, dentro del Área de Ciencias Sociales se ha realizado un desglose ajustado también a la clasificación de la ANEP. ${ }^{8}$

D3. Estructura y contenido del artículo. Esta dimensión mide 19 variables relacionadas con la estructura y contenido científico del artículo y la calidad de la investigación. En relación con la estructura, se analiza una batería de variables en torno a si el artículo contiene los elementos característicos de título, resumen y palabras clave (Villagrán y Harris, 2009). Para que el artículo sea más fácil de localizar y tenga una mayor difusión, los textos escritos en otros idiomas ajenos al inglés que, como se ha reseñado anteriormente, es el preferente en este campo, deben al menos incluir estos elementos principales (título, resumen y palabras clave) también en inglés, según los criterios del ISI -Institute for Scientific Information- (Ruis-Pérez et al., 2006). Además, se estima si el artículo sigue el modelo de redacción IMRyD (Introducción, Metodología, Resultados y Discusión). Estas variables tienen una relación directa con la calidad de la investigación, como demuestra el hecho de que formen parte de los indicadores para obtener el Sello de Calidad que otorga la FECYT como entidad de

\footnotetext{
${ }^{7}$ Todas las áreas y descriptores utilizados se presentan a continuación y las áreas concretas que engloban pueden consultarse en el siguiente enlace: http://ow.ly/1pUt30jZz2D (última consulta 07/03/2018)

${ }^{8}$ El desglose de la ANEP incluye las siguientes subáreas. Los descriptores, en este caso, son de elaboración propia:

Sociología (SO)

Técnicas de la Investigación Social (TIS)

Ciencia Política y de la Administración (CPA)

Periodismo (PE)

Comunicación Audiovisual (CA)

Publicidad (PU)

Geografía Humana (GH)
} 
referencia española para la evaluación de la calidad de las revistas científicas. ${ }^{9}$ Se busca así cuantificar si estos criterios son recogidos en las revistas que publican asuntos relacionados con la comunicación de la ciencia.

En el caso de las palabras clave, términos o lexemas que sirven para clasificar y direccionar las entradas en los sistemas de indexación y de recuperación de la información en las bases de datos (Tous y Matter, 2012), se registrarán todas las incluidas en los artículos que componen la muestra, con el objetivo de comprobar si existe uniformidad al respecto y construir un tesauro específico sobre esta materia, utilizando como criterio de inclusión aquellas palabras clave que aparecen en dos o más artículos, con el fin de ayudar a los autores a la hora de seleccionar dichas cadenas de palabras para sus trabajos y mejorar la localización posterior de los mismos en las bases de datos.

En cuanto al contenido se evalúan una serie de aspectos considerados en estudios de metanálisis previos (Humanes, 2007; Villagrán, 2009; Martínez Nicolás y Saperas Lapiedra, 2011) como el campo de estudio, la temática, el enfoque investigador o la metodología aplicada. En cuanto al campo de estudio, se han considerado los elementos fundamentales del proceso comunicativo esbozados por Lasswell (1985) como uno de los teóricos referentes en la investigación de la comunicación, clasificando los trabajos en función de si estudian de forma predominante al emisor, al canal, al mensaje, al receptor o a los efectos.

\footnotetext{
${ }^{9}$ Más información sobre el Sistema de Evaluación de la Calidad de Revistas Científicas de la
} FECYT disponible en el siguiente enlace: http://ow.ly/9arR30iZz5x (última consulta: 7/03/2018) 
Figura 1. Modelo de comunicación de Lasswell utilizado como base para el análisis de contenido y su posterior revisión.

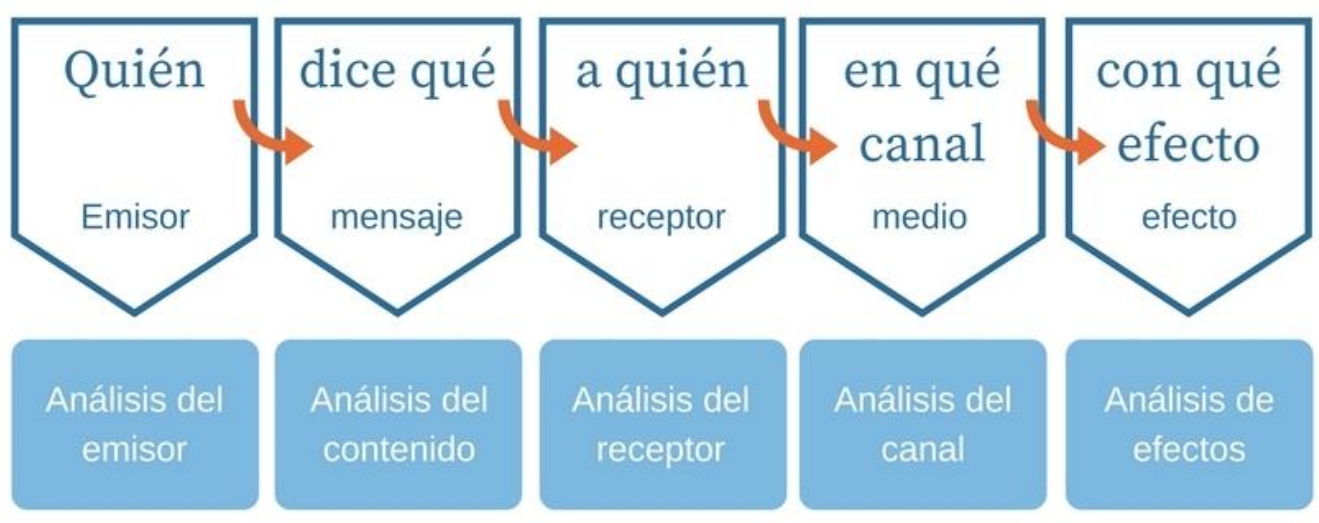

Fuente: elaboración propia a partir de Lasswell (1985).

La variable temática hace referencia a si se realiza un estudio de caso en relación con la comunicación de un área científica concreta y, en la misma línea, si se trata de un estudio relativo a la comunicación de riesgos, ya que durante las búsquedas bibliográficas se detectó que era un objeto de investigación frecuente, y se trata así de cuantificarlo. Por otro lado, se estudia el enfoque investigador (teórico, empírico o mixto), si existe o no capítulo metodológico y su profundidad (si es solo informativo o si es detallado) y la perspectiva dominante (cuantitativa, cualitativa o mixta). Estos elementos están también muy relacionados con la calidad de la investigación, ya que la selección y explicación del enfoque metodológico es un criterio fundamental de la buena investigación (Khotari, 2004). Y adquiere una especial relevancia en el caso de las Ciencias Sociales, donde históricamente se ha sembrado la duda de si constituyen en realidad una ciencia, precisamente por la diversidad de enfoques que pueden emplearse, por las técnicas de investigación aplicadas y por la falta de información presente en los estudios acerca de las mismas, entre otros aspectos (Neuman, 2011).

Se analiza además el apoyo bibliográfico de los textos y la autocitación como elementos relacionados igualmente con la calidad de la investigación, "ya que pueden informar de la minuciosidad e importancia de los estudios previos que sustentan su justificación y discusión, situación que invita a la credibilidad", (Casterá et al., 2008:s.p.). En referencia a la autocitación, es un elemento importante para calcular el factor de impacto de las revistas (Castillo y Carretón, 2010). 
Por otro lado, se han incluido dos variables relativas al uso de recursos informáticos en la investigación (Khotari, 2004), si existen referencias al respecto y qué programas se emplean. En la actualidad, la comunidad científica dispone de diversos programas tanto de pago como de acceso abierto para su uso en investigación cuantitativa (como SPSS, PSPP, Infostat, Statgraphics, etc.) y cualitativa (por ejemplo, NVivo, Atlas.ti o Aquad). El objetivo es determinar si los softwares estadísticos generalizados en otros campos de conocimiento (John y Johnson, 2001; Dembe et al., 2011) se han incorporado ya a este campo de estudio o si por el contrario la investigación se realiza de forma básica o de manera manual.

En dos últimas variables cuantitativas se registra si se trata de una investigación financiada y si existe declaración de conflictos de interés. La primera cuestión se recoge frecuentemente en los artículos de cualquier disciplina y está directamente relacionada con la segunda variable, ya que uno de los asuntos que puede entrar en conflicto de interés es la financiación y el sostenimiento económico de la investigación. Este último aspecto tiene que ver con la ética, la independencia y la transparencia en la investigación (Smith, 1998) y su declaración es un requisito creciente en revistas de diversos ámbitos, como el de la medicina clínica, gracias al trabajo de grupos internacionales que han abogado por ello desde los años 70, como el International Committee of Medical Journal Editors -ICMJE- (Culebras y García de Lorenzo, 2009). Se trata así de cuantificar hasta qué punto es un requisito incluido en las revistas en que se publican asuntos centrados en la comunicación como criterio de calidad de estas (Delgado López-Cózar et al., 2006).

La dimensión análisis de contenido se completa con dos apartados de carácter cualitativo. En el primer apartado se añaden valoraciones y/o reflexiones acerca de cada artículo. De esta forma, es posible comentar aspectos relevantes derivados de la observación que no pueden ser recogidos por los métodos cuantitativos. En el segundo aparado se registran las citas literales más relevantes respecto al objeto de estudio. Para ello, se crea un botón denominado "citas" en la base de datos diseñada con el software Filemaker con el que se asocian, para cada entrada, las citas recogidas y las páginas donde se encuentran. La información recogida en ambos apartados ha sido la base para el desarrollo del posterior estudio de revisión. 
Imágenes 3 y 4. Capturas de pantalla de la aplicación propia diseñada con el software Filemaker para la gestión de citas.
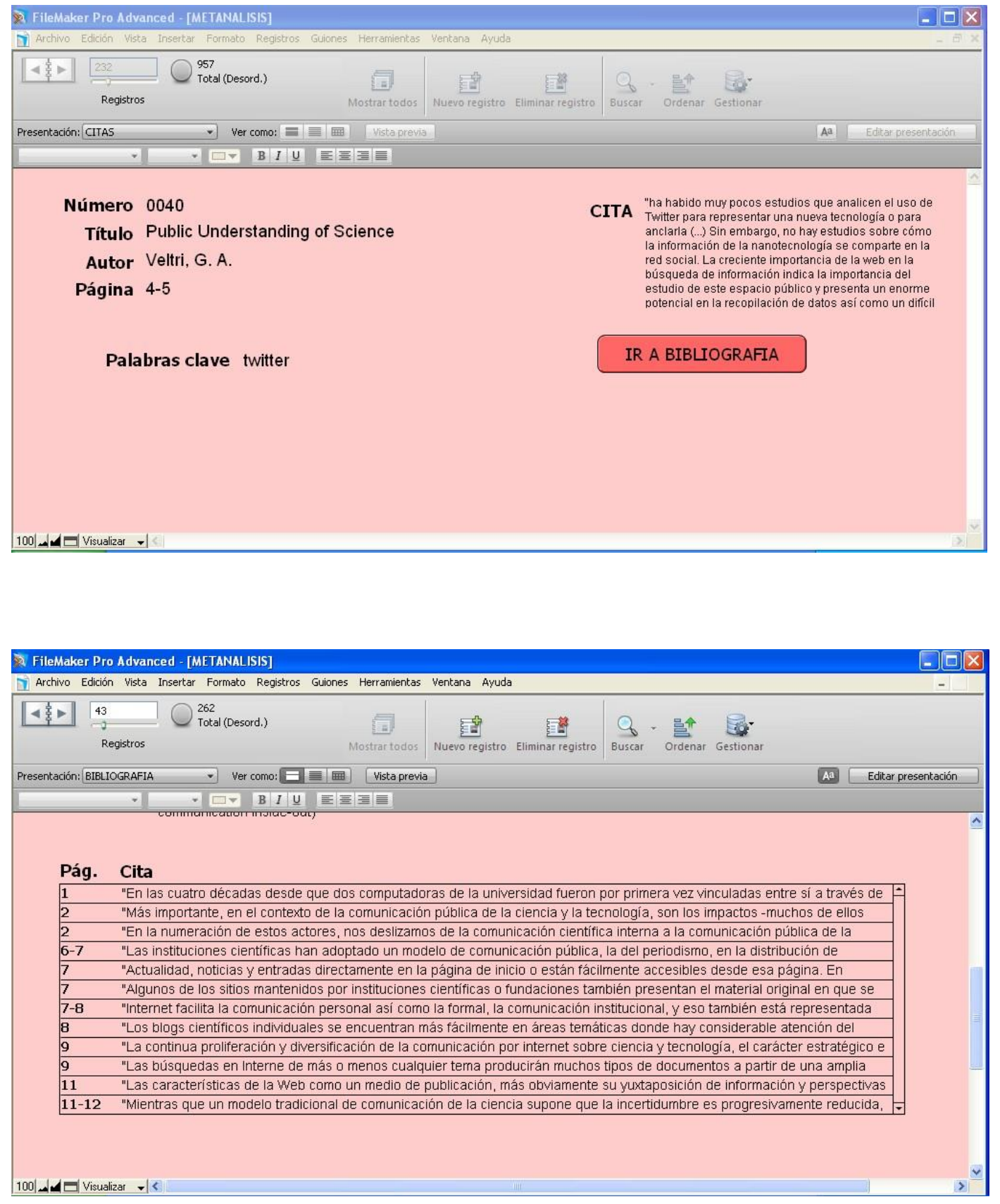

D4. Datos sobre la revista. El objetivo de esta dimensión es recopilar una serie de indicadores bibliométricos básicos, en torno a las características descriptivas de la revista -nombre, país de origen, área de conocimiento a la que perteneceasí como a su visibilidad e impacto -factor de impacto y cuartil-. Los estudios bibliométricos tienen como fin el tratamiento y análisis cuantitativo de las 
publicaciones científicas y forman parte de los estudios sociales de la ciencia (Bordons, 1999; Rocha y Zauith, 2016).

Los datos relativos al factor de impacto y al cuartil se toman del SClmago Journal Rank, que proporciona un índice de calidad (SFR Indicator) relativo de las revistas incluidas en la base de datos Scopus, como una de las fuentes bibliográficas cuya calidad está unánimemente reconocida a nivel internacional y es especialmente valorada por los bibliómetras y cienciómetras (Falagas et al., 2008; Quintás-Froufe, 2015; Gómez Núñez, 2015).

\subsection{RESULTADOS}

La investigación sobre comunicación de la ciencia en Internet parece seguir una evolución paralela a la de la propia red. Se inicia a mediados de los años 90, con un primer trabajo publicado y titulado: Could the internet balkanize Science? (Van Alstyne y Brynjolfsson, 1996), y experimenta un crecimiento sostenido en el tiempo hasta 2008, cuando esta progresión se acentúa notablemente. Es el año 2013 el que registra un mayor número de trabajos, 40 (el 19,51\% del total), a partir de él, se observa un descenso acusado de la productividad. 
Gráfico 1. Evolución temporal del número de artículos publicados.

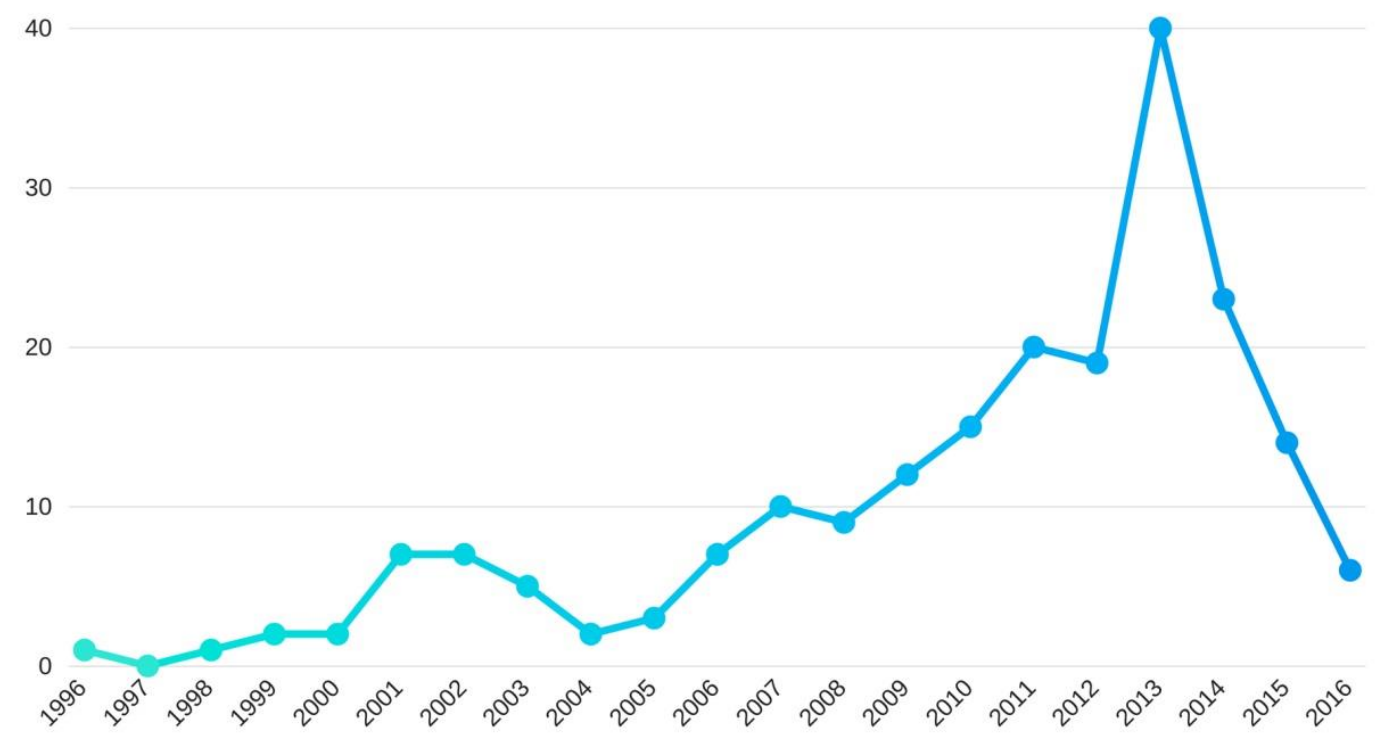

Fuente: elaboración propia

El inglés, al igual que en la mayor parte de las disciplinas académicas (Ammon, 2001; Enrique Hamel, 2007), es el idioma científico de referencia que también impera en la investigación analizada. Tres de cada cuatro artículos localizados emplean el inglés, casi un $20 \%$ el castellano y solo un $6,34 \%$ el portugués.

La accesibilidad al artículo está estrechamente relacionada con el idioma, siendo los artículos no escritos en inglés los más accesibles. El 97,5\% de los artículos en castellano y el $92,31 \%$ de los artículos en portugués son de libre acceso, El caso del inglés es diferente. Aunque la tendencia Open Access es palpable (el 63,82\% de los artículos en inglés estudiados lo es), un porcentaje aún elevado de estos artículos sigue siendo de pago $(36,18 \%)$.

Tabla 1. Accesibilidad a los artículos según el idioma.

\begin{tabular}{|c|c|c|c|c|c|c|c|c|}
\hline & \multicolumn{2}{|c|}{ Inglés } & \multicolumn{2}{|c|}{ Castellano } & \multicolumn{2}{|c|}{ Portugués } & \multicolumn{2}{|c|}{ Total } \\
\hline Abierto & 98 & $63,82 \%$ & 39 & $97,50 \%$ & 12 & $92,31 \%$ & 148 & $72,20 \%$ \\
\hline De pago & 54 & $36,18 \%$ & 1 & $2,50 \%$ & 1 & $7,69 \%$ & 57 & $27,80 \%$ \\
\hline Total & 152 & $100,00 \%$ & 40 & $100,00 \%$ & 13 & $100,00 \%$ & 205 & $100,00 \%$ \\
\hline
\end{tabular}

Fuente: elaboración propia

La comunidad científica internacional parece seguir optando en buena medida por revistas que requieren suscripción, pese a que esto, a priori, le puede restar difusión (Antelman, 2004; Harnad y Brody, 2004). No obstante, la emergencia de redes 
sociales académicas como ResearchGate y Academia.edu puede paliar esta situación, al permitir un acceso abierto a los artículos bajo petición. Para ahondar en este nuevo escenario se recogió una segunda variable para los artículos de pago, que medía la posibilidad de un acceso abierto secundario a través de dichas redes sociales académicas.

Tabla 2. Posibilidad de acceso abierto secundario a través de RRSS académicas de los artículos de pago en inglés.

\begin{tabular}{|c|cr|}
\hline Artículos de pago & \multicolumn{2}{c|}{ Inglés } \\
\hline Sin acceso secundario en RRSS académicas & 14 & $25,45 \%$ \\
\hline Con acceso secundario en RRSS académicas & 40 & $74,55 \%$ \\
\hline Total & 54 & $100,00 \%$ \\
\hline
\end{tabular}

Fuente: elaboración propia

Los resultados obtenidos apuntan a un alto impacto de las redes sociales académicas como canales alternativos de difusión de la investigación. Un 74,55\% de los artículos registrados de pago pueden obtenerse previa solicitud en ResearchGate y/o Academia.edu. De este modo, ya sea por vía directa o indirecta, los investigadores en comunicación de la ciencia a través de Internet pueden acceder al 92,68\% de los artículos publicados sin coste alguno.

\subsubsection{AUTORÍA DE LA INVESTIGACIÓN}

Prácticamente la mitad de los artículos sobre comunicación de la ciencia en Internet tienen un único autor $(46,83 \%)$, lo que sugiere que no hay grandes equipos de investigación trabajando en la actualidad en esta línea y que el interés en la misma es fundamentalmente personal. En este sentido, un 35,12\% de los trabajos tienen dos o tres autores, lo que también indica una ausencia de amplias colaboraciones, solo presentes en un $18,05 \%$ de los artículos.

No toda la investigación sobre comunicación de la ciencia en Internet es estrictamente académica. Otros actores relacionados con la comunicación de la ciencia contribuyen a un mayor conocimiento de este objeto de estudio, de modo que en casi un 16\% del total de 205 artículos analizados, el autor o alguno de los coautores es periodista en activo $(11,71 \%)$, divulgador científico $(3,41 \%)$ o técnico procedente del mundo de la empresa $(0,49 \%)$. 
Gráfico 1. Número (A) y perfil de los autores (B).
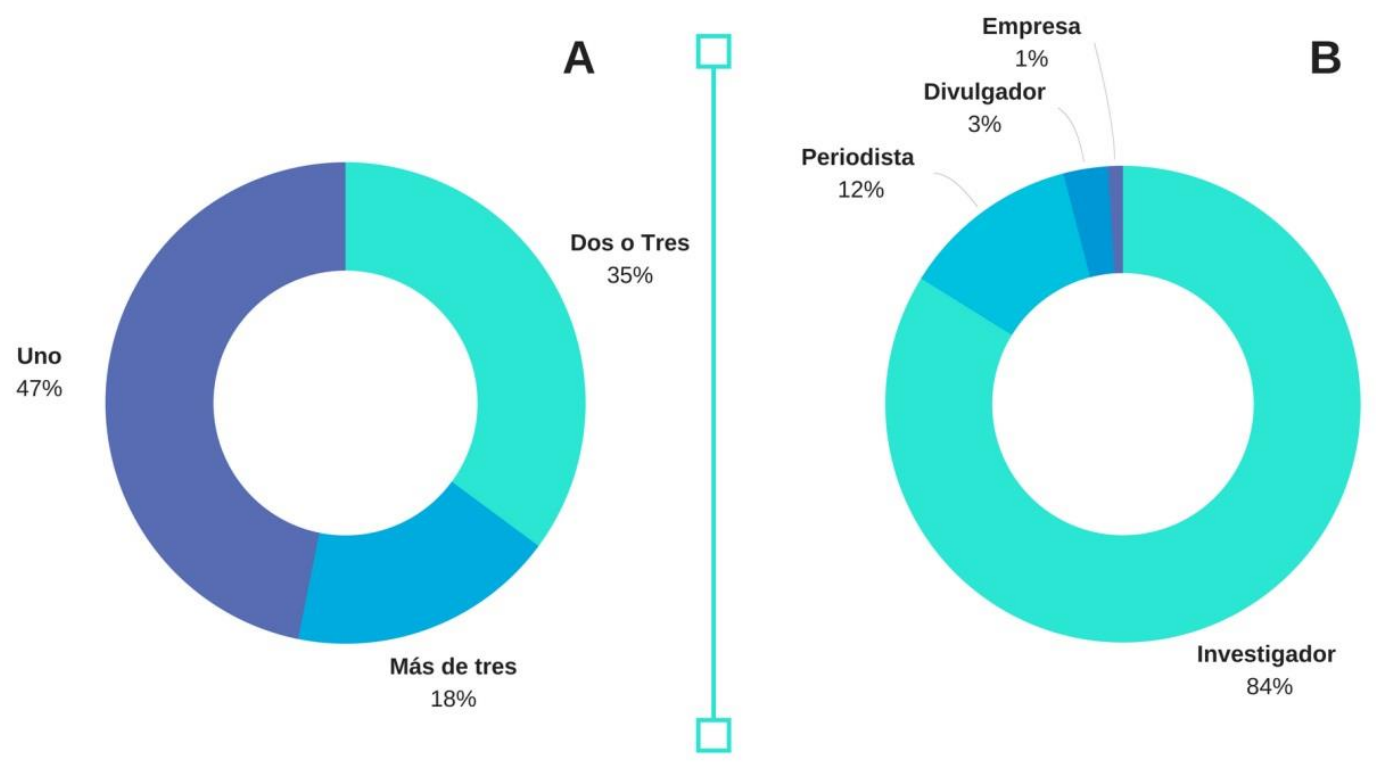

Fuente: elaboración propia

Solo una veintena de académicos tienen 2 o más artículos publicados en esta línea de investigación, como primeros autores. Richard Holliman, investigador de The Open University (Reino Unido), es el autor más productivo con 4 artículos. Dominique Brossard y Ashley A. Anderson10, dos investigadoras que durante años han formado parte del mismo equipo de investigación en la Universidad de Wisconsin-Madison (Estados Unidos), son primeras autoras de 3 artículos cada una. También Stuart Allan, adscrito en la actualidad a la Universidad de Cardiff (Reino Unido), y Carlos Elías, de la Universidad Carlos III de Madrid (España), firman 3 artículos cada uno.

${ }^{10}$ Ashley A. Anderson está adscrita actualmente a la Universidad Estatal de Colorado (Estados Unidos). 
Tabla 3. Listado de autores más productivos. Primeros autores de 20 más artículos.

\begin{tabular}{|c|c|}
\hline Autor & No artículos \\
\hline Richard Holliman & 4 \\
\hline Ashley A. Anderson & 3 \\
\hline Carlos Elías Pérez & 3 \\
\hline Dominique Brossard & 3 \\
\hline Stuart Allan & 3 \\
\hline Alessandro Delfanti & 2 \\
\hline Alina Pérez Martínez & 2 \\
\hline Ana Bellón Rodríguez & 2 \\
\hline Cristiane de Magalhães Porto & 2 \\
\hline Geoff Brumfiel & 2 \\
\hline Ginger Pinholster & 2 \\
\hline Hadas Shema & 2 \\
\hline Herly Alejandra Quiñónez Gómez & 2 \\
\hline Laura Bonetta & 2 \\
\hline Lourdes López-Pérez & 2 \\
\hline Marie-Claire Shanahan & 2 \\
\hline Monica Macedo-Rouet & 2 \\
\hline Nan Li & 2 \\
\hline Paige Brown Jarreau & 2 \\
\hline Stephan Winter & 2 \\
\hline
\end{tabular}

Fuente: elaboración propia

En cuanto a la perspectiva de género, la proporción entre mujeres y hombres es equilibrada en las tres variables medidas. Incluso hay más mujeres autoras principales que hombres en este objeto de estudio (55,12\% frente al $44,88 \%)$. La presencia de mujeres en coautoría se da asimismo en el 75,23\% de los artículos con 2 o más autores y el equilibrio entre hombres y mujeres en los equipos de investigación es efectivo en el $87,25 \%$ de los trabajos analizados. 
Gráfico 2. Género del autor principal (A), presencia de mujeres en coautoría (B) y equilibrio entre hombres y mujeres en los equipos de investigación (C).

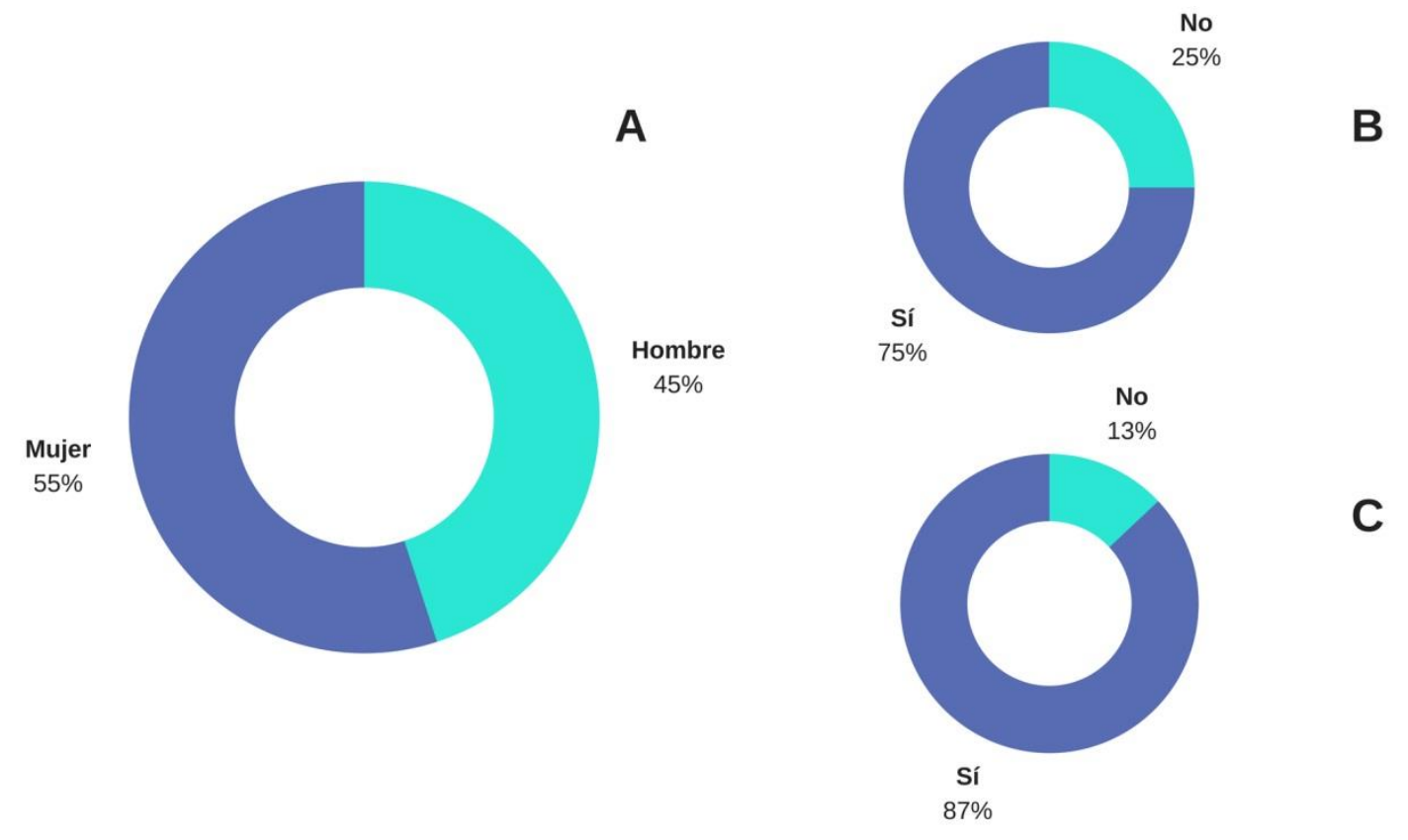

Fuente: elaboración propia

En relación con los países de afiliación de los primeros autores, se han contabilizado investigadores procedentes de 28 países distintos. Los países con mayor productividad científica general son prácticamente los mismos que los más productivos en investigación de la comunicación de la ciencia en Internet, con Estados Unidos claramente a la cabeza. ${ }^{11}$

\footnotetext{
${ }^{11}$ Se tiene en cuenta el Ranking por países que elabora anualmente SJR (Scimago Journal \& Country Rank). Más información disponible sobre dicho Ranking en: http://ow.ly/K8Dq30k0GAF (última consulta 07/03/2018)
} 
Tabla 4. Comparativa de los 10 países más productivos sobre comunicación de la ciencia en Internet vs SJR Country Ranking.

\begin{tabular}{|c|c|}
\hline $\begin{array}{c}\text { Países de los autores } \\
\text { principales }\end{array}$ & SJR Country Ranking \\
\hline Estados Unidos & Estados Unidos \\
\hline España & China \\
\hline Reino Unido & Reino Unido \\
\hline Brasil & Alemania \\
\hline Canadá & Japón \\
\hline Alemania & Francia \\
\hline Italia & Canadá \\
\hline Israel & Italia \\
\hline China & India \\
\hline Holanda & España \\
\hline
\end{tabular}

Fuente: elaboración propia

Relacionando el país de procedencia con el idioma del texto, mientras que en portugués la investigación sobre comunicación de la ciencia en Internet está claramente dominada por los investigadores brasileños $(84,62 \%)$, en castellano predominan los españoles (70\%) y en inglés la autoría principal más frecuente es la norteamericana $(44,03 \%)$.

Se observa asimismo que los investigadores procedentes de países de habla castellana publican únicamente en castellano, salvo los argentinos $-50 \%$ castellano y $50 \%$ inglés- y los españoles $-87,32 \%$ castellano y $12,52 \%$ inglés-. En el caso de los investigadores de habla portuguesa, publican indistintamente en portugués o en inglés -los portugueses un $50 \%$ en inglés y un $50 \%$ en portugués, y los brasileños un $21,5 \%$ en inglés y un $78,5 \%$ en portugués-. 
Gráfico 3. Países de afiliación de los primeros autores y porcentaje de artículos publicados en inglés, castellano y/o portugués.

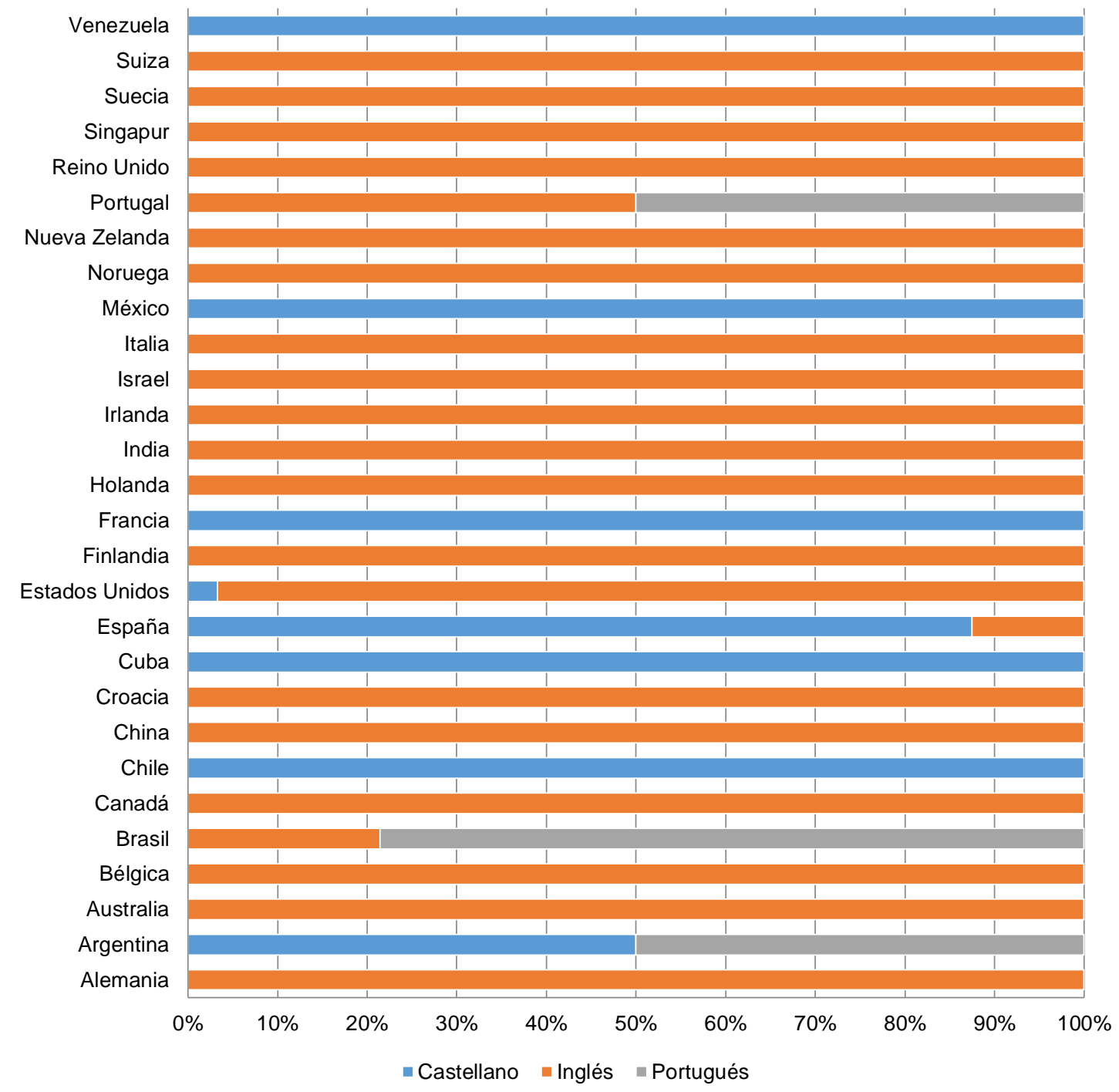

Fuente: elaboración propia

El alcance de las colaboraciones y las redes científicas en esta línea de investigación es muy limitado, tal y como apuntan otros trabajos de metanálisis en el ámbito de la comunicación (Escribà y Cortiñas, 2013). En la mayor parte de los artículos en coautoría -que solo son la mitad de los analizados, frente a otros metanálisis que elevan la tasa de coautoría hasta el 65\% (Sancho et al., 2006) -, la colaboración se reduce a investigadores que proceden de la misma institución $(45,92 \%)$. La colaboración es regional, es decir, se produce entre investigadores de diferentes entidades del mismo entorno local en un 10,2\% de los artículos en coautoría y se amplía a entidades de otros puntos de la misma nación en un $23,47 \%$. En solo 2 
de cada 10 artículos en coautoría, esta tiene un alcance internacional, y si se tiene en cuenta el total de los artículos, solo 1 de cada 10 la tiene.

Gráfico 4. Alcance de la colaboración en los artículos en coautoría.

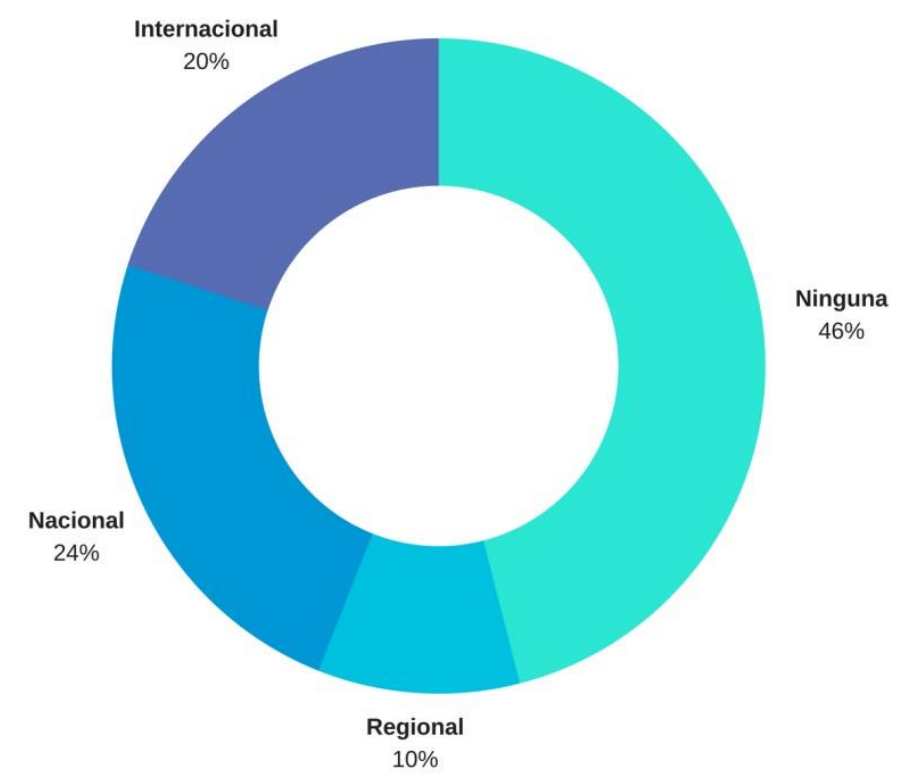

Fuente: elaboración propia

En relación con los países de afiliación de los autores secundarios, resulta significativo que en total se han registrado solo 18 países, es decir, las colaboraciones parecen circunscribirse a entornos muy concretos, lo que ofrece pistas sobre dónde se está desarrollando mayormente la investigación en este campo. Teniendo en cuenta los artículos en inglés, Estados Unidos es de nuevo el país donde se adscriben la gran mayoría de los autores secundarios $(62,91 \%), 54$ puntos por delante del siguiente país en relevancia, Brasil (8,61\%). 
Gráfico 5. Países de afiliación de los autores secundarios de los artículos en inglés.

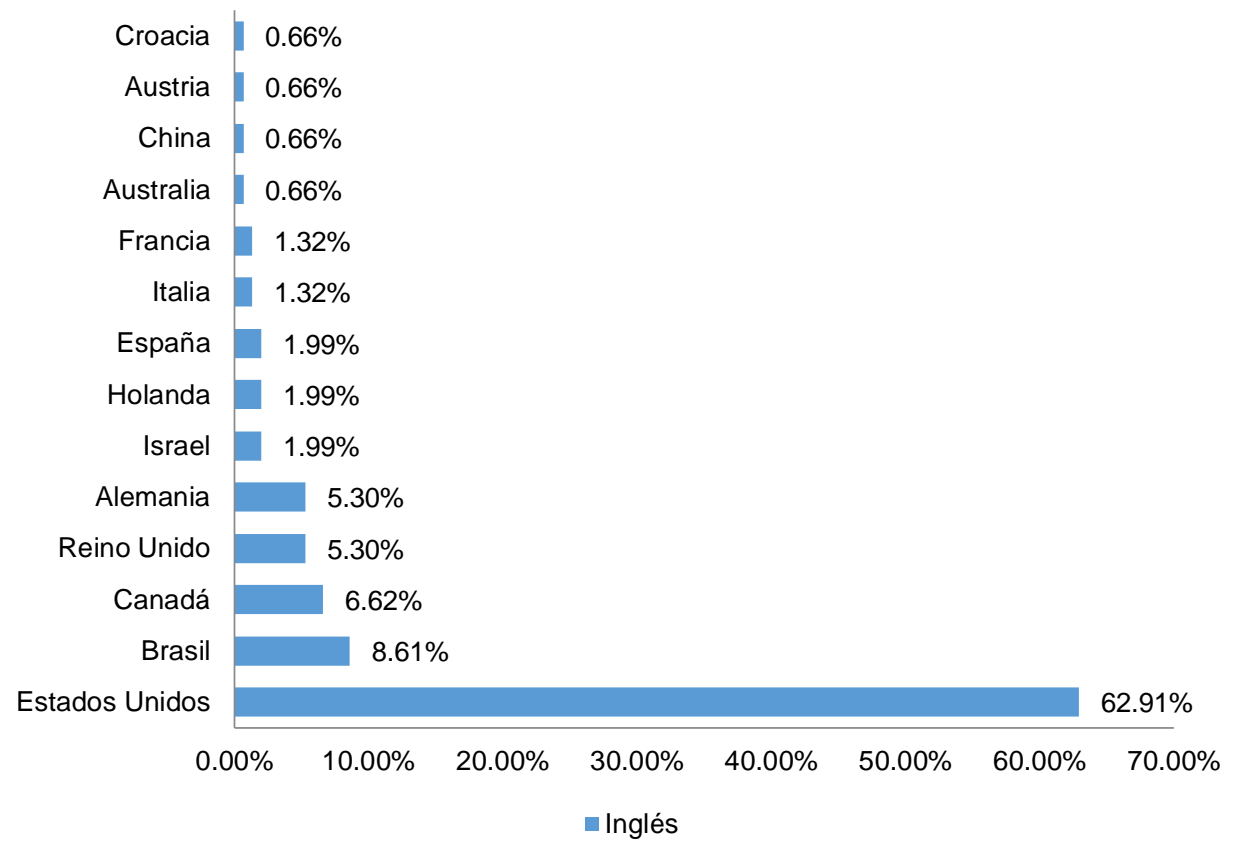

Fuente: elaboración propia

La Universidad de Wisconsin (Estados Unidos) es la más productiva en esta línea de investigación (encabeza 11 artículos y 51 de sus investigadores son coautores de distintos trabajos). A partir del nombre del autor principal y de la afiliación de los autores principales y secundarios se ha detectado un grupo de investigación liderado por Dietram A. Sheufele, Ashley A. Anderson y Dominique Brossard en el Departamento de Comunicación de Ciencias de la Vida de la Universidad en Madison, que incluye entre sus líneas de investigación la comunicación de la ciencia a través de medios digitales; en concreto, la comunicación de la nanotecnología y su difusión a través de la web. Los editores de la revista Nature, con 5 artículos, y las universidades de California (Estados Unidos) -con 4 autorías principales y 6 coautorías- y Nottingham (Reino Unido) -con 4 artículos principales y 3 coautorias, son también las entidades con más trabajos en esta línea.

En idioma castellano, son tres universidades españolas, la Carlos III de Madrid, la del País Vasco y la de Granada, con 3 artículos cada una, las más productivas en este objeto de estudio. En portugués, tan solo dos instituciones brasileñas cuentan con más de un artículo cada una, la Fundaçao Oswaldo Cruz y la Universidad Federal de Pernambuco, con 2.

En cuanto a la disciplina de los autores principales, la mayor parte de la investigación sobre comunicación de la ciencia en Internet es realizada por autores 
procedentes de áreas ajenas a la comunicación, una situación que había sido advertida previamente en un trabajo relacionado con el periodismo científico (Moreno Castro, 2003). Solo proceden de este ámbito el $44,39 \%$ de los primeros autores, y un $12,68 \%$ más a otros ámbitos de las ciencias sociales (sociología, técnicas de la investigación social, ciencia política y de la administración, periodismo, comunicación audiovisual, publicidad y geografía humana).

Al margen de las ciencias sociales, se han registrado otras 11 disciplinas de las que proceden los primeros autores. Las más frecuentes son educación $(14,75 \%)$, medicina clínica (14,75\%), filología y filosofía (14,75\%), biología física y de sistemas (13,11\%) y biología vegetal, animal y ecosistemas (9,84\%).

Gráfico 6. Disciplinas de los 117 autores principales que no proceden de las ciencias sociales y relación con el idioma del artículo.

\begin{tabular}{|ccccc|}
\hline Disciplina & Inglés & Portugués & Castellano & Total (117) \\
\hline AGR & $1,64 \%$ & $1,64 \%$ & $0,00 \%$ & $3,28 \%$ \\
\hline BFS & $11,48 \%$ & $0,00 \%$ & $1,64 \%$ & $13,11 \%$ \\
\hline BMED & $6,56 \%$ & $0,00 \%$ & $0,00 \%$ & $6,56 \%$ \\
\hline BVAE & $9,84 \%$ & $0,00 \%$ & $0,00 \%$ & $9,84 \%$ \\
\hline CT & $3,28 \%$ & $0,00 \%$ & $0,00 \%$ & $3,28 \%$ \\
\hline ECO & $1,64 \%$ & $0,00 \%$ & $0,00 \%$ & $1,64 \%$ \\
\hline EDUC & $13,11 \%$ & $0,00 \%$ & $1,64 \%$ & $14,75 \%$ \\
\hline FFI & $11,48 \%$ & $3,28 \%$ & $0,00 \%$ & $14,75 \%$ \\
\hline FI & $3,28 \%$ & $0,00 \%$ & $0,00 \%$ & $3,28 \%$ \\
\hline HA & $1,64 \%$ & $1,64 \%$ & $0,00 \%$ & $3,28 \%$ \\
\hline HU & $1,64 \%$ & $0,00 \%$ & $0,00 \%$ & $1,64 \%$ \\
\hline MCLI & $13,11 \%$ & $0,00 \%$ & $1,64 \%$ & $14,75 \%$ \\
\hline PS & $3,28 \%$ & $1,64 \%$ & $0,00 \%$ & $4,92 \%$ \\
\hline QMC & $4,92 \%$ & $0,00 \%$ & $0,00 \%$ & $4,92 \%$ \\
\hline Total (117) & $\mathbf{8 6 , 8 9 \%}$ & $\mathbf{8 , 2 0} \%$ & $\mathbf{4 , 9 2} \%$ & $\mathbf{1 0 0 , 0 0 \%}$ \\
\hline
\end{tabular}

Fuente: elaboración propia

Aproximadamente 1 de cada 5 artículos analizados cuenta con autores procedentes de dos o más disciplinas. Teniendo en cuenta el idioma del texto, los autores que publican en inglés son los que realizan más investigación pluridisciplinar, mientras que aquellos que lo hacen en castellano son menos pluridisciplinares. 
Tabla 5. Pluridisciplinariedad de la investigación en función del idioma del artículo.

\begin{tabular}{|c|ccccccccc|} 
& \multicolumn{2}{c}{ Inglés } & \multicolumn{2}{c}{ Castellano } & \multicolumn{2}{c}{ Portugués } & \multicolumn{2}{c}{ Total } \\
\hline Pluridisciplinar & 39 & $19,02 \%$ & 2 & $0,98 \%$ & 4 & $1,95 \%$ & 45 & $21,95 \%$ \\
\hline No pluridisciplinar & 45 & $21,95 \%$ & 12 & $5,85 \%$ & 5 & $2,44 \%$ & 62 & $30,24 \%$ \\
\hline Sólo un autor & 68 & $33,17 \%$ & 26 & $12,68 \%$ & 4 & $1,95 \%$ & 98 & $47,80 \%$ \\
\hline Total (205) & 152 & $74,15 \%$ & 40 & $19,51 \%$ & 13 & $6,34 \%$ & 205 & $100,00 \%$ \\
\hline
\end{tabular}

Fuente: elaboración propia.

La colaboración pluridisciplinar más frecuente se produce entre investigadores de distintas áreas dentro de las ciencias sociales (33,03\%). También se han registrado coocurrencias significativas entre ciencias sociales y medicina clínica $(9,17 \%)$, ciencias sociales y biomedicina (8,2\%), medicina clínica y biología física y de sistemas $(4,92 \%)$ y educación y ciencias sociales $(4,59 \%)$. 


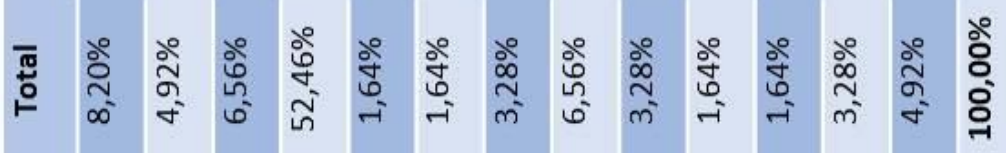

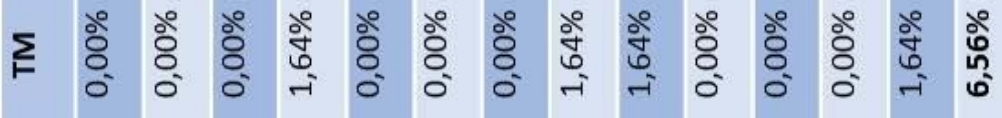

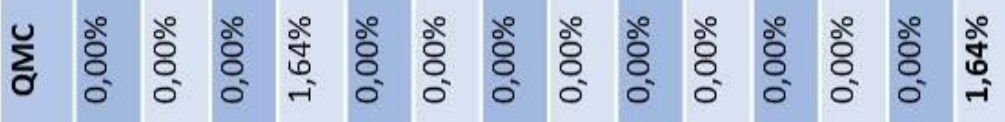

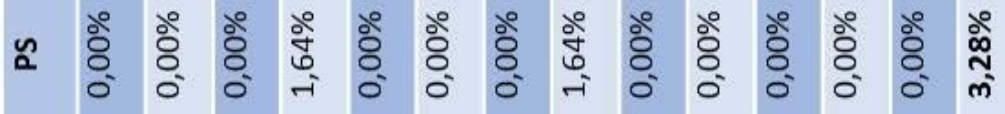

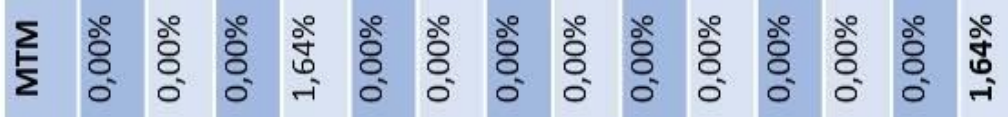

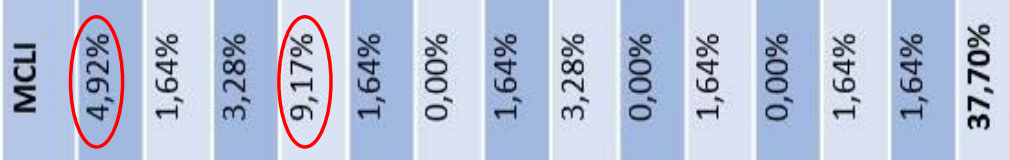

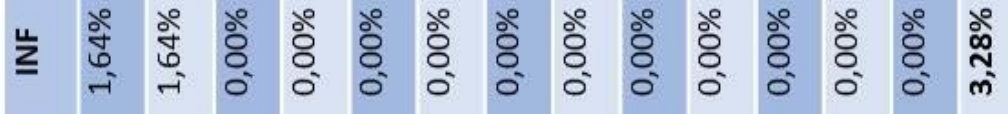

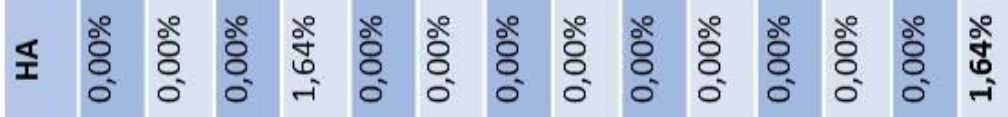
ч

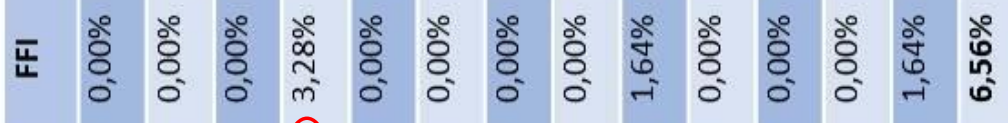
乡 豙

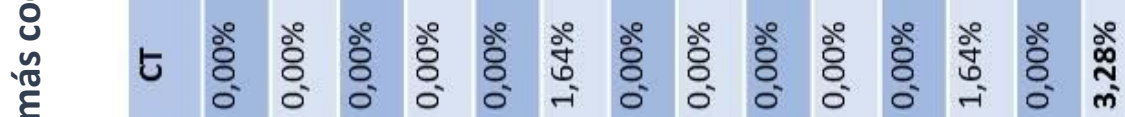

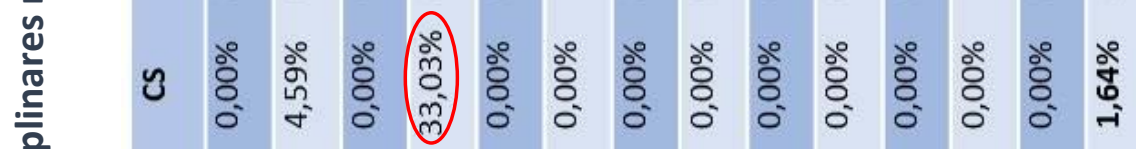

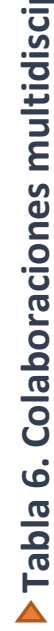

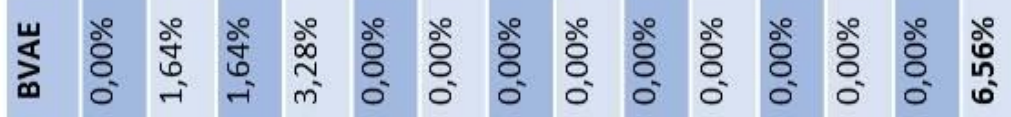

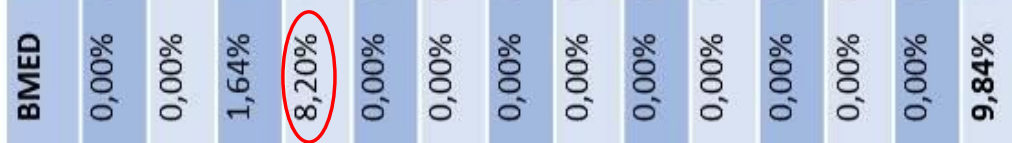

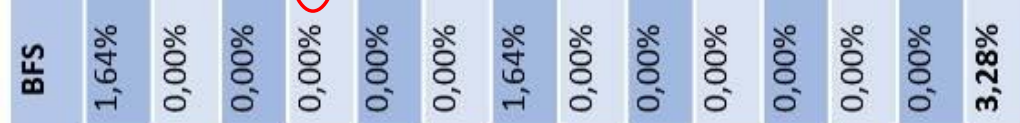




\subsubsection{ESTRUCTURA Y CONTENIDO DE LA INVESTIGACIÓN}

En relación con la estructura, la presencia de resumen $(79,51 \%)$ es más frecuente que la inclusión de palabras clave $(53,66 \%)$ en los artículos analizados. En el caso de los artículos en castellano o portugués, se estimó además su traducción a inglés como criterio de calidad que utilizan entidades de referencia como FECYT en España. En el caso del título, es traducido al inglés en el 60,38\% de los artículos en castellano o portugués. Cuando se incluyen palabras clave en los artículos, estas son traducidas en un $70,45 \%$ de los casos analizados, un porcentaje mayor que el que registra la traducción del resumen $(65,22 \%)$, quizás debido a la importancia de las palabras clave como elementos clave para la localización posterior del artículo en las bases de datos.

Tabla 7. Estructura del artículo: presencia de resumen y palabras clave. Traducción al inglés de resumen, palabras clave y título en los artículos en castellano y portugués.

\begin{tabular}{|ccc|ccc|}
\hline Abstract & & & Traducción de abstract & \\
\hline No & 42 & $20,49 \%$ & No & 16 & $34,78 \%$ \\
\hline Sí & 163 & $79,51 \%$ & Sí & 30 & $65,22 \%$ \\
\hline Total & 205 & $100,00 \%$ & Total & 46 & $100,00 \%$ \\
\hline Palabras clave & & & Traducción palabras clave & \\
\hline No & 95 & $46,34 \%$ & No & 13 & $29,55 \%$ \\
\hline Sí & 110 & $53,66 \%$ & Sí & 31 & $70,45 \%$ \\
\hline Total & 205 & $100,00 \%$ & Total & 44 & $100,00 \%$ \\
\hline Título & & & Traducción de título & & \\
\hline No & 0 & $0,00 \%$ & No & 21 & $39,62 \%$ \\
\hline Sí & 205 & $100,00 \%$ & Sí & 32 & $60,38 \%$ \\
\hline Total & 205 & $100,00 \%$ & Total & 53 & $100,00 \%$ \\
\hline
\end{tabular}

Fuente: elaboración propia

Otro de los criterios que se utilizan para evaluar la calidad de los artículos, el modelo de redacción IMRyD (Introducción, Metodología, Resultados y Discusión), se utiliza solo en el 39,02\% de los artículos. Las diferencias en el uso del modelo IMRyD en función del idioma son significativas. Mientras que casi la mitad de los artículos en inglés ya adopta este enfoque (45,39\%), en castellano el porcentaje se reduce al $27,5 \%$. Resulta especialmente llamativo que ninguno de los artículos en portugués lo aplica. 
Tabla 8. Uso del modelo de redacción IMRyD en relación con el idioma del artículo.

\begin{tabular}{|cccccccccc|}
\hline Modelo IMRyD & & Castellano & & Inglés & & Portugués & Total \\
\hline No & 29 & $72,50 \%$ & 83 & $54,61 \%$ & 13 & $100 \%$ & 125 & $60,98 \%$ \\
\hline Sí & 11 & $27,50 \%$ & 69 & $45,39 \%$ & 0 & $0,00 \%$ & 80 & $39,02 \%$ \\
\hline Total & 40 & $100 \%$ & 152 & $100 \%$ & 13 & $100 \%$ & 205 & $100 \%$ \\
\hline
\end{tabular}

Fuente: elaboración propia

Por otro lado, la recogida de las palabras clave ha permitido la construcción de un tesauro específico sobre comunicación de la ciencia a través de Internet (Anexo III). Aunque el criterio inicial seleccionado para la construcción del mismo fue el registro de las palabras clave que se repetían en 2 o más artículos, finalmente se ha decidido incluir el total de las palabras registradas, ya que la repetición de palabras clave no es frecuente en la muestra analizada y el registro completo puede ser de utilidad para la comunidad investigadora. En inglés, tan solo 61 de las 330 cadenas de palabras recuperadas se repite en 2 o más ocasiones (el 18,48\%), y lo mismo sucede con en castellano (solo se repiten 20 de 104 palabras clave, el 19,23\%) y en portugués (2 de 36 , el 5,55\%), quizás debido a que se trata de un objeto de investigación relativamente nuevo o a la heterogeneidad y la dispersión de la investigación realizada hasta la fecha.

En relación con el contenido de los artículos, la primera variable medida es el campo de estudio, utilizando como criterio los elementos característicos del proceso comunicativo planteado por Lasswell (1985). De este modo, el canal es el objeto de estudio preferende en la investigación de la comunicación de la ciencia a través de Internet $(39,51 \%)$, seguido a una distancia notable del mensaje (20\%). Los efectos de la comunicación son, por el contrario, el campo menos estudiado $(6,34 \%)$.

Del total de artículos analizados, 70 realizan estudios de caso en temáticas científicas concretas $(34,14 \%)$. Las temáticas preferentes son, por este orden, la medicina clínica (28,57\%), la biología vegetal, animal y de ecosistemas $(21,43 \%)$ y la tecnología de materiales (15,71\%). Asimismo, el estudio de la comunicación de riesgos de carácter científico y tecnológico es una línea de investigación frecuente $(15,12 \%)$. 
Gráfico 7. Campos de estudio (A) y temáticas de los estudios de caso (B).
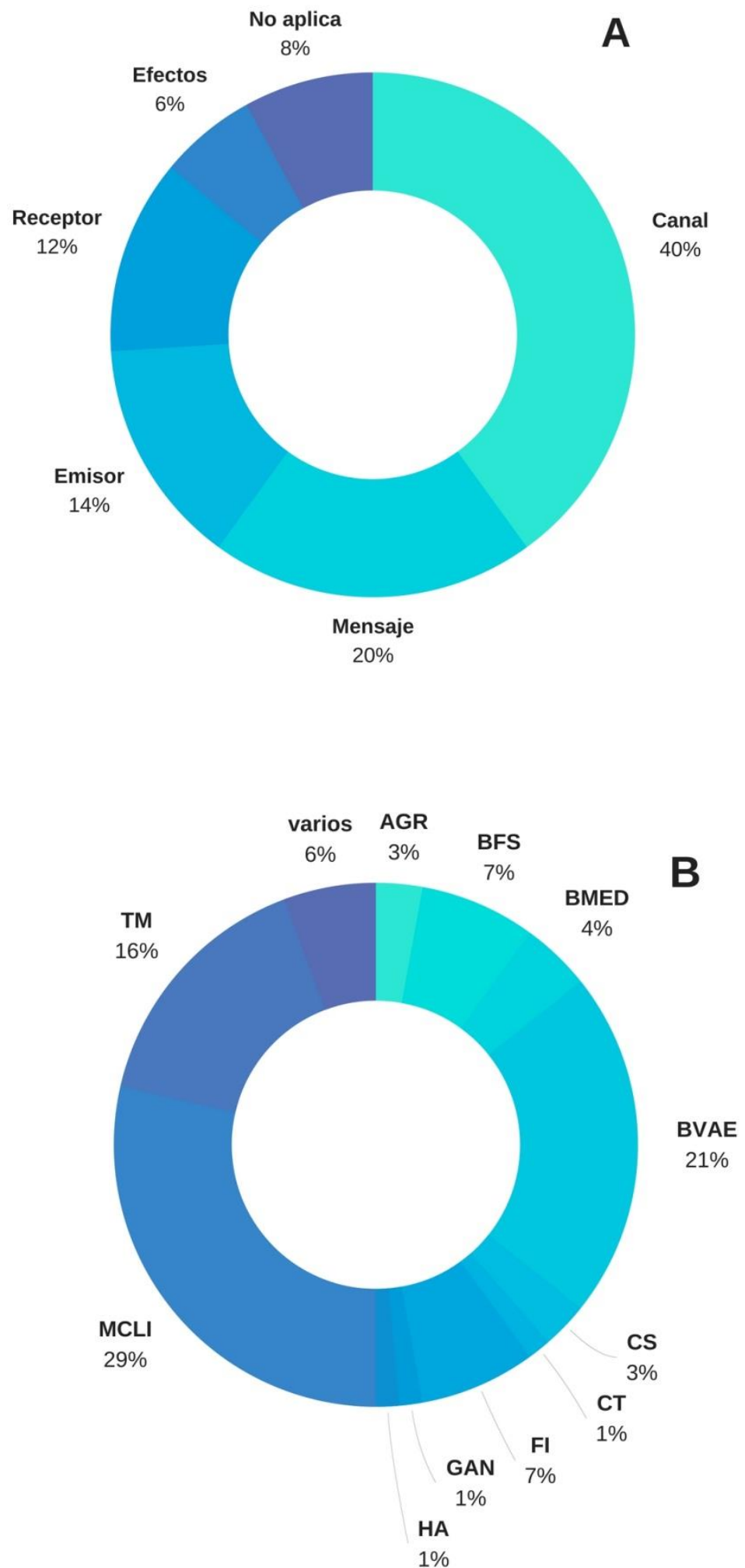

Fuente: elaboración propia 
En relación con el enfoque investigador, los datos totales muestran un ligero predominio de la investigación empírica (42,93\%) frente a la teórica (40,98\%), y en solo el $16,1 \%$ de los artículos se observa un enfoque mixto. La perspectiva metodológica dominante en la muestra analizada es la cualitativa $(61,46 \%)$, mientras que la cuantitativa se aplica en un $26,86 \%$ de los artículos y solo el $11,22 \%$ emplea métodos mixtos.

Son significativas las diferencias registradas en estas dos variables en función del idioma del artículo. La investigación desarrollada en inglés registra mejores datos en relación con el uso de enfoques mixtos $(18,42 \%)$, aunque en cualquier caso el porcentaje es reducido. También se observa que en la investigación teórica es la más frecuente en castellano $(57,5 \%)$, mientras que el empírico es el enfoque más aplicado en portugués $(44,08 \%)$ e inglés $(44,08 \%)$.

Tabla 9. Enfoque investigador y perspectiva metodológica en función del idioma del artículo.

\begin{tabular}{|ccccccccc}
$\begin{array}{c}\text { Enfoque } \\
\text { investigador }\end{array}$ & & Castellano & & Inglés & & Portugués & Total \\
\hline Empírico & 11 & $35,00 \%$ & 67 & $44,08 \%$ & 7 & $53,85 \%$ & 85 & $42,93 \%$ \\
\hline Teórico & 23 & $57,50 \%$ & 57 & $37,50 \%$ & 4 & $30,77 \%$ & 84 & $40,98 \%$ \\
\hline Mixto & 6 & $7,50 \%$ & 28 & $18,42 \%$ & 2 & $15,38 \%$ & 36 & $16,10 \%$ \\
\hline Total & 40 & $100,00 \%$ & 152 & $100,00 \%$ & 13 & $100,00 \%$ & 205 & $100,00 \%$ \\
\hline $\begin{array}{c}\text { Perspectiva } \\
\text { metodológica }\end{array}$ & & Castellano & & Inglés & & Portugués & & Total \\
\hline Cualitativa & 33 & $82,50 \%$ & 85 & $55,92 \%$ & 8 & $61,54 \%$ & 126 & $61,46 \%$ \\
\hline Cuantitativa & 5 & $12,50 \%$ & 46 & $30,26 \%$ & 4 & $30,77 \%$ & 55 & $26,83 \%$ \\
\hline Mixta & 1 & $2,50 \%$ & 21 & $13,82 \%$ & 1 & $7,69 \%$ & 23 & $11,22 \%$ \\
\hline Sin información & 1 & $2,50 \%$ & 0 & $0,00 \%$ & 0 & $0,00 \%$ & 1 & $0,49 \%$ \\
\hline Total (205) & 40 & $100,00 \%$ & 152 & $100,00 \%$ & 13 & $100,00 \%$ & 205 & $100,00 \%$ \\
\hline
\end{tabular}

Fuente: elaboración propia

Las metodologías cualitativas son las más frecuentes en los tres idiomas analizados, aunque con diferencias importantes entre ellos -en castellano representan el $82,5 \%$, en portugués el $61,54 \%$ y en inglés el 55,92\%-. En ninguno de los tres idiomas la aplicación de una perspectiva metodológica mixta es significativa. No obstante, son los artículos en inglés los que integran en mayor medida dicho planteamiento $(13,82 \%)$, el más recomendado para obtener unos resultados más sólidos en la investigación en Ciencias Sociales (Duffy, 1987; Morse, 1991). 
La presencia de capítulo metodológico detallado se ha registrado solo en un 34,15\% del total de artículos, lo que parece indicar un déficit de transparencia investigadora en este campo. En un 10,73\% de los artículos existe capítulo metodológico, pero es meramente informativo, mientras que en la mayoría de los casos no existe ninguna referencia a la metodología $(41,46 \%)$ o aparece una mención somera en otro apartado $(13,66 \%)$.

En línea con esa falta de explicación metodológica, la mención expresa al software utilizado en la investigación se observa solo en un 19,02\% de los trabajos, pese a que en muchos casos parece obvio su uso. En total, se hace referencia a 26 software diferentes en la muestra, siendo los más citados NVivo y SPSS.

Tabla 10. Contenido del artículo: descripción metodológica, uso de software, bibliografía, autocitación, financiación y declaración de conflictos de interés.

\begin{tabular}{|c|c|c|c|c|c|}
\hline \multicolumn{2}{|l|}{ Capítulo metodológico } & \multicolumn{3}{|c|}{ Software } & \multirow[b]{2}{*}{$80,98 \%$} \\
\hline No & 85 & $41,46 \%$ & No & 166 & \\
\hline Mención en otros apartados & 28 & $13,66 \%$ & Sí & 39 & $19,02 \%$ \\
\hline Sí, informativo & 22 & $10,73 \%$ & Total & 205 & $100,00 \%$ \\
\hline Sí, detallado & 70 & $34,15 \%$ & & & \\
\hline Total & 205 & $100,00 \%$ & & & \\
\hline Bibliografía & & & Itocitaci & & \\
\hline No se incluyen referencias & 28 & $13,66 \%$ & No & 109 & $53,43 \%$ \\
\hline Escasas referencias & 51 & $24,88 \%$ & Sí & 95 & $46,57 \%$ \\
\hline Rastreo sin otra met. & 67 & $32,68 \%$ & Total & 205 & $100,00 \%$ \\
\hline Rastreo con otra met. & 59 & $28,78 \%$ & & & \\
\hline Total & 205 & $100,00 \%$ & & & \\
\hline Financiacion & & & lar. conf & & \\
\hline No & 152 & $74,15 \%$ & No & 185 & $90,24 \%$ \\
\hline Sí & 53 & $25,85 \%$ & Sí & 20 & $9,76 \%$ \\
\hline Total & 205 & $100,00 \%$ & Total & 205 & $100,00 \%$ \\
\hline
\end{tabular}

Fuente: elaboración propia

Otra de las variables medidas relacionadas con la calidad de la investigación, el rastreo bibliográfico, es una de las que registra mejores datos. El $61,46 \%$ de los artículos incluye 15 o más referencias bibliográficas, pero solo el $28,78 \%$ refiere autores cuya metodología se ha replicado total o parcialmente. No obstante, es también destacable el $13,66 \%$ de artículos recogidos que no cita referencia alguna. En este sentido, la autocitación, un elemento importante para calcular el factor de impacto de las revistas está presente en casi la mitad de los artículos (46,57\%). 
Las dos últimas variables recogidas en esta dimensión son la mención a la financiación de la investigación y la declaración de conflicto de interés. Pese a la relación que tienen ambas, se hace referencia a financiación en el 25,85\% de los artículos, pero solo hay declaración de conflicto de interés en el 9,76\%, lo que sugiere otro déficit de carácter ético y una falta de exigencia de las revistas académicas en este sentido.

\subsubsection{DATOS SOBRE LA REVISTA}

Las revistas que más artículos publican sobre comunicación de la ciencia en Internet pertenecen, como cabía esperar, al campo de la comunicación de la ciencia y son, por este orden, Journal of Science Communication-JCOM, Science Communication y Public Understanding of Science.

No obstante, un $45,59 \%$ de los artículos se han publicado en revistas que no pertenecen al área de comunicación ni a las ciencias sociales en general, lo que sugiere que la comunicación de la ciencia en Internet es un asunto considerado transversal a todas las ciencias y que suscita un interés general entre la comunidad académica y científica. En el mismo sentido incide el hecho de que las grandes revistas multidisciplinares como Science, PLOS ONE o Nature se encuentren también entre las que más artículos han publicado sobre este asunto.

Tabla 11. Listado de revistas con mayor número de artículos publicados sobre comunicación de la ciencia en Internet.

\begin{tabular}{|c|c|}
\hline Revista & Número de artículos \\
\hline JCOM & 26 \\
\hline Science Communication & 14 \\
\hline Public Understanding of Science & 9 \\
\hline Journalism & 9 \\
\hline Science & 5 \\
\hline PLoS ONE & 5 \\
\hline Nature & 4 \\
\hline Journal of Computer Mediated Communication & 3 \\
\hline Journal of Nanoparticle Research & 3 \\
\hline Mètode: Revista de difusión de la Investigación & 3 \\
\hline PLoS biology & 3 \\
\hline Mediatika & 3 \\
\hline
\end{tabular}

Fuente: elaboración propia 
En total, se han registrado 119 revistas pertenecientes a 20 disciplinas diferentes, siendo las más frecuentes, después de las ciencias sociales y las multidisciplinares, la biología física y de sistemas (5,88\%), la medicina clínica $(4,41 \%)$, la biología vegetal, animal y de ecosistemas $(4,41 \%)$, la informática (3,92\%), la educación (3,43\%) o la filosofía y la filología (2,45\%).

Las revistas de Estados Unidos (34,21\%) y de Reino Unido (33,55\%) son las que aglutinan buena parte de la investigación sobre comunicación de la ciencia en Internet que se publica en inglés, un resultado que puede ser extrapolable a prácticamente cualquier campo de estudio. Asimismo, las revistas españolas concentran en gran medida la investigación que se publica en castellano $(74.36 \%)$, del mismo modo que las revistas brasileñas $(92,31 \%)$ centralizan los artículos escritos en portugués.

Tabla 11. País de origen de la revista en relación con el idioma del artículo.

\begin{tabular}{|ccccc|}
\hline País & Castellano & Inglés & Portugués & Total \\
\hline Alemania & $0,00 \%$ & $3,29 \%$ & $0,00 \%$ & $2,45 \%$ \\
\hline Argentina & $5,13 \%$ & $0,00 \%$ & $0,00 \%$ & $0,98 \%$ \\
\hline Australia & $0,00 \%$ & $0,66 \%$ & $0,00 \%$ & $0,49 \%$ \\
\hline Brasil & $0,00 \%$ & $0,00 \%$ & $92,31 \%$ & $5,88 \%$ \\
\hline Canadá & $0,00 \%$ & $1,32 \%$ & $0,00 \%$ & $0,98 \%$ \\
\hline Colombia & $2,56 \%$ & $0,00 \%$ & $0,00 \%$ & $0,49 \%$ \\
\hline Cuba & $5,13 \%$ & $0,00 \%$ & $0,00 \%$ & $0,98 \%$ \\
\hline Desconocido & $0,00 \%$ & $0,66 \%$ & $0,00 \%$ & $0,49 \%$ \\
\hline España & $74,36 \%$ & $0,66 \%$ & $0,00 \%$ & $14,71 \%$ \\
\hline Estados Unidos & $0,00 \%$ & $34,21 \%$ & $0,00 \%$ & $25,49 \%$ \\
\hline Holanda & $0,00 \%$ & $4,61 \%$ & $0,00 \%$ & $3,43 \%$ \\
\hline India & $0,00 \%$ & $0,66 \%$ & $0,00 \%$ & $0,49 \%$ \\
\hline Italia & $2,56 \%$ & $16,45 \%$ & $0,00 \%$ & $12,75 \%$ \\
\hline México & $5,13 \%$ & $0,00 \%$ & $0,00 \%$ & $0,98 \%$ \\
\hline Noruega & $0,00 \%$ & $0,66 \%$ & $0,00 \%$ & $0,49 \%$ \\
\hline Portugal & $0,00 \%$ & $0,00 \%$ & $7,69 \%$ & $0,49 \%$ \\
\hline Reino Unido & $0,00 \%$ & $33,55 \%$ & $0,00 \%$ & $25,00 \%$ \\
\hline Singapur & $0,00 \%$ & $0,66 \%$ & $0,00 \%$ & $0,49 \%$ \\
\hline Suecia & $0,00 \%$ & $0,66 \%$ & $0,00 \%$ & $0,49 \%$ \\
\hline Suiza & $0,00 \%$ & $1,32 \%$ & $0,00 \%$ & $0,98 \%$ \\
\hline Venezuela & $2,56 \%$ & $0,00 \%$ & $0,00 \%$ & $0,49 \%$ \\
\hline Total (205) & $100,00 \%$ & $100,00 \%$ & $100,00 \%$ & $100,00 \%$ \\
\hline & & & & \\
\hline
\end{tabular}

Fuente: elaboración propia 
Al cruzar estos datos con variables relativas a la calidad de la investigación, como el factor de impacto, se observa que, en total, un $24,39 \%$ de las revistas recogidas no están indexadas en el SJR, de las cuales el 40\% son españolas y el 16\% brasileñas.

Asimismo, el factor de impacto medio de los artículos analizados se sitúa en 2,72 y la distribución por cuartiles indica que casi la mitad de los artículos se ha publicado en revistas situadas en el primer cuartil de su especialidad $(43,41 \%)$.

De nuevo se observan importantes diferencias al cruzar el cuartil, como indicador de referencia en relación con la calidad de la investigación, con el idioma del texto. Además, es en el único cruce de variables en el que se ha encontrado una correlación estadísticamente significativa aplicando el coeficiente de Pearson $(0,35$ correspondiente con una correlación positiva-baja).

El desglose de los datos muestra que el inglés es el idioma en el que se publica la investigación de mayor calidad (57,89\% de artículos publicados en el primer cuartil), frente al portugués $(7,69 \%$ de textos en el primer cuartil) y al castellano (ningún texto en el primer cuartil). En el mismo sentido, el $69,23 \%$ de los artículos en portugués y el $65 \%$ de los artículos en castellano se han publicado en revistas no indexadas en SJR, lo que sugiere un déficit de calidad investigadora en estos idiomas.

Tabla 12. Cuartil en que se encuadran las revistas en función del idioma del texto.

\begin{tabular}{|c|c|c|c|c|}
\hline Cuartil & Castellano & Inglés & Portugués & Total general \\
\hline 1 & $0,00 \%$ & $57,89 \%$ & $7,69 \%$ & $43,41 \%$ \\
\hline 2 & $15,00 \%$ & $8,55 \%$ & $0,00 \%$ & $9,27 \%$ \\
\hline 3 & $12,50 \%$ & $21,71 \%$ & $15,38 \%$ & $19,51 \%$ \\
\hline 4 & $7,50 \%$ & $1,97 \%$ & $7,69 \%$ & $3,41 \%$ \\
\hline No indexado & $65,00 \%$ & $9,87 \%$ & $69,23 \%$ & $24,39 \%$ \\
\hline Total (205) & $100,00 \%$ & $100,00 \%$ & $100,00 \%$ & $100,00 \%$ \\
\hline
\end{tabular}

Fuente: elaboración propia

Finalmente, se ha relacionado el cuartil con otras variables como el género, la internacionalidad, la pluridisciplinariedad y la financiación, con el objetivo de conocer si la calidad de la investigación está vinculada, en algún caso, con estos factores. Respecto al género, pese a que mujeres son primeras autoras de más artículos $(55,12 \%$ del total), la calidad de estos parece menor. Un 39,82\% de los artículos encabezados por mujeres se encuadra en el primer cuartil frente a un $47,83 \%$ de los firmados por hombres. Las mujeres también cuentan con mayor proporción de artículos no indexados (un $25,66 \%$ frente a un $22,83 \%$ en el caso de los hombres). 
Tabla 13. Género, internacionalidad, pluridisciplinariedad y financiación.

\begin{tabular}{|c|c|c|c|}
\hline Cuartil & Hombre & Mujer & Total general \\
\hline 1 & $47,83 \%$ & $39,82 \%$ & $43,41 \%$ \\
\hline 2 & $7,61 \%$ & $10,62 \%$ & $9,27 \%$ \\
\hline 3 & $17,39 \%$ & $21,24 \%$ & $19,51 \%$ \\
\hline 4 & $4,35 \%$ & $2,65 \%$ & $3,41 \%$ \\
\hline No indexado & $22,83 \%$ & $25,66 \%$ & $24,39 \%$ \\
\hline Total & $100,00 \%$ & $100,00 \%$ & $100,00 \%$ \\
\hline Cuartil & No internacional & Si internacional & Total general \\
\hline 1 & $41,85 \%$ & $57,14 \%$ & $43,41 \%$ \\
\hline 2 & $8,70 \%$ & $14,29 \%$ & $9,27 \%$ \\
\hline 3 & $19,57 \%$ & $19,05 \%$ & $19,51 \%$ \\
\hline 4 & $3,80 \%$ & $0,00 \%$ & $3,41 \%$ \\
\hline No indexado & $26,09 \%$ & $9,52 \%$ & $24,39 \%$ \\
\hline Total & $100,00 \%$ & $100,00 \%$ & $100,00 \%$ \\
\hline Cuartil & No pluridisciplinar & Si pluridisciplinar & Total general \\
\hline 1 & $40,63 \%$ & $53,33 \%$ & $43,41 \%$ \\
\hline 2 & $8,75 \%$ & $11,11 \%$ & $9,27 \%$ \\
\hline 3 & $19,38 \%$ & $20,00 \%$ & $19,51 \%$ \\
\hline 4 & $4,38 \%$ & $0,00 \%$ & $3,41 \%$ \\
\hline No indexado & $26,88 \%$ & $15,56 \%$ & $24,39 \%$ \\
\hline Total & $100,00 \%$ & $100,00 \%$ & $100,00 \%$ \\
\hline Cuartil & No financiado & Sí financiado & Total general \\
\hline 1 & $38,16 \%$ & $58,49 \%$ & $43,41 \%$ \\
\hline 2 & $6,58 \%$ & $16,98 \%$ & $9,27 \%$ \\
\hline 3 & $22,37 \%$ & $11,32 \%$ & $19,51 \%$ \\
\hline 4 & $3,29 \%$ & $3,77 \%$ & $3,41 \%$ \\
\hline No indexado & $29,61 \%$ & $9,43 \%$ & $24,39 \%$ \\
\hline Total & $100,00 \%$ & $100,00 \%$ & $100,00 \%$ \\
\hline
\end{tabular}

Fuente: elaboración propia

Por otro lado, la internacionalidad y la pluridisciplinariedad de los grupos de investigación se relacionan con la calidad de los trabajos que realizan. Los grupos internacionales publican un $16 \%$ más en revistas del primer cuartil, y los grupos pluridisciplinares un $13 \%$ más. Por último, la financiación de la investigación también parece ser un indicador de calidad. Los artículos que cuentan con financiación publican un $20 \%$ más en revistas del primer cuartil que los que no la tienen. Paralelamente, es más frecuente que los artículos que carecen de financiación se publiquen en revistas no indexadas que los que sí la tienen (también un 20\% más). 


\subsection{CONCLUSIONES Y DISCUSIÓN}

La revisión sistemática desarrollada ha posibilidado un mayor conocimiento y comprensión del estado de la investigación sobre comunicación de la ciencia en Internet, en general, y el periodismo científico, en particular, realizada hasta el 31/12/2016 en tres idiomas: inglés, castellano y portugués. El enfoque metodológico diseñado trata de integrar la perspectiva RRI y la metodología podrá ser replicada por otros investigadores en cualquier otro estudio de metanálisis con independencia del área de conocimiento, lo que supone una de las principales aportaciones de este trabajo.

Una de las principales conclusiones que se pueden extraer es que la investigación sobre comunicación de la ciencia en Internet es amplia pero no parece constituir un campo de estudio sólido y consolidado, entendiendo que para serlo se deberían haber identificado, al menos, distintos grupos de investigación especializados en la materia con una cierta tradición en este tipo de estudios, trabajos referentes, unas bases teóricas reconocibles, algunos criterios de estudio comunes y un cierto equilibrio metodológico. De este modo, es posible confirmar la H1 en su totalidad.

Otra de las conclusiones más destacadas es que, a diferencia de otros campos de conocimiento, la investigación sobre comunicación de la ciencia en Internet no solo es llevada a cabo por académicos especializados en la materia, sino que constituye un objeto de estudio transversal a prácticamente cualquier disciplina científica, en línea con lo planteado en la $\mathbf{H} \mathbf{2}$.

De este modo, se puede determinar que esta investigación se despliega en dos vertientes: una acotada y otra transversal. Como disciplina de investigación acotada, es realizada por investigadores académicos procedentes de esta área y publicada en revistas de su campo como Science Communication, Public Understanding of Science o Journal of Science Communication (JCOM) y en otras generales del área como Journalism o Written Communication.

Por otro lado, como disciplina de estudio de carácter transversal, es un objeto de estudio ocasional y/o complementario para investigadores procedentes de cualquier disciplina científica, desde la biología a la cristalografía, pasando por la traducción o la filosofía, cuyo interés común reside en conocer cómo se encuentra la comunicación de su disciplina en el actual cambiante y revolucionario contexto de la Web. Esta investigación transversal es publicada en revistas científicas especializadas en áreas diversas como ecancer, Ethics in science and environmental politics, Progress in 
physical geography o Biotechnology Journal, así como en otras multidisciplinares de gran impacto como Nature, Science o PLOS ONE.

El hecho de que la mayor parte de los autores registrados cuente únicamente con un artículo en este campo indica que no se trata de una línea de investigación consolidada. Asimismo, los resultados obtenidos para las variables número de autores, multidisciplinariedad, internacionalidad y alcance de la colaboración apuntan a que, efectivamente, los trabajos en esta línea son llevados a cabo por equipos muy reducidos, no multidisciplinares y con una escasa colaboración internacional. Incluso, el hecho de que prácticamente la mitad de los artículos analizados tenga un único autor parece indicar que el interés por este objeto de estudio es en buena medida personal.

Aunque es difícil trazar un perfil tipo de autor principal, se refuta en parte la H3, ya que este se aproximaría a una mujer de origen anglosajón, que publica en inglés y procede de un área ajena al periodismo.

Por otro lado, en línea con un campo de investigación escasamente consolidado, existe una significativa heterogeneidad en los términos utilizados como palabras clave. En este sentido, la elaboración de un tesauro específico sobre la materia puede ayudar a los investigadores a seleccionar aquellas palabras clave que ya han sido utilizadas anteriormente en otros estudios, mejorando su localización posterior y contribuyendo a que este campo de investigación obtenga una mayor relevancia en el futuro.

La publicación en revistas de acceso abierto es la opción preferente entre la comunidad científica estudiada. Y es la primera opción para la investigación publicada en castellano y portugués, posiblemente para paliar el déficit de impacto que puede ocasionar la publicación en un idioma ajeno al inglés. Paralelamente, los autores de artículos en inglés que publican en revistas de pago parece que están utilizando las redes sociales académicas para poner a disposición de la comunidad sus trabajos. Aunque serán necesarios más trabajos para ahondar en este planteamiento, el acceso abierto como perspectiva de la RRI parece estar más relacionado con esquivar esas restricciones editoriales que pueden suponer un menor impacto para los artículos que con un enfoque de transparencia y cooperación científica.

Los resultados también permiten confirmar que la investigación centrada en el canal de Internet y en las herramientas que la red facilita para el acceso, la producción y la distribución de contenidos de carácter científico, como los blogs, es la más frecuente. Los estudios de caso recogidos se centran, asimismo, en temáticas relacionadas con 
la salud y el medio ambiente. La comunicación de riesgos constituye también un objeto de estudio preferente.

Del mismo modo, la proporción de trabajos que plantea un enfoque integral, teórico y empírico, es muy baja; al igual que la que propone enfoques metodológicos mixtos, cuantitativos y cualitativos. Por último, aunque en ocasiones la utilización de software para procesar los datos parece obvia, es paradógico que a lo largo del artículo no se mencione el nombre del programa utilizado.

Por otro lado, la calidad general de los trabajos en función de los parámetros analizados, es baja. La mayoría de los artículos no cuenta con capítulo metodológico y, los que sí lo tienen, es escasamente detallado. En el mismo sentido, aunque el rastreo bibliográfico es amplio, en general, no se refieren otros artículos que empleen la misma metodología, posiblemente, por esa heterogeneidad teórica y empírica que caracteriza esta línea de investigación. En cambio, sí se ha comprobado que es muy frecuente la autocitación, pese a no constituir una práctica recomendable. En esta misma línea, la mayor parte de los artículos incluye resumen y palabras clave y, en el caso de los artículos en castellano y portugués, se traducen casi siempre al inglés, quizás también para aumentar el impacto de los trabajos en línea con lo reportado en otras variables.

Si bien es cierto que la calidad de los artículos difiere significativamente en función del idioma del texto, la calidad tampoco es alta en general atendiendo a las variables de factor de impacto y cuartil.

Se han observado diferencias significativas en función del idioma en otros parámetros analizados. Atendiendo a la filiación de los primeros autores y de los autores en coautoría, al país de origen de las revistas o al propio idioma del texto, se puede concluir que existe un claro imperio de la investigación de origen anglosajón respecto a este objeto de estudio, un predominio probablemente extrapoable a la práctica totalidad de disciplinas y áreas de conocimiento.

En este sentido, se advierten importantes diferencias respecto a la calidad de los trabajos en función del idioma, siendo los artículos en inglés los que obtienen mejores resultados en el total de las variables medidas que tienen que ver con la calidad de la investigación -estructura IMRyD, enfoque de estudio, desarrollo metodológico, profundidad bibliográfica, etc.-. De este modo, la revisión sugiere que la investigación publicada en castellano y portugués tiene, en general, una calidad menor. Esto puede ser debido, por un lado, a la falta de recursos a la hora de realizar sus trabajos, ya que se ha observado que la financiación, como es razonable, constituye un elemento 
diferencial cuando se relaciona con la publicación en revistas de alto impacto. Así pues, sería conveniente que las administraciones de todos los niveles trataran de incrementar la cuantía de sus programas para la financiación de la l+D+i en ámbitos como las ciencias sociales y concretamente la comunicación de la ciencia, con el fin de que estos investigadores no se queden rezagados en un área que, como apunta este estudio, genera un interés general y es transversal a todos los campos de conocimiento.

Al margen de la financiación, la pluridisciplinariedad y la internacionalidad también están directamente relacionadas con la publicación de artículos en revistas de mayor impacto, por lo que se propone a la comunidad académica que publica en castellano y portugués un acercamiento mayor a otros grupos de investigación, de otros países y de otras áreas de conocimiento, para enriquecer sus trabajos, tal y como sucede en otras disciplinas (Cummings y Kiesler, 2005; González-Alcaide et al., 2006; GonzálezAlcaide et al., 2009; Belinchón Carmona, 2010; Aleixandre Benavent, 2013; ÁvilaToscano, 2014).

En relación con las dimensiones de la $R R I$ estudiadas, se pueden realizar algunas reflexiones. En lo referente al acceso abierto, aunque es la opción preferida de la comunidad científica estudiada, sobre todo de la que publica en castellano y portugués, sería interesante conocer si el interés último de los investigadores es compartir conocimientos para hacer avanzar la ciencia y/o cumplir con las recomendaciones de transparencia y responsabilidad cuando se trata de una investigación financiada con fondos públicos, tal y como persigue la RRI, o si se tienen otros fines igualmente lícitos, como incrementar la visibilidad y el impacto final de estos trabajos.

En cuanto al género, aunque se observa un equilibro en todas las variables medidas (género del autor principal, presencia de mujeres en coautoría y equilibrio entre hombres y mujeres en los equipos de investigación) es destacable cómo, pese a ser primeras autoras con mayor frecuencia, estos trabajos están publicados en revistas de menor calidad, lo que indica que podría existir una brecha en este sentido. Se necesitarán más estudios para ahondar en este planteamiento.

Finalmente, se pueden plantear algunas mejoras respecto a la ética y la responsabilidad, como la necesidad de procurar una mayor transparencia en los enfoques metodológicos, un asunto clave para garantizar la certeza de los resultados y la posible replicabilidad de los mismos. Es fundamental para apoyar la credibilidad de las ciencias sociales una descripción más detallada de los métodos, la selección de las 
muestras, la recogida de los datos y su compilación y análisis (Neuman, 2011). Un aspecto que se echa especialmente en falta es la especificación del/los software/es utilizados en las labores anteriormente señaladas, algo que solo se menciona excepcionalmente. Al mismo tiempo, se debería exigir a las revistas un mayor compromiso con la declaración de conflictos de interés como elemento fundamental para promover la transparencia en la investigación (Smith, 1998), ya que apenas un $10 \%$ de los artículos estudiados la incluye.

Tras la revisión sistemática, en los próximos apartados se presenta un estado de la cuestión que tiene que objetivo compendiar y sintetizar el contenido de todas las obras analizadas anteriormente, así como de otras referencias que no han formado parte del análisis cuantitativo, al no ser artículos publicados en revistas académicas, pero igualmente importantes para explicar el actual contexto de la comunicación de la ciencia en Internet y las implicaciones que el mismo está teniendo en el periodismo científico. Muchas de estas cuestiones son también extrapolables al periodismo en general.

Se han seguido de nuevo los elementos contemplados en el proceso comunicativo del modelo de Lasswell (1985) para organizar la información, de modo que los próximos apartados se centrarán en responder a las siguientes cuestiones:

- En lo relativo al canal: ¿Qué influencia está teniendo Internet como canal de comunicación científica? ¿Cuáles son sus rasgos distintivos y cómo afectan a la información y a los contenidos de carácter científico? ¿Qué ventajas y desventajas acarrean estas características a la información científica? ¿Cómo afectan herramientas como blogs o redes sociales al periodismo científico? ¿Qué usos están teniendo estas herramientas en la comunicación de la ciencia?

- En lo referente al mensaje: ¿Qué particularidades tiene el mensaje científico en Internet? ¿Es este mensaje distinto al de los medios tradicionales? ¿Cómo se presenta este mensaje a nivel de estructura y contenido? ¿Se han adoptado los rasgos de multimedialidad, hipertextualidad, interactividad y actualización?

- En cuanto al receptor: ¿En qué medida el público en general y el público interesado en ciencia, en concreto, están accediendo a la red para informarse? ¿Cuál es el perfil de estos públicos? ¿Qué tipo de información buscan y de qué modo? ¿Están participando en los contenidos?

- Sobre los efectos: ¿Cómo afecta la Internet a la construcción de significados, la comprensión de temas científicos o la percepción de los argumentos de la ciencia? ¿Cómo influye la fuente en la credibilidad de la información online? 
¿Qué efectos tiene la lectura hipertextual de contenidos científicos? ¿Y la multimedialidad?

- Finalmente, sobre el emisor: ¿Cuál es la situación del periodista científico en el entorno online? ¿En qué medida ha cambiado Internet sus prácticas profesionales y sus roles tradicionales? ¿Qué otros actores están emitiendo contenidos científicos en Internet? ¿Cuáles son sus particularidades y sus intereses? ¿Están desplazando estos actores al histórico papel del periodista de mediador entre la ciencia y el público?

Aunque, siguiendo un orden lógico, debería constituir el primer apartado, el emisor de contenidos científicos en Internet se estudia en último término ya es aquí donde se han observado las mayores implicaciones para el periodismo científico y este apartado contextualiza el estudio de caso que se expone en el tercer bloque. 


\section{INTERNET COMO CANAL: UN NUEVO ESPACIO PARA LA COMUNICACIÓN DE LA CIENCIA}

La literatura científica describe varios rasgos distintivos de Internet en cuanto a la difusión de información, en general, y de información científica, en particular, con claras implicaciones en cuanto al desempeño del periodismo científico.

- En primer lugar, se encuentra la accesibilidad y la posibilidad de difundir información a gran escala (Cline y Haynes, 2001). La red aún está en su infancia en comparación con otros medios de comunicación, como la radio o la televisión, y como la mayoría de las innovaciones que penetran en un sistema social, su adopción en todo el mundo no se ha distribuido equitativamente entre los estratos sociales, por eso algunos autores se refieren a la estratificación digital en lugar de a brecha digital (Carracedo Verde, 2006). Sin embargo, la historia de la tecnología ha demostrado que estas barreras se sobrepasan con el paso del tiempo y que estos medios, como la televisión o la radio, llegan a estar disponibles casi universalmente.

Sin dejar de lado este contexto, en la actualidad cualquier persona con conexión a Internet tiene acceso a una cobertura científica mayor que nunca antes en la historia. Pero esto no significa que la ciencia esté llegando a más gente. Algunos trabajos advierten que los que acceden a estos contenidos están altamente interesados en ciencia y que es difícil que un ciudadano medio busque información científica de la que no haya tenido un conocimiento anterior (Nature, 2009). De este modo, Internet estaría fomentando una comunidad de interesados en ciencia que se retroalimenta, sin abrir el abanico más allá (Fernández de Lis, 2013).

La casualidad también parece estar jugando un papel en cómo las personas acceden a información científica online, ya que algunos estudios estiman que hasta dos tercios de los usuarios de Internet consultan información científica cuando acceden en busca de otro tipo de información (Horrigan, 2006). Por ello, los cibermedios están tratando de ampliar el alcance de sus contenidos empleando otras tecnologías que posibilita la Web, como la sindicación, las redes sociales o las RSS (Hermida, 2010). Otra opción de acceso a información científica son los agregadores automatizados como Google News o Yahoo News, que recogen los patrones de navegación de los usuarios y su actividad en redes sociales y les proporcionan información destacada acorde a sus preferencias (Brossard, 2013). También otras 
técnicas como el clickbait podrían ahondar en esta tendencia (Chakraborty et al., 2016; García Orosa et al., 2017).

Aunque la literatura en la materia aún es escasa, los dispositivos móviles también han supuesto un importante avance en la accesibilidad y la difusión de información científica, periodística o no. Las plataformas móviles siguen evolucionando e incluso los nuevos vehículos empiezan a contar con sistemas que les permiten conectarse a la red para obtener información sobre cualquier tema e interactuar con otras personas online, avanzando en la transmedialidad (Canavilhas, 2018).

- En segundo lugar, la inmediatez del canal online es uno de los desafíos más acuciantes a los que se enfrentan los profesionales del periodismo científico (Birch, 2011). En Internet las noticias se vuelven obsoletas con gran velocidad y aumenta en los profesionales la sensación de que su trabajo exige demasiada rapidez. Asociada a esta acuciante situación, los periodistas manifiestan que las nuevas tecnologías han influido negativamente en el tiempo que emplean para investigar los temas y producir la información (Pont Sorribes et al., 2013), lo que puede generar riesgos en materia de veracidad y rigor profesional. Cualquier persona con conexión a la red puede publicar rápidamente sus propias informaciones y opiniones sin necesidad de atenerse a las normas y códigos que rigen la profesión periodística, adelantándose a estos profesionales (Birch, 2011).

- En tercer lugar, el contexto online permite liberar al periodista científico de la rigidez espacio-temporal impuesta por los medios tradicionales (Hermida, 2010). Algunos autores consideran que esto es bueno para la divulgación científica porque aumenta las posibilidades de que los usuarios encuentren noticias científicas (Brossard, 2013; Parra Castillo 2013). Otros autores creen que, en la práctica, el medio online se utiliza como repositorio de publicado previamente en formato impreso o de lo emitido en medios audiovisuales. Incluso, que se utiliza para publicar las noticias científicas que no "pasaron el corte" para su publicación en unos periódicos cuyo tamaño se está viendo cada vez más mermado. Para Hermida (2010), Internet puede ser la solución a la desaparición de las secciones de ciencia en algunos periódicos y a los recortes en las plantillas de periodistas científicos.

La ingente producción de noticias científicas en el medio online entra de nuevo en conflicto con aspectos éticos como la calidad o la fiabilidad de la 
información (Koolstra et al., 2006; Pitrelli, 2011). También sobre la falta de control sobre la difusión, ya que el periodista tiene hoy un manejo limitado sobre cómo se modificará y difundirá su contenido una vez se publique en Internet (Brossard, 2013).

- En cuarto lugar, como ya se ha esbozado, la fiabilidad de la información científica es uno de los mayores problemas que está originando Internet" (Koolstra et al., 2006; Pitrelli, 2011). Tradicionalmente, el público ha asumido con certeza la información científica que podía leer impresa o visionar en sus medios de cabecera, ya que periodistas y medios de comunicación eran garantes de contenidos confiables a través de la marca y la reputación (Bucchi y Trench, 2008). La situación ha cambiado drásticamente y muchas de las informaciones científicas que circulan por la Web no están contrastadas, no llegan a unos estándares de calidad mínimos y están salpicadas de cierta espectacularización y entusiasmo generalizado (Hetland, 2015). Además, cualquier usuario es ahora capaz de convertirse en prescriptor o detractor de instituciones, marcas y profesionales gracias a la facilidad para publicar y viralizar mensajes que ofrece Internet, muchas veces bajo el amparo del anonimato (Priest, 2013; Oughton, 2010; Bell, 2012).

Estos mismos problemas se han trasladado también a la diseminación académica de la ciencia, tal y como advierten algunos autores (Wilkins, 2008; Oghton, 2010), con la facilidad para publicar online trabajos que no han pasado el proceso de revisión por pares (Campbell, 2017) o la búsqueda de notoriedad y autopromoción mediante herramientas de participación (Thomas, 2009).

Con una oferta de contenidos científicos prácticamente ilimitada, conseguir la atención del público supone todo un reto. Y la primera ventana del público a esta información es fundamentalmente el motor de búsqueda, con Google a la cabeza, que no discrimina la información veraz de la falsa, solo la notoriedad de la misma (Elías, 2013).

Así, uno de los mayores problemas desafíos es la construcción de filtros y servicios para discriminar la información científica confiable de la que no lo es, y ayudar a los lectores a encontrar fuentes fiables dentro del "bazar bullicioso" repleto de comerciantes que pujan por llamar la atención que es Internet (Trench, 2007). Según Bucchi y Trench (2008), todos los actores 
implicados en la comunicación pública de la ciencia deben adaptarse a una nueva fase en la que los criterios de calidad deben ser fundamentales para todas las partes involucradas. Esto implica el desarrollo de indicadores de calidad y estándares en el desempeño de la comunicación que permitan a los usuarios realizar un proceso de evaluación. Para Clarke (2009), la revisión por pares debería ser el punto de referencia para aquellos que se dedican a la comunicación pública de la ciencia, como son los periodistas. Clines y Haynes (2001) añaden otros indicadores como la disponibilidad de códigos éticos y profesionales, actualización de la información, la precisión, la organización lógica, la legibilidad o la inteligibilidad.

Diversos autores apuntan al papel de los periodistas científicos y de las instituciones científicas como claves para paliar el problema de la fiabilidad de la información online. En cuanto a los periodistas científicos, Internet pone en valor esta especialidad profesional (Moreno Castro, 2013), ya que están sujetos a éticas y códigos profesionales también en la red, que otorgan a la información periodística una credibilidad fundamental en un entorno muy complejo (Trench, 2007; Elías, 2013). Respecto a universidades y centros de investigación, algunos autores opinan que deberían jugar un papel básico a la hora de ayudar a discernir entre información cierta y falsa, difundiendo sus resultados científicos en la Web (Elías, 2013). Y también los propios científicos, según el mismo autor, deberían implicarse en rebatir mensajes falsos o fraudulentos en la red.

- En quinto lugar, la interacción, junto con la velocidad y la disponibilidad de la información, es la base de las nuevas herramientas desarrolladas específicamente en Internet como blogs, foros, redes sociales, podcast o webcast, medios que promueven la participación y facilitan la expresión de opiniones por parte de los usuarios (Minol et al., 2007; Holliman, 2010). Estas herramientas convierten los procesos de información unidireccionales de arriba abajo-, propios de los medios de comunicación tradicionales, en formas de diálogo interactivo. De esta forma, se crean nuevos modos de ser ciudadano y de formar parte en el debate público (Picardi y Regina, 2008), así como nuevas formas para comunicar la ciencia, más ricas (Trench, 2007) En el ámbito del ciberperiodismo científico, el carácter interactivo del canal online ofrece nuevas y enriquecedoras posibilidades de comunicación entre el periodista y el lector (Sanz Pérez de Guzmán, 2002), quien puede, por ejemplo, indicar sus preferencias, felicitar o corregir al periodista o hacer 
comentarios y preguntas en torno a un artículo. Internet también facilita nuevas vías de comunicación entre los propios lectores, en línea con el modelo de participación de la comunicación de la ciencia (Trench, 2007).

- Aunque no es una característica técnica, sí es un rasgo distintivo para el periodismo científico en el entorno online, y para el periodismo en general, la falta de un modelo de negocio solvente en los cibermedios (Seabra, 2012). La literatura pone sobre la mesa esta cuestión y algunos estudios incluso cuantifican esta situación. En una encuesta realizada a 326 profesionales y expertos en la comunicación de la ciencia -periodistas científicos, responsables de gabinetes institucionales de centros de investigación, científicos e investigadores en comunicación- se detectó, por un lado, una tendencia a la disminución de los salarios y los ingresos en los medios de comunicación, y por otro, un aumento de los recursos en las relaciones públicas de los centros de investigación y una comunicación directa entre científicos y público en el medio online (Gerber, 2011).

Según un editorial de la revista Nature (2009), el periodismo científico es una de las numerosas víctimas de la crisis que viven los medios de comunicación desde el cambio de siglo y, aunque es difícil conocer qué efectos han tenido estos recortes en la comprensión pública de la ciencia, ya entonces parecía palparse la sensación de que la calidad de la cobertura estaba disminuyendo.

Algunos autores han sido más tajantes y han hablado de una "desintegración generalizada" de los medios de comunicación y de sus modelos de negocio subyacentes, así como de una disminución asociada de la credibilidad del periodismo científico (Gerber, 2014; Seabra, 2014). Para Nielsen (2009) los periódicos están encerrados en la producción de un producto de calidad que, desde el punto de vista publicitario -principal fuente de ingresos- es comparable a lo mejores blogs, pero a un coste mucho mayor. Cada vez hay más personas dispuestas a adentrarse en la divulgación a cambio de incentivos no monetarios y, cuando un recurso es abundante, se reduce su valor (Holliman, 2011; Parra Castillo, 2013). El problema de la abundancia gratuita lleva a los cibermedios a experimentar con nuevos formatos y servicios con el fin de generar ingresos sostenibles (Holliman, 2011; Brown, 2014), un modelo que aún no se ha encontrado (De Semir, 2010; Allemand, 2013). Determinados autores apuestan por un modelo de negocio digital que agregue a pequeños públicos y atraiga anunciantes, al mismo tiempo que se 
desarrollan contenidos científicos especializados para audiencias segmentadas -la denominada estrategia long tail- ${ }^{12}$ (Ribas, 2012).

\subsection{PERIODISMO CIENTÍFICO Y CIBERMEDIOS}

El entorno informativo está afrontando una situación de enormes cambios: los medios tradicionales están perdiendo importancia en favor de los medios sociales (Brossard, 2013). Aunque la VIII Encuesta sobre Percepción Social de la Ciencia y la Tecnología (2016) apunta que casi el $75 \%$ de los españoles que se informa sobre ciencia en Internet lo hace a través de redes sociales, la prensa digital sigue teniendo bastante pujanza y se sitúa como tercer medio en Internet, con casi un $60 \%$ del total de citas, tras los vídeos, con un 62\%. Según otros estudios, los medios digitales generalistas son los principales canales por los que se informan sobre ciencia y tecnología aquellos que han concluido estudios universitarios (Moreno Castro, 2013).

Estos datos ponen de manifiesto que los cibermedios (Díaz Noci y Salaverría, 2003) y el periodismo siguen manteniendo un cierto status en el nuevo entorno online de la comunicación de la Ciencia. Profesionales del gremio como Pablo Jáuregui, redactor jefe de El mundo y elmundo.es, afirman Internet ha mejorado una oferta informativa que se veía muy limitada en el formato impreso. "Mientras en la edición impresa sólo contamos por lo general con una página diaria bajo la cabecera de ciencia, en la Web la oferta informativa del campo científico se despliega en varios portales diferenciados (Ciencia, Salud, Medio Ambiente y Tecnología), todos ellos con mucho éxito de público" (Jáuregui 2013:11-12).

Frente a la falta de fiabilidad, estos cibermedios seleccionan los contenidos que aparecen en sus ediciones online y lo hacen siguiendo criterios periodísticos mediante un proceso de selección, recontextualización del discurso y edición (Moreno Castro, 2013). Además, estos contenidos hacen referencia en muchos casos a publicaciones científicas que han pasado un proceso de revisión por pares y por tanto están validados a través de los filtros de la propia comunidad científica. Además, los medios de comunicación de mayor tamaño cuentan con asesores científicos en sus consejos de redacción para garantizar el rigor de los temas publicados.

Por otro lado, en cuanto a inmediatez, los cibermedios se sitúan a caballo entre la prensa tradicional, la radio y la televisión, ya que pueden poner la información a disposición de los usuarios prácticamente en tiempo real, al estilo de los medios de

\footnotetext{
${ }^{12}$ Más información sobre la estrategia long tail en: Anderson, C. (2004). "The Long Tail". Wired. Disponible en: http://ow.ly//5nM30k3YQ8 (última consulta 07/03/2018)
} 
emisión tradicionales, fundamentalmente de la radio (Moreno Espinosa, 2010). No obstante, esta misma autora consideraba que la prensa generalista española seguía volcada entonces en su edición impresa mientras que para la edición digital se reelaboraban noticias de teletipo, a modo de "avanzadilla" de lo que iba a ser abordado con amplitud al día siguiente en la versión en papel (González-Pedraz, 2014a).

Algunos trabajos empíricos exploran los contenidos de ciencia presentes en los cibermedios, así como las oportunidades y limitaciones de este tipo de medios. Uno de los primeros trabajos es el de Marín Murillo y Armentia Vizuete (2002) sobre nueve versiones digitales de periódicos españoles. Con relación a las potencialidades, estos autores destacan que los cibermedios pueden dar lugar a una contextualización y profundización mayor de la información científica gracias al mayor espacio disponible y a la hipertextualidad, y que la multimedialidad es de gran utilidad para reforzar la explicación de conceptos complejos, como también subraya Jáuregui (2013). No obstante, en aquel momento muchos cibermedios aún no habían explorado estas posibilidades y el volcado de contenidos de la edición impresa a la digital era la estrategia habitual. También en aquel momento algunos cibermedios empezaban a diferenciar estas informaciones en distintas secciones, fundamentalmente de ciencia, salud y tecnología, algo que en la actualidad es tónica común (González-Pedraz et al., 2017).

Otros trabajos, como el de Jiménez et al. (2014), señalan la escasez de contenidos científicos presentes en la prensa digital local y regional, en concreto, en las ediciones digitales de los periódicos extremeños más importantes, Hoy y El Periódico de Extremadura. Sólo el $0,23 \%$ de las noticias publicadas en Hoy y el 0,324\% de las noticias de El Periódico de Extremadura responden a esta temática, evidenciando un desinterés social y una infravaloración de la actividad científica y su divulgación. Este dato contrasta con el obenido por Torres et al. (2014) en un estudio comparativo de la prensa impresa y digital generalista de México, donde los contenidos científicos representan el 13,25\% del total de la información publicada.

Paralelamente, las revistas de divulgación científica, como los periódicos tradicionales, se han adaptado a los formatos digitales. Así, las principales revistas de divulgación científica en formato impreso cuentan hoy en día con edición digital, al igual que se han creado revistas divulgativas nativas de Internet, denominadas ezines. Minol et al. (2013) definen un e-zine como un portal de Internet con el estilo de una revista, es decir, con un contenido editorial elaborado por periodistas y columnistas, compuesto por artículos de diversa índole, opinión, entrevistas, etc. Para 
este autor, un e-zine tiene la apariencia de una revista clásica, pero incorpora las funcionalidades que posibilita la Web, como herramientas para la participación.

Algunos autores considersan que las revistas divulgativas como New Scientist o Scientific American son el formato idóneo para la divulgación científica, ya que ofrecen información periodística, pero con una citación de fuentes similar a la de un artículo científico (Warden, 2010). Para la misma autora, estos formatos evitan los problemas que los científicos achacan tradicionalmente a los medios medios de comunicación: la tendencia al sensacionalismo, informar sobre resultados de la investigación básica como si fueran inmediatos, ignorar el contexto de la investigación o no dar lugar a la incertidumbre científica, lo que también se ha puesto de manifiesto en estudios posteriores (Guenther et al., 2017).

Magalhães Porto (2007) valora también este formato, aludiendo a un e-zine que se ha convertido en uno de los sitios web más importantes para la divulgación científica en Brasil junto a la revista Pesquisa Fapesp, la revista Comciência, creada en 1999 por la primera promoción de periodistas especializados en ciencia de la Universidad Estatal de Campinas (Unicamp) como sitio al que acudir en busca de información fiable y contrastada sobre ciencia y tecnología, para tratar de paliar precisamente esta problemática.

\subsection{BLOGS, REDES SOCIALES Y COMUNICACIÓN CIENTIIFICA}

En torno al año 2004, como se ha explicado en el capítulo introductorio, surge la Web 2.0, una segunda generación en la historia del desarrollo de la tecnología web, más dinámica y participativa. Este dinamismo vino dado, en gran medida, por la emergencia de herramientas que facilitaban la interacción entre los usuarios, como los blogs y las redes sociales. En el ámbito de la comunicación online de la ciencia, ambas herramientas han tenido un gran impacto pero sobre todo los blogs (Griffiths 2007; Wang et al., 2010; Blanchard, 2011), como muestra en el interés que ha despertado como objeto de investigación entre la comunidad científica y que se ha visto reflejado en la revisión sistemática: de los 205 artículos analizados 75 abordaban, en parte o en su totalidad, los blogs y su influencia. Por ello, uno de los apartados más exhaustivos de este estado de la cuestión es el referido a las relaciones entre blogs, comunicación de la ciencia y periodismo científico. 


\subsubsection{EL IMPACTO DE LOS BLOGS EN LA COMUNICACIÓN DE LA CIENCIA Y EL PERIODISMO CIENTÍFICO}

Cuando en abril de 1997 el desarrollador de software neoyorquino Dave Winer escribió la primera entrada de su blog Scripting News, era difícil imaginar que en 2014 las principales plataformas de blogs en Internet iban a alojar más de 440 millones de bitácoras. ${ }^{13}$ El considerado "padre" de los blogs (Orihuela, 2007; Fernández, 2007) fue pionero con su Scripting News sobre tecnología y política.

Un blog es un sitio web en forma de diario online con entradas regulares o post en los que su autor o grupo de autores comunica y expresa ideas, experiencias personales, trabajos de investigación, noticias o simplemente contenidos de otros sitios; que pueden ir acompañados de elementos multimedia (como imágenes, vídeos, audios o infografías) e hipertexto, y que pueden ser comentados por los lectores de la llamada blogosfera ${ }^{14}$ (Wilkins, 2008; Griffiths, 2007; García Álvarez de Toledo y Fernández Sánchez, 2011).

Además, son una de las principales tecnologías sociales que están posibilitando a las personas con acceso a Internet publicar contenidos de forma libre y gratuita. Además, al permitir la interacción de los lectores a través de los comentarios y la sindicación de contenidos, estas herramientas han promovido la creación de comunidades online (Amsen, 2006; De Semir, 2010). Los comentarios de un blog constituyen una faceta interesante, ya que en ocasiones sirven para complementar la información y en otras generan debate (Minol et al., 2007; Griffiths, 2007; Blanchard 2011; García Álvarez de Toledo y Fernández Sánchez, 2011).

Los blogs son publicaciones libres que pueden tratar temas generalistas o dirigirse a una o varias temáticas concretas. Dentro de estas temáticas, los blogs de ciencia son frecuentes y han ido adquiriendo cierta entidad propia, sobre todo gracias a científicos y centros de investigación, que han visto en ellos una herramienta de difusión útil para llegar a un público amplio (Chalmers, 2009; Wang et al., 2010; Colson, 2011). Uno de los principales cambios que han originado los blogs en la comunicación de la ciencia es precisamente la posibilidad de comunicación directa entre científicos y público no necesariamente iniciado en la ciencia (Magalhães y Almeida, 2009; Gomes y Flores, 2012).

\footnotetext{
${ }^{13}$ Aunque no se han localizado datos concluyentes, diversas informaciones apuntan que las principales plataformas, Tumblr, Squarespace y WordPress acumulan más de 440 millones de blogs: http://ow.ly/i3YP30jYrFv (última consulta 04/03/2018).

${ }^{14}$ El término Blogosfera procede del inglés Blogoshpere que fue acuñado el 10 de septiembre de 1999 por Brad L. Graham (Dash, 2010; Axelrod, 2010).
} 
Numerosos autores han tratado de conceptualizar los blogs de ciencia como una parcela específica dentro de la comunicación de la ciencia, algunos centrándose más en el contenido y otros en la autoría. La concepción más sencilla es la aportada por Wilkins (2008), quien los definía como aquellos blogs que tienen como principal intención difundir y comentar temas relacionados con la ciencia. De forma más amplia, Shanahan (2011) concibe los blogs de ciencia como una categoría diversa que incluye -aunque no limita- a los blogs que revisan y critican estudios científicos, analizan noticias de ciencia, abordan áreas de interés en la investigación, documentan vivencias en la ciencia y proporcionan un lugar para la escritura de científicos que se están iniciando en la tarea investigadora. Para Luzón (2013), los blogs de ciencia implican escribir sobre estas temáticas aunque conforman un modo heterogéneo de comunicación que engloba distintos productores (investigadores, profesores e incluso periodistas científicos), tipos de contenido, propósitos y audiencias.

Kouper (2010) considera blogs de ciencia a aquellos escritos por científicos o periodistas científicos, y subraya su potencial para convertirse en un nuevo modelo de periodismo científico, así como en una herramienta que puede ser utilizada por las instituciones académicas para difundir información científica y facilitar conversaciones sobre ciencia. Puschmann (2014) apunta que el término blog de ciencia hace referencia a una variedad que complementa a la comunicación científica tradicional de artículos de revista y monografías académicas y también al periodismo científico, y que puede ser beneficioso para ambos, científicos y periodistas, en su esfuerzo de comunicar ciencia a un público general, como se abordará más adelante.

En vista de la caída sufrida por el periodismo científico, sobre todo en los medios tradicionales, los blogs son vistos por algunos investigadores como una excelente oportunidad de ganar ventaja en relación con la divulgación científica (Kjellberg, 2010; Wang et al., 2010; Colson, 2011, pudiendo eludir el filtro de los periodistas (Carroll, 2007). Algunos científicos también han visto el potencial de este medio para comunicarse con otros colegas (Tola, 2008; Flores y Gomes, 2013).

\section{EL PERFIL DEL BLOGUERO DE CIENCIA}

Para ahondar precisamente en esta cuestión, el perfil del bloguero, diversos autores han realizado trabajos empíricos a partir de la técnica de la encuesta. Aunque las muestras seleccionadas y las variables medidas son diversas, se pueden extraer algunos datos relevantes. Kovic et al. (2008) arrojaron que la mayoría de blogueros de salud eran investigadores (un 54\%). Estos investigadores blogueros pertenecían a distintas categorías y niveles profesionales: desde estudiantes universitarios a 
científicos de alto nivel (Tola, 2008). Esto puede deberse a que las universidades, aunque han sido lentas en apreciar los blogs como medios valiosos (Batts et al., 2008), después han animado a sus miembros a bloguear, como un medio para ampliar su alcance y su visibilidad (Mauranen, 2013) y también para promocionarse (Lewenstein, 2009), como muestra que más del $80 \%$ se autocite en las entradas (Shema et al., 2012).

Estos últimos autores han esbozado un perfil tipo del científico bloguero: hombre, estudiante de graduado o doctorado que bloguea con su nombre propio. También han mostrado la preferencia de estos blogueros por el uso de la revista científica de alto impacto como fuente, así como un marcado interés paralelo por las redes sociales (el $90 \%$ tenía al menos una cuenta activa en Twitter). Aunque casi el $60 \%$ de los científicos blogueros estaba afiliado a un centro de investigación, la mayoría no blogueaba a través de su institución (Shema et al., 2012). En este sentido, Wagner et al. (2011) indicaban que la mayoría de blogueros de genética daban a conocer públicamente sus nombres completos (81\%) y aportaban información biográfica (67\%). En este caso, solo el 7\% estaba afiliado a alguna institución académica o sanitaria.

Como se ha apuntado, universidades y centros de investigación han tardado en incorporar los blogs como medio de comunicación directa con el público. Aunque ahora casi todas las instituciones científicas cuentan con plataformas para que sus miembros puedan mantener blogs bajo el paraguas corporativo, la mayor parte de las iniciativas de este tipo comenzaron desde abajo hacia arriba, es decir, partieron de los propios investigadores. En España, según una encuesta elaborada por la Red de Bibliotcas Universitarias (REBIUN) de la Conferencia de Rectores de las Universidades Españolas (CRUE), ${ }^{15}$ el $48 \%$ de las instituciones científicas españolas contaba ya con una plataforma corporativa de blogs en 2014.

Al margen de los científicos blogueros, diversos trabajos recogen cómo periodistas y aficionados comunican sus informaciones e inquietudes científicas a través de los blogs (Amsen, 2006; Carrington, 2008; Puschmann y Mahrt, 2012)

Esbozar el perfil del bloguero de ciencia es relevante ya que el objetivo con el que comunica cada actor es distinto. Para Carrington (2008), mientras que los científicos buscan transmitir su propia ciencia o los problemas a los que se enfrentan los científicos; los periodistas desean informar sobre ciencia a través de un medio diferente a los convencionales, mientras que los aficionados pretenden comentar la

\footnotetext{
${ }^{15}$ Acceso completo a la Encuesta de buenas prácticas en redes sociales de las universidades y centros de investigación disponible en: http://ow.ly/Kmou30k5xDv (última consulta el 08/03/2018)
} 
ciencia, supervisar la política científica y sus posibles efectos. Para los periodistas científicos blogueros, los blogs constituirían una extensión de su trabajo de oficina pero solo a veces cobrarían por esta labor, pese a escribirlos con la misma dedicación que los artículos de prensa, tal y como señalaba Colson (2011). Los periodistas científicos también valoraban la posibilidad de interactuar con los lectores y la mayor libertad a la hora de escribir en los blogs (Shanahan, 2011; Colson, 2011).

Otros autores han analizado si los blogs constituyen o no un nuevo género periodístico (Kouper, 2010; Mauranen, 2013), y coinciden en que los blogs son tan heterogéneos en su escritura y modos de redacción que no pueden conformar un género en sí mismo.

\section{MOTIVACIONES Y FUNCIONES DE LOS BLOGUEROS CIENTÍFICOS}

Resumiendo las aportaciones de los autores que han estudiado los blogs como canal de comunicación científica, se han identificado 13 funciones de los blogs científicos, algunas de ellas extrapolables a las funciones de los blogs de cualquier temática:

1. Publicar sin intermediario: para los científicos, los blogs permiten superar las limitaciones y la rigidez de los canales formales de publicación, los libros y las revistas científicas (Kjellberg, 2010). Desde el punto de vista de la divulgación y de la comunicación a un público amplio, también permiten traspasar las barreras de los medios de comunicación tradicionales y del intermediario periodista, expandiendo el número de "voces" escuchadas en las noticias científicas y tratando de influir en el periodismo tradicional (Walejko y Ksiazek, 2010). Para los periodistas y los redactores científicos, los blogs también eliminan el filtro de los medios de comunicación a los que tradicionalmente han tenido que pertenecer para publicar sus temas (Wilkins, 2012).

2. Repositorio personal: los blogs son una herramienta de fácil manejo para narrar las vivencias diarias y las opiniones de sus autores, en este caso en el campo de la ciencia (Carrington, 2008).

3. Difusión selectiva de información científica: los blogs son un medio de difusión selectiva de noticias, análisis y comentarios que son seleccionados por los propios blogueros, quienes actúan como filtro de temas que pueden ser interesantes desde la perspectiva científica y facilitando a los lectores la selección y el acceso a este tipo de información dentro de la Web (Kjellberg, 2010; Jarreau, 2015), así como resolviendo malentendidos relacionados con la ciencia (Wilkins, 2012). 
4. Aproximación a un público amplio: los blogs permiten comunicar a un público general suprimiendo las barreras espacio-temporales de los medios tradicionales: cualquier persona puede acceder a un blog en el momento que desee y desde cualquier parte del mundo. Para los científicos, los blogs son un puente entre la esfera científica y el público en general (Kjellberg, 2010; Mahrt y Puschmann, 2014), a través de la adaptación y simplificación del lenguaje académico (Gomes y Flores, 2012).

5. Conversación: como canal de comunicación de la Web 2.0, los blogs fomentan la conversación y la discusión de ideas entre autores y lectores (Flores y Gomes, 2013). Para los científicos, los blogs sirven para obtener una rápida retroalimentación con otros colegas sobre el trabajo que realizan, sobre sus enfoques personales e incluso posibilitan encontrar soluciones comunes y compartir ideas (Mahrt y Puschmann, 2014). De cara al público en general, los blogs traspasan el modelo de la albafetización científica en la que "el que sabe" habla y "el que no sabe" escucha. Los blogs promueven la interacción y el diálogo entre ambos (Carroll, 2007).

6. Mejorar las habilidades comunicativas: la escritura de entradas y el diálogo con los lectores sirven para mejorar las capacidades narrativas de los blogueros (Kjellberg, 2010). Esto es especialmente relevante para los científicos, que dependen en buena medida de sus habilidades comunicativas para avanzar en su carrera profesional -escribiendo artículos, presentando comunicaciones en congresos, redactando proyectos de investigación, impartiendo docencia, etc.-. Para Ranger y Bultitude (2016), la pasión por la escritura es una de las principales motivaciones de los blogueros de ciencia.

7. Fomentar el apoyo a la ciencia: un texto sencillo y en primera persona permite acercar la ciencia a un público general, promoviendo actitudes favorables hacia la misma (Torres-Salinas y Cabezas Clavijo, 2008; Puschmann, 2014; Ranger y Bultitude, 2016).

8. Incrementar la visibilidad de los centros de investigación: en los blogs se pueden publicar las noticias y actividades de los centros de investigación, aumentando su visibilidad y el impacto de sus actividades (Mauranen, 2013).

9. Aumentar la red de contactos: formar parte de la blogosfera permite entrar en contacto con otros científicos y expertos de otras áreas, lo que puede contribuir a la propia investigación fomentando nuevas colaboraciones y el intercambio de planteamientos y experiencias (Kjellberg, 2010).

10. Complementar a los medios de comunicación: los blogs de ciencia complementan la información que se publica en los medios de comunicación 
tradicionales, como se abordará con mayor profundidad en próximos apartados. Para algunos autores (Griffiths, 2007; Gramling, 2008) son un foro para desacreditar información científica mal elaborada por los medios de comunicación. Para otros autores sirven para ampliar noticias y añadir diversos puntos de vista a una misma información. Los blogueros también cubren historias que pueden ser importantes para el público y que a veces pasan por alto los medios de comunicación (Wikins, 2008).

11. Mostrar la Ciencia como un proceso: los científicos se han quejado históricamente de que los medios de comunicación muestran la ciencia como un conjunto de resultados y no como un proceso fruto del esfuerzo humano (Blanchard, 2011). Los blogs pueden poner rostro a la ciencia y a los problemas que enfrenta (Nature Methods, 2009; Wilkins, 2012). También pueden ayudar a paliar la mitificación de la ciencia, al situar la investigación en su contexto y citar trabajos anteriores, mostrando que la ciencia no se reduce a grandes avances o aplicaciones inmediatas (Wilkins, 2008).

12. Estar actualizado: para los científicos los blogs son un medio para mantenerse actualizado en los últimos avances de un campo de investigación y para refrescar sus conocimientos anteriores (Kjellberg, 2010).

13. Defensa del lector: Ribeiro (2006) plantea el papel de los blogs como medio para potenciar la figura del defensor del lector en el ámbito del periodismo científico. A su juicio, dada la complejidad de las cuestiones que envuelven esta práctica profesional, es necesario un medio de control, de observación y de reflexión. Tradicionalmente, el defensor del lector se ha ocupado de estas cuestiones, publicando una columna semanal o mensual en la página de un periódico o de una web con las críticas, defensas y explicaciones pertinentes. Para el defensor del lector u ombudsman, como el autor lo denomina haciendo referencia al término sueco original, los blogs son un mecanismo de autorregulación que promueve la participación del público en el proceso de comunicación social, lo que permite optimizar su labor.

\section{PLATAFORMAS Y AGREGADORES DE BLOGS DE CIENCIA}

Las denominadas plataformas o comunidades de blogs (Michael, 2013) ofrecen plantillas que permiten a los usuarios disponer, en poco tiempo, de un blog atractivo sin necesidad de contar con grandes conocimientos informáticos (García Álvarez de Toledo y Fernández Sánchez, 2011). Existen grandes plataformas de blogs generalistas, gratuitas y de libre acceso, dedicadas a todo tipo de temáticas -como Tumblr, adquirida por Yahoo! en 2013; Wordpress, un gestor de contenidos de la 
empresa Automattic que permite además crear bitácoras, o Blogger, comprada por Google en 2003 (Freitas, 2014) y comunidades de blogs específicas de ciencia, tecnología e innovación. Una de las pioneras fue ScienceBlogs (http://scienceblogs.com/) lanzada en febrero de 2006, a la que se accedía sólo por invitación, que anunció su final en octubre de $2017 .{ }^{16}$ Sigue en funcionamiento otra, ScienceBlog (http://scienceblog.com/) que, como su eslógan refleja (Science news straight from the source), se nutre de comunicados de prensa emitidos por organizaciones de investigación de todo el mundo y también acoge blogs de usuarios interesados en ciencia. Está presente en la red desde agosto de 2002. Por otro lado, la plataforma Wired (www.wired.com/) tiene una perspectiva más aplicada, centrada en la innovación. Además de alojar blogs, cuenta con una revista impresa, organiza eventos en vivo y está presente en otros medios de comunicación ${ }^{17}$.

Diversas regiones en el mundo cuentan con sus propias plataformas de blogs de ciencia, como China y la comunidad de blogs CSDN (www.csdn.net/); también las principales asociaciones científicas, como la American Association for the Advancement of Science (http://membercentral.aaas.org/blogs) y la británica Royal Society (https://royalsociety.org/stay-in-touch/blogs/); las revistas científicas con mayor impacto como Science (http://blogs.sciencemag.org/) y Nature (http://blogs.nature.com/); y las revistas de carácter divulgativo como Scientific American (http://blogs.scientificamerican.com/) o National Geographic (www.nationalgeographic.com/ng-blogs/) cuentan con sus propias comunidades de blogs (Chalmers, 2009).

Por otro lado, en los últimos años los blogs han fomentado la sindicación de contenidos, ofreciendo su información en formatos como RSS. Este formato puede leerse con un tipo específico de software (los denominados agregadores) que aglutinan todos los contenidos deseados en un único punto de lectura (Cobos, 2004; Ogden, 2013). En una blogosfera repleta de autores, este tipo de herramientas permite a los "recién llegados" entrar a formar parte de la conversación y ganar visibilidad, redirigiendo lectores a sus blogs (Tola, 2008).

Entre los principales agregadores de blogs de ciencia se encuentra ScienceSeeker (http://scienceseeker.org/), un proyecto puesto en marcha por ScienceOnline, una entidad sin ánimo de lucro que busca fomentar el debate entre la comunidad científica

\footnotetext{
${ }^{16}$ Más información sobre el cierre de ScienceBlogs en: http://ow.ly/89L830k63Vq (última consulta 07/03/2018)

${ }_{17}$ Según sus editores, a través de estos diferentes medios Wired llega a cerca de 30 millones de personas mensualmente: http://ow.ly/p5ZD30k64gV (última consulta 07/03/2018)
} 
a través de conferencias y proyectos centrados en la comunicación. Este agregador recoge entradas de más de 1.200 blogs y otras fuentes de información científica y los organiza por temáticas. ${ }^{18}$ Uno de los agregadores más populares fue ResearchBlogging (http://researchblogging.org/), creado en 2007, donde se publicaban, en siete idiomas, solo post que citaban artículos revisados por pares, con el fin de contribuir a la selección y puesta a disposición de los usuarios de solo contenidos rigurosos y relevantes sobre investigación científica (Wilkins, 2008; Fausto et. al 2012). Este agregador cesó su actividad en junio de 2017, sin que se haya obtenido información del porqué de la decisión.

\section{EL CONTENIDO DE LOS BLOGS DE CIENCIA}

En la blogosfera de ciencia los contenidos son elaborados de forma bastante heterogénea (Wilkins, 2008; Porto y Palacios, 2012; Gomes y Flores, 2012; Mauranen, 2013). Mientras algunas entradas se quedan en la superficie de los temas, otras abordan las cuestiones con mayor profundidad y, con frecuencia, se reproduce material de otros sitios (Kouper, 2010) una variedad de mensajes que se relacionaría con la variedad de fines para los que los blogueros escriben sobre ciencia (Luzón, 2013). Para algunos autores, elementos multimedia, hipertexto, actualizaciones, correcciones y la libertad en la longitud de los textos ayudan a mejorar la precisión de los contenidos de ciencia en relación a los medios impresos (Michael, 2013; Mauranen, 2013).

Diversos trabajos profundizan en el contenido de los blogs científicos estudiando como variables las fuentes que utilizan, los temas que abordan, las características del discurso o la autocitación (Goldstein, 2009; Walejko y Ksiazek, 2010; Shema et al., 2012; Gomes y Flores, 2012; Luzón, 2013; Oliveira Fagundes, 2014; Sharman, 2014; Segado Boj et al., 2014), coincidiendo en que los blogs científicos se caracterizan en cuanto a contenido por un distanciamiento del lenguaje académico, una función divulgativa, una adecuación al medio online y el uso de distintas estrategias comunicativas para acercarse al lector y ganar audiencia.

Las estrategias adoptadas por los blogueros a la hora de comunicar sus mensajes son uno de los objetos de estudio más frecuentes en relación con los blogs de ciencia. En cuanto a la selección de los temas, Oliveira Fagundes (2014) señala que coinciden en gran medida con los que están en la agenda de los medios de comunicación y no en la agenda de la ciencia, junto con asuntos para despertar la curiosidad del público,

\footnotetext{
${ }^{18}$ Más información sobre la política de agregación de contenidos de ScienceSeeker en:
} http://ow.ly/hAc730k64Wy (última consulta 07/03/2018) 
lo que a su juicio pone de manifiesto el esfuerzo de los blogueros por atraer a lectores ajenos al mundo académico y aumentar el impacto de su comunicación. Según la misma autora, estrategias como el uso de títulos atractivos $y$, a veces, sensacionalistas o la publicación de encuestas, inciden en estos mismos fines. Para Thorsen (2013), los blogs que abordan el día a día de los investigadores atraen a un número considerable de lectores y ayudan a "humanizar" a los científicos y su trabajo.

En relación al discurso, los blogs de ciencia constituyen espacios discursivos híbridos que incorporan prácticas de los discursos público y privado/personal -con auto-referencias, un carácter informal o la expresión de sentimientos-, desde un discurso popularizado -con humor, metáforas o referencias al lector- (Luzón, 2013; Segado-Boj et al., 2014).

Algunos estudios refieren aspectos de mejora en los blogs de ciencia: un mayor aprovechamiento del vídeo, del audio y de los gráficos interactivos para explicar la ciencia; una mayor transparencia en cuanto a la explicitación de los objetivos del blog; que las entradas sean bien datadas e identificadas; mejorar la navegación a través del blog y utilizar en mayor medida etiquetas para agrupar los contenidos (Jiménez Hidalgo y Salvador Bruna, 2007; Segado-Boj et al., 2014; Ranger y Bultitude, 2016). Precisamente, trabajos como los de Batts et al. (2008), Lagu et al. (2008) o Goldstein (2009) han sido críticos con el contenido de los blogs de ciencia, al considerar que no utilizan fuentes autorizadas y que existen pocos mecanismos de control de calidad, pese a que ser la fuente más privilegiada por los motores de búsqueda.

Ashlin y Ladle (2006) cuantificaron errores en la información científica ambiental presentada en los blogs y pusieron de manifiesto la dificultad para evaluar la calidad de la información. A su juicio, mientras los científicos acuden a los medios de comunicación periodísticos para detectar y corregir errores, muchos no son conscientes del discurso que se está produciendo en los blogs. Por ello, consideran que deben participar activamente en la blogosfera para fomentar la presencia de opiniones informadas y, asimismo, que estas y otras actividades de divulgación formen parte de la actividad reconocida de un investigador.

La mención a artículos revisados por pares, la verificación de las fuentes al estilo periodístico, que el bloguero sea miembro de una institución reconocida o que tenga una buena reputación, es decir, que reciba buen feedback, podrían ayudar a evaluar la calidad de un blog de ciencia (Colson, 2011). 


\section{LA FIGURA DEL LECTOR DE BLOGS DE CIENCIA}

La posibilidad de llegar a una audiencia amplia eludiendo las barreras espaciotemporales es uno de los principales argumentos de los blogs frente a otro tipo de formas de comunicación de la ciencia (Blanchard, 2011). Además, la conexión de los blogs con redes sociales como Facebook o Twitter permite aumentar su difusión (Oliveira Fagundes, 2014).

No obstante, buena parte de los lectores de blogs de ciencia tiene algún tipo de relación con ella (Kouper (2010). Así, los blogs asociados a temas concretos, como la física, pueden alcanzar una pequeña audiencia, a menudo con los mismos conocimientos e intereses de su autor, lo cual a veces motiva que el nivel técnico de las entradas sea complejo e inapropiado para lectores legos (Chalmers, 2009). Por ello, tanto Chalmers como otros autores (Oliveira Fagundes, 2014) han puesto en tela de juicio que muchos blogs sean un canal de comunicación útil entre investigadores y público general, incluso entre los propios investigadores (Lewenstein, 2009). Tampoco en el momento de mayor auge de los blogs, Wilkins (2008) consideraba que estos fueran a desplazar a otras formas de comunicación de la ciencia, como las revistas de divulgación, a su juicio, las más populares para un público general interesado en ciencia. No obstante, el autor destacaba la influencia de los blogs al recordar que muchas revistas envíaban notificaciones a los blogueros para asegurarse de que sus artículos eran vistos y comentados en la blogosfera.

La figura del lector adquiere una especial relevancia en los blogs de ciencia debido a las posibilidades de participación e interacción que ofrece este canal. A diferencia de otros tipos de comunicación, en los blogs los lectores se involucran activamente en los temas de discusión, hacen preguntas o expresan desaprobación, mientras que el bloguero no se limita a dogmatizar, sino que se enfrenta a la respuesta del público (Thorsen, 2013) contribuyendo, para algunos autores, a una construcción colectiva de conocimiento (Batts et al., 2008; Blanchard, 2010). En esta línea, revistas como Cell o PLOS ONE han permitido a los usuarios comentar sobre los artículos publicados online. Sin embargo, la experiencia de estas revistas sugiere que los lectores son reacios a participar en este tipo de foros (Nature, 2009; Lewenstein, 2009).

Así Oliveira Fagundes (2014) piensa que, si bien los blogs de ciencia tienen un importante potencial para el intercambio de información y experiencias, su transformación en un canal de discusión se encuentra aún en proceso de construcción y legitimación. Para los periodistas científicos, la retroalimentación con los lectores a 
través de los blogs sí tendría un valor, ya que les ayuda a conocer, por ejemplo, cómo la gente entiende sus artículos (Hermida, 2010).

Litteck (2012) llevó a cabo una encuesta entre lectores de blogs de ciencia y distinguió tres tipos perfiles: lectores con una formación académica, periodistas científicos y legos. Los tres grupos valoraron los blogs de ciencia como un medio informativo, aunque también informal, y a veces incluso un canal de entretenimiento. Los legos resaltaron la alta calidad de la información proporcionada por los blogueros, y los lectores académicos opinaron que los blogs pueden proporcionar más precisión y mayor calidad que el periodismo científico. Por el contrario, los periodistas científicos fueron más críticos y no consideraron los blogs como un sustituto de la cobertura de la investigación.

\section{LOS BLOGS DE CIENCIA COMO FUENTE DE INFORMACIÓN PERIODÍSTICA}

Aunque los periodistas no consideren que los blogs puedan desplazarlos en su función de canalizar la ciencia hacia un público general, sí son conscientes de su potencial, por ejemplo, como fuente de información. Así, diversos autores han analizado cómo los periodistas están utilizando los blogs como una de sus principales fuentes de información en Internet (Kovic et al., 2008; Nature, 2009; Chalmers, 2009; Colson, 2011; Dunwoody, 2014; Mahrt y Puschmann, 2014).

En una encuesta a periodistas científicos, Colson (2011) comprobó que, si bien estos profesionales, cuando bloguean, utilizan otros blogs como fuente, a la hora de escribir artículos para formatos impresos son más conservadores y confían en fuentes tradicionales como las revistas y los artículos revisados por pares, expertos reconocidos o agencias internacionales especializadas. Cuando se les preguntó si habían utilizado la información de un blog para escribir un artículo periodístico, el 27\% respondió afirmativamente pero sólo el $22 \%$ había citado el nombre del bloguero en el texto, una mala praxis que constituiría una interesante línea de investigación en este ámbito.

Algunos autores reportan buenos y malos resultados en el uso de blogs de ciencia como fuente periodística. En el lado positivo, Odgen (2013) y Mahrt y Puschmann (2014) reportan el caso del blog de Rosie Redfield, que fue ampliamente recogido en los medios. Redfield cuestionó en su blog el artículo de la NASA publicado en la revista Science en torno al descubrimiento de una nueva cepa bacteriana capaz de nutrirse con arsénico, que después fue refutado, y pasó de 100 a 200.000 visitas en su 
blog, lo que a su vez demuestra el efecto que pueden llegar a tener los blogs en el contexto de la comunicación online de la ciencia.

En el lado negativo, Chalmers (2009) recordaba el caso de un científico involucrado en los experimentos del Gran Colisionador de Hadrones, quien publicó una entrada en su blog con datos científicos aún no contrastados que tuvo eco en la revista New Scientist. El caso suscitó polémica y el científico trató de matizar los resultados en sucesivas entradas. Por ello, Chalmers advertía que los periodistas debían ser cautelosos a la hora de utilizar información presente en blogs, particularmente si trabajan con una única fuente.

\section{DISCREPANCIAS Y CONVERGENCIAS ENTRE BLOGS Y PERIODISMO CIENTÍFICO}

Hoy día, el público espera informarse sobre ciencia y sobre otros temas de su interés con una gran inmediatez, y para ello utiliza las herramientas que les provean más rápido, ya sean blogs, cibermedios o cada vez más redes sociales (Gross, 2008; Claussen et al., 2013; Brown, 2015). En esta disputa por las audiencias confluyen blogs y periodismo, una relación no exenta de discrepancias que ha sido ampliamente abordada en la investigación de la comunicación de la ciencia en Internet (Blanchard, 2011; Mauranen, 2013). Buena parte de la literatura en torno a la relación entre blogs y periodismo ha enfrentado a uno contra el otro 0 , al menos, ha puesto a cada uno en un extremo (Carroll, 2007; Warden, 2010) por ejemplo, en la lucha por ver quien tiene una mayor credibilidad (Shanahan, 2011; Bell, 2012).

Mientras algunos autores son críticos con los periodistas y creen que los blogs no sólo mejoran el periodismo científico, sino que podrían llegar a sustituirlo; otros consideran que los periodistas son imprescindibles y que los blogueros, independientemente de su perfil, no están entrenados para cumplir determinadas labores necesarias para ofrecer una información de calidad, como el contraste de las fuentes.

Muchos autores, quizás debido a que buena parte de los trabajos han sido desarrollados por investigadores ajenos al ámbito de la comunicación, tal y como ha evidenciado la revisión sistemática, son especialmente optimistas respecto al papel de los blogs de ciencia. De este modo, se han recogido diversos argumentos favorables a los blogs frente al periodismo científico. Chalmers (2009) apuntaba que son vistos por los usuarios como la antítesis de los medios de comunicación tradicionales, ya que son libres de las restricciones establecidas por las estas publicaciones y emergen de una cultura promovida por los entusiastas de la Web. También subrayaba que un 
número cada vez mayor de científicos está utilizando los blogs precisamente como herramienta para desacreditar informaciones que perciben como impreciso 0 engañosas en los medios de comunicación. Walejko y Ksiazek (2010) coinciden en que los blogueros pueden desafiar al periodismo científico dando altavoz a actores tradicionalmente marginados en los medios de comunicación. A su juicio, aunque los blogueros científicos no están entrenados como periodistas, poseen los conocimientos especializados necesarios para evaluar fuentes de una forma crítica. Además, al estar inmersos en la comunidad científica, tendrían menos problemas a la hora de encontrar y evaluar las mejores fuentes de un tema científico determinado.

En la misma línea, algunos blogs de ciencia ofrecen acceso sin restricciones a los mecanismos internos de la investigación, lo cual es difícil de conseguir desde un periodismo formal (Carroll, 2007). Además, al permitir una comunicación directa con el público, los científicos pueden dar a conocer sus áreas de especialización con una profundidad que no se puede lograr en la mayoría de los artículos periodísticos (Warden, 2010). Carrington (2008) distinguía otra diferencia entre blogueros y periodistas científicos: mientras que los primeros pueden aprovecharse de un formato conversacional más libre, que permite plantear preguntas a lo largo de la entrada que pueden ser contestadas por los lectores e incorporar las respuestas al texto; en los relatos periodísticos las historias tienen una introducción, un nudo y un desenlace.

También son variados los argumentos favorables al periodismo científico que se han esgrimido en la literatura. En este caso, son sobre todo los investigadores que proceden del ámbito de la comunicación los que realizan un alegato en favor de la profesión periodística. Mooney (2009) explicaba que los blogs tienen audiencias más pequeñas y especializadas y que la mayoría de los blogueros no tiene formación adecuada y, de hecho, no informa. El mismo autor apuntaba otra diferencia de carácter "moral", la necesidad de apoyar a los periodistas en los malos momentos laborales que están viviendo. "Rara vez nos tomamos tiempo para mirarnos el uno al otro. Nos falta sentido de la solidaridad", (Mooney, 2009:s.p.). Colson (2011) señalaba que los periodistas científicos reprochan a los blogueros no actuar como "perro guardián" aunque a su vez cuestionaba si esta labor, realmente, les pertenecía, ${ }^{19}$ y aseguraba que todavía son necesarias las prácticas periodísticas tradicionales como la recolección y selección de la información, la investigación periodística o la edición.

${ }^{19}$ Ver más sobre la teoría del "perro guardián" en: Martínez Albertos, J. L. (1998). "La Tesis del 'perro-guardián': revisión de una teoría clásica”. Periodística, 99-110. 
Gross (2008) consideraba que el periodismo científico no debía sentir tanto el impacto de los blogs, ya que a su juicio sólo un número muy reducido de científicos en activo escribía en ellos. Para este autor, los blogs podían ser útiles para dirigir la mirada a determinados temas de interés, pero no iban a sustituir a la información periodística.

En este sentido Allemand (2013), quien fuera redactora jefe de la revista La Recherche, mostraba su escepticismo en relación a los blogs de ciencia aludiendo a su experiencia. "Es extraordinariamente difícil dar continuidad al blog de un investigador, salvo que se le remunere por su trabajo, como se haría en una crónica en la revista (...). La realidad es que los investigadores tienen poco tiempo disponible y son reticentes a publicar textos poco exactos (...). Hoy en día, la continuidad que tienen los blogs científicos de Francia se debe en su mayor parte a que los autores reciben una retribución por hacer esta actividad. $Y$ son, sobre todo, periodistas. La mayoría de los investigadores que mantenían un blog hace unos años han vuelto a sus investigaciones" (Allemand, 2013:72-73).

La validez de los blogs como fuente de información científica confiable es otro argumento recurrente en la confrontación entre blogs y periodismo científico. Chalmers (2009) recordaba que los blogueros, frente a los periodistas, no tienen el deber de ser equilibrados y de mostrar opiniones a ambos lados de un argumento. También afirmaba que sus entradas se basan en gran medida en temas recogidos en los medios de comunicación tradicionales, comunicados de prensa y entradas de otros blogs, y que raramente generaban material nuevo. Otra diferencia radicaba en el tema de las agendas. Frente a los usuarios de los blogs, los lectores de un medio de comunicación podían confiar en que la agenda de un periodista científico estaba movida principalmente por su prestigio como redactor, con su visión personal relegada a las páginas de opinión. En la misma línea, Wilkins (2008) destacaba la falta de control de calidad, la reescritura de textos ya publicados y la ausencia de edición en los blogs. Además subrayaba que muchos blogs eran herramientas para la autopromoción de las ideas de investigadores que no eran capaces de traspasar el filtro de la revisión por pares, proporcionando una información no contrastada y no veraz.

Según otros autores, la heterogeneidad de los blogs también se sitúa en su contra. Kouper (2010) argumentaba que, si bien es cierto que algunos blogs proporcionan información y explican asuntos complicados, sus evaluaciones son a menudo triviales y raramente proporcionan una crítica extensa o visiones encontradas en las publicaciones polémicas. La multiplicidad de formatos y contenidos de los blogs 
presentaría así un desafío más que una oportunidad para la participación del público en la ciencia. El hecho de que no hayan logrado constituirse como un género en sí mismo, se traduce para Kouper en expectativas rotas e incertidumbre para el usuario, lo que dificultaría la fidelización los lectores y una participación más amplia del público en esta forma de comunicación de la ciencia.

En esta misma línea, Trench (2012) recordaba que la historia de Internet se ha caracterizado precisamente por olas de expectativas, que se incrementaron con la Web 2.0, de la que los blogs forman parte. Como explicaba este autor, aunque los blogs se han presentado como herramientas para la comunicación de la ciencia altamente interactivas y basadas en contenido generado por el usuario, la realidad es que su uso ha sido muy parcial y desigual y su potencial no parece haberse desarrollado plenamente. Tampoco se ha definido el lugar de los blogs en el ecosistema actual de la publicación académica, lo que podría influir de algún modo en el panorama expuesto (Puschmann, 2014).

\section{UN PUNTO DE CONSENSO: LOS BLOGS DE CIENCIA COMO COMPLEMENTO}

Otras voces sitúan la disyuntiva en un punto medio, y es que los blogs podrían complementar al periodismo científico. La demostración de esta convergencia se puede mostrar con ejemplos prácticos: algunos blogueros son citados en los periódicos, entrevistados por los periodistas, participan en los debates radiofónicos y son invitados a conferencias y encuentros organizados por los medios. Al mismo tiempo, los periodistas son requeridos por los blogueros como expertos para publicar algún comentario en torno a una noticia de última hora e incluso como invitados para contribuir con una entrada (Warden, 2010).

Blogueros y periodistas deben ser conscientes de que su futuro mutuo depende de la forma en que se complementen entre sí y que "no son ni rivales ni compañeros, solo dos jugadores diferentes en el campo de la comunicación de la Ciencia" (Colson, 2011:900). Los blogs y las formas tradicionales de comunicación se pueden, por tanto, combinar para avanzar en la divulgación y la discusión de la ciencia (Mahrt y Puschmann, 2014).

Carl Zimmer, en su blog The Loom -http://blogs.discovermagazine.com/loom/-, abogaba por una convivencia pacífica entre blogueros de ciencia y periodistas científicos. Este autor no creía que los blogs fueran a suplantar nunca a los medios periodísticos y señalaba que los blogs podían actuar como un nuevo mecanismo de control de calidad. No obstante, dejaba claro: "Es cierto que los principales medios de 
comunicación están actualmente bajo un montón de presiones y limitaciones financieras, pero eso no puede ser una excusa para hacer pésimos reportes de ciencia, es decir, distorsionar una investigación, exagerar los resultados o escribir sobre comunicados de prensa. De hecho, deben hacer todo lo contrario: los periodistas científicos deben esforzarse por ser más excelentes si quieren que la gente continúe leyéndolos fielmente" (Zimmer, 2009:sp).

\subsubsection{LA CIENCIA EN LAS REDES SOCIALES}

Las redes sociales son un objeto de investigación emergente en el campo de la comunicación online de la ciencia (Gerber, 2012; Pinholster y Ham, 2013; Pont Sorribes et al., 2013; Montenegro y Escudero, 2013; Kahle et al., 2016; Büchi, 2017; Melo, 2017; Pérez-Rodríguez et al., 2018).

Las redes sociales son comunidades virtuales útiles para el intercambio de información sobre ciencia, el fomento de la discusión y la construcción de relaciones, un medio de gran alcance y rentable para llegar a las masas (Claussen et al., 2013). Desde el punto de vista de la audiencia, Moreno Castro (2013) distingue dos escenarios a la hora de utilizar redes sociales como medio de información sobre ciencia: usarlas de forma selectiva, lo que implica que el usuario es capaz de identificar las fuentes y el valor de la información que se presenta; y usarlas de manera no selectiva, lo que supone que el usuario no diferencia ni la fuente de información ni la autenticidad de la misma.

Existe la paradoja de que las redes sociales pueden ser vistas como competidoras de los medios de comunicación tradicionales y, sin embargo, se utilizan asiduamente en la actualidad como aliados dentro de las rutinas (ont Sorribes et al., 2013). Recientemente, se ha analizado el valor de las redes sociales para incrementar la implicación ciudadana y la interacción (Gil de Zúñiga et al., 2018) así como la responsabilidad de los medios en los contenidos sociales (Broersma y Graham, 2012).

De todas ellas, Twitter es la que está teniendo una influencia más palpable en la comunicación de la ciencia en Internet. Según la última Encuesta de Percepción Social de la Ciencia de FECYT, correspondiente a 2016, Internet fue el medio de comunicación para informarse sobre ciencia y tecnología más citado en primer lugar por la población española. Dentro de Internet, el 75,4\% de los encuestados manifestó informarse a través de redes sociales, un porcentaje que ha crecido exponencialmente desde 2010 , cuando solo el $18,4 \%$ afirmó informarse sobre ciencia y tecnología por 
esta vía. En concreto, el 37,3\% lo hace a través de Twitter, un porcentaje que se eleva hasta el $51,9 \%$ en la franja de edad de 15 a 24 años.

En la literatura, diversos trabajos han investigado las redes sociales, en general, y Twitter, en particular, como herramienta para la comunicación de la ciencia. Como apunta Ribas (2012), las personas que se dedican a la comunicación de la ciencia utilizan cada vez más la tecnología digital y las redes sociales. Muchos periodistas de ciencia promocionan los artículos que escriben a través de las redes sociales, las universidades y centros de investigación distribuyen a través de ellas sus comunicados de prensa, y los científicos destacan sus publicaciones con el objetivo de ganar en impacto (Peters et al., 2014). A ellos se suman otros actores, expertos y no expertos, que participan en este sistema cooperativo (De Semir, 2010) y favorecen la multiplicación y el efecto viral de los mensajes de temática científica y tecnológica (Fernández de Lis, 2013).

Hoy en día, los primeros datos sobre cualquier primicia científica o tecnológica se hacen públicos a través de Twitter (Brown Jarreau, 2014; Büchi, 2017). Incluso, los propios profesionales del periodismo de ciencia utilizan las redes sociales para estar informado de las últimas novedades, para mantener un contacto directo con las fuentes y para contrastar informaciones en tiempo real (Pont Sorribes et al., 2013). Según los mismos autores, Twitter $(96 \%)$ es la red social más utilizada por los periodistas de ciencia y su semejanza con la recepción de teletipos es una de las razones que más contribuyen a su uso.

Así, gran parte de los trabajos que analizan el uso de redes sociales en la comunicación de la ciencia se centran en Twitter. Precisamente, cómo los periodistas y los gabinetes de comunicación de los centros de investigación utilizan esta y otras redes sociales (Montenegro y Escudero, 2013; Kahle et al., 2016; Quiñónez Gómez y Sánchez Colmenares, 2016) centra diversos estudios. También el uso que científicos y académicos hacen de Twitter (Bonetta, 2009; Nentwich y König, 2014) o el impacto de esta red social en relación con la publicación científica (Mandavili, 2011; Liang et al. 2014).

El discurso público en Twitter y la percepción del riesgo sobre temas que suscitan algún tipo de controversia, tales como la nanotecnología o la energía nuclear, son objeto de otros trabajos (Veltri, 2012; Runge et al., 2013; Li et al., 2016). Estudios recientes apuntan a que Twitter ejerce una función de recomendación de información científica al vincular a recursos web, conectar a los usuarios y dirigir su atención hacia determinados temas (Büchi, 2017). 
Uno de los trabajos más novedosos en materia de redes sociales y comunicación de la ciencia es el desarrollado por Pérez-Rodríguez et al. (2018), en el que se aplica la Teoría de Redes al estudio de los agentes, las redes de comunicación y los flujos de información sobre ciencia en Twitter. Dicho estudio detecta que los perfiles más productivos son los personales, lo que sugiere que el nivel de actividad en Twitter depende en gran medida del compromiso personal. Los científicos, con un $37 \%$ de la actividad total, son el tipo de agente más destacado en la comunicación de la ciencia en Twitter, seguido, muy por detrás, por periodistas (19\%) y medios de comunicación (15\%). El mismo trabajo también indica que la comunicación de la ciencia en Twitter está más centrada en lo promocional -publicidad de eventos, programas e iniciativasque en la difusión de contenidos y opiniones sobre ciencia.

\section{LA PRESENCIA DE CIENTÍFICOS E INSTITUCIONES DE INVESTIGACIÓN EN LAS REDES SOCIALES Y SU INFLUENCIA EN EL PERIODISMO CIENTÍFICO}

Un solo vistazo a las funciones técnicas de las redes sociales pone de manifiesto su potencial para las actividades académicas, desde la producción y distribución de conocimiento a la difusión a un público general, la promoción del trabajo científico, el aumento de la visibilidad o la conexión de la ciencia con su entorno económico y social (Nentwich y König, 2014; Shema et al., 2012). La actividad de los científicos, pero también de los centros de investigación, en las redes sociales tiene influencia en el campo del periodismo científico ya que, como se ha expuesto, puede ser interpretada como una competencia de los periodistas en su misión de informar a un público general. También revistas netamente académicas tienen presencia en las redes sociales (Soler-Tovar, 2014; Benchimol et al., 2014).

En relación a universidades y centros de investigación, la encuesta de la Red de Bibliotcas Universitarias (REBIUN) realizada en 2014 sobre 64 universidades y centros de investigación españoles ponía de manifiesto que todos, sin excepción, están presentes en redes sociales. Todas estas instituciones, menos una, contaba con un perfil en Facebook, todas menos dos en Twitter, 49 estaban presentes también en YouTube, 27 en Linkedln y 29 en otras redes sociales. Pese a este gran interés, la encuesta mostraba que el mantenimiento de las cuentas se realizaba con escasa profesionalización, ya que solo el $67 \%$ contaba con una unidad, sección o servicio encargado de la administración de estas cuentas, una información relevante que puede servir como base para un estudio más amplio en este sentido.

En el caso de los científicos, Bonetta (2009) abordaba, en un momento aún incipiente, la forma en que los investigadores se habían unido a Twitter a través de las 
valoraciones de varios de ellos. Aseguraba que un número creciente de usuarios estaba encontrado en esta red social un lugar en el que compartir sus puntos de vista sobre los artículos científicos recientemente publicados, sus presentaciones o sus discusiones, así como información sobre becas, política científica, etc., un planteamiento en el que después han coincidido Mandavili (2011) y Darling et al. (2013). Teniendo en cuenta el ciclo de vida de una publicación científica, Twitter puede constituir un gran "departamento virtual" en el que colegas pueden ayudar a generar, compartir y refinar nuevas ideas. Asimismo, a la hora de llevar estas nuevas ideas a manuscritos, Twitter puede ser utilizado como un espacio informal para el examen previo de las obras en curso -pre-revisión por pares- (Darling et al., 2013).

También respecto a la comunicación pública de la ciencia, Twitter es considerada por los científicos una forma de hacer más accesible la investigación, informando sobre el trabajo diario en un laboratorio y publicando los resultados finales (Darling et al., 2013), así como difundiendo y educando en valores (Shiffman, 2012). Por otro lado, algunos investigadores consideran el potencial de Twitter como un arma de doble filo, debido a las dificultades de mantener un debate científico a través de mensajes cortos (Bonetta, 2009), en aquel momento, 140 caracteres.

Así, Twitter es tan valorado por algunos como denostado por otros (Gerber, 2012), que alegan los problemas que puede generar en cuanto a propiedad intelectual, a la puesta en circulación de resultados previos a su publicación o a la tergiversación de los mensajes científicos (Darling et al., 2013).

Un trabajo muy novedoso en este sentido es el desarrollado por Liang et al. (2014) quienes han proporcionado la primera evidencia empírica de que las interacciones con periodistas y las menciones en Twitter pueden ayudar al científico en su carrera profesional, contribuyendo a un mayor impacto de sus trabajos. Asimismo, determinan que la presencia de los científicos en Twitter amplifica el impacto de sus trabajos en los medios de comunicación. Se trata de una línea de investigación muy interesante que daría otro motivo de peso a la comunidad científica para divulgar sus trabajos, al margen de los tradicionales argumentos de rendición de cuentas a la sociedad, compromiso con la alfabetización científica, fomento de las vocaciones, etc.

\subsubsection{EMISIÓN AUDIOVISUAL ONLINE, DISPOSITIVOS MÓVILES Y CIENCIA}

Con el desarrollo de Internet se han ido adaptando, paralelamente, formatos que ya existían en los medios de comunicación tradicionales, como los relacionados con la 
televisión o la radio. Es el caso del webcast, similar a una emisión de televisión o radio en su objetivo pero concebido para Internet, facilitando por ejemplo la interacción. De esta forma, se unen las cualidades de la radio y la televisión a las características propias del formato digital y de la Web.

La investigación sobre la emisión audiovisual de contenidos científicos online es limitada, quizás debido a que el potencial real de estas herramientas y de estos contenidos aún no se ha explotado lo suficiente. Además, las aportaciones son fundamentalmente teóricas. No obstante, algunos grupos de investigación están poniendo en marcha estudios en esta materia para profundizar, por ejemplo, en las tendencias y formatos narrativos utilizados por el vídeo online de contenido científico. ${ }^{20}$

Para algunos autores, los medios audiovisuales no son adecuados para comunicar conceptos o abstracciones, por lo que no serían especialmente apropiados para transmitir ciencia (Calvo Hernando, 1997; León, 2002; Elías, 2008). En el caso de la televisión, los contenidos se seleccionan en función de la capacidad para despertar emociones y sentimientos, constatando una tendencia hacia el sensacionalismo y dejando a un lado los asuntos de mayor complejidad conceptual, ya que la información tampoco se trata en profundidad (León, 2002; Gutiérrez Lozano, 2002; Elías, 2008).

Esto, además, puede derivar en una imagen distorsionada del discurso científico (Calvo Hernando, 1997). León (2002) diferenciaba entre los contenidos científicos que gozan de buena acogida por parte de los telespectadores -como aquellos que humanizan la ciencia, aquellos sobre los que la audiencia ya tiene referencias anteriores y los que ponen de manifiesto las razones por las que el espectador puede estar interesado-, y los que no -como los asuntos netamente científicos o los que resultan desconocidos-.

En uno de los escasos trabajos localizados, Koolstra et al. (2006) confrontaron qué medio de comunicación era mejor para informar sobre ciencia, si la televisión o Internet, siendo los dos medios preferidos por las audiencias interesadas en ciencia (National Science Board, 2014; Eurobarómetro Especial 401, 2013; VIII Encuesta de Percepción Social de la Ciencia de FECYT, 2016) y por los profesionales del periodismo científico en su objetivo de alcanzar una audiencia lo más amplia posible. Los autores concluyeron que, en aquel momento, ambos medios, con sus ventajas y limitaciones, estaban equilibrados en cuanto a transmisión de información, nivel de confianza percibida y acceso del público. Aunque hayan pasado 12 años, es posible que esta misma situación se mantenga, aunque serían necesarios nuevos trabajos

20 Es el caso del proyecto 'El vídeo online como herramienta para comunicar la ciencia': http://ow.ly/hl7J30k9QYL (última consulta 07/03/2018) 
comparativos para actualizar las tendencias. Más recientemente, se ha analizado el rigor científico de los vídeos difundidos online a través de Youtube, el cual pone de relieve el riesgo de desinformación al que se enfrentan los consumidores de vídeo en esta red social (Bortoliero y León, 2017).

En relación con el audio, autores como Redfern (2009) han observado un cambio sin precedentes en la forma en que las personas escuchan sobre ciencia gracias al carácter asincrónico de Internet (Picardi y Regina, 2008), de modo que los oyentes buscan programas de ciencia a la demanda en la Web, se suscriben a servicios de podcast y los descargan en sus dispositivos móviles (Redfern, 2009).

El término podcast ${ }^{21}$ describe la producción y oferta de archivos de audio a través de Internet (Minol et al., 2007). Asensi (2013) los definía como pequeños programas de radio, en este caso sobre ciencia, que se pueden difundir a través de múltiples plataformas online. No obstante, algunos autores consideraban que otros términos como "audio multiplataforma" podían ser más precisos a la hora de reflejar el panorama digital y designar a las nuevas formas de audio que se comparten en la red (Redfern, 2009).

Para Picardi y Regina (2008), las radios han visto en los podcast y en Internet, en general, una alternativa a la divulgación científica convencional a través de las ondas, ya que los podcast reúnen el lenguaje de la radio tradicional (con una duración específica de los reportajes, un tratamiento especial de los contenidos científicos reunidos en un programa y un ritmo de conversación rápido) con los canales de distribución de la red.

Al igual que otras herramientas útiles para la comunicación de la ciencia que han surgido a raíz de Internet, como los blogs o las redes sociales, los podcast pueden ser creados por personas ajenas a la profesión periodística. Centros de investigación, organizaciones científicas o aficionados a la ciencia han entrado en competición con los periodistas científicos en la producción de podcast (Picardi y Regina, 2008; Redfern, 2009). En cambio, según este último autor, la calidad separa una emisión profesional del resto.

Son interesantes algunas experiencias, como las de 'Naked Scientists', un proyecto puesto en marcha por científicos, doctores y comunicadores de la Universidad de Cambridge en Reino Unido con el objetivo de ayudar al público en general a entender y relacionarse con el mundo de la ciencia, la tecnología y la medicina (Smith, 2011).

${ }^{21}$ Podcast procede de la unión de las palabras iPOD (referente al dispositivo de audio digital portátil diseñado y comercializado por la empresa Apple) y broadcasting (en inglés radiodifusión). Más información en Minol et al. (2007). 
Lanzado en 2001 y vigente en 2018, ${ }^{22}$ 'Naked Scientists' fue uno de los primeros programas de podcast científicos y ha llegado a alcanzar una audiencia semanal cercana al millón de oyentes, con su reproducción en cadenas como la BBC (Reino Unido), ABC (Australia) o Primedia (Sudáfrica). Lo que comenzó como una serie de podcast de aficionados se ha expandido gracias a Internet, alcanzando una gran audiencia a un bajo coste. Una encuesta aplicada a oyentes reveló además que la mitad no tenía formación científica, con una media de edad de 35 años y una presencia importante de mujeres (Smith, 2011).

Aún más incipiente es la investigación sobre comunicación de la ciencia a través de dispositivos móviles, en la que se analicen las posibilidades y desafíos que presenta como nueva forma de consumo de contenidos de ciencia. La mayor parte de los trabajos se centran en la alfabetización y la educación científica (Scanlon et al., 2005; Jones et al., 2006) más que en la divulgación, sobre la cual solo se ha localizado una referencia que analiza experiencias innovadoras puestas en marcha en diversas partes del mundo, como Science@Mobile, en la India (Sharman, 2014).

${ }^{22}$ Más información y podcast de 'Naked Scientist' en: http://ow.ly/1Kmy30k9Tor (última consulta el 07/03/2018. 


\section{EL MENSAJE PERIODÍSTICO SOBRE CIENCIA EN INTERNET}

El mensaje periodístico que aborda la ciencia y se publica en Internet presenta una serie de condicionantes que han sido ampliamente abordados en la literatura, fundamentalmente desde el punto de vista de las fuentes y las prácticas periodísticas en el contexto online, la temática de la información y el uso de las características propias de los cibermedios.

Este tipo de mensajes han sido definidos como aquellos "que comunican la situación de los trabajos de investigación que se realizan, en qué estado se encuentran, qué resultados se han obtenido, las conclusiones teóricas y prácticas de la comunidad investigadora, si determinados campos han dejado de tener interés para la comunidad, o si hay otras nuevas disciplinas en las que conviene potenciar la investigación" (García Álvarez de Toledo y Fernández Sánchez, 2011:7).

En general, la producción de la información científica presenta una serie de particularidades respecto a otros contenidos periodísticos, como la complejidad de los temas abordados y su 'traducción' a un lenguaje asequible, una asincronía entre los periodistas y sus fuentes, sobre todos los científicos, que producen a un ritmo diferente, y la reticencia de parte de la comunidad científica a difundir mensajes divulgativos en los medios de comunicación (Loose y De Lima, 2013). Asimismo, mientras en los medios tradicionales el público asumía los contenidos publicados por sus medios de cabecera, en Internet la situación ha cambiado y pueden seleccionar solo aquellos mensajes que se ajusten a sus preferencias (Jang, 2013).

No obstante, para algunos profesionales los criterios de noticiabilidad no habrían cambiado en la Web, siendo los avances novedosos en un determinado campo, publicados en revistas científicas de alto impacto y aquellos que tienen implicaciones sociales interesantes los que obtienen una mayor cobertura; sin obviar que disponer de elementos multimedia atractivos multiplica el impacto de un contenido científico online (Moreno Espinosa, 2010; Jáuregui, 2013). Uno de estos criterios, la proximidad, no parece ser seguido en los cibermedios donde, con independencia del espacio geográfico, predomina la información científica de origen anglosajón (Banda, 2003; Adam, 2012; Loose y De Lima, 2012; Martín y Ponce, 2012; Pérez-Rodríguez, 2016).

Uno de los asuntos que sí habría cambiado en buena medida el nuevo entorno online es el criterio de jerarquización de la información científica, seguramente extrapolable a todo tipo de información. En las secciones de ciencia se sigue atendiendo a los tradicionales criterios de relevancia (Moreno Espinosa, 2010) pero, 
cada vez más, a la actualización de los contenidos -lo más importante es lo más nuevo- y al número de clicks, difusiones, comentarios y/o votos obtenido por un contenido -lo más importante es lo más visto, comentado y difundido- (Elías, 2008). A diferencia de otras especialidades periodísticas, la ciencia no siempre tiene su sección dentro de un medio, tampoco en Internet, englobándose este tipo de contenidos en otras como salud, medio ambiente o tecnología, o en grandes contenedores como sociedad, en los que se entremezcla con otros contenidos variopintos (Martín y Ponce, 2012).

En cuanto a los géneros periodísticos más utilizados para dar cobertura a la ciencia, el nuevo medio parece no haber impulsado los suyos propios (Moreno Espinosa, 2010). De este modo, son la noticia y el reportaje, con una adaptación al nuevo canal basada fundamentalmente en la inclusión de contenido multimedia y de herramientas para la interactividad-, los más extendidos también en el contexto de los cibermedios (Torres et al., 2014; De Moraes y Maia, 2014).

En relación a la estructura, algunos autores aluden a la existencia de un formato homogéneo de tres partes en la información científica online: una primera parte en la que se resume la noticia y se aportan los primeros datos -titular y entradilla-; una segunda en la que se detalla el trabajo, la metodología, los avances que realiza en relación al conocimiento establecido y los resultados; y una tercera en la que se trata de confirmar la relevancia de la investigación para la audiencia, resaltando las implicaciones sociales de la misma y las expectativas que abre, y eludiendo aspectos relacionados con la verificación del material, la discusión o el análisis por parte de otros investigadores ajenos al estudio reportado (Loose y De Lima, 2012; Dos Santos, 2014).

Dos Santos (2014) también ha sugerido una "supervalorización" de los resultados de la investigación, lo que Cascais (2003) define como "mitología de los resultados", la cual ignora la actividad científica como proceso. Internet podría estar agravando este problema, debido al modo de consumir información en la red, aunque serían necesarios más estudios en este sentido para probar esta idea.

La misma autora ha evidenciado la utilización de patrones discursivos propios del habla cotidiana en estos contenidos, lo que mostraría la tensión existente entre información científica y entretenimiento y la tendencia de los medios de comunicación hacia un formato cada vez más conversacional. Asimismo, el modo que en que el periodista proyecta las voces de los científicos a lo largo del texto, combinando la citación -el discurso directo- y con el relato -el discurso indirecto- se emplearía para 
legitimar el reporte científico al que se hace referencia en el texto. A juicio de esta autora, a pesar del uso recurrente de citaciones, existe una ausencia de diferentes perspectivas, lo que restringiría el discurso desde el punto de vista científico y no se ofrecería a la audiencia el conocimiento necesario para que puedan valorar las implicaciones del asunto, en línea con lo sugerido por Rogers (2000) o Martín y Ponce (2012). Esto pondría de manifiesto una "falsa democratización de la ciencia", en la que el periodista asume un papel de mero informante, reproduciendo la opinión de la comunidad científica y restringiendo el proceso de divulgación a una simplificación de los descubrimientos científicos.

Por otro lado, algunos trabajos analizan uno de los elementos básicos de cualquier texto periodístico y uno de los principales reclamos de cara al lector, el titular. En el caso de los contenidos científicos publicados en los cibermedios, los titulares cumplen los patrones comunes, al ser cortos, simples y elípticos (Molek-Kozakowska, 2014). El hecho de que la composición de estos titulares científicos no difiera del estilo característico de cualquier otro titular periodístico hace que se repitan las limitaciones convencionales de estas estructuras, según la misma autora, quien apuntaba a una "domesticación" y a una "celebración" de la ciencia, reseñando un menor número de aspectos negativos que en otras especialidades periodísticas.

Finalmente, los trabajos académicos que analizan la autoría de la información científica online sugieren una preponderancia en la mención a las agencias de noticias, fundamentalmente las internacionales, como AFP, Reuters o la BBC (Loose y De Lima, 2012; Martín y Ponce, 2012; Ruiz Jiménez et al., 2014). Otros estudios han observado diferencias en la autoría de la información en función del formato del medio, siendo los periodistas en plantilla los autores más frecuentes en formatos impresos, y las agencias y la modalidad 'redacción' -utilizada habitualmente cuando se reproducen notas de prensa- las más comunes en los formatos digitales (Kandachi, 2001; González-Pedraz, 2013).

\subsection{PREFERENCIAS TEMÁTICAS}

Las preferencias temáticas dentro del amplio y heterogéneo mundo de la ciencia son, sin duda, el objeto de estudio predilecto en relación al mensaje periodístico. Es interesante la aportación teórica de Ribas (2012), quien diferencia tres tipos de temáticas principales reportadas por los medios: una cultural, aquella que trata de responder a las grandes preguntas de la humanidad -como cuál es el origen de la vida o el Universo- en la que se incluirían, por ejemplo, la biología o la evolución humana; 
una ciencia práctica, que aborda el conocimiento aplicado a la vida cotidiana -como las vacunas o la contaminación- y que engloba cuestiones relacionadas con la salud, el medio ambiente o la tecnología; y una ciencia social, referida a la cobertura de las implicaciones sociales y económicas de la ciencia, como los costes y beneficios de la investigación, la financiación de la actividad científica y sus resultados en términos de calidad de vida, bienestar o desarrollo económico. Russell (2009) hablaba también de la existencia de una serie de "historias globales" de todo el espectro de la ciencia que son reflejadas recurrentemente en todos los medios, con independencia del país, como las células madre, el genoma humano, las nuevas tecnologías energéticas, la evolución o la exploración espacial.

Multitud de autores han tratado de cuantificar, mediante la metodología del análisis de contenido, los asuntos más recogidos por los cibermedios. Sin embargo, resulta difícil establecer tendencias dada la gran variabilidad en la recogida y análisis de datos en estos estudios. No obstante, apuntan a que la astronomía, la salud y la medicina y el medio ambiente, en uno $u$ otro roden, son las temáticas más frecuentes en los medios digitales (Loose y delima, 2012; Martín y Ponce, 2012; Torres et al., 2014; Ruiz Jiménez et al., 2014; López-Pérez y Olvera-Lobo, 2015).

En la literatura, son igualmente frecuentes los estudios de caso sobre la cobertura mediática de determinados asuntos que tienen una base científica. La salud es el más trabajado (Biermann et al., 1999; Baker et al., 2003; Tian y Stewart, 2005; Warden, 2010; Moreno Espinosa, 2010; Pérez Martínez, 2011; Pérez Martínez, 2012; O’Connor y Joffe; 2014; Bohlin y Höst, 2014), ya que tiene una particularidad que le otorga especial relevancia de cara a la audiencia, y es que es un tema que afecta, directa 0 indirectamente, a todas las personas (Tian y Stewart, 2005; Cullen, 2013).

Durante mucho tiempo, según Cullen (2013), el tratamiento informativo de la Salud ha consistido en la presentación de datos de carácter epidemiológico, es decir, información sobre casos de una determinada enfermedad, el número de muertes que causa, etc. Una información que, si bien es importante para los gestores públicos, resulta de escaso interés para el público en general, que exige cada vez más información práctica para su vida cotidiana, por ejemplo, para preservar su salud.

Biermann et al. (1999) ya señalaban, en un trabajo pionero en torno a la evaluación de la fiabilidad de la información en Internet sobre un tipo de cáncer, su preocupación por la existencia de información inexacta o engañosa en un pequeño número de páginas web, en aquel momento, lo que podría tener efectos negativos sobre usuarios 
vulnerables. Un planteamiento que se ha puesto también sobre la mesa en estudios posteriores (Cline, 2001; Eastin, 2001; Berland et al. 2001; Pérez Martínez, 2012)

Así, algunos autores valoran inciativas puestas en marcha para promover un enfoque más crítico de la cobertura periodística de la salud, como Media Doctor, creado en 2004 con el objetivo de evaluar y mejorar la exactitud de la información sobre fármacos y tratamientos que se publica en los medios de comunicación australianos, o el portal Health News Review en Estados Unidos, que proporciona a los redactores una herramienta para evaluar fuentes de información y afirmaciones sobre salud (Berland et al., 2001; Cullen, 2013). Biermann et al. también apostaban, ya a finales de los 90 , porque los profesionales de la medicina tomaran un papel activo en la identificación y creación de contenidos precisos y en la alfabetización científica online para aprovechar el enorme potencial que ya observaban, apelando incluso a que estas actividades fueran parte de la formación académica de posgrado de los sanitarios. En cambio, no parece que hayan adoptado este papel activo y la información sobre salud imprecisa, sesgada y/o engañosa sigue siendo uno de los mayores problemas informativos en Internet (Pérez Martínez, 2012; Di Pietro, 2013; O’Connor y Joffe; 2014).

Junto a los estudios de caso relacionados con la salud, destacan por su abundancia en la literatura los trabajos en torno a la comunicación online de la nanotecnología, una línea de investigación en la que se ha especializado el único grupo localizado en el trabajo de revisión sistemática, el conformado por Ashley A. Anderson, Dominique Brossard, Dietram A. Scheufele y otros colaboradores del Departamento de Comunicación de las Ciencias de la Vida de la Universidad de Wisconsin-Madison (Estados Unidos).

Como objeto de estudio de interés, Anderson et al. (2012) señalan que la nanotecnología es representativa de un conjunto cada vez mayor de tecnologías emergentes que destacan por su complejidad, y un candidato interesante para estudiar la discusión pública de procedimientos tecnológicos y sus posibilidades, incluidos los riesgos. Además, como uno de los campos científicos más prometedores, se ha cubierto en gran medida en todo tipo de medios de comunicación (Li et al., 2013). La cobertura periodística se restringe en gran parte a noticias sobre desarrollos concretos, incluso, sugieren que cuando un periodista observa que se ha cubierto una noticia sobre nanotecnología en otro medio es cuando percibe que es relevante para su propia cobertura (Anderson et al., 2012). 
Este equipo ha desarrollado investigaciones centradas en diversos aspectos de la comunicación online de la nanotecnología, como la búsqueda de información en Google, las audiencias, los contenidos o las diferencias en la cobertura entre medios impresos y digitales (Anderson et al., 2010; Ladwig et al, 2010; Xenos et al., 2011; Cacciatore et al., 2012; Liang et al., 2012; Anderson et al., 2012; Li et al, 2013; Anderson y Brossard, 2013). Estos trabajos constatan la tendencia de los usuarios a acudir a Internet para informarse sobre ciencia, así como su interés por las aplicaciones de la nanotecnología, sobre todo las que tienen que ver con la salud. Además, estos estudios evidencian el importante papel que está teniendo la web y, en concreto, los cibermedios, en el conocimiento y la comprensión pública de la nanotecnología, lo que podría ser extrapolable a otras disciplinas científicas y tecnológicas.

También se han localizado otros estudios relacionados con la comunicación de la nanotecnología en Internet ajenos a este grupo de investigación, como los de Veltri (2012) y el Runge et al. (2013), centrados en Twitter, y entorno a la energía nuclear (Oltra et al., 2014; Li et al., 2016).

Una tercera temática principal sobre la que se han localizado diferentes estudios de caso es el Medio Ambiente en general, y el Cambio Climático en particular. Como objeto de estudio, Trench (2012) señalaba que la ciencia climática es especial, ya que está marcada por las complicadas interpretaciones de los registros históricos, las inciertas evidencias prehistóricas y su difícil extrapolación hacia tendencias futuras. Además, este tema tiene fuertes implicaciones políticas y éticas, y el conocimiento colectivo sobre el mismo está representado a nivel mundial por una plataforma 'cuasi' política, el Panel Intergubernamental sobre el Cambio Climático (IPCC). Por todo ello, según el mismo autor, la ciencia climática ha sido tradicionalmente atractiva para todo tipo de medios de comunicación, especialmente para los cibermedios y los medios sociales. En esta línea se ha estudiado el debate online que genera el cambio climático (Rogers y Marres, 2000), la precisión de la información publicada (Ashlin y Ladle, 2006), el discurso periodístico (Picó Garcés, 2014) o el caso del 'Climategate' (Holliman, 2011b; Jaspal et al., 2012; Trench, 2012; Koteyko et al., 2013). Este último caso es paradigmático, ya que la filtración de los datos y documentos de la Unidad de Investigación Climática de la Universidad de East Anglia (Reino Unido) en las semanas anteriores a la Cumbre de Copenhague de las Naciones Unidas (COP - 15), en 2009, se extendió rápidamente a través de cibermedios y blogs y motivó un gran revuelo en la comunidad científica, al dar argumentos a los escépticos de las explicaciones antropogénicas que justificarían el cambio climático. 
Junto a estas temáticas que han concentrado la mayor parte de los estudios de caso localizados -salud, nanotecnología y cambio climático- se encuentran otras, con algunos trabajos puntuales, como la física (Chalmers, 2009), la biotecnología (Brossard, 2012), la botánica (Osterrieder, 2013), la evolución (Goldstein, 2009) o la microbiología (López-Goñil y Angulo, 2013).

Un enfoque habitual de todos estos trabajos, como se ha observado en la revisión sistemática, es el de la comunicación de riesgos. Se trata de investigaciones en las que se profundiza, principalmente, en crisis sanitarias globales como el mal de las vacas locas (Kandachi, 2001) o la gripe porcina (Russell, 2009); crisis alimentarias (Regan et al., 2014; Taylor et al., 2015); o posibles riesgos tecnológicos como los cultivos transgénicos (Byrne et al, 2002) o el daño pulmonar debido a la inhalación de nanopartículas (Anderson et al, 2012). En este sentido, la información periodística online sería particularmente apropiada en la comunicación de riesgos, ya se que actualizada frecuentemente, lo que es relevante en campos que tienen una rápida evolución; facilita contenidos multimedia, que mejoran la comprensión de nuevos conceptos o temas complejos, y permite el acceso a través de hipertexto a contenidos más detallados o a diferentes perspectivas y sus aplicaciones (Byrne et al., 2002)

\subsection{FUENTES INFORMATIVAS}

Internet ha producido cambios sustanciales en relación con las fuentes habituales de los periodistas científicos. La investigación en esta línea se ha movido en dos vías: una relacionada con el emisor -qué fuentes dicen utilizar los periodistas científicos- y otra asociada con el mensaje -qué fuentes son citadas en los artículos periodísticos-.

Aunque, gracias a la red, los periodistas tienen la posibilidad de acceder e incorporar más fuentes -suscripción online a servicios de prensa, newsletters, RSS, etc.-, los grandes proveedores de información científica, como por ejemplo la NASA, están hoy al alcance de cualquier usuario de la Web, lo que obliga al periodista a ser especialmente cuidadoso en su trabajo si no quiere perder credibilidad (Elías, 2008). Para el mismo autor, esta mayor facilidad de acceso a las fuentes internacionales ha liberado al corresponsal en el extranjero de tener que cubrir este tipo de información compleja y ha favorecido la figura del periodista especializado en ciencia, que sólo ocasionalmente tendría que desplazarse como enviado especial.

Las revistas científicas son la fuente más recurrente en el contexto de Internet. En una encuesta realizada en 2007 a periodistas de 27 países, recogida en el informe de la Comisión Europea European Research in the Media: what do media professionals 
think, el 62\% confirmó utilizarlas como principal fuente. Internet, en general, se mencionó en segundo lugar (54\%) y las agencias de noticias en tercero (40\%). Estos datos se ajustan a los reportados en algunos análisis de contenido (De Lima, 2012; López-Pérez y Olvera-Lobo, 2015) que confirman a las revistas científicas y a las universidades y centros de investigación como fuentes más utilizadas.

Que en la red se pueda acceder más fácilmente a muchas fuentes no parece ser sinónimo del uso de varias fuentes en un mismo artículo o de una mayor diversificación de las mismas. Ya en 1999, Stocking apuntaba que los periodistas utilizaban una sola fuente cuando abordaban un tema científico, salvo en el caso de asuntos de controversia, como el cambio climático, en los que los periodistas sí recogían múltiples voces incluso para abordar materias en las que sí existía un consenso. Esta situación se sigue reportando en el contexto de los cibermedios (Loose y De Lima, 2012; Taylor et al. 2015), lo que favorecería la demanda de buena parte de la comunidad científica de controlar la cobertura mediática de la ciencia (Peters et al., 2014). En relación al uso de una única fuente, Loose y De Lima realizan una interesante reflexión referida a la ética profesional:

"Tal aspecto está relacionado con la voluntad de los periodistas de minimizar el grado de incertezas científicas que serán relatadas en sus materias, tanto para generar más impacto al público por la ausencia de dudas o fragilidades como por la percepción todavía vigente de la ciencia como incuestionablemente exacta, correcta y verdadera. (...) Es síntoma de un periodismo acomodado, poco desconfiado, que se contenta en ser portavoz de una fuente especialista $y$ que está inmerso en una rutina de producción muchas veces no compatible con los anhelos y perspectivas del periodismo científico" Loose y De Lima (2012: 96-97).

La literatura ha recogido de forma recurrente esa tendencia a un periodismo acomodado en Internet, en paralelo o inherente a una dependencia informativa de fuentes organizadas -fuentes institucionales que facilitan mucha información corporativa, generalmente interesada, como universidades y centros de investigación(Trench, 2009; Calloni et al., 2009; Granado, 2011; Murcott y Williams, 2013; Cullen, 2013).

Así, buena parte de la labor diaria del periodista científico se concentra hoy en la identificación y la selección de temas interesantes dentro de la "montaña" de comunicados de prensa que inundan la bandeja de entrada de su correo electrónico (Murcott y Williams, 2013). Esta situación ha derivado en lo que Davies (2009) 
denominó 'churnalism', la simple reescritura de notas de prensa procedentes de fuentes organizadas, en lugar de la localización y elaboración de temas propios. Asimismo, la reducción de costes y de personal en las redacciones y la falta de tiempo de los escasos profesionales en plantilla, que además deben cubrir los formatos tradicionales y los digitales, también estaría favoreciendo tales prácticas (Cullen, 2013).

Desde luego, el hecho de que una parte fundamental de lo que debe ser trabajo el periodista esté ahora "externalizado" a las relaciones públicas y a la comunicación institucional está conduciendo a una disminución de la calidad de este tipo de periodismo especializado (Moraes y Maia, 2014). Aunque el 'churnalism' rellena de forma fácil y barata páginas y minutos de emisión, a la larga hace un flaco favor a la ciencia y a la sociedad (Murcott y Williams, 2013; Shäfer, 2017).

Las editoriales que publican las revistas científicas de mayor impacto están estableciendo, de forma consciente, la agenda de la ciencia en los medios con su política de embargos (Peterson, 2001). Sus gabinetes de comunicación envían a los periodistas sus previsiones semanales, con un margen de entre tres y siete días para el levantamiento del embargo, un tiempo en el que el periodista debe explicarle al editor de su medio el tema que desea reportar, hablar con los científicos responsables de la investigación y, al menos, contactar con algún científico independiente en el caso “ideal” (Holding, 2007; Gross, 2008). La aceleración que produce este proceso en la labor periodística y la competencia entre todos los cibermedios por los cliks tiene como producto piezas periodísticas cortas y rápidas en su lectura, con titulares anecdóticos, que limitan mucho la cobertura de la ciencia (Gross, 2008; Loose y De Lima, 2012; Fernández de Lis, 2013; Martínez Valdés y Rodríguez Luna, 2014).

Algunos autores advierten que, con Internet, se está acentuando la estandarización de los encuadres y la homogeneización de los contenidos de ciencia evidenciado en la prensa tradicional, un fenómeno que estaría alcanzando una dimensión global con los periodistas científicos de todo el mundo recibiendo, recogiendo y publicando a la vez las mismas informaciones de las revistas (Granado, 2011; De Moraes y Maia, 2014; López-Pérez y Olvera-Lobo, 2015)

\subsection{EL MENSAJE CIENTÍFICO EN INTERNET VS PAPEL}

Según algunos aurores, los cibermedios repiten los mismos esquemas del periodismo impreso, pese a que los primeros conforman un nuevo medio que requiere 
otro tipo de tratamiento para aprovechar las potencialidades que ofrece multimedialidad, hipertextualidad, interacción y actualización- (Martín y Ponce, 2012).

En este sentido, Hermida (2010) subrayaba que un artículo de 200 palabras redactado para un formato impreso no puede transferirse directamente a un formato web, al igual que un guión concebido para la televisión sería un texto pobre convertido en un artículo de periódico. Por ello, considera que a la hora de plantear un tema científico los periodistas deben jugar con las fortalezas de cada medio. Asimismo, Russell (2009) advertía que, si bien estas nuevas herramientas permiten ofrecer contenidos creativos y una amplia variedad de formatos de información científica, la ingente cantidad de contenidos presentes en la web y los comentarios desinformados originan el riesgo de "predicar a los convertidos", fragmentar a la audiencia y reforzar la opinión desinformada. Por ello, parece que aún queda mucho camino por recorrer en los próximos años para garantizar un trabajo periodístico científico de alta calidad en Internet (Schäfer, 2011).

En la misma línea, Moreno Espinosa (2010) señalaba que, efectivamente, la información que se recoge en la versión digital de los medios es la misma que se publica en el formato papel, aunque esta sí cuenta con las adaptaciones necesarias para el canal de Internet, con recursos complementarios como infografías, imágenes, vídeo, sonido y herramientas para la interactividad con la audiencia, lo que a su juicio contribuye a incrementar el conocimiento sobre un tema e incide en el aspecto divulgativo. Al margen de estos elementos de apoyo, la misma autora refiere:

"Las bases del periodismo que se hace en Internet no distan demasiado de los preceptos más clásicos de la prensa tradicional puesto que los géneros que se utilizan en la red son los mismos que se han consolidado en el periodismo clásico, las fuentes que surten las noticias también son las mismas $y$, aunque en modelos de organización distintos, la jerarquización de la información también atiende a preceptos de importancia" (Moreno Espinosa, 2010:328).

En un análisis sobre la adaptación del texto al formato electrónico desde un punto de vista periodístico, Macedo-Rouet (2002) apuntaba que, aunque no se reproduce fielmente el modelo de la versión impresa, la edición digital no cuenta con muchas modificaciones, sino que se produce una transposición de contenido en la que se altera ligeramente la estructura y las fuentes del texto.

Allemand (2013), redactora jefe de la revista de divulgación científica francesa La Recherche, de la que es redactora jefa, describía en qué aspectos Internet ha cambiado el panorama de este tipo de publicaciones impresas. Explicaba que, si bien 
La Recherche contaba con una página web desde 1995, en ella se encontraban fundamentalmente los artículos de la revista en papel. Asimismo, el sitio sirve para realizar promoción de la revista impresa. Situación similar se observó en otras revistas examinadas por la misma autora. Esencialmente, se presentan noticias -cuya elaboración es variable, dependiendo fundamentalmente de los recursos humanos disponibles, están producidas para la web o tomadas de la versión impresa- y se difunde la imagen de marca. Del mismo modo, las aplicaciones para dispositivos móviles de estas publicaciones, se trata solo de una trasposición del formato papel al formato digital, a modo de "copia electrónica". También indicaba que, aunque se centran en la versión impresa, las revistas de divulgación científica francesas no están totalmente ausentes del campo de los blogs, ya que de forma puntual -por ejemplo, durante expediciones paleontológicas o en el lanzamiento de satélites- se abrían algunas bitácoras. En cuanto a las redes sociales, refirió que no se invertía en ellas porque publicar regularmente exigía tiempo que no se ve recompensado con beneficios inmediatos en términos económicos. Aunque se trata de un estudio interesante en cuanto a su planteamiento, sería necesario realizar una actualización para conocer, por ejemplo, si estas revistas ya consideran las redes sociales como elemento clave en la gestión de intangibles como la interacción con los lectores o la imagen de la marca.

Más allá de las diferencias a nivel estructural y de formato entre las versiones impresas y online de los medios que publican información científica, algunos estudios efectúan comparativas en torno a la cobertura y los contenidos presentes en ambas versiones. En un análisis cuantitativo y cualitativo de las versiones convencionales y online de la CNN, la CBS y The New York Times en relación a la cobertura del mal de las vacas locas en el año 2000, Kandachi (2001) determinó que la CNN era el medio que contaba con unas mayores diferencias entre ambas versiones. Mientras que solo se emitieron dos noticias sobre el mal de las vacas locas en el año 2000, en CNN.com se publicaron 87 piezas periodísticas, incluido un apartado en su sección 'Cobertura en Profundidad' (In-Depth Coverage). Con relación a los textos publicados en la web, la misma autora destacaba que el usuario puede obtener una información completa mediante el uso de hipervínculos a sitios a cargo de instituciones gubernamentales y otras organizaciones -macronavegación-. Por el contrario, en la CBS y The New York Times no se encontraron diferencias significativas entre las versiones tradicional y online en cuanto al número de piezas periodísticas publicadas. En el caso de The New York Times, publicó el mismo tipo de informaciones en ambos formatos respecto a la cobertura del mal de las vacas locas. 
Kandachi concluía que estos resultados pueden ser debidos, en parte, a que la CNN se dirige a un público internacional y que por ello hace uso de la capacidad de Internet para que los usuarios puedan acceder a sus informaciones desde cualquier parte del mundo, utilizando su web como "red de arrastre". Mientras, la CBS y The New York Times son medios de comunicaciones eminentemente nacionales y parecen emplear la web como un mero "escaparate" para atraer más audiencia a sus versiones convencionales. En este sentido, la autora señalaba que tanto los medios tradicionales como los cibermedios cuentan con fortalezas y debilidades. En el caso de los medios online, apunta que la información reportada es más completa gracias a la mayor disposición de espacio y a las posibilidades de interacción.

Uno de los trabajos académicos más completos en este sentido es el de Cacciatore et al. (2012), un análisis comparativo entre el mensaje periodístico recogido en medios tradicionales -prensa de Estados Unidos- y el publicado en cibermedios -en concreto en el agregador de noticias Google News y en el agregador de blogs Google Blogssobre la cobertura de tecnologías emergentes a lo largo de seis años. En primer lugar, comparan el volumen de dicha cobertura en relación a otro tema, la energía nuclear. En segundo lugar, contrastan los aspectos concretos que se abordan. En cuanto al volumen de información, mostraron una cobertura similar en la prensa impresa, en Google News y en Google Blogs de ambos temas, nanotecnología y energía nuclear. No obstante, se encontró una disminución constante de la cobertura de la nanotecnología en la prensa tradicional después de 2006 quizás motivada, a juicio de los autores, por un descenso en el número de eventos relacionados con la nanotecnología -como el Premio Nobel de Química por el descubrimiento de los fullerenos en años anteriores- o por una disminución generalizada de la cobertura científica en los medios de comunicación estadounidenses. Por otro lado, se determinó que Google News cubrió más temas relacionados con la nanotecnología y la energía nuclear que la prensa impresa; y que Google Blogs aumentó constantemente la cobertura de ambos temas en los últimos cuatro años analizados.

Respecto a los aspectos concretos abordados, el estudio apunta diferencias claras en la cobertura de la nanotecnología en prensa impresa y digital. En el soporte digital se encuentran con mayor frecuencia contenidos temáticos relacionados con nanotecnología y medio ambiente y, en general, los autores aprecian que el contenido temático se distribuye de forma más uniforme en la cobertura online, con una mayor presencia de asuntos relacionados con las aplicaciones, la política reguladora y las implicaciones sociales de la nanotecnología. Por el contrario, la prensa impresa ofrece 
una perspectiva más limitada, centrada en gran medida en aspectos relacionados con la salud, los negocios y la investigación.

En virtud de estos resultados, Cacciatore et al. concluyen que los cibermedios y los blogs están ofreciendo nuevas y diferentes visiones de la nanotecnología en lugar de limitarse a amplificar las representaciones proporcionadas por la prensa tradicional, lo que puede contribuir a una diferente percepción y conocimiento de esta rama tecnológica por parte del público. Esto puede deberse a que en el entorno digital existe una variedad más amplia de productores de contenido. Asimismo, sugieren que determinados asuntos tienen una mayor probabilidad de seguimiento en los blogs, que no siguen la misma agenda que los medios impresos. De este modo, el estudio apoya la idea de que Internet tiene un discurso más diverso sobre la nanotecnología y que por tanto los usuarios que realicen búsquedas en Google para consultar problemas relacionados con la nanotecnología encontrarán una variedad de contenido mayor y más equilibrado que la basada exclusivamente en medios impresos.

En la misma línea, Anderson et al. (2012) investigaron las diferencias en el ciclo informativo y en las dinámicas de atención en medios de comunicación impresos y online a partir del estudio de piezas periodísticas en torno a un tema determinado, la muerte de trabajadores en una factoría china por daño pulmonar debido a la inhalación de nanopartículas. Los autores comprobaron la prevalencia y la persistencia del tema en los cibermedios frente a la prensa impresa, con una presencia diez veces mayor y a lo largo de casi un mes, y determinan que los medios online se rigen por un ciclo informativo diferente que puede desempeñar un papel cada vez más importante en la visibilización de cuestiones científicas. Otros estudios recientes han abordado cómo es representada la incertidumbre científica en medios impresos y digitales (Guenther et al., 2017; Jenson et al., 2017; Krakow et al., 2018).

\subsection{MULTIMEDIALIDAD, HIPERTEXTUALIDAD, INTERACCIÓN Y ACTUALIZACIÓN}

La elaboración de contenidos periodísticos de carácter científico supone un rompecabezas para los redactores. "Traducir" estos temas para que sean comprendidos por un público general requiere probar diferentes enfoques, modelos y medios, diferentes piezas que deben engranarse hasta componer el puzzle. Tradicionalmente, los periodistas han optado por usar texto e imágenes (Mol, 2011), sin embargo, el entorno digital ha abierto un abanico de posibilidades para este tipo de mensajes periodísticos, pudiendo llegar al público de forma innovadora (Hermida, 
2007; Russell, 2009). Estas posibilidades se asocian a los rasgos propios de los cibermedios: la hipertextualidad, la multimedialidad, la interacción y la actualización (Salaverría, 2005).

Multitud de autores han realizado aportaciones a nivel teórico y empírico en torno a la utilización y aprovechamiento de estas características en la información científica, por ejemplo, cuáles son las más utilizadas, cómo se aplican o qué efectos ejercen sobre el mensaje. Incluso, en el ámbito metodológico se ha propuesto un modelo de estudio de la arquitectura de la información de los cibermedios que realizan periodismo científico (Sarmento et al., 2004).

En relación con la multimedialidad, Internet posibilita la combinación de texto, imágenes, gráficos, vídeo y audio, unos recursos que, conjugados, permiten facilitar la comprensión del mensaje periodístico científico y ayudan al público general a tener una visión más contextualizada y multidimensional de los asuntos reportados (Byrne et al, 2002; Hermida, 2007; Gomes da Silva, 2012; Seabra, 2012). Así, diversos autores coinciden en destacar el potencial que tienen los recursos multimedia en el terreno de la información científica (Sabbatini y Maciel, 2005; Jáuregui, 2013; Rodrigues Pereira et al., 2014).

Como puso de manifiesto la redactora y productora de contenidos del sitio web de la CNN Elizabeth Landau durante el seminario Communicating Science Across Online and Social Media, organizado por EurekAlert! en 2013, los elementos gráficos como fotografías o vídeos juegan un papel clave en la "venta" de la información científica, siendo a su juicio tan importantes como el titular. Siguiendo la práctica de los propios científicos, quienes utilizan figuras e imágenes para representar mecanismos, sistemas, y conceptos que envuelven procesos -como reacciones químicas o procesos climáticos-, la información periodística puede llegar a ser más comprensible a través de un tratamiento multimedia (Sabbatini y Maciel, 2005; Mol, 2011).

El periodista científico de 'The New York Times' James Gorman destacó en el seminario de EurekAlert! que el material que los propios investigadores capturan o crean para ilustrar por ejemplo fenómenos biológicos, como vídeos o animaciones, son materiales excelentes para que los contenidos periodísticos ganen atractivo y aumenten la conciencia pública sobre la importancia del tema. No obstante, la mera presencia de diferentes recursos no configuraría por sí misma una pieza multimedia. Para que esto se produzca, cada recurso tiene que ser complementario y no redundante (Hermida, 2010). 
Pese a lo expuesto a nivel teórico, algunos trabajos empíricos apuntan a que, en realidad, la multimedialidad es un rasgo aún poco explotado en la información científica presente en los cibermedios (González-Pedraz, 2014a). Incluso la misma fotografía, el elemento gráfico clásico de la prensa, es infrautilizado en muchos cibermedios (Martín y Ponce, 2012). Tan solo algunos creados expresamente para comunicar ciencia en diferentes formatos y soportes -como Ciência 2.0-23, parecen estar aprovechando este potencial (Gomes da Silva, 2012).

Dentro de la multimedialidad, se ha estudiado el uso de la infografía ${ }^{24}$ como recurso de interés en la información científica. Este elemento tiene la particularidad de facilitar una lectura más rápida y fácil de la información, y se identifica por la adopción de elementos gráficos en combinación con una tipografía atractiva estéticamente, para reducir precisamente la carga textual (Sabbatini y Maciel, 2005; Mol, 2011; Rodrigues Pereira et al., 2014).

Gracias a este atractivo visual, los infográficos son particularmente populares entre los usuarios de información científica en los cibermedios (Schäfer, 2011; Rodrigues Pereira et al., 2014). Sabbatini y Maciel (2005) categorizaban las infografías científicas publicadas en los principales cibermedios españoles y observaban una predominancia de las de tipo instructivo o demostrativo (89,5\%), con una representación gráfica en varias pantallas cuya alternancia es controlada por el usuario, en la que se explica el funcionamiento de determinados sistemas o cómo algunos eventos ocurren. Un elemento multimedia que, a juicio de estos autores, resulta bastante eficiente desde el punto de vista didáctico. No obstante, crear una buena infografía científica requiere de una gran habilidad, ya que supone analizar datos de manera crítica, establecer conclusiones, valorar su relevancia y utilizar un software para su diseño (Mol, 2011). Además, al igual que con la información textual en Internet, el usuario tiene que llevar a cabo un proceso de selección y evaluar si se trata o no de un recurso confiable.

En referencia a otro de lo de los rasgos de los cibermedios, la hipertextualidad, son escasos los estudios que se centran en su uso por parte de los periodistas científicos. Aunque los enlaces posibilitan el acceso a información más detallada o a diferentes perspectivas sobre un mismo asunto científico (Byrne et al., 2002; Trench, 2007), tampoco parece que sea un recurso explotado (Bell, 2012).

${ }^{23}$ Más información sobre el portal de información científica multimedia Ciência 2.0: http://ow.ly/crc630kd7WI (última consulta el 07/03/2018)

${ }^{24}$ Definida por Mol (2011) como una representación visual gráfica de información, datos 0 conocimientos, a menudo combinados con texto, cuyo fin es transmitir un mensaje, presentar grandes cantidades de información de forma resumida y fácil de entender, mostrar datos y descubrir relaciones causa-efecto, y monitorear periódicamente la evolución de ciertos parámetros. 
En un trabajo teórico, este último autor indicaba que el hipertexto no había transformado la comunicación de la ciencia o, al menos, no la había transformado tanto como podría conseguir, debido a un uso deficitario en algunas ocasiones y erróneo en otras, algo que había sido referido previamente por Macedo-Rouet (2002).

"El enlace es una forma retórica como cualquier otra forma de comunicación. Su colocación, pensar en cómo, dónde y cuándo se va a enlazar, es sin duda parte del arte de la escritura moderna. Sin embargo, está infrautilizado. Los sistemas de gestión de contenido con los que trabajan muchos redactores profesionales son difíciles a la hora de trabajar con ellos, lo que limita la expresión hipertextual de un escritor" (Bell, 2012:3).

Aunque Martín y Ponce (2012) constataron un uso muy reducido del hipertexto en noticias de ciencia publicadas en cibermedios argentinos, González-Pedraz (2014a) observaba que hasta el $80 \%$ de piezas periodísticas sobre ciencia incluía enlaces, dentro o fuera del texto, que dirigían en partes igual tanto a otras informaciones dento del propio cibermedio -la denominada micronavegación (Díaz Noci y Salaverría, 2003)-, como hacia fuera del mismo -macronavegación, según los mismos autores-.

En cualquier caso, es fundamental racionalizar el uso de los enlaces a lo largo del texto (Martínez Valdés y Rodríguez Luna, 2004) y que se apliquen correctamente a lo largo de la información científica. Esto requiere una exigencia y una planificación estructural mayor, de lo contrario, se puede producir una lectura hipertextual de idas y venidas, desorientación, dificultades para reconocer las distintas fuentes y, como consecuencia, una interpretación inadecuada de la información científica (MacedoRouet, 2002). 


\section{EL ACCESO A LA RED DE LAS AUDIENCIAS INTERESADAS EN CIENCIA}

Internet ha facilitado en gran medida el acceso a la información científica por parte del público (Hermida, 2010; De Semir, 2010). Y el público, cada vez más, recurre a entornos en línea para buscar información sobre ciencia y seguir los desarrollos científicos (Brossard, 2013). Las nuevas formas de participación -por ejemplo, a través de las redes sociales-, la creación de contenidos dirigidos a distintos segmentos de público o la emergencia de contenidos generados por los propios usuarios, han llevado a reconfigurar y extender el concepto de audiencia en la red (Holliman et al., 2009). A continuación se desgrana una serie de consideraciones generales sobre los cambios que ha traído la web respecto a la recepción de información científica.

- En primer lugar, el receptor dispone hoy de información científica actualizada las 24 horas del día y accesible desde cualquier lugar gracias a las facilidades de acceso que brindan Internet y los dispositivos móviles (Holliman et al., 2009; Horning Priest, 2009; Hermida, 2010).

- En segundo lugar, con millones de ciudadanos accediendo a Internet en todo el mundo, las audiencias con potencial interés en contenidos científicos son enormes (Holliman et al., 2009; Mauraren, 2013). A su vez, el mayor desafío para el periodismo científico es precisamente cómo llegar a esos públicos ya que, si un usuario carece de interés, puede fácilmente ignorar la información en la red, incluso más que en los medios tradicionales (Bubela et al., 2009).

Por otro lado, la visión del público como un elemento homogéneo y singular se ha diluido en la red, donde las audiencias interesadas en ciencia pueden ser de diverso tipo -desde los propios científicos a entidades que financian la investigación, políticos, periodistas, ONG's, sociedad civil y, por supuesto, público general- y con múltiples razones para estar interesado en estos temas -educación, entretenimiento, debate, etc.- (Calloni et al., 2009: Hansen, 2009; Horning Priest, 2009). En la comunicación de la ciencia están involucrados procesos complejos relacionados con todas las etapas de la investigación, tales como la planificación, la financiación, la producción, la difusión o su aplicación. Cada uno de estos procesos implica a muchos actores y, por ello, una visión unidireccional, unidimensional e indiferenciada del público como la tradicional no es acertada (Calloni et al., 2009; Holliman et al., 2009). 
- En tercer lugar, dada la esta multiplicidad de audiencias, los cibermedios tienen que desarrollar contenidos dirigidos a cada uno de estos posibles segmentos de público y evolucionar con ellos a modo de servicios a la demanda (Horning Priest, 2009; Holliman et al., 2009; Oughton, 2010). Al igual que otras disciplinas, como la medicina, la comunicación es cada vez más personalizada y los medios masivos tradicionales están dando paso a otros más específicos que tratan de llegar a segmentos muy concretos de público (Hermida, 2010; De Semir, 2013). Según Horning Priest (2009), el aumento progresivo del ancho de banda de Internet se ha asociado a un incremento de la interactividad, a una desmasificación de los medios tradicionales y a una individualización de los contenidos.

Por otra parte, la competencia por las audiencias es abrumadora en la red y esto aumenta la importancia de la estructuración y presentación de los contenidos (Yaros, 2011). Antes, algunos pocos medios de comunicación llegaban con apenas esfuerzo a audiencias masivas. Ahora, llegar ahora al mismo número de personas requiere mucho más esfuerzo (De Semir, 2013). Asimismo, la infinita cantidad información disponible en la red hace que el valor percibido de la misma esté decayendo (Oughton, 2010) y, aunque muchas fuentes son fiables, los públicos no las están encontrando fácilmente (Bubela et al., 2009).

- En cuarto lugar, los usuarios pueden elegir entre distintos medios y soportes para acceder a la información científica en Internet, desde webs a correo electrónico, pasando por blogs, podcast, cibermedios, redes sociales, etc. (Trench, 2007; De Semir, 2010). En este nuevo contexto, algunos autores consideran que la utilización del verbo "consumir" refleja mejor el cambio social que está viviendo la información científica y, la información en general, ya que las audiencias elige activamente a qué mensajes acceder, cuándo, dónde y desde qué vía (Horning Priest, 2009; De Semir, 2010).

- Así, en quinto lugar, Internet ha modificado el patrón de recepción de información sobre ciencia y tecnología. Revuelta y Corchero (2010) explicaban que, de la tradicional recepción pasiva, caracterizada porque la información llegaba al ciudadano sin que este tuviera que realizar un esfuerzo específico para encontrarla -un patrón típico de los medios de comunicaciones convencionales-, se ha pasado a una búsqueda activa. En este nuevo patrón, característico del entorno online, el ciudadano hace un esfuerzo específico por acceder a una determinada información científica. 
- En sexto lugar, las posibilidades de participación e interacción (engagement) con la información científica es uno de los cambios más importantes que ha traído Internet. El público ya no solo se limita a leer, escuchar y observar; sino que realiza comentarios, críticas y sugerencias, comparte contenidos y crea los suyos propios (Holliman et al., 2009; Mauraren, 2013). En este importante aspecto se profundizará en los siguientes apartados.

- En séptimo lugar, en cuanto a la medida de las audiencias, las estimaciones que tradicionalmente dependían de las cifras de ventas en los quioscos, las cartas al editor o las tasas de espectadores y oyentes son mucho más sencillas y precisas en Internet, donde los datos de navegación proporcionan información instantánea a periodistas e editores de ciencia (Peters et al., 2014). Además, conocer los contenidos científicos de mayor éxito permite a los cibermedios seleccionar sus portadas en función de las preferencias del usuario (Elías, 2009).

- Por último, es importante el diseño centrado en el usuario. El diseñador web debe tener en cuenta a las audiencias y los contenidos científicos que dispone para dotar a los distintos tipo de usuarios de portadas y/o menús de inicio adaptados a sus necesidades (Horning Priest, 2009).

\subsection{EL RECEPTOR DE CONTENIDOS CIENTÍFICOS EN LA WEB: DATOS Y PERFIL}

Multitud de encuestas y barómetros han estudiado la recepción de contenidos científicos en las últimas décadas, centrados especialmente en evaluar la capacidad de la sociedad para entender la ciencia y la tecnología y en medir actitudes hacia las mismas, en línea con el movimiento británico de comprensión pública de la ciencia o public understanding of science (Muñoz, 2002). Dentro de estas encuestas se han introducido, paulatinamente cuestiones asociadas al uso de los medios de comunicación como fuente de información científica para los ciudadanos.

Además del creciente acceso a Internet como fuente de información científica (Science annd Engineering Indicators, National Science Board, 2014; Eurobarómetro Especial 401, 2013; VIII Encuesta de Percepción Social de la Ciencia, FECYT, 2016), tal y como se explica en el apartado introductorio, de estas encuestas se pueden extraer otros datos interesantes respecto al perfil de los usuarios de información científica online, ya que las variables que miden son cruzadas con datos sociodemográficos. 
En el ámbito europeo, el Eurobarómetro Especial 401 (2013) apuntaba que los hombres son, en general, más proclives a informarse sobre ciencia y tecnología en Internet que las mujeres. También sugería diferencias en relación a la edad, el nivel educativo y el grado de interés en ciencia. Estos datos son extrapolables al ámbito nacional, donde la VIII Encuesta de Percepción Social de la Ciencia (2016) señala un mayor acceso a Internet como fuente de información científica entre los más jóvenes las personas de 15 a 34 años-, algo más en hombres que en mujeres, y entre las personas con formación universitaria. Además, tanto a nivel europeo como a nivel nacional, Internet es utilizado en mayor grado cuando el usuario afirma estar interesado en ciencia y tecnología. Por otro lado, los cibermedios son los preferidos a medida que aumenta la edad y el nivel formativo, en línea con los hallazgos de los últimos Science and Engineering Indicators (2016) de Estados Unidos.

Moreno Castro (2013) ya había apuntado previamente que el nivel educativo marcaba diferencias significativas en el uso de Internet para acceder a información científica. Al cruzar dos variables de la VI Encuesta de Percepción Social de la Ciencia y la Tecnología en España, el consumo de información de ciencia y tecnología en Internet y el nivel de estudios terminados, comprobó que aquellos que cuentan con Bachillerato o estudios universitarios muestran una actitud más proactiva hacia la ciencia. Asimismo, destacaba que graduados, licenciados e ingenieros que se informan de ciencia en Internet lo hacían fundamentalmente a través de cibermedios generalistas y/o especializados.

En esta línea, Brossard (2013) había sugerido que el consumidor de información científica online estaba lejos de ser representativo de la población general, ya que tendía a ser más conocedor de la ciencia, con mayor nivel formativo y mayoritariamente hombre. En este mismo sentido, el Pew Internet \& American Life Project (2006) detallaba que casí el $80 \%$ de aquellos que accedían a información científica en Internet se describía a sí mismo como "informado" sobre ciencia y casi el $70 \%$ consideraba tener "muy buena" o "buena" comprensión de la ciencia. Unos resultados acordes a los obtenidos por Anderson et al. (2010) en un trabajo centrado en la búsqueda de información sobre nanotecnología en Internet. La evidencia disponible es congruente con la tesis de que en Internet "se predica a los convertidos" (Russell, 2009), en relación a que son mayoritariamente los interesados en ciencia los que acceden a este tipo de información online.

Aunque es una encuesta que no se ha replicado posteriormente, es interesante la información obtenida en el Pew Internet \& American Life Project (2006), puesto que no se han localizado trabajos posteriores que indaguen en el cómo y el porqué del acceso 
a contenidos científicos online y en la fiabilidad percibida de dicha información. Según este documento, el $80 \%$ de los usuarios de ciencia online verificaba de algún modo la fiabilidad de la información científica que consultaba. Al preguntar el porqué de dicho acceso, el 13\% consideraba que en Internet había más contenidos científicos que en otros medios, y el $12 \%$ creía que en la web hay información no disponible en otros lugares. Uno de los datos más significativos que aporta este informe es que el $65 \%$ había llegado a información científica recurriendo a la web con otro propósito en mente, al igual que habían reportado Weigold y Treise (2004) en población juvenil, lo que ofrece una idea del potencial de este canal para captar nuevos públicos y atraer a los más jóvenes. Internet es además el medio que mayor confianza suscita entre los más jóvenes y el preferido como opción rápida, sin coste y de fácil acceso para hacer búsquedas de cualquier índole (Domínguez Gutiérrez, 2014). Casi un 60\% de los jóvenes afirma pasar entre 3 y 4 horas diarias conectado a Internet, aunque ese tiempo se dedica, fundamentalmente, a realizar tareas, mantener redes sociales, chatear y revisar el correo electrónico, según el mismo autor. Para atraer a los más jóvenes a la información científica, Weigold y Treise (2004) y Seabra (2012) apuestan por sitios web y contenidos más atractivos, interactivos, participativos y que conjuguen información y un aspecto lúdico.

Teniendo en cuenta, precisamente, que muchos usuarios acceden a información científica acudiendo a la red con otro propósito en mente, Oughton (2010) planteaba dos perfiles de usuarios de información científica en Internet: aquellos que navegan a conveniencia y que acceden a la Web por ocio, sin un fin particular; y los que buscan activamente una información científica determinada. A juicio de este autor, los primeros son los potenciales consumidores de información científica más importantes, a los que se puede despertar el interés en ciencia; mientras que captar la atención de los segundos puede ser difícil, en función de la capacidad del medio de atraer su atención.

Revuelta y Corchero (2010) referían que los buscadores activos eran más críticos en cuanto al papel desempeñado por los distintos medios de comunicación respecto a la información científica, la confianza que otorgaban a los medios tradicionales era menor y además creían que la atención que prestaban a estos temas era reducida. Por ello, frente a los receptores pasivos, los buscadores activos apostaban por Internet como medio favorito para buscar información sobre ciencia y tecnología.

En uno de los estudios más recientes, Brown (2014) investiga la correlación entre el interés por la información científica y el uso de distintos medios y herramientas online, concretamente, dispositivos móviles, motores de búsqueda, correo electrónico, Twitter, 
Facebook y otras redes sociales y podcast; a partir de los datos de la encuesta Biennial Media Consumption realizada en Estados Unidos en 2012. El acceso a información científica online a través de dispositivos móviles, correo electrónico, Twitter y podcast se correlacionó significativamente con el interés por la información científica. Al igual que en los estudios anteriormente referidos, la edad -los más jóvenes-, el sexo -los hombres- y la educación -las personas con estudios superioresse correlacionaron positivamente con el consumo de estos contenidos.

\subsection{ALFABETIZACIÓN CIENTÍFICA Y MEDIÁTICA}

En los últimos 50 años, los medios de comunicación y otras formas de aprendizaje informal han cumplido un papel fundamental en el mantenimiento de la alfabetización científica en los adultos (Miller, 2010). El papel de la escuela en la educación formal se reduce a transmitir conocimientos científicos básicos (Sánchez Ramos y Barradas Briviesca, 2014), pero estos niveles de formación, incluso en los países desarrollados, son bajos (Priest, 2013). Para Miller (2010), la necesidad de la población adulta de adquirir nuevos conocimientos sobre la ciencia después de las etapas escolares es evidente. Asuntos como las células madre, la nanotecnología o el calentamiento global no estaban incluidos en los libros de texto hace tres décadas porque eran objetos de investigación emergentes, de forma que los adultos de 40 años o más no ha podido aprender sobre ellos a través de la educación reglada. Para el mismo autor, el ritmo acelerado del desarrollo científico conlleva que la mayoría de las personas ajenas a la academia aprenderá más sobre ciencia tras salir de la escuela formal que durante ella. Y, cuando la educación formal termina, los medios de comunicación generalistas se convierten en las herramientas más accesibles para conocer los nuevos descubrimientos científicos, las controversias, determinados eventos y el propio trabajo investigador (Nisbet et al., 2002; Xenos et al., 2010).

Cuando los nuevos asuntos científicos son integrados en los medios de comunicación y en el discurso público, los adultos con cursos universitarios crean una mayor variedad de construcciones científicas en sus mentes y son capaces de utilizar los conocimientos anteriores para dar sentido a la nueva concepción con mayor rapidez que los adultos que carecen de dichas construcciones (Miller, 2010). Por ello, este autor consideraba que la educación formal y el aprendizaje informal deben ser aliados en el avance de la alfabetización científica y abogaba por mejorar las competencias de lectura como clave para aumentar la proporción de adultos con conocimientos científicos. 
"Sin una base sólida de lectura y conocimientos científicos básicos, incluso el mejor periodismo científico o comunicación de la ciencia caerán en oídos sordos (...) Los adultos con habilidades de lectura y escritura débiles tienen problemas significativos en la lectura de un periódico, la etiqueta de un medicamento o una póliza de seguro, y también en el uso de Internet. La lectura es realmente fundamental para casi todas las formas de comunicación" Miller (2010:268).

Aunque estos planteamientos, seguramente, se puedan extrapolar a los cibermedios, serían interesantes nuevos estudios en torno al papel de los mismos en la alfabetización científica en el contexto digital.

Paralelamente a la importancia de la alfabetización científica después de la educación reglada, las herramientas digitales y el entorno online también requieren nuevas competencias por parte de los ciudadanos. Los nativos digitales aún son una parte pequeña de la población, de modo que, la mayor parte, sobre todo los adultos mayores, no están familiarizados y requieren una alfabetización mediática que les dote de capacidades para el acceso, el análisis, la evaluación y la participación en los contenidos periodísticos online, para no quedar atrás (Holliman, 2010; De Semir, 2010; Priest, 2013).

Para los consumidores de información online, Internet presenta tanto oportunidades como desafíos (Treise et al. 2013). Cuando un usuario introduce ciertos términos en un motor de búsqueda, en un segundo puede observar que existen millones de sitios que ofrecen información científica a un solo click. Pese a estas facilidades de acceso, a priori, saber cuál de estos sitios ofrece información actualizada, precisa y fehaciente supone un gran reto (Macedo-Rouet, 2002; Treise et al., 2013). De Semir (2010:60) alude a la existencia de una fractura digital y educativa que define como "carencia de un fácil y asequible acceso tecnológico y, sobre todo, de suficiente capacitación intelectual para saber usar este instrumento", lo que en su opinión sigue siendo común en las sociedades occidentales, aunque en los últimos años se haya corregido en algún grado esta tendencia, y lo que justifica las políticas públicas para la promoción de la cultura científica y tecnológica que siguen poniéndose en marcha.

La búsqueda de información científica en Internet demanda una alfabetización mediática por encima de la media: es necesario distinguir entre los diferentes tipos de información y emisores, artículos de revistas académicas, informes auto-publicados, opiniones procedentes de grupos interesados, contenidos corporativos y empresariales o información periodística, entre otros (Trench, 2009). Tal y como 
sostenía este autor, muchas de estas fuentes, como las editoriales de acceso abierto y gratuito, ponen a disposición los artículos de las revistas académicas, ofreciendo no solo a los científicos, sino también al público en general, el acceso a una cantidad de información online sin precedentes. El problema es ahora aumentar la capacidad de las personas de encontrar contenidos científicos útiles, de juzgar las fuentes confiables de las que no lo son, de dar sentido a informaciones distintas y a veces completamente enfrentadas, y de participar en la comunicación y la discusión.

Aunque muchos piensen que Internet es una enciclopedia gigante con información disponible sobre todos los temas cuándo y dónde el usuario quiera sin embargo, es un medio altamente estructurado y se necesita capacitación para comprender cómo y por qué cierta información es más fácil de encontrar y cómo esto puede cambiar con el tiempo y en función de la plataforma que se esté utilizando (Calloni et al., 2009).

Moreno Castro (2013) explicaba de forma clarificadora esta nueva situación:

"En internet hay cantidades ingentes de páginas web que están al alcance de todos los públicos con información poco rigurosa; esto es, existen millones de páginas basura, de blogs, foros y portales con información acientífica, en los que se argumenta con falacias sobre cuestiones tecnológicas. (...) Asimismo, otras informaciones de interés para los ciudadanos que serían "alternativas", tampoco son visibles por el "ruido" que produce de toda la información que hay contenida en la red. Dado que no existe un programa algorítmico que nos conduzca hacia sitios web que no contengan bulos (hoax), leyendas urbanas o mensajes encadenados, el usuario tiene que adoptar una posición proactiva con la búsqueda de contenidos científicos para lograr dirigirse a aquellos espacios donde los contenidos a los que accede sobre ciencia y tecnología estén verificados por una comunidad de expertos o una institución científica" (Moreno Castro, 2013:127-128).

Coinciden en la reflexión López-Goñil y Angulo (2013), Elías (2013) y Fernández de Lis (2013), quienes afirman que la "democracia de Internet" permite que la página web de un charlatán pueda tener el mismo posicionamiento, o incluso mayor, que la de un experto contrastado en su campo.

En este contexto, Moreno Castro (2010) diferencia dos tipos de consumidores de información científica online: aquellos que no discriminan entre las distintas fuentes de información y que, por tanto, le otorgan la misma credibilidad a todas, y aquellos que buscan activamente información científica en cibermedios, instituciones públicas y privadas, organismos de investigación y publicaciones especializadas, es decir, siguiendo un criterio de selección y evaluación informativa. En la misma línea, 
Revuelta y Corchero (2010) consideran que el ciudadano ideal de la sociedad del conocimiento no es el que más preparación tiene, sino aquel que es capaz de buscar información científica que es de su interés de forma precisa y efectiva.

De este modo, la alfabetización mediática es un aspecto clave en el contexto online (De Semir, 2013). En opinión de este último autor, es necesario aumentar la capacidad de los usuarios para encontrar información científica de utilidad y relevancia, discriminar la información confiable de la que no lo es, dar sentido a la amplia variedad de contenidos a los que se enfrentan y participar en la discusión cuando sea oportuno.

López-Goñil y Angulo (2013) hacían una reflexión mirando hacia el futuro que, seguramente, se pueda trasladar ya al presente, y es que que una de las habilidades más importantes que los profesores tienen que enseñar a los escolares es cómo juzgar e integrar la información procedente de diversas fuertes online para crear una opinión propia.

\subsection{LA BÚSQUEDA DE INFORMACIÓN CIENTIIFICA ONLINE: MODOS Y TENDENCIAS}

A través de la Web es posible acceder a millones de contenidos científicos, pero aún se sabe poco acerca de las estrategias y patrones de búsqueda que utilizan las audiencias para encontrar esta información (Anderson, 2010; Dunwoody, 2014). estudio de estos comportamientos es uno de los objetos de investigación principales recogidos en la literatura respecto al receptor de contenidos científicos online (Priest, 2013). El interés de estos trabajos se centra en el público en general pero también en públicos específicos, como los jóvenes y los propios científicos. La metodología más utilizada en estos trabajos es la encuesta aunque también se exploran algunas técnicas novedosas.

Es el caso de dos trabajos publicados en 2009 por Baram-Tsabari y Segev, quienes exploran el interés del público en temas de ciencia y tecnología a partir de los datos proporcionados por tres herramientas web, Google Trends, Google Zeitgesit y Google Insights, y los comparan con el interés en las pseudociencias. Entre 2004 y 2008 , periodo en que se desarrolló el estudio, los autores observaron un interés decreciente en la búsqueda de asuntos relacionados con la ciencia y tecnología, a excepción del calentamiento global. Algunos términos científicos compartieron el mismo interés que otros pseudocientíficos, e incluso, términos pseudocientíficos como "astrología" fueron más buscados que otros científicos como "astronomía. Los autores concluyen que la combinación de estas tres herramientas proporcionadas por Google puede ser útil 
para conocer los intereses del público en ciencia al margen de las tradicionales encuestas. Aunque es un trabajo interesante desde el punto de vista metodológico, sería interesante realizar nuevos análisis utilizando las mismas herramientas para conocer cómo han evolucionado estas tendencias en la última década.

Centrados en una audiencia específica, los propios científicos, Allgaier et al. (2013) observaron que se mantenían dependientes de las narrativas periodísticas, tanto en sus formas tradicionales como online, para obtener información general sobre asuntos científicos. Ocho de cada diez acudía a cibermedios y prácticamente el 100\% valoraba la infuencia de los mismos en la opinión y la percepción pública de la ciencia, lo que ofrece una idea de la importancia que la comunidad científica otorga al trabajo periodístico.

Gráfico 16. Uso de medios e influencia percibida, en porcentajes, hacia la opinión pública y los decisores políticos de neurocientíficos norteamericanos y alemanes.
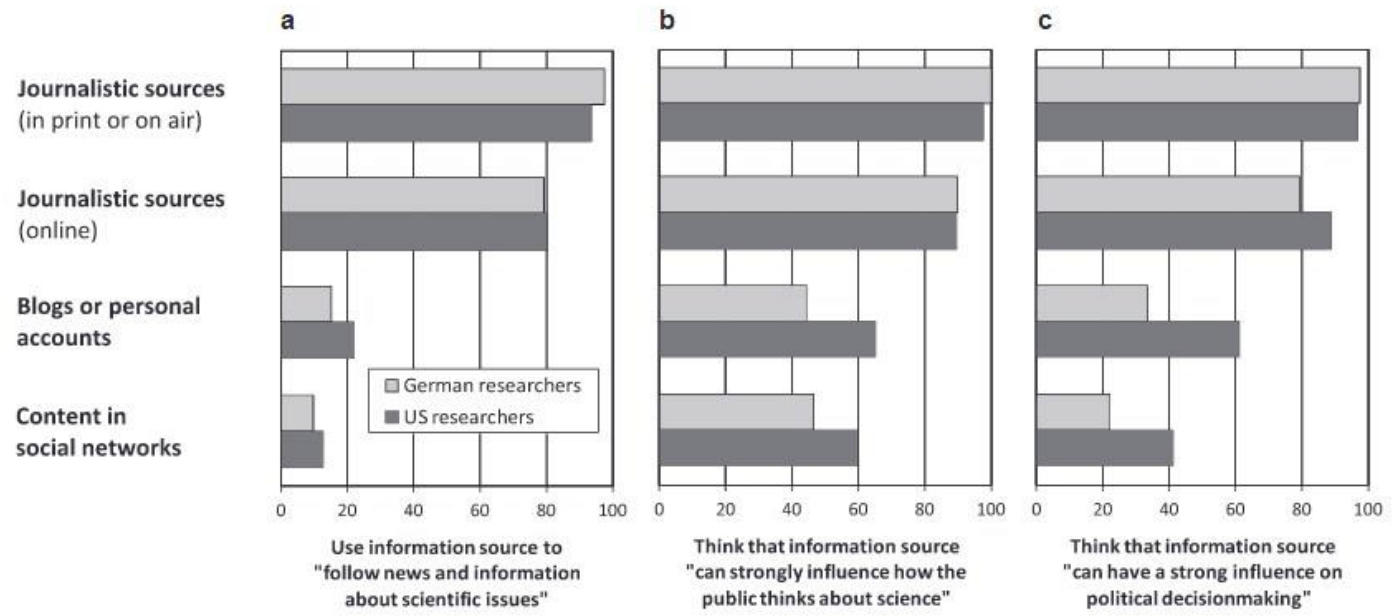

Fuente: Allgeier et al. (2013)

Por otro lado, la literatura destaca la influencia de los motores de búsqueda en el acceso a la información científica presente en Internet. Su utilidad y su facilidad de acceso han hecho que se confirme como la principal herramienta de los usuarios online (Cacciatore, et al., 2012). Así, el 90\% de los usuarios que acude a la Web para ampliar información sobre un asunto científico concreto recurre a buscadores, según recogía el Pew Internet \& American Life Project (2006).

En relación a la información científica, los motores de búsqueda permiten a los usuarios acceder a los contenidos periodísticos pero también a otras fuentes disponibles online. Asimismo, tienen el potencial de llegar a grandes audiencias y de 
ayudar al público a comprender la información científica gracias a los recursos complementarios que ofrecen, como imágenes, audio, vídeo, diccionarios, enciclopedias o hipervínculos (Cacciatore et al., 2012). Sin embargo, autores como Berland et al. (2001) o Macedo-Rouet (2002) aludían a las limitaciones de los motores de búsqueda que dan acceso a esta amplia variedad de fuentes ya que, a su juicio, no han conseguido acompañar el crecimiento en el número de sitios web y recursos con técnicas de búsqueda más efectivas, lo que requiere al usuario dominar el medio para no pasar horas conectado infructuosamente, sin encontrar la información científica deseada.

Aunque los motores de búsqueda son percibidos por los usuarios como fuentes de información justa e imparcial, especialmente en comparación con los medios de comunicación tradicionales, en realidad proporcionan información parcial en función de los criterios que tiene en cuenta el algoritmo que aplican (Li et al., 2010; Fernández de Lis, 2013; Elías, 2015: Novin y Meyers, 2017). De este modo, el método de búsqueda que utilizan los motores es un elemento clave para conocer por qué los usuarios acceden a determinados contenidos científicos en detrimento de otros. En el caso del buscador por excelencia en la actualidad, Google, se basa en la metodología PageRank descrita por Page et al. (1998). Este método es el que decide qué enlaces y recursos se posicionan primero. Diversos estudios muestran cómo los usuarios son más propensos a seleccionar enlaces que se encuentran en los primeros lugares de la primera página de resultados de Google, incluso cuando el vínculo es menos relevante para la búsqueda que han realizado, una tendencia que puede justificarse en la predisposición de las personas a realizar atajos cognitivos (Ladwig et al., 2010).

Algunos autores advierten del potencial de los buscadores de situar información pseudocientífica y anticientífica en las primeras posiciones de búsqueda (Elías, 2015), ya que los algoritmos no jerarquizan la información en función de la calidad o de la veracidad de los contenidos, sino en virtud de las redes de enlace o del número de reproducciones, como sucede por ejemplo con los vídeos. Elías (2013) recordaba el caso de los mensajes antivacunas emitidos a través de Youtube por una religiosa durante la crisis de la gripe A en España en 2012. Al introducir los términos "vacuna" y "gripe A" en Google, el sistema sugería "efectos secundarios" y en ese contexto el vídeo de la religiosa aparecía en las primeras posiciones, junto con páginas web que ofrecían información contrastada y blogs "anticientíficos", en la misma proporción. Este vídeo contribuyó al rumor viral que sostenía que las vacunas frente a la gripe $A$ eran peligrosas, lo que tuvo repercusiones reales, puesto que sobraron millones de dosis. Las consecuencias de esta situación fueron tanto económicas -el consiguiente 
despilfarro de dinero público-, como sanitarias -una población no vacunada puede contribuir a propagar una enfermedad-, y ofrecen una idea del potencial de Internet para propagar información acientífica y de los peligros que esta situación puede acarrear.

Ladwig et al. (2010) van un paso más allá y señalan que esta característica del buscador Google, denominada Google Suggest, tiene un rol determinante a la hora de guiar y dirigir las búsquedas de información científica en Internet, jugando un papel central como conductor entre la ciencia y el público. Tras analizar los términos de búsqueda de información sobre nanotecnología en Google y las palabras sugeridas por Google Suggest en relación a este tema entre 2008 y 2009. Observaron un aumento de palabras clave que relacionaban nanotecnología y salud, impulsadas por esta herramienta de Google diseñada para aumentar la eficiencia en la búsqueda mediante el historial de búsquedas anteriores de otros usuarios, pero condicionada por otros factores, como el pago por publicidad en el buscador, que también incluye el pago por figurar como sugerencia.

Como resultado, estos autores planteaban serias dudas sobre la calidad y el valor de la información científica online encontrada a través de buscadores. Para el caso de la nanotecnología, los resultados de las búsquedas en Google influyeron en las búsquedas posteriores de otros usuarios, lo que reforzó aún más las sugerencias del buscador y creó una espiral de auto refuerzo que cimentó un vínculo entre salud y nanotecnología en el entorno de noticias online. Esto reduciría la complejidad y el detalle de la información que los ciudadanos pueden encontrar en la Web, una situación que podría extrapolarse a otros asuntos científicos.

En la misma línea, Li et al. (2010) examinaron el grado en que Google favorecía ciertos tipos de contenidos en detrimento de otros. Los autores se preguntan qué tipo de contenido es más probable de encontrar cuando un usuario acude a Google para buscar información sobre nanotecnología, si existían diferencias entre los contenidos mejor y peor posicionados, y cómo la peculiaridad de los resultados de búsqueda se relacionaba con la imagen y la comprensión pública de las ciencias emergentes. Observaron que en las primeras posiciones de resultados se encontraban mayormente temas relacionados con aspectos técnicos, ambientales y sobre riesgos de la nanotecnología, y advirtieron que los investigadores del ámbito de la comunicación debían ser conscientes de la información arbitraria que devolvían los motores de búsqueda en torno a las ciencias. 
En un trabajo similar, Liang et al (2012) simularon varias búsquedas sobre asuntos relacionados con la nanotecnología en Google y analizaron los títulos y resúmenes que aparecían en los primeros 10 resultados. En este caso, comprobaron que la mayoría de sitios que aparecían en los primeros lugares no eran específicos sobre nanotecnología y que se abordaban temas relacionados con la política más que con las aplicaciones de la misma o sus implicaciones sociales. Estos trabajos coinciden en que los resultados de las búsquedas en Google juegan un rol clave en la formación de conocimiento sobre nanotecnología, en las actitudes del público hacia esta tecnología emergente, y en último término, en la regulación y la financiación pública de la misma.

Otras características que valora la metodología PageRank que ha sido objeto de estudio es la red de enlace, o lo que es lo mismo, el conjunto de enlaces que apuntan hacia una URL en particular, en cinco cibermedios de América Latina (Gouveia y Kurtenbach, 2004). Se trata de una información que se puede consultar con facilidad y que, a juicio de estos autores, debería ser parte de la evaluación rutinaria de un sitio web. Dicho trabajo apunta que, para América Latina, una red de 100 a 200 enlaces es bastante común, aunque observan claras diferencias entre los cibermedios. Por ejemplo, aquellos que incluyen contenidos en inglés son capaces de crear una red de enlace mayor.

La eficiencia de los motores de búsqueda a la hora de localizar información sobre un asunto concreto es otro objeto de investigación frecuente. Un estudio de caso en torno a la búsqueda de un asunto de salud en particular encontró que solo uno de cada cinco enlaces devueltos por los motores de búsqueda en inglés y uno de cada ocho devueltos en castellano conducía a una web con contenido relevante, y también halló deficiencias en la disponibilidad de información clave, especialmente significativa en los sitios en castellano, donde menos de la mitad de los temas que los paneles de expertos consideran relevantes estaban cubiertos mínimamente (Berland, et al., 2001). Los mismos autores reflexionan sobre la importancia de estos hallazgos cuando los ciudadanos toman decisiones médicas con la información que encuentran en Internet.

También se han localizado, aunque en menor medida, estudios que comparan la cobertura de la nanotecnología entre medios impresos, blogs y resultados de los motores de búsqueda y la mejora del posicionamiento de los contenidos científicos online (Cacciatore et al., 2012).

Por último, se ha localizado un trabajo que aplica un enfoque novedoso al estudio de las búsquedas científicas por Internet. Segev y Baram-Tsabari (2012) utilizan una combinación de tres herramientas de Google (Google Trends, Google Insights y 
Google News) para comprender mejor cómo el sistema educativo y los medios de comunicación motivan la búsqueda de información científica a través de Internet. Los investigadores correlacionaron el volumen de búsquedas específicas en las herramientas de Google con la cobertura que estos temas recibieron en los medios y el calendario académico, y comprobaron que la búsqueda activa de conocimientos científicos podría ser resultado no solo del sistema escolar formal, sino también de la cobertura de los medios de comunicación. Otras consultas científicas no pudieron ser explicadas ni por el calendario escolar ni por los medios de comunicación, lo que indicaría la existencia de otras motivaciones para que la gente busque información científica. Por ejemplo, temas como la Luna llena parecían estar motivados por la experiencia directa sobre el evento. En trabajos más recientes han analizado cómo los patrones de búsqueda de información sobre ciencia y tecnología en Google y Wikipedia cambian con el tiempo (Segev y Sharon, 2017).

Por otro lado, el porqué algunos usuarios seleccionan determinadas noticias científicas en detrimento de otras es otro de los asuntos abordados. Uno de los trabajos más novedosos en su planteamiento y metodología es el de Jang (2013), quien relacionó cómo influyen las actitudes y creencias preexistentes de los usuarios de Internet en la selección de noticias científicas. En concreto, realizó un experimento en el que expuso a noticias sobre cuatro temas controvertidos -células madre, evolución, alimentos genéticamente modificados y calentamiento global- a 238 participantes voluntarios a los que primero se había aplicado una encuesta para registrar sus actitudes previas. De cada uno de los temas se presentó, en una página web, una noticia a favor, una en contra y una neutral, y se registró la selección realizada por los participantes y la duración de la visita. Aunque estudios precedentes habían evidenciado que las personas son más propensas a elegir información consonante con sus actitudes y creencias preexistentes cuando se enfrentan a una gran variedad de puntos de vista en torno a un mismo tema, una tendencia sobre todo observada en el ámbito de la información política, en el campo de la informacion científica la tendencia es diferente. Este estudio apunta que, en general, los usuarios se sienten más atraídos por noticias científicas en disonancia con sus creencias. Solo aquellos que percibían tener grandes conocimientos científicos tendieron a buscar artículos congruentes con sus pensamientos.

También en esta línea, Winter y Krämer (2012) investigaron la selección de información científica en blogs a partir de sendos estudios experimentales. Sus resultados sugieren que los lectores que desean información sobre un tema controvertido prefieren los mensajes que reflejan todas las caras sobre el asunto y que 
están conectados con fuentes expertas, quizás porque consideran que estas proporcionan una mayor calidad y utilidad informativa.

Este planteamiento ofrecería una interpretación positiva del potencial de la Web como fuente de información para la población en general, así como de las prácticas de los legos, que se guiarían por señales de credibilidad y calidad a la hora de seleccionar contenidos online. Esto mitigaría los efectos de la "democracia" de Internet y el sesgo de los motores de búsqueda reseñados anteriormente, y ofrecerían importates pistas a los periodistas científicos a la hora de enfocar sus artículos.

\subsection{INTERACTIVIDAD Y PARTICIPACIÓN EN CONTENIDOS CIENTÍFICOS}

Una de las características del ciberperiodismo, la interactividad (Díaz Noci y Salaverría, 2003), ha revolucionado las relaciones entre usuarios y contenidos en Internet. El tradicional papel del receptor, limitado a leer, escuchar o visionar mensajes periodísticos de forma pasiva, ha dado un vuelco a partir de la llamada Web 2.0, siendo reemplazado por la participación activa (Blanchard, 2011; Cacciatore et al., 2012; Jang, 2013). El receptor se ha convertido en un actor principal, capaz de crear sus propios medios de comunicación y de compartir, amplificar y comentar vídeos, imágenes o textos (Carmona Jiménez, 2006; Blanchard, 2011; Veltri, 2012). Según Zhang et al. (2015), los contenidos también parecen haber avanzado desde un modelo de presentación de la ciencia como oficial, formal y autoritario, donde el estilo lingüístico predominante era el monólogo, a uno que fomenta la conversación, la accesibilidad y la participación, en el que se estiman las opiniones y necesidades del lector.

Es el paradigma de la convergencia mediática planteado por Jenkings (2008): más allá de la interconexión entre los distintos medios tradicionales en Internet, está emergiendo una transformación cultural promovida por las nuevas formas de interactividad y participación, el denominado engagement (Norris, 2001).

Así, una tarea de los periodistas científicos de hoy es aportar valor añadido a la información a través de estas nuevas herramientas para la participación (Hermida, 2010). Los lectores están tomando parte en la discusión y están demostrando un interés activo en las cuestiones científicas, contribuyendo a una naturaleza autocorrectora de la web, según el mismo autor, ya que tienden a señalar errores e imprecisiones de la información. De este modo, la participación podría ser beneficiosa para la profesión periodística y también para la propia ciencia a largo plazo, ya que 
propiciaría un mayor compromiso público. En el mismo sentido se expresaban Pearce et al. (2015), quienes apostaban por las nuevas formas participativas para una comunicación sobre el cambio climático más fructífera.

Pero, ¿realmente estas herramientas están fomentando la participación del público? ¿en qué términos? Laslo et al. (2011) y (Mauraren, 2013) consideraban que, efectivamente, los públicos ahora no solo seleccionan, leen y procesan la información, sino que también hacen comentarios al respecto y debaten online, creando nuevos contenidos que son leídos a continuación por otros. Otros autores, como Shanahan (2010) y Dunwoody (2014) recuerdan que Internet ha abierto líneas de comunicación directas no solo entre emisores (periodistas) y receptores (público), sino también con los propios científicos. Las dinámicas de interacción entre estos agentes constituyen una línea de investigación emergente, en especial a través de comentarios realizados por el público en respuesta a noticias científicas.

En un primer momento, los foros fueron la principal herramienta para interacción de los públicos en Internet. Eran considerados como fuentes valiosas de información científica y actuaban como espacios públicos donde la audiencia compartía conocimientos y recursos, desarrollaba sus propias ideas sobre la ciencia y proveía retroalimentación a los propios medios de comunicación (Birch y Weitkamp, 2010).

Después, han sido los comentarios a las noticias los que han abierto las posibilidades de participación: una interacción de igual a igual entre emisores periodistas- y receptores -públicos- donde el reconocimiento del "status" se negocia y en parte es determinado por las reacciones de los demás participantes (Shanahan, 2010). La sección de comentarios de los cibermedios presenta además una oportunidad, según la misma autora, para la interacción entre científicos y no expertos, aquellos que no tienen acceso a los foros científicos para expresar su opinión. Horning Priest (2009) iba un paso más allá y sostenía que el acceso a todo tipo de opiniones expertas y no expertas propiciará una mayor implicación de la audiencia en la política científica.

Los editores han encontrado que la audiencia es más proclive a participar mediante comentarios que a través de cartas y correos electrónicos al editor, y se encuentran satisfechos con el éxito alcanzado (Amsen, 2006). En la misma idea coincidía Luzón (2013), quien subrayaba que las ventajas de los comentarios frente a las cartas al editor: son más rápidos, la publicación se asegura, llegan a un público más amplio y permiten la discusión inmediata con cualquier persona interesada en la materia. 
Los comentarios emitidos en noticias científicas son, precisamente, uno de los objetos de estudio más comunes en la literatura resecto al engagement. El objetivo de estos trabajos es examinar cómo los lectores integran y dan sentido a la información científica, cómo desarrollan representaciones sociales de temas científicos, cuál es su opinión sobre el tema en cuestión, cómo interactúan con el cibermedio, la relevancia de la ciencia en sus vidas o las interacciones entre periodistas, lectores y científicos a través de los comentarios.

En torno a este tema, Secko et al. (2011) aludían a la idea de relato científico "inacabado", en referencia a las posibilidades de interacción con los lectores posteriores a la publicación de un contenido científico en un cibermedio. El trabajo detecta una apertura de la narrativa del periodismo científico online a través de la interacción que facilitan los comentarios, por ejemplo, cuestionando la autoridad del periodista o sus prácticas periodísticas -lo que observan de forma clara en los contenidos que proporcionan consejos prácticos para los lectores, quienes en sus comentarios reinterpretan lo escrito por el periodista o proporcionan sus propios consejos-; un "reenfoque" generalizado de los temas mediado por los comentarios; un mayor esfuerzo de los periodistas, como redactores de contenidos científicos online que son contestados, y de los lectores, como participantes de dichos contenidos; y la significativa existencia de comentarios negativos.

Respecto a esta sección, el mismo estudio apuntaba que los propios periodistas veían una parte negativa, una posible distorsión de las piezas periodísticas mediada por los comentarios. No obstante, reseñaban una parte positiva, y es que los comentarios públicos consituían una herramienta fundamental en la elaboración del relato periodístico, incluso, que a menudo publicaban una pieza periodística con escasa información y los comentarios se utilizaban para completar y concluir posteriormente la narración. Una forma innovadora de componer el relato periodístico mediante la participación que constituye una fórmula interesante para revitalizar el periodismo científico en Internet. Asimismo, los periodistas rastreaban la sección de comentarios para obtener nuevos ángulos y nuevas fuentes potenciales sobre un tema.

Asimismo, los comentarios son útiles como fuente de datos para conocer las representaciones sociales de la ciencia, es decir, los esquemas cognitivos que los individuos desarrollan con el tiempo mediante sus experiencias (Len-Ríos et al., 2014). Las representaciones sociales reflejadas en los comentarios online permiten conocer cómo los ciudadanos conectan con la ciencia en sus vidas cotidianas y perciben la relación entre ciencia, individuo y sociedad. Algunos estudios en esta línea apuntan la 
tendencia de algunos usuarios a cambiar su interpretación acerca de un asunto científico cuando leen comentarios (Winter y Krämer, 2016) o que la mayor parte de los comentaristas tiende más a explicar su experiencia personal que a hablar sobre la evidencia científica o a mezclar ambas (Shanahan, 2010; Len-Ríos et al., 2014)

Otros análisis de comentarios a noticias sobre cambio climático muestran un discurso muy polarizado en los comentarios, una tendencia a la denigración de los científicos que, o bien defienden el cambio climático, o bien lo cuestionan, o la negación pura y simple de la evidencia científica (Jaspal et al., 2012); un afianzamiento de los estereotipos científicos y políticos, así como una contestación hacia los argumentos escépticos (Koteyco et al., 2013); y una homogeneización del discurso junto con un elevado nivel de interacción y debate en los comentarios online Collins y Nerlich, 2015). Otros tabajos defienden que la experiencia de las fuentes de información tiene una influencia significativa en la credibilidad del artículo reflejada en los comentarios de los lectores (Pjesivac et al., 2018).

Uno de los aspectos más señalados en la literatura es la importante presencia de comentarios incívicos e insultantes en las noticias online sobre ciencia (Secko et al., 2011; Brossard, 2013). Algunos trabajos atribuyen esta prevalencia precisamente a la posibilidad de comentar de forma anónima (Secko et al., 2011; Mol, 2011). Las malas interpretaciones de los hechos presentados en las noticias científicas y las acusaciones vertidas hacen dudar, incluso, del potencial positivo de los comentarios públicos (Secko et al., 2011; Trench, 2012; Peters et al., 2014). A juicio de Labarre (2007), estos comentaristas incívicos incomodan a los comentaristas serios e impiden mantener un debate intelectual. Para Brossard (2013), el problema no es que se den estas discusiones, sino la total ausencia de reprimenda social ante comportamientos irrespetuosos en la Web.

Ante este comportamiento, conocido como trolling -en referencia a los usuarios trolls que interrumpen la discusión con comentarios incendiarios, irrespetuosos o insultantes-, se ha convertido en tónica habitual en los cibermedios que, ante esta situación, los cibermedios pueden actuar de tres formas: manteniendo el comentario abierto y libre, adoptando mecanismos de moderación con reglas generales que especifican lo que debería ser excluido, o bloqueando directamente todos los comentarios. Por esto último han optado importantes cibermedios como la revista Popular Science, ${ }^{25}$ que decidió en 2013 suprimir la sección de comentarios (Walsh, 2015). No obstante, la mayor parte de los cibermedios sigue apostando por la

\footnotetext{
${ }^{25}$ Más información sobre la revista divugativa Popular Science: http://ow.ly/TUil30kiSF1 (última consulta 07/03/2018)
} 
participación y opta por diferentes formas de moderación, más o menos restrictivas (Brossard, 2013).

Por último, algunos estudios sobre comentarios sugieren un mayor debate ante temas determinados como las relaciones entre ciencia y religión, el caso 'climategate', la medicina alternativa o la política científica (Trench, 2012), así como una deriva de la discusión hacia teorías no fundamentadas, opiniones políticas y rencores personales, una situación que, aunque sea tan antigua como la propia ciencia, el entorno online está facilitando, con comentarios diseminados y discutidos de forma rápida y sencilla (Chalmers, 2009; Mauraren, 2013). Algunos autores aluden, incluso, a que algunos autores de contenidos científicos y algunos medios estarían recurriendo a realizar comentarios radicales para fomentar, de manera encubierta, la participación (Blanchard, 2011).

Pese a todo, parece claro que los receptores de contenidos científicos en Internet quieren participar de la discusión, sea de la forma que sea, y en el futuro se verá si los cibermedios logran encontrar modelos que posibiliten un debate constructivo (Brossard, 2013). 


\section{LOS EFECTOS DE LOS CIBERMEDIOS EN LA COMUNICACIÓN DE LA CIENCIA}

El presente capítulo aborda la investigación de los efectos que producen en las audiencias los contenidos científicos publicados en los cibermedios. No obstante, es importante introducir brevemente las aportaciones de la literatura sobre los efectos de los medios para tener una visión más integrada del objeto de estudio en su contexto teórico.

La información que se publica en los medios de comunicación influye en las audiencias alterando sus actitudes, percepciones y comportamientos (McCombs, 1996). La investigación sobre la comunicación de masas ha analizado de forma recurrente los orígenes de dicha influencia. Ya a principios del siglo pasado, Lippmann (1922) destacó el papel de los medios de comunicación en la definición del mundo. Sin embargo, los primeros estudios en torno a los efectos de los medios se desarrollaron en los años 40 y se centraron en el impacto de los mismos sobre el comportamiento de los votantes en las campañas electorales en Estados Unidos. Estos primeros estudios se basaban en la creencia de que los medios de comunicación tenían capacidad de cambiar las actitudes de los votantes y de persuadirlos, aunque observaron que existía una multitud de factores que entraban en juego y actuaban junto a los medios condicionando sus efectos (McCombs, 1996).

Klapper (1974) realizó un completo compendio de la infinidad de trabajos empíricos llevados a cabo en los años 50 y 60 -cerca de un millar- en torno a los efectos de los medios. Estos estudios se desplazaron hacia las implicaciones cognitivas a largo plazo y sugerían que los medios informativos tienen unos efectos limitados sobre el público. Rodríguez-Polo (2011) valoraba algunas ideas de interés recogidas en el manual de Klapper que se han discutido en relación a nuestro objeto de estudio:

- Los medios informativos tienden a mantener y reforzar opiniones previas en la audiencia más que a cambiarlas.

- Cuando el público carece de opinión previa sobre un determinado asunto, los medios ejercen una influencia mayor.

- Cuando una persona está predispuesta a cambios de actitud, los medios pueden llegar a ejercer como "palanca".

- Determinados aspectos de la comunicación -como las fuentes, las características de los medios, el mensaje o el clima de opinión- tienen incidencia directa en su eficacia persuasiva. 
En Internet, los emisores de información científica pueden adjuntar material contextual, aumentar el número de fuentes, incluir contenido multimedia y establecer nuevas formas de comunicación con el público gracias a las herramientas de participación; sin embargo, no estaba claro si la comunicación de la ciencia a través de la Web es más o menos eficaz que la que se realiza a través de los formatos tradicionales, y cómo los usuarios entienden y hacen uso de estos contenidos (Macedo-Rouet et al., 2003).

Para obtener información sobre este asunto se han realizado diversos estudios a partir de encuestas y, sobre todo, métodos experimentales, fundamentados en la exposición de determinados grupos de personas a contenidos científicos seleccionados y la monitorización de su comportamiento. En base a estos métodos, se ha observado que los cibermedios sí jugarían un papel crucial en los procesos de generación de actitudes hacia determinados temas científicos (Taddicken, 2013), aunque no promovería un mayor respaldo hacia las cuestiones científicas (Weber et al., 2016).

Algunos estudios han analizado los efectos en relación a la hipertextualidad. Macedo-Rouet et al. (2003) se preguntaron si había cambios en la construcción de significados, en la comprensión de temas científicos y en la percepción de los argumentos de la ciencia cuando el público accedía a los cibermedios a informarse, en relación a la prensa tradicional. Esta disyuntiva se basaba en que, aunque en ambos formatos, impreso y digital, el lenguaje escrito prevalecía, habia grandes diferencias en la forma en que se mostraban y conectaban estos elementos textuales, motivadas por el hipertexto. Detectaron una correlación positiva entre la experiencia previa del usuario y la comprensión de una noticia en el entorno digital. En cambio, la comprensión fue ligeramente menor en el grupo de lectura digital motivada, básicamente, por los documentos complementarios a los que se accedía a través de hipertexto. También que los lectores tienden a sentirse desorientados en el entorno online, con problemas para estimar el tamaño de los documentos y la dificultad para leer tablas y gráficos. No obstante, los usuarios valoraron en mayor medida la lectura digital.

Estos resultados son similares a los obtenidos en un estudio posterior por Yaros (2011) que confirmó una significativa relación entre el interés del individuo en el contenido de la noticia científica con la comprensión de dicho contenido. También observó que una estructura narrativa lineal combinada con enlaces lineales obtenía los mejores resultados respecto a la comprensión; y que la coherencia del texto, independientemente de la estructura del mismo, era clave en la comprensión de la 
información científica. Estos resultados sugieren que la coherencia entre texto e hipertexto es quizás tan importante como la coherencia únicamente del texto, y abren la puerta a explorar nuevas oportunidades y nuevas estrategias para comunicar información científica en los cibermedios.

Al margen de la hipertextualidad, se han localizado algunos trabajos que abordan los efectos de la multimedialidad. Smith et al. (2014) analizaron qué atractivo tienen las imágenes astronómicas a través de tres tipos de pantallas -una gran pantalla de alta definición, una tableta y un smartphone- y qué tipo de información mejora la comunicación y comprensión de estas imágenes en dispositivos móviles. Los autores hallaron que el tamaño de la plataforma móvil es clave tanto para expertos como para el público en general, obteniendo la pantalla más grande valores muy superiores a la más pequeña. En relación a qué tipo de información mejora la comprensión de estas imágenes, mostraron que el formato conversacional, aquel que comienza con una pregunta redactada de una manera informal a la que prosigue una respuesta divulgativa, fue la estructura comunicativa preferida.

En relación a otra de las características propias de los cibermedios, la interacción, los estudios localizados en torno a los efectos se centran básicamente en una de las herramientas para la participación del público, los comentarios. Dichas investigaciones han abordado, básicamente, el papel de los comentarios irrespetuosos e insultantes en la percepción de riesgos en torno a las tecnologías emergentes, en concreto hacia la nanotecnología. Estos trabajos muestran que la exposición a comentarios incívicos puede inducir una mayor polarización de las opiniones de partidarios y detractores de esta tecnología respecto a sus riesgos potenciales y que un tratamiento más cercano de la nanotecnología podría mitigar los efectos de la falta de civismo (Brossard y Scheufele, 2013; Anderson et al., 2013; Regan et al., 2014).

\subsection{EFECTOS DE LA FUENTE EN LA CREDIBILIDAD DE LA INFORMACIÓN CIENTIIFICA EN INTERNET}

Las fuentes de información tienen una incidencia directa en la influencia que ejercen los medios sobre las audiencias (Klapper, 1974; Rodríguez-Polo, 2011). En la literatura respecto a nuestro objeto de estudio se ha analizado, en particular, la relación entre las fuentes y la credibilidad de la información científica.

Tradicionalmente, las investigaciones en torno a la credibilidad de los medios han comparado a la televisión y a la prensa, con un conjunto de estudios que sugiere una mayor credibilidad percibida de la televisión frente a los periódicos (Eastin, 2001). En 
la actualidad, Internet se ha hecho hueco entre estos canales tradicionales y millones de personas utilizan la red como canal para informarse sobre ciencia, pero el flujo libre y no regulado de los proveedores de información, ajenos a los periodísticos, crea múltiples riesgos a los que buscan y confían en la información online, ya que en muchos casos los usuarios no son conscientes de quién elaboró el material, cuándo fue actualizado por última vez o si este es preciso. Según el mismo autor, la situación es especialmente grave en el caso de la información sanitaria en Internet, ya que buena parte de la información disponible en la Web no está firmada por expertos y profesionales de la salud y tampoco por el tradicional intermediario periodista. En los casos en los que la información es falsa o imprecisa, las personas con problemas sanitarios no recibirían una información adecuada.

Este autor evaluó la percepción de la credibilidad de la información sobre salud en Internet y encontró que tanto el conocimiento previo del lector y como la experiencia de la fuente, afectaban a la percepción de la credibilidad del mensaje. No obstante, todos los participantes en el experimento de Eastin atribuyeron un cierto nivel de credibilidad a todas las informaciones, independientemente de la experiencia de su autor, lo que apunta ciertos problemas en la evaluación de la información sobre salud online.

En la misma línea, Treise et al. (2003) examinaron la percepción de la credibilidad en función del dominio de la Web y concluyeron que los usuarios otorgan mayor credibilidad a la información procedente de un dominio .gov. También que la fuente es más experta cuando procede de un sitio .gov, y que el autor del artículo de estos sitios es más objetivo en comparación con el de un sitio .com. Asimismo, los usuarios atribuyeron mayor credibilidad a una web con un nombre muy reconocido -NASA-, que además creen que es la fuente más experta.

Otros autores, como Minol et al. (2007), consideran que cuando un usuario visita una web por primera vez, su evaluación de la información científica depende decisivamente de si ha recibido o no la información que era objeto de su búsqueda, es decir, si ha cumplido con sus expectativas.

También en relación a la credibilidad de las fuentes, Allgeier et al (2013) comprobaron que los científicos ven en las fuentes periodísticas, tanto las tradicionales como las digitales, "mucha influencia" en cómo el público piensa acerca de determinados temas científicos. Para los autores, esto tiene que ver con que los ciudadanos siguen valorando el proceso de selección al que se somete la información 
en los canales periodísticos, lo que les libera de ser responsables de evaluar la importancia de cada contenido o la credibilidad de la fuente.

Respecto a la opinión pública hacia la Ciencia, en concreto hacia la nanotecnología, Lee y Scheufele (2006) analizaron la deferencia hacia la autoridad cientíifica como fuente experta presente en las noticias de tres medios de comunicación diferentes: televisión, prensa y cibermedios. Esta investigación comprobó que las personas que confían en la prensa y en la web para obtener información científica reportan mayores niveles de conocimiento sobre nanotecnología, mientras que aquellos que declaran informarse a través de la televisión muestran mayores niveles de deferencia hacia la autoridad científica. El acceso a cibermedios se correlacionó positivamente con una actitud más positiva hacia la ciencia y con un apoyo a la investigación básica, aunque ésta no tuviera beneficios sociales inmediatos. Por otro lado, se reportó un uso de Internet complementario a la recopilación de información sobre tecnologías emergentes, un aspecto en el que la incluencia de los medios tradicionales -televisión y prensa- es mínima, según los mismos autores.

Este planteamiento se alinea también con el estudio de Lee y Scheufele (2006) en el que se indica que los contenidos periodísticos posibilitan a los usuarios de diferentes niveles educativos disponer de información científica, de modo que las fuentes expertas de las noticias online podrían estar ayudando a reducir las brechas de conocimiento.

\subsection{ESTUDIO DE LOS EFECTOS A PARTIR DE LAS TEORÍAS DE LA AGENDA SETTING Y EL FRAMING}

Dos de las principales teorías sobre las que se asientan actualmente buena parte de las investigaciones en torno a los efectos de los medios de comunicación en la opinión pública, las de la Agenda Setting y el Framing, son también la base de algunos trabajos que estudian los efectos de los cibermedios en la comunicación de la ciencia.

La Teoría de la Agenda Setting, postulada en 1972 por McCombs y Shaw, establece una correlación entre los temas de interés público y los temas de interés mediático. A partir de un estudio empírico en torno al periodo electoral estadounidense, dichos autores determinaron que las expectativas de voto estaban directamente relacionadas con la información consumida por los electores en los medios. La Teoría de la Agenda Setting fue madurada y ampliada en sucesivos trabajos empíricos desarrollados por McCombs y Shaw y, posteriormente por otros autores, bajo la premisa de que los temas más relevantes para el público (la agenda del público) son los que los medios 
señalan como más importantes (agenda de los medios), y que esta selección por parte de los medios sitúa determinadas cuestiones en primer plano, apartando e incluso ocultando la importancia de otras.

Siguiendo a McCombs y Shaw, la Teoría de la Agenda Setting pone énfasis en los efectos cognitivos, considerando que esta jerarquización no afecta a la actitud o a la percepción que el público tiene sobre un tema determinado, sino que sólo le mostrará en qué asuntos debe pensar, una premisa que ya planteó Cohen (1963). Del mismo modo, la Teoría de la Agenda Setting infiere que los medios no solo actúan a largo plazo, sino que constituyen la única fuente posible, en la práctica, para la mayoría del público. Sin embargo, la irrupción y generalización de Internet en las últimas dos décadas puede haber modificado este planteamiento, ya que su impacto en la forma de hacer periodismo es indudable (Hermida, 2010; Peters et al. 2014).

En relación a la comunicación de la Ciencia, Peterson (2001) postulaba que, pese a que Internet proporciona acceso a enormes cantidades de información, cuando se trata de información periodística unas pocas fuentes pueden llegar a imponer la agenda para la difusión de la información científica.

No obstante, este planteamiento esbozado a principios del pasado siglo también puede haberse visto transformado con la irrupción de la Web 2.0 y la consiguiente apertura de los canales de participación, lo que ha podido impactar de forma sustancial en la agenda mediática de la ciencia (Minol et al., 2007). Para estos autores, los medios de comunicación ya no orientan a la gente en qué temas deben pensar, sino que es el público el que le dice a los medios de qué asuntos quieren saber, una cuestión que podría extrapolarse al periodismo en general. Holliman (2011a) coincide en que el periodismo se ha vuelto más sensible a lo que el público pide, consume, responde y debate en tiempo real en la red. Para este autor, en la actualidad los editores de noticias científicas pueden evaluar al instante los datos sobre los temas que generan más tráfico y debate en los cibermedios, pudiendo responder rápidamente a estas tendencias y adaptando su selección de temas en función de las preferencias de los usuarios.

En este sentido, Hart y Leiserowitz (2009) recogieron datos del tráfico en una serie de sitios web sobre cambio climático, así como datos de la cobertura mediática días antes y después del estreno de la película El Día de Mañana (2004) dirigida por Roland Emmerich. Determinaron que las webs en torno al cambio climático registraron un mayor tráfico desde 10 días antes del estreno de la película hasta 19 días después y una mayor cobertura periodística del cambio climático, lo que sugiere una fuerte 
correlación entre el énfasis de los medios de comunicación sobre un determinado tema y la importancia atribuida por parte del público a dicha cuestión.

La Teoría del Framing o del encuadre también ocupa un lugar destacado en los estudios en torno a los efectos de los medios de comunicación en la opinión pública (Sádaba, 2001). El término frame surge de los trabajos de Gregory Bateson (19041980) en el campo de la psicología y fue retomado más tarde por el sociólogo Erving Goffman (1922-1982), quien le aportó su dimensión social.

Según Koziner (2013), los estudios sobre comunicación son herederos de esta perspectiva. Cualquier texto periodístico, como una noticia, está formado por estructuras narrativas que organizan el discurso. La estructura de la noticia es sistemática, basada en una serie de convenciones narrativas que ofrecen una explicación acerca de quién está haciendo qué, dónde, cuándo y con qué propósito. Es decir, es una construcción de la realidad alrededor de un eje central de pensamiento en una determinada perspectiva o encuadre que llaman la atención sobre algunos aspectos de la realidad en detrimento de otros, un marco de interpretación para los públicos que se exponen a dicho mensaje (Ardèvol-Abreu, 2015).

Trasladando la Teoría del Framing al periodismo científico, el público prestará más atención a ciertas dimensiones del debate científico sobre las demás en función de cómo el problema se enmarque en la cobertura de las noticias (Bubela et al., 2009). Para Brossard (2012), a través de los procesos de construcción de la agenda y del framing, grupos interesados pueden influir en la cobertura mediática de la ciencia y en la forma en que se contextualiza en el debate público.

Los marcos simplifican cuestiones complejas, otorgando un mayor peso a determinadas consideraciones y argumentos sobre otros. En el contexto de la comunicación de la ciencia, "el encuadre es una realidad inevitable" (Bubela et al., 2009:215). Los mismos autores otorgan a los marcos una importancia fundamental en relación a los efectos de la comunicación de la ciencia. A su juicio, los marcos son utilizados por el público lego como esquemas interpretativos para dar sentido y discutir sobre las cuestiones científicas; por los periodistas para condensar asuntos complejos en reportajes los más interesantes y atractivos posible; por los responsables políticos para definir las opciones de política y tomar decisiones; y por los científicos para comunicar la importancia de sus hallazgos.

En relación con el público lego, Brossard (2012) considera que un marco puede ser entendido como una terminología especial o "pista visual" que permite al público no especializado dar sentido a los fenómenos científicos complejos colocándolos en 
modelos mentales o esquemas cognitivos que ya poseen. Es decir, para esta autora, los marcos no modificarían percepciones sobre la ciencia, sino que reforzarían las preexistentes.

Laslo et al. (2011) se preguntaron si los marcos individuales son simplemente réplicas de los marcos que presentan los medios de comunicación y si los miembros de la audiencia juegan un papel activo en la construcción de significados o en la resistencia a los marcos mediáticos, alrededor de asuntos científicos. Los hallazgos de dicho estudio sugieren que las respuestas a estas cuestiones son no, en el primer caso, y utilizando el contenido del artículo periodístico como detonante para discutir sobre cualquier aspecto importante para ellos, en el segundo. Los autores apuntan que, cuando las cuestiones morales están involucradas, el público puede sentir la obligación moral de expresar su punto de vista. Por otro lado, este tipo de actitudes se relacionarían con la forma de verse a sí mismos, algo que no puede cambiarse fácilmente.

Por otro lado, Secko et al. (2011) advierten de un "remarco" de la información científica a partir de los comentarios de la audiencia. Comprobaron que la audiencia utiliza elementos estructurales de la propia narrativa periodística y que se puede alterar una información científica publicada un cibermedio equilibrando la argumentación proporcionada por el periodista y realizando una crítica más amplia. 


\section{LA MULTIPLICIDAD DE EMISORES EN EL CONTEXTO ONLINE}

Hasta la aparición de Internet, debido al elevado coste y a las dificultades que suponía la elaboración de cualquier producto de los medios de comunicación de masas, éstos estaban en manos de un limitado número de personas y organizaciones productoras de información, lo que restringía la gama de opciones a las que tenían acceso los receptores, pero aseguraba que estos proveedores realizaban una inversión sustancial para proveer información de calidad (Treise et al., 2003). En el caso de la información científica, esta calidad ha venido tradicionalmente dada porque un periodista especializado era el encargado de realizar un ejercicio de "traducción" de los procesos científicos a productos accesibles para el público en general, a través de los medios de comunicación tradicionales (Brossard, 2013).

En cambio, con la llegada de Internet se ha producido un fuerte aumento en el número y la variedad de los actores emisores de información científica (Shanahan, 2010). Es lo que Lemos (2009) denominaba "liberación del polo de emisión", una redefinición de la figura del autor y también del receptor, que ya no sólo recibe informaciones, sino que pasa a producirlas y difundirlas en la red. En la misma línea, Brossard (2013) y Allemand (2013) apuntan que, en Internet, el emisor de información científica se desdibuja ya que los usuarios, entre los que se encuentran los propios científicos, han adoptado roles que tradicionalmente han pertenecido a los profesionales de la comunicación.

Para algunos autores, este cambio de escenario podría traer consigo efectos positivos como un aumento en el aprendizaje colaborativo, un mayor compromiso social con la ciencia o un incremento en las oportunidades para las relaciones públicas (Shanahan, 2010), un asunto, este último, que como veremos se ha estudiado en profundidad y tiene importantes implicaciones (Shäfer, 2017).

Fahy y Nisbet (2011) aludían a la confluencia de dos formas de publicación de información científica en la red: la auto-publicación a través de blogs, redes sociales y sitios web personales y la publicación por parte de periodistas científicos profesionales. Los científicos se han incorporado a la auto-publicación y comunican información y opiniones directamente con el público. Para los periodistas esto supone un reto, ya que no sólo tienen que buscar temas de la forma tradicional, también bucear en este nuevo entorno e interpretar y analizar asuntos científicos que ya se están discutiendo en otras plataformas online. También para Fahy y Nisbet, esta gran expansión de la información científica ha traído una percepción menor de los 
periodistas científicos como principales divulgadores de contenido científico, un asunto que se abordará a lo largo de este capítulo.

Es el fenómeno definido en la literatura como "desintermediación" (Lederbogen, 2004; Trench, 2009; Elías, 2009; De Semir, 2010): el papel de los periodistas como mediadores entre la ciencia y el público en general se ha esfumado en la red. Ya no se puede seguir hablando de los periodistas científicos como única conexión entre científicos y público, ya que la audiencia puede acceder a la web y consultar información ajena a los medios periodísticos (Brossard, 2013), como datos y conocimiento científico que tradicionalmente ha estado en manos de la propia comunidad académica (Porto y Palacios, 2012).

De este modo, Internet ha motivado una "crisis de los mediadores". Los periodistas científicos están perdiendo su poder como filtros para garantizar la calidad de la información y cediendo terreno a otros agentes en el papel de mediadores (Bucchi y Trench, 2008). Estos nuevos agentes, universidades, centros de investigación, científicos, sociedades científicas, revistas académicas o aficionados, entre otros, utilizan además los formatos que han sido hasta ahora de dominio exclusivo de los periodistas científicos como noticias, entrevistas o reportajes. (Fahy y Nisbet, 2011; Calloni et al., 2009). Esto obliga a repensar la figura del periodista científico (Porto y Palacios, 2012), que está en riesgo de ser anulado si no se adapta con éxito a los cambios del entorno (Trench, 2007; Brown, 2014).

De Semir (2010) considera que esta "desintermediación" tiene un lado positivo y un lado negativo. Del lado positivo, permite acercar a la sociedad a las fuentes de información científica y, del lado negativo, se pierde el papel regulador del periodista fundamentado en su búsqueda de la veracidad y la objetividad, aunque habría que preguntarse si realmente los periodistas científicos estaban cumpliendo esa labor o si, por el contrario, sus prácticas e intereses han inducido precisamente a un descrédito social.

A continuación, se enumeran los distintos agentes que están actuando como emisores en el proceso de la comunicación científica online. Se expone cómo científicos, centros de investigación, ciudadanos y otros actores emergentes se han sumado a la comunicación de la ciencia en Internet y se detallan los rasgos distintivos de dicha comunicación, sus prácticas e intereses. Por último, se analiza cómo estos agentes, apoyados en Internet, han influido en la figura del periodista científico y cómo las relaciones públicas de universidades y centros de investigación están alcanzando una influencia cada vez mayor. 


\subsection{LOS CIENTÍFICOS COMO EMISORES EN INTERNET}

"Nuestra misión de diseminar el conocimiento será incompleta si la información no es puesta a disposición de la sociedad de manera expeditiva y amplia. Es necesario apoyar nuevas posibilidades de diseminación del conocimiento, no solo a través de la manera clásica, sino también del paradigma del acceso abierto por medio de Internet. Definimos el acceso abierto como una amplia fuente de conocimiento humano y patrimonio cultural aprobada por la comunidad científica (...) Para que se pueda alcanzar la visión de una representación del conocimiento global y accesible, la Web del futuro tiene que ser sustentable, interactiva y transparente".

Extracto de la Declaración de Berlín sobre el acceso abierto (2003).

Con este texto consensuado, científicos de varias instituciones de investigación europeas convocadas por la Sociedad Max Planck pusieron de manifiesto, ya a principios de siglo, el potencial de Internet en la difusión del conocimiento y el patrimonio cultural científico, y la necesidad de que este conocimiento tenga un acceso abierto a escala global.

La comunicación ha sido siempre una actividad transversal en la carrera del científico. Según Ziman (1979), un descubrimiento no llega a existir sólo en virtud de la autoridad moral o el talento literario de su creador, sino por su reconocimiento y apropiación por parte de toda la comunidad científica, y la comunicación de la ciencia juega un papel fundamental en este sentido. Para el mismo autor, la comunicación asegura la continuidad de la ciencia ya que, a partir de esta difusión, otros investigadores pueden desarrollar sus investigaciones, corroborar o refutar los datos y definir nuevos campos de estudio.

Pero Internet ha modificado esta actividad tanto en su vertiente interna o formal -la comunicación entre los propios científicos-, canalizada tradicionalmente en publicaciones académicas, congresos y otros encuentros profesionales; como en su vertiente externa o informal -la comunicación entre los científicos y el público en general-, reflejada habitualmente en actividades de divulgación científica como charlas o jornadas de puertas abiertas en las instituciones de investigación (Calloni et al., 2009).

Herramientas online como plataformas de acceso abierto o redes sociales han cambiando la forma en que los científicos comunican e intercambian información. Aunque se utilizaron inicialmente en la divulgación científica, estas herramientas se 
están convirtiendo poco a poco en nuevos canales que fomentan la conversación entre científicos, ajenas a las conferencias y a las salas de café de las instituciones académicas (Rowan, 2001). Wilcox (2012) va más allá y cree que las nuevas plataformas de comunicación en Internet pueden transformar la propia investigación científica.

Para algunos autores, Internet incluso está abriendo nuevas posibilidades para mejorar el propio sistema científico, desde la metodología de los estudios y su comunicación hasta la evaluación, la promoción y la certificación Rowan (2011). Uno de los aspectos en el que coinciden varios autores en relación al potencial de Internet para la comunicación formal de la ciencia es su carácter "autocorrector" (Devi, 2013), su posibilidad para el filtrado colaborativo (Callini et al., 2009; Delfanti, 2008) y para la revisión por pares pública (Trench, 2012; Griffiths, 2007).

Un ejemplo son los repositorios documentales de acceso abierto, los numerosos servicios online para la gestión de referencias bibliográficas, como CiteULike o Mendeley (Fausto et al., 2012), o las plataformas de registro de investigadores, como ResearcherID u ORCID (Álvarez de Toledo y Fernández Sánchez (2011). Otras herramientas, como las redes sociales Academia.edu o ResearchGate, están facilitando la comunicación entre los científicos, conectando a investigadores con los mismos intereses, permitiendo el intercambio de recursos y difundiendo sus trabajos (Devi, 2013).

Internet está desdibujando las fronteras entre ciencia abierta y cerrada (Delfanti, 2008; Warden, 2010; Puschmann, 2014), pero la comunicación online no se tiene en cuenta aún en la mayoría de evaluaciones y asignaciones de fondos para la investigación (Gerber, 2012). Por ello, muchos investigadores siguen viendo en la literatura académica formal el principal medio de comunicación científica, considerando además que las formas tradicionales de publicación garantizan el enriquecimiento y la conservación de la ciencia, frente a un contenido científico en Internet volátil y perecedero (Calloni et al., 2009).

En este contexto, algunos autores señalan la necesidad de disponer de nuevos sistemas de medida para evaluar el alcance de la información científica que se transmite a través de herramientas online como incentivo para los científicos (Fausto et al., 2012; Gerber, 2012). Tradicionalmente esta valoración, denominada métrica científica, ha permitido cuantificar la producción científica en función de parámetros como el factor de impacto de la revista en que se publica una investigación y su número de citas. 
Pero las herramientas online pueden proporcionar también datos cuantificables sobre el interés activo, el uso y el alcance de de la difusión de la ciencia. Estas medidas alternativas surgidas a partir de Internet, denominadas Altmetrics, tienen en cuenta, por ejemplo, en cuántas bases de datos online se recogen estos estudios, cuántas visualizaciones y descargas tienen los artículos o cuántas veces se hace referencia a los mismos en medios sociales como blogs o redes sociales, e incluso en los cibermedios (McFedries, 2012; Galligan y Dyas-Correia, 2013).

Precisamente, son los medios sociales y los cibermedios los que cuentan con una mayor audiencia mensual de científicos, frente a los sistemas de comunicación de la ciencia tradicionales como conferencias o artículos publicados en revistas (Bik y Goldstein, 2013). Sin embargo, aunque Altmetrics es un enfoque prometedor, todavía se encuentra en una fase conceptual y por el momento existe una brecha creciente entre los científicos que comunican de forma tradicional con los que experimentan con las nuevas posibilidades que ofrece Internet (Gerber, 2012; Puschmann y Mahrt, 2012).

Las nuevas tecnologías solo establecen el marco y los verdaderos desafíos y soluciones para alcanzar una comunicación de la ciencia totalmente abierta dependen de un cambio en la arraigada cultura académica y en el propio sistema de creación de conocimiento al que están acostumbrados los investigadores (Gerber, 2014). Además, la exactitud del contenido generado por los usuarios, el acceso universal al mismo y la confidencialidad de los resultados plantean, entre otros factores, barreras para esta apertura según (Warden, 2010).

\subsubsection{COMUNICACIÓN EXTERNA O INFORMAL EN INTERNET}

Internet ha producido un vuelco en la comunicación de la ciencia de dentro hacia afuera, abriendo muchos aspectos de la investigación previamente ocultos para el público en general (Trench, 2009). La comunidad científica ha sido tradicionalmente poco comunicativa fuera de sus propios canales (Marín Murillo y Armentia Vizuete, 2002), pero cada vez son más los científicos que, a través de la Web, detallan su trabajo y difunden públicamente sus trabajos y sus opiniones (Montgomery, 2009; Seabra, 2012). Estos científicos asumen el papel de periodistas ciudadanos (Thorsen, 2013) y fomentan la respuesta del público a través de comentarios (Montgomery, 2009), contribuyendo a salvar la barrera históricamente infranqueable entre científicos y legos (Thorsen, 2013). 
Esto es posible, como se ha subrayado, gracias a la "desintermediación" que propicia el canal online, que pone a disposición de los científicos, y de cualquier usuario en general, herramientas que les permiten comunicarse de manera directa con una audiencia amplia y diversa sin la tradicional "mediación" de los periodistas (Lederbogen, 2004; Bucchi y Trench, 2008; Thorsen, 2013; Oliveira Fagundes, 2014).

A partir de los estudios realizados por varios autores se pueden extraer las motivaciones que los científicos esgrimen para comunicar públicamente la ciencia a través de Internet.

1. Las herramientas digitales posibilitan trasladar el entusiasmo y la pasión por la ciencia y el trabajo científico que realizan (Fernández de Lis, 2013; Brown, 2009). Además Internet es un medio interactivo, de bajo coste y que permite comunicar en tiempo real la ciencia que se realiza en un punto concreto de la geografía y situarla en el mapa de la ciencia mundial (Alvarado, 2013).

2. Internet facilita la escritura en un formatos fáciles y accesibles, ayudando al científico a desarrollar sus habilidades comunicativas (Davies y Glasser, 2014)

3. Algunos científicos buscan en la comunicación pública de la Ciencia a través de Internet desviarse de los medios de comunicación tradicionales (Colson, 2011), tratando de mitigar los problemas tradicionalmente asociados con el tratamiento informativo de los temas científicos (Thorsen, 2013).

4. La comunicación pública online puede incrementar el interés ciudadano por la ciencia. El público en general prefiere, según algunos trabajos, obtener información sobre los hallazgos científicos a través de los propios investigadores más que de los tradicionales mediadores, los periodistas (Mauranen, 2013). Los periodistas científicos son percibidos como un paso adicional entre la investigación y la audiencia y, aunque se invite al público a participar en el debate a través de Internet, todo está distanciado de la investigación primaria, según la misma autora, quien añade que la comunicación directa de los científicos con la audiencia constituye una alternativa interesante y produce un contacto directo entre la investigación y el lector.

5. El uso de herramientas digitales puede aumentar la visibilidad del científico (Davies y Glasser, 2014), dando protagonismo a sus publicaciones e incluso incrementando su número de citas (Darling et al., 2013; Bik y Goldstein, 2013). También otorga mayor visibilidad al laboratorio, departamento o universidad de la que se informe (Brown, 2009). 
6. Si la investigación es financiada por fondos públicos, los científicos tienen el deber moral de comunicar los resultados de esa inversión a los contribuyentes. En este sentido, la red es un aliado de los investigadores en un intento de buscar la responsabilidad y la legitimidad, a través de la comunicación pública de sus trabajos (Oliveira Fagundes, 2014).

7. Escribir sobre las nuevas investigaciones, normalmente publicadas en artículos científicos, requiere estar al día de la literatura y realizar una comprensión más profunda de los textos, lo que es positivo para la propia carrera del científico (Calloni et al, 2009; De Semir, 2010; Davies y Glasser, 2014).

8. Algunos investigadores utilizan Internet para desarrollar ideas y fomentar la colaboración antes de la revisión por pares (Davies y Glasser, 2014).

9. Internet permite conectar a investigadores que se encuentran en diferentes partes del mundo y que trabajan en distintas disciplinas Brown (2009). Además, gracias al carácter dialógico de muchas herramientas digitales es posible entablar debate con otros investigadores (Brumfiel, 2009; Colson 2011).

10. También obtener una comprensión más profunda en torno a temas de programación, funcionamiento de los motores de búsqueda en Internet o a cómo se optimiza el posicionamiento en la Web, un conocimiento que tiene uso práctico también de cara a la carrera académica (Davies y Glasser, 2014).

11. La creación de recursos online como figuras, mapas o diagramas puede contribuir al desarrollo de recursos didácticos innovadores que pueden tener otro usos, por ejemplo, a nivel docente (Davies y Glasser, 2014). Al mismo tiempo, para alcanzar el objetivo de llegar a un público amplio es necesario explicarse de forma fácil y sencilla, sin utilizar jerga ni tecnicismos, lo que aumentará la capacidad del científico de enseñar a nivel docente esos mismos conceptos (Brown, 2009).

12. La presencia de la comunidad científica en la red puede convertirse en una poderosa fuerza para promocionar causas importantes para la propia ciencia y conectar con los decisores políticos (Bik y Goldstein, 2013).

Pese a estas motivaciones, algunos investigadores son aún reticentes a la hora de utilizar las herramientas que les brinda Internet en la comunicación pública de la Ciencia (Colson, 2011; Osterrieder, 2013) y participan en ellas de forma aún conservadora (Gregory, 2009). Puschmann (2014) y otros autores consideran que herramientas como blogs o wikis son vistas, para la mayoría de los científicos, como “distracciones poco atractivas de su trabajo real (...) Una versión 'online' de la charla de la sala de café, con el ruido de fondo que va en contra de la ética de la información 
académica revisada por expertos (Calloni et al., 2009). No obstante, como parece lógico, los científicos más jóvenes y por tanto más familiarizados con la utilización de estas herramientas digitales parecen estar haciendo un mayor uso (Gregory, 2009).

La revista Nature invitaba a los científicos en su editorial 'Filling the void' a sumarse a todas las iniciativas surgidas de Internet que pueden ayudar a que la ciencia penetre mejor en el ciclo de noticias. "Los científicos están a punto de llegar a más gente que nunca, pero solo si pueden abrazar la misma tecnología que ellos han desarrollado", (Nature, 2009:260).

En la misma línea, Rowan señalaba que:

"Puede parecer contraproducente para los científicos airear sus trapos sucios en público, pero en un mundo donde los medios de comunicación están dominados por los pseudo-debates manufacturados sobre la realidad del cambio climático, la seguridad de las vacunas o la evolución, el valor de dar al público una ventana a un verdadero debate científico parece que no puede ser sobreestimada (...) Internet no solo proporciona un recurso permanente y de más fácil acceso entre los científicos de dentro de un campo, sino que también ayuda a difundir información importante con mayor facilidad a los que están fuera" (Rowan, 2011:sp).

Para algunos autores, el hecho de que los científicos ganen relevancia como comunicadores públicos de la ciencia en detrimento de los periodistas podría tener implicaciones en la representación pública de la ciencia. Así, si la selección periodística se sustituye por una auto-selección, los temas presentados al público y la forma en que se elaboran los temas cambiará (Peters et al., 2014). La selección que realizan habitualmente periodistas y editores sigue criterios como la relevancia social. Por ello, los mismos autores consideran que la cobertura científica que lleva a cabo un medio de comunicación de contrastada solvencia envía un mensaje diferente al público que si el tema es presentado por el sitio web de una universidad. "La autopresentación de la ciencia no puede reemplazar la función de representatividad/vigilancia realizada por periodistas y editores cuando seleccionan un tema relevante para el consumo público" (Peters et al., 2014: sp).

Fleischman y Szalinski (2014) esbozan una serie de consejos para aquellos científicos que tienen interés en adentrarse en la comunicación pública de la ciencia, fundamentados en la familiarización con el trabajo periodístico. Un conocimiento que puede ayudarles no solo a comunicar mejor, sino a establecer relaciones más fructuosas con periodistas y medios. En primer lugar, estos autores recomiendan seguir diariamente la sección de ciencia de los principales medios de comunicación 
internacionales, para examinar cómo los redactores profesionales presentan artículos de carácter divulgativo, cómo los estructuran o qué tipo de recursos literarios utilizan para que el texto llegue mejor al público.

En segundo lugar, aconsejan a los científicos inscribirse en algún curso de periodismo donde poder aprender la redacción de noticias y perfeccionar sus habilidades comunicativas. En esta línea, proponen practicar la escritura todos los días en un blog y publicar trabajo editado, por ejemplo, en portales como ASCB Post ${ }^{26}$, un foro online en torno a la biología celular en el que se publican noticias científicas, comentarios y se alojan blogs. Por otro lado, destacan la importancia de estar en redes sociales, como Twitter, para estar informado sobre actualidad científica general, conectar con otros escritores y difundir los artículos que se elaboran, y sugieren participar en los encuentros organizados por entidades como la AAAS (American Association for the Advancement of Science) o la NASW (National Association of Social Workers) y solicitar una estancia relacionada con la comunicación de la Ciencia en algún centro de referencia.

\subsubsection{LAS RELACIONES ENTRE CIENTIIFICOS Y PERIODISTAS CIENTÍFICOS}

La literatura científica ha estudiado comúnmente las relaciones existentes entre científicos y periodistas en el proceso de comunicación de la Ciencia (Véiliverronen, 1993; Revuelta, 1999; Peters, 2013; Casino, 2014), unas relaciones no exentas de tensiones que se mantienen también en el canal online (Colson, 2011).

Las diferencias de apreciación en torno a la comunicación pública de la ciencia entre ambos son notables y genera históricos puntos de fricción: desde los criterios de noticiabilidad a la provisionalidad de los resultados científicos, pasando por el interés de los periodistas por los estudios científicos más conflictivos y extravagantes o a las confusiones con el lenguaje, lo que motiva que aún muchos investigadores sean reacios a abrir las puertas de sus laboratorios a los periodistas (Lederbogen, 2004; Bellón Rodríguez, 2014). Asimismo, los científicos desean ejercer control sobre el mensaje periodístico y consideran que los periodistas deberían permitirles revisar los textos que los citan antes de su publicación, y no tener la última palabra en la forma en que un tema científico es cubierto (Peters et al., 2014).

Por su parte, algunos periodistas creen que los científicos no ponen interés en comprender sus prácticas ni el funcionamiento de los medios de comunicación.

\footnotetext{
${ }^{26}$ Más información sobre ASCB Post en: http://ow.ly/14yT30kpTp4 (última consulta 07/03/2018)
} 
"Los periodistas dedicamos buena parte de nuestro trabajo a entender el día a día de los científicos, pero son pocos los científicos que entienden el día a día de los periodistas, y pocos también los que están dispuestos a divulgar los resultados de sus investigaciones, en buena parte por un entendible miedo a que éstas sean maltratadas o malinterpretadas por periodistas sobreinformados o infraformados" (Fernández de Lis, 2013:19).

En el mismo sentido, algunos autores instan a los científicos a asegurarse de que los periodistas tienen la información completa para transmitir a sus audiencias y a intensificar sus intervenciones públicas dentro de sus labores para contribuir a la alfabetización y educación científica (Gomes da Silva, 2012; Jaafar y Giam, 2012).

Por su parte, los científicos piensan que la calidad de la cobertura informativa en los medios de comunicación convencionales ha disminuido y que los periodistas no cumplen plenamente con el rol de watchdog (perro guardián) en el ámbito de la ciencia (Colson, 2011).

Otros científicos consideran que los periodistas muestran la ciencia como un conjunto de resultados - la "mitología de los resultados" de Cascais (2003)- y no como un proceso complejo fruto del esfuerzo humano (Blanchard, 2011; Bellón Rodríguez, 2014), y ven en las herramientas web una forma de rebatir la información científica que a su juicio no ha sido bien recogida por los periodistas (Griffiths, 2007; Gramling, 2008).

La adopción de herramientas online por parte de los periodistas y la emergencia de una cultura participativa puede ayudar a disminuir la actitud de desconfianza de los científicos, quienes tienen la oportunidad de puntualizar o corregir la información a través, por ejemplo, de sus comentarios en las noticias o de las redes sociales (Luz, 2012). Algunos trabajos apuntan que el impacto en prensa puede resultar clave a la hora de incrementar las citas obtenidas por un artículo científico, lo que supondría un estímulo para que los científicos fueran más proclives a publicar sus trabajos en los medios de comunicación (Elías, 2009), un efecto que podría multiplicarse con los cibermedios y el amplio acceso a Internet en la actualidad.

¿Y qué opina el público en torno a esta disyuntiva? Una interesante encuesta a ciudadanos europeos sobre qué figura es más adecuada para explicar el impacto de la ciencia en la sociedad, mostró que solo el 16-20\% de los participantes consideraba a los periodistas. La mayoría (un 63\%) prefería que los propios científicos se encargaran de comunicar directamente al público los resultados de sus trabajos (Gerber, 2014). 


\subsection{LOS PERIODISTAS CIENTÍFICOS CIUDADANOS}

En oposición al clásico patrón uno a muchos -one to many- de los medios de comunicación tradicionales, Internet fomenta el modelo de muchos a muchos -many to many- (Pont Sorribes et al., 2013). Según estos autores, la distinción entre emisor y receptor se hace imprecisa en la red, donde ha emergido un nuevo modelo de usuario: el prosumidor (acrónimo de las palabras productor y consumidor) o usuario proactivo. Mientras en los inicios de Internet, como hemos visto, los usuarios se limitaban a observar pasivamente contenidos creados por otros, en la actualidad las herramientas web pasan a ser plataformas para la difusión de contenidos generados por los usuarios (Islas-Carmona, 2008; Porto y Palacios, 2012). Es lo que Lemos (2009) denomina "cibercultura posmasiva".

De este modo, emisor y receptor ya no ocupan lugares tan claramente definidos dentro del proceso de comunicación, sino que participan en un ambiente de interacción universal y plural (Porto y Palacios, 2012). En este sentido, la línea divisoria entre el profesional -aquel que es retribuido por su trabajo como periodista- $y$ el aficionado -el que invierte parte de su tiempo libre en realizar el mismo trabajotambién se desdibuja (Parra Castillo, 2013).

La emergencia de los llamados "medios ciudadanos" en Internet ha permitido la proliferación de una gran cantidad de voces antes reprimidas por los medios de comunicación de masas (Porto y Palacios, 2012), los cuales contaban con el monopolio en la emisión de información.

La facilidad en el acceso a tecnologías como teléfonos móviles, cámaras de fotos digitales, ordenadores portátiles o conexión a Internet (Holliman, 2007), que en la actualidad se pueden encontrar integradas en un mismo dispositivo móvil -smartphone o tableta-, permite a "periodistas aficionados" investigar, elaborar y difundir información, así como participar a través de comentarios o en redes sociales en artículos publicados por los medios de comunicación o por otros usuarios (Fahy y Nisbet, 2011).

Este periodismo ciudadano (Meso Ayerdi, 2005; Seabra, 2012; Fondevila Gascón, 2013) se ha trasladado también al ámbito de la ciencia. Como resultado, la ciudadanía ha ganado protagonismo como emisor de la comunicación científica, en diversos canales y emitiendo cualquier tipo de contenido (Ribas, 2012). Para Elías (2013), gracias a la red, cualquier persona puede transmitir sus conocimientos y experiencias en torno a la ciencia, formando un conocimiento compartido y una información nueva más exacta. 
Esta creciente comunidad de aficionados emitiendo sus propios contenidos científicos online apunta a una "desprofesionalización" del periodismo científico y a una “desinstitucionalización” de la comunicación de la ciencia en general (Gerber, 2014).

Trench (2007) aseveraba que muchas personas que producen información científica pueden definirse a sí mismos justificadamente como periodistas científicos ciudadanos. El mismo autor apuntaba que es una realidad ineludible y que tiene claras implicaciones en la práctica del periodismo centífico tradicional. En el mismo sentido, Allan (2009) apuntaba que el periodismo ciudadano amenaza con asaltar las murallas de la profesión periodística, mientras que Gerber (2014) consideraba incluso que el periodismo ciudadano estaría destruyendo la base económica del periodismo científico.

Esto es debido, según Winter y Krämer (2012), a que en herramientas online participativas como wikis, blogs o redes sociales cada vez se encuentran más contenidos emitidos por legos en lugar de información generada por expertos o periodistas profesionales. Para Parra y Castillo (2013), la autoría individual está palideciendo frente a la autoría colectiva: los periodistas aficionados contribuyen a la mejora y ampliación de los contenidos científicos, ofreciendo nuevos enfoques, puntos de vista o datos complementarios. Los mismos autores consideran que la vocación es el incentivo más poderoso para realizar un buen trabajo, una vocación que tienen muchos periodistas pero también muchos aficionados.

No obstante, el periodismo ciudadano también plantea interrogantes. Algunos autores sugieren las fuentes de información ciudadanas pueden ser menos fiables que las periodísticas (Winter y Krämer, 2012; Elías, 2013) y que sería necesario desarrollar herramientas que permitan distinguir la información ciudadana fiable de la no verídica (Seabra, 2012).

Otros autores hacen referencia a los intereses de estos periodistas ciudadanos. Estos emisores aficionados que se adentran en el campo de la comunicación científica, en un área determinada o en el debate en torno a temas como el cambio climático, la evolución o las células madre, cuentan con afinidades políticas, personales o profesionales que hacen que sea fácil que solo participen en sitios en Internet alineados a sus visiones sobre el mundo (Fahy y Nisbet, 2011; Holliman, 2011a).

No obstante, algunos medios están empezando a experimentar con fórmulas híbridas que a medio camino entre el periodismo científico y el periodismo ciudadano. Se trata de determinadas herramientas, nuevas secciones u otras formas de 
comunicación de la ciencia que aprovechan el potencial de Internet para incluir al público como elemento activo en el proceso comunicativo. Es el caso de varios periódicos alemanes como el Frankfurter Allgemeine Zeitung, que cuentan con secciones de "periodismo participativo", "periodismo ciudadano" o "periodismo de código abierto" que experimentan con tal interacción, aunque estas nuevas formas de transición, como las califican Minol et al. (2007), se encuentran aún en fase temprana de desarrollo.

Estas fórmulas híbridas parten de la idea de que los periodistas están dispuestos a adoptar nuevas formas de conectividad con el público convencidos de que la calidad de sus productos se verá enriquecida (Allan, 2009). Algunos autores no solo apoyan esta idea sino que animan a los profesionales a explorar el potencial, y también los posibles peligros, de ese "periodismo de código abierto" (Minol et al., 2007).

Los usuarios pueden contribuir a la elaboración de piezas periodísticas, por ejemplo, cediendo imágenes que han capturao 'in situ' de una noticia o produciendo galerías online (Holliman, 2011a), como en el caso de los temas relacionados con la meteorología o los días en que se producen determinados fenómenos astronómicos. También a la selección de los temas, ya que los datos que proporciona la web en torno al impacto que tiene cada pieza periodística permite dar prioridad a las historias que mayor interés despiertan en los lectores.

Uno de los elementos que más se está utilizando para integrar la participación activa de los lectores en el proceso comunicativo es el uso de herramientas para la realización de comentarios y sugerencias en los medios digitales. Según Holliman (2011a), de ello se desprende que las piezas periodísticas sobre ciencia pueden ser influenciadas por las contribuciones que se realizan más allá de la sala de redacción. Sin embargo, matiza que estas fórmulas no parecen equivaler a una democratización de la información, y que revistas y gabinetes de comunicación siguen manteniendo un lugar privilegiado en la definición de la agenda setting de la ciencia.

Waldrop (2008) describía un interesante experimento realizado por la revista Scientific American, en la cual trabaja como periodista, en torno a la participación del usuario en el proceso de elaboración de un artículo de temática científico-tecnológica. Se trata de una sección de puesta en marcha por la edición digital de la revista bajo el título Edit This, en la cual se anima a los lectores a realizar comentarios y sugerencias en torno a un borrador de un artículo del propio Waldrop, titulado Science 2.0: Great new tool or great risk. El texto aborda cómo los investigadores están empezando a aprovechar herramientas como wikis o redes sociales como una forma potencialmente 
transformadora de hacer Ciencia. El "proyecto" de artículo se publicó en formato digital varios meses antes de hacerlo en papel y lanzó varias cuestiones al aire para que fueran valoradas por los usuarios en sus comentarios: “¿qué piensa usted del propio artículo? ¿hay errores?¿simplificaciones?¿lagunas?¿qué piensa usted de la noción Ciencia 2.0? ¿las herramientas 2.0 harán la ciencia mucho más productiva? (...)”. Con las aportaciones realizadas por los lectores, se dio forma al nuevo artículo colaborativo que finalmente se editó en la versión impresa de la revista. Este experimento híbrido entre periodismo científico y periodismo ciudadano es una interesante fórmula para hacer partícipe a una audiencia cada vez más activa en el proceso de producción de contenidos científicos.

En cualquier caso, ni los periodistas científicos ni los aficionados pueden aislarse indefinidamente, sino que deben convivir en el actual contexto online de la comunicación de la ciencia en el que tienen una influencia recíproca (Minol et al., 2007).

\subsection{REVISTAS, AGENCIAS Y OTROS AGENTES}

La mayor parte de las revistas de carácter académico y de las revistas de divulgación científica han dado el salto a Internet, aunque en la gran mayoría de los casos mantienen aún su edición impresa, según algunos autores, por razones meramente de prestigio (Meso Ayerdi y Díaz Noci, 2002). Este "salto" tiene que ver con las ventajas que, para estas publicaciones, puede brindar Internet, como la reducción de los costes de producción, la multimedialidad o la accesibilidad inmediata de la información en la red, de modo que la periodicidad es ahora una decisión editorial y no una imposición técnica.

Otro de los beneficios que puede ofrecer tener una versión online es, como hemos visto, la interacción con los lectores. No obstante, Chalmers (2009) señala que estas revistas no generan el nivel de participación, por ejemplo en número de comentarios, que presentan muchos blogs mantenidos por científicos o las redes sociales.

De cara a los lectores, para Meso Ayerdi y Díaz Noci (2002) las revistas más prestigiosas tienen asegurado su público, de forma que la versión digital no se utiliza como complemento o como medio publicitario de la edición impresa, sino que se cobra una suscripción para acceder a los contenidos de la web, como en el caso de la revista Nature; mientras que otras como National Geographic optan por un acceso libre a la versión online. Para Trench (2009), las revistas con mayor impacto como Nature o Science sí que utilizan sus ediciones digitales como escaparate de sus contenidos y 
de otros servicios que tienen a la venta. Elías (2009) añadía que Science y Nature cuentan con una sofisticada política de comunicación online y se han convertido en medios de comunicación de masas con una particularidad, y es que al "disfrazarse" de fuentes pueden seguir imponiendo su agenda al resto de medios.

No obstante, el público de estas revistas no se circunscribe únicamente a los lectores interesados en materia de ciencia y tecnología. Las revistas científicas y de divulgación están empezando a ofrecer versiones del mismo tema en diferentes formatos dirigidos a diferentes tipos de lectores, entre ellos, los propios periodistas y medios de comunicación (Rusell, 2010). La oferta es variada: desde noticias y reportajes que se envían al correo electrónico de los suscriptores, a especiales online, servicios de noticias actualizadas, podcast, vídeos de Youtube o notas de prensa que se envían a los periodistas y que se actualizan por RSS, para que los medios de comunicación recojan los últimos hallazgos científicos que publican (Trench, 2009).

Uno de los servicios más ofrecidos por las revistas académicas es el envío a los periodistas científicos de notas de prensa bajo embargo, unos días antes de su publicación "oficial". Generalmente, estos comunicados de entre 100 y 200 palabras se presentan en estilo periodístico y con un titular elaborado para ser entendido por todos los públicos. Incluyen además el contacto de alguno de los autores de la investigación -normalmente el teléfono y el correo electrónico- para facilitar la ampliación de información por parte de los medios y el artículo científico completo. Por ejemplo, el servicio de prensa de Nature envía sus comunicados a más de 4.000 periodistas de todo el mundo. Otras revistas, como European Respiratory Journal (ERJ), remite por correo electrónico notas de prensa de los seis temas con mayor impacto mediático que se publicarán en su próximo número (Trench, 2009).

Como se ha reseñado en apartados anteriores, algunos autores advierten que la emisión de comunicados de prensa por parte de las revistas académicas más prestigiosas está originando una fuerte dependencia en el periodismo científico (Calloni et al., 2009; Trench, 2009; Granado, 2011; Murcott y Williams, 2013). Son una de las fuentes más utilizadas por los periodistas, debido a que el sistema de revisión empleado por estas publicaciones ofrece la garantía de que se trata de información fiable. Sin embargo, algunos autores desconfían de la neutralidad de estas revistas poniendo como ejemplo la investigación biomédica, ya que a su juicio la industria farmacéutica trata de "colocar" sus estudios en las publicaciones científicas como forma de legitimar sus resultados (Calloni et al., 2009). Por ello, los periodistas necesitan entrenamiento para entender cómo se produce el conocimiento científico y cuáles son sus limitaciones. 
Elías (2009), en cambio, sostenía que son estas revistas -tradicionales fuentes- las que actualmente están realizando periodismo científico, ya que ofrecen a los periodistas suscritos reportajes, audios y vídeos completamente elaborados. Incluso, el mismo autor refería que el orden en el que aparecen los comunicados de estas revistas influía directamente en su impacto mediático, ya que aquellos que se sitúan en las primeras posiciones son los que obtienen una mayor difusión.

Por otra parte, vaticinando un escenario que en la actualidad es recurrente, Fernández Muerza (2005) apuntaba que Internet "podría ser el medio ideal para crear agencias de prensa formadas por profesionales del periodismo y la divulgación, las cuales podrían ofrecer una variada oferta de artículos de divulgación a los medios de comunicación que no puedan o no quieran permitirse el "lujo" de tener en sus plantillas un periodista científico, y que tampoco pueden encontrar dicho servicio ni en calidad ni en cantidad suficientes en las agencias de prensa generalistas" (Fernández Muerza, 2005:sp).

Más de una década después, existen agencias de noticias especializadas que operan a distinta escala geográfica: la norteamericana (EurekAlert!), la europea (AlphaGalileo), la lberoamericana (DiCYT) o la española (SINC) son algunas de ellas.

Estas agencias están muy vinculadas a los centros de investigación del espacio geográfico al que atienden y que son las fuentes primarias de la información que distribuyen junto con las principales revistas científicas. De hecho, gran parte de su material, aunque quizás con alguna demora, está también disponible desde las fuentes institucionales originales (Trench, 2007).

El objetivo y funcionamiento de todas estas agencias de noticias especializadas es similar. Se trata de servicios de información online que canalizan información científica desde universidades, centros de investigación y revistas académicas, -y también temas propios, en el caso de DiCYT y SINC- hacia los medios de comunicación tradicionales y digitales y hacia público de diverso tipo con presencia en la red, ya que cuentan con herramientas para acceder y compartir noticias, como RSS o redes sociales, así como la posibilidad de valorar y comentar los contenidos por parte de los usuarios (Trench, 2009; Devi, 2013). En este sentido, para García Álvarez de Toledo y Fernández Sánchez (2011) la misión principal de estas agencias es difundir conocimientos científicos para su rápida aparición en medios de comunicación, buscadores y redes sociales.

En relación con los medios de comunicación, según la encuesta 'European Research in the Media: what do media professionals think', realizada por la Comisión 
Europea en 2007, el $90 \%$ de los periodistas consideraba que las agencias de noticias científicas proporcionan un fácil acceso a la información. En este sentido, otra investigación llevada a cabo entre periodistas científicos europeos señaló que el sitio más consultado por estos profesionales para encontrar información científica es una de estas agencias, en concreto, y paradójicamente -dado que se trata de la agencia norteamericana y la encuesta se realizó entre periodistas europeos-, es EurekAlert!. En sexto lugar se encuentra otra de estas agencias de noticias científicas, la europea AlphaGalileo (Granado, 2011).

Teniendo en cuenta que estos servicios de noticias científicas se nutren fundamentalmente de comunicados elaborados por universidades, centros de investigación y revistas académicas, las agencias podrían estar contribuyendo a la dependencia informativa de fuentes organizadas planteada a lo largo de este trabajo (Trench, 2009; Calloni et al., 2009; Granado, 2011; Murcott y Williams, 2013).

A continuación, se exponen los datos básicos de cuatro de las principales agencias de noticias científicas. La primera, tanto por su relevancia como por su volumen de contenidos y usuarios, es EurekAlert! -www.eurekalert.org-, el servicio de noticias científicas online de la Asociación Estadounidense para el Avance de la Ciencia (AAAS, por sus siglas en inglés), la sociedad científica más grande del mundo, editora de la revista científica Science. Creada en 1996 por el entonces director de comunicación de la AAAS Nan Broadbent, en 2006 ya prestaba servicio a más 5.000 periodistas registrados de todo el mundo (Pinholster y O'Malley, 2006) ${ }^{27}$. Morton (1996) explica que EurekAlert! ofrece a los periodistas noticias de ciencia embargadas procedentes de las principales revistas académicas, comunicados de prensa de instituciones de investigación, motores de búsqueda de información, servicio de correo electrónico de titulares de noticias científicas, bases de datos de fuentes de información y datos sobre las Web de las principales revistas científicas y entidades que se dedican al periodismo científico. Según apuntan sus propios promotores en la web, EurekAlert! proporciona un lugar en el que universidades, centros médicos, revistas, agencias gubernamentales, corporaciones y otras organizaciones dedicadas a la investigación en todo el mundo pueden incorporar sus noticias y difundirlas a los medios registrados. Esta agencia ofrece también al público en general sus noticias y recursos multimedia (imágenes, vídeos y audios) e información en castellano, portugués, alemán, francés, japonés y chino.

\footnotetext{
${ }^{27}$ Los datos actualizados sobre el número de periodistas registrados en EurekAlert! no está disponible su sitio web.
} 
Respecto al acceso a EurekAlert!, los periodistas pueden registrarse de forma gratuita aportando la documentación que acredite su condición de profesional independiente; mientras que los denominados PIOs (Public Information Officers), el personal que trabaja en los gabinetes de comunicación de las instituciones de investigación, deben abonar una suscripción por subir sus contenidos a la plataforma. El público en general tiene acceso a todas las áreas de la web salvo a la sección de noticias embargadas -a la que solo pueden acceder los periodistas acreditados- y a una base de datos de expertos.

El equivalente europeo de este sitio es AlphaGalileo -http://www.alphagalileo.org/-. Creada en 1997 como parte del Consejo Británico de Investigación en Física de Partículas y Astronomía (PPARC, por sus siglas en inglés), en 1998 se transfirió a la Asociación Británica para el Avance de la Ciencia. Posteriormente, Alemania y Francia contribuyeron a su sostenimiento y durante un corto periodo (2001-2003) fue mantenida por la Comisión Europea. Desde 2003, AlphaGalileo es una compañía independiente sin ánimo de lucro (López, 2009). Del mismo modo que en EurekAlert!, los periodistas acreditados tienen acceso a información bajo embargo procedente de las principales revistas científicas. Asimismo, pueden recibir un servicio de alertas en el correo electrónico sobre la información publicada en función del área científica, idioma o tipo de contenido, entre otros (Holding, 2007). Según señalan sus promotores en el propio sitio, AlphaGalileo cuenta con más de 7.500 periodistas registrados procedentes de 90 países. Asimismo, parte de los contenidos del portal pueden ser consultados en varios idiomas (inglés, castellano, alemán y francés), también por el público en general. A diferencia de EuekAlert!, los contenidos no solo se clasifican por áreas de conocimiento, sino también por regiones (África, Asia, El Caribe, Europa, Latinoamérica, Oriente Medio, América, Oceanía y Extraterritorial). Además, el portal cuenta con un calendario de eventos, bases de datos de expertos o galería de imágenes (Trench, 2009). En cuanto al acceso al portal por parte de las organizaciones de investigación, AlphaGalileo ofrece tres tipos de suscripciones de pago. El servicio ofrece además diferentes paquetes para promocionar conferencias y espacios publicitarios.

A escala Iberoamericana, en 2008 se puso en marcha la Agencia Iberoamericana para la Difusión de la Ciencia y la Tecnología (DiCYT) -www-dicyt-com-. Esta agencia surge en 2003 en seno del Instituto de Estudios de la Ciencia y la Tecnología (ECYT) de la Universidad de Salamanca, con el objetivo de crear un sistema regional de información que facilitara a los medios de comunicación el acceso a noticias especializadas en temas científicos y tecnológicos en el ámbito de la comunidad 
autónoma de Castilla y León (Sabbatini et al., 2004). Tras cinco años de andadura, se creó el proyecto Red DiCYT-Red Iberoamericana de Divulgación Científica, Educación y Cultura, con el objetivo de fortalecer las relaciones entre investigadores, educadores e instituciones y personas vinculadas a la cultura de habla hispana y portuguesa. En la actualidad, DiCYT presta sus servicios a dos tipos de destinatarios: usuarios registrados, principalmente medios de comunicación, que tienen acceso a las informaciones en un área restringida durante un plazo de dos días, tras los cuáles, las informaciones pierden la exclusividad y pasan a estar en el área pública; y el público en general, que tiene acceso a los contenidos en abierto sin necesidad de un registro previo. Este espacio tiene como objetivo, como indican los gestores del sitio, incrementar la información científica disponible para los ciudadanos y, en consecuencia, sus conocimientos sobre estas áreas, es decir, su cultura científica. Los usuarios del Área Restringida deben acreditar su trabajo como periodistas en un medio de comunicación y solicitar a la Agencia las preceptivas claves de acceso, de carácter gratuito. Una vez aprobado dicho acceso, a cada usuario se le asigna un registro personalizado que le permite descargarse las informaciones y los materiales complementarios (fotografías, vídeos y audios).

Finalmente, a nivel español, en 2008 se crea el Servicio de Información y Noticias Científicas (SINC) bajo el auspicio de la Fundación Española para la Ciencia y la Tecnología (FECYT) del Ministerio de Economía y Competitividad. Como explican sus promotores en el portal de la agencia --www.agenciasinc.es-, el servicio ofrece noticias, reportajes, entrevistas y materiales audiovisuales (vídeos, fotografías, ilustraciones e infografías) bajo una licencia Creative Commons 3.0, que permite copiar, distribuir, comunicar públicamente y transformar, también para uso comercial, siempre y cuando se cite a SINC como fuente. SINC está dirigido a periodistas, científicos y ciudadanos para dar a conocer los últimos desarrollos de la ciencia. Aunque también publica información internacional, esta agencia pone especial énfasis sobre los trabajos españoles y en los temas de actualidad científica. Los usuarios que lo deseen pueden realizar dos tipos de registro, en función de su perfil, como institución o como periodista, ambos gratuitos ${ }^{28}$.

Al margen de revistas y agencias de noticias, otro tipo de actores como agencias gubernamentales, sociedades y academias científicas, fundaciones, ONGs e incluso empresas también se han unido a la corriente de la información científica online y mantienen sus propios sitios en los que ofrecen noticias en torno a la profesión

${ }^{28}$ La página web de SINC no proporciona datos sobre el número de instituciones de investigación y periodistas registrados. 
investigadora, comentan las oportunidades de determinados asuntos científicotecnológicos e incluso ofrecen recursos de carácter educativo (Montgomery, 2009).

En el caso de las empresas, generan sus propios contenidos y los envían a los medios de comunicación para que se hagan eco de ellos, generalmente, a través de sus gabinetes de marketing y comunicación. Sin embargo, hasta el momento se han localizado escasos estudios que aborden el papel que desempeñan las empresas como emisoras de contenidos científicos. Tan solo García-Hernández et al. (2017) se han aproximado al estudio de la reórica presente en las webs de las empresas biotecnológicas, mostrando que precisamente no parecen estar familiarizadas con la divulgación científica, ya que su discurso no es apropiado para no iniciados.

\subsection{EMISORES EMERGENTES: UNIVERSIDADES Y CENTROS DE INVESTIGACIÓN}

Según recogía el Pew Internet \& American Life Project (2006), la mitad de los internautas de Estados Unidos ha estado alguna vez en el sitio web de algún centro de investigación o revista científica, siendo preferidos la revista National Geographic (23\% había estado alguna vez en ella), Geological Survey -el principal sitio gubernamental para obtener información sobre la Tierra- (23\%) y la web de la NASA (19\%).

La relevancia de estos datos radica en que ponen de manifiesto la importancia que están adquiriendo las instituciones científicas como fuentes de información para el público general y por tanto como emisores dentro del proceso de comunicación científica. Elías (2009) afirmaba incluso que las fuentes institucionales han pasado de estar restringidas a los periodistas a ser en sí mismas medios de comunicación de masas, al estar accesibles para cualquier usuario que recurre a Internet.

Las relaciones públicas corporativas en ámbito de la ciencia se han convertido en un fenómeno generalizado en los centros de investigación en años recientes (Trench, 2009). Mientras en la década de los 90 estos comunicadores profesionales eran raras excepciones, hoy apenas hay una sola universidad o centro sin un departamento de comunicación (Gerber, 2014). Estos centros han visto en Internet la posibilidad de proporcionar información de una forma fácil, barata y creíble para persuadir a sus públicos (Trench, 2009).

Es lo que Peters denominó en su ponencia en el Media for Science (2010) "mediatización" de la ciencia, un proceso caracterizado por la institucionalización de los departamentos de prensa, por el hecho de que la comunicación de la ciencia se considera parte de la labor del científico, por una profesionalización en el contacto con 
los medios y por un uso estratégico de éstos para los fines de la institución. A juicio del mismo autor esta "mediatización" tiene efectos positivos y negativos: por un lado, fomenta una mayor visibilidad de la ciencia y un mayor impacto de ésta en las políticas públicas y, por otro, puede minar la confianza pública en la ciencia y que se haga un uso interesado de ella.

Como se ha subrayado, el auge de la comunicación corporativa en los centros de investigación ha sido propiciado por Internet, que permite a estas entidades comunicarse efectivamente con dos tipos de públicos: por una parte, los medios de comunicación, con el fin de que éstos recojan sus informaciones y las difundan al público general; y por otra parte, directamente con el propio público general, sin la mediación de los periodistas. Esto es posible porque buena parte de los servicios ofrecidos por las páginas web de las instituciones científicas están dirigidos a periodistas y medios de comunicación, pero también son accesibles por parte de cualquier usuario presente en la red con un simple registro (Trench, 2009; Granado, 2011).

Así, las instituciones científicas han adoptado el modelo de comunicación pública del periodismo en la distribución de información a los diferentes públicos. Los sitios de estos centros cuentan con secciones de noticias o equivalentes en los que presentan información científica con un estilo periodístico, adelantándose en cierta medida a la interpretación que realizan los periodistas que trabajan en los medios de comunicación (Trench, 2009).

Esto conlleva un riesgo, tal y como recoge la literatura, y es que unos medios de comunicación cuyo trabajo se realiza cada vez más deprisa, sobre todo en la prensa digital, y cuyas plantillas de periodistas científicos profesionales se han visto mermadas en los últimos años, pueden publicar la información directamente de la fuente y contribuir a los intereses sesgados de las instituciones de investigación (Granado, 2011).

Para autores como Gerber (2014), los profesionales de la comunicación corporativa y las relaciones públicas han sido entrenados para difundir los resultados de investigación como una historia de éxito bien contada, contribuyendo a la formación de una imagen distorsionada de la realidad científica.

De este modo, ya sea directa o indirectamente, los departamentos de comunicación y relaciones públicas de las organizaciones científicas tienen gracias a la red más influencia que nunca sobre lo que dice el público acerca de su trabajo (Brumfiel, 2009; Shäfer, 2017). 
Por ejemplo, en el ámbito de las ciencias del espacio, la NASA y su homóloga europea, la ESA, proporcionan en sus sitios gran cantidad de recursos para su uso por parte de los medios de comunicación, pero que también pueden ser utilizados por los muchos aficionados activos en Internet que cuentan con páginas personales, blogs 0 perfiles en redes sociales, una demostración más de la "difuminación" de fronteras en la comunicación científica. Notas de prensa que se envían por correo electrónico, resúmenes de las apariciones en prensa o secciones de noticias son características comunes en estos sitios que proporcionan además audio y vídeo con entrevistas a los investigadores implicados en las informaciones (Trench, 2009).

Así, desde el punto de los centros de investigación y las universidades, es patente que en la era de Internet deben desarrollar la comunicación corporativa y aprovechar las herramientas que la web pone a su disposición (De Semir, 2010).

Para Ribas (2012) la estrategia comunicativa de las instituciones de investigación debe ser descentralizada y requiere de comunicadores profesionales en todas las áreas activas de la institución para multiplicar el impacto. Además, buena parte de los sitios web de estos centros ofrecen versiones en inglés, lo que indica que su público es global. Algunos sitios también presentan el material original, en bruto, en el que se basan las noticias y enlazan sus informaciones a las revistas científicas correspondientes (Trench, 2009).

\subsubsection{LAS ESTRATEGIAS DE COMUNICACIÓN ONLINE}

Diversos estudios abordan las estrategias de comunicación online de universidades y centros de investigación. Sendos trabajos realizados por Lederbogen y Trebbe (2003) y Lederbogen (2004) analizan la estrategia digital de relaciones públicas de universidades e instituciones de investigación alemanas a partir de una revisión sobre los proveedores de información científica, dos encuestas a los usuarios de páginas web institucionales y un análisis de contenido de estos sitios.

Estos autores aseguran que las relaciones públicas determinan los temas y el calendario de la información científica que se publica en los medios de comunicación. Según sus estimaciones, la información elaborada por universidades y centros de investigación no universitarios representa entre el $60 \%$ al $90 \%$ del total de la información científica que se difunde en los medios. Esto pone de manifiesto la influencia de las relaciones públicas en la determinación de qué temas científicos se representan en los medios y la dependencia a su vez de estos medios del trabajo realizado por las relaciones públicas. 
En este sentido, es muy ilustrativo el artículo publicado por la que fuera defensora del lector de El País, Milagros Pérez Oliva, recogido por De Semir (2010):

"El llamado periodismo de fuentes, aquel que se ejerce desde los gabinetes de comunicación de organismos públicos y privados, cuenta cada vez con más profesionales y tiene cada vez más influencia en la determinación de la agenda informativa. [...] La necesidad de dar respuesta a las demandas informativas y hacer frente a la presión, siempre apremiante, de un número cada vez mayor de medios llevó a los responsables políticos de las instituciones públicas y a los gestores de las grandes corporaciones privadas a canalizar la información a través de gabinetes de prensa. Poco a poco, sin embargo, se ha ido imponiendo la tendencia a transformar esos gabinetes de comunicación en instrumentos de control político de la información".

En este sentido, el trabajo de Lederbogen (2004) ponía de manifiesto que el objetivo de comunicación más importante para universidades y centros de investigación universitarios es mejorar su perfil y aumentar su reconocimiento. En relación a la información que proporcionan, en el caso de las universidades se refiere principalmente a la docencia, a los programas de estudios y a las actividades de investigación; mientras que en el caso de las organizaciones de investigación la principal información son los resultados y procesos científicos. Los medios de comunicación y los estudiantes son dos públicos objetivo de especial relevancia para los gabinetes de prensa y relaciones públicas, quienes también están interesadas en llegar a los pares de la comunidad científica, tal y como apunta el mismo trabajo.

Para ello, disponen de una amplia variedad de herramientas de comunicación, aunque principalmente emiten comunicados de prensa. Otorgan especial importancia a la información disponible en Internet y la imagen corporativa juega un papel más importante para los centros de investigación que para las universidades. Respecto a la evaluación, apenas detectaron iniciativas para la medir de la eficacia de las actividades de relaciones públicas que realizan, pese a la importancia de la monitorización de las acciones que se llevan a cabo en cualquier plan de comunicación.

Según este autor, los gabinetes de prensa y relaciones públicas de las entidades de investigación consideran que sus tareas son: publicar notas de prensa, administrar los sitios web institucionales, la presentación de actividades académicas y la difusión de proyectos de investigación. 
El estudio de Lederbogen señalaba que, hasta ese momento, las universidades y centros de investigación apenas habían aprovechado Internet como herramienta de marketing y relaciones públicas, ya que la información no estaba claramente segmentada a las distintas audiencias. También observaban una sobrecarga de información en sus webs.

En cuanto a estas audiencias, el mismo trabajo indicaba que un $41 \%$ eran científicos, un $37 \%$ estudiantes de secundaria y universitarios, un $14 \%$ periodistas y un $2 \%$ empresas. Los servicios dirigidos a la prensa fueron considerados un punto clave de información no sólo por parte de los periodistas, sino también para los académicos, estudiantes de secundaria, universitarios y empresas, ya que aquí encuentran información actual y fácil de entender. Esto apoya la idea de que estas entidades deben contar con servicios de prensa amplios y bien preparados, situados en un lugar central, por ejemplo, en forma de revista de noticias o portal de actualidad en la página principal.

El diseño de esto servicios de prensa tiene como eje central el texto escrito, a veces enriquecido con ilustraciones y fotografías. Los elementos multimedia son un recurso poco explotado. Sólo una pequeña proporción de los textos ha sido especialmente concebida para su publicación en la web, y el inglés se utiliza en la mayoría de las publicaciones (Lederbogen y Trebbe, 2003).

En otro trabajo, Jaskowska (2004) analiza si los servicios web que ofrecen universidades, academias científicas y centros de investigación polacos se ajustan a las necesidades de los diferentes públicos objetivo. Los resultados indican, en línea con Lederbogen y Trebbe (2003), que el grupo de público más importante para las universidades son los estudiantes y los científicos; para las academias científicas los propios científicos y las organizaciones industriales, y para los centros de investigación las organizaciones industriales. En este caso, al contrario que en el citado trabajo de Lederbogen y Trebbe, existía poca información dirigida al público en general, y era prácticamente inexistente la información destinada a profesores y periodistas. Además, los sitios web de las instituciones científicas polacas aprovechaban en un grado muy bajo la interactividad que ofrece Internet.

En la misma línea, Massoli (2007) analizó los sitios web de 66 instituciones de investigación europeas con el fin de identificar el modelo de comunicación científica seleccionado e implementado online para alcanzar a los diferentes públicos objetivos: si es un modelo basado simplemente en la transmisión de información o si es un modelo más centrado en el fomento de las relaciones y el diálogo. Para ello se 
midieron 68 indicadores como la identidad institucional, los servicios interactivos o el grado de internacionalización. En cuanto a las estrategias diseñadas para atender al público en general y a los medios de comunicación, las instituciones científicas analizadas demostraron no tener demasiado cuidado con la presentación online de sus gabinetes de prensa. Sólo el $20 \%$ de los sitios tenía una sección de prensa y un $23 \%$ un departamento online de comunicación o relaciones públicas.

Como apunta el mismo autor, los profesionales de la comunicación de la ciencia suelen estar "ocultos", siendo lo que más destaca su producción: notas de prensa, vídeos, folletos institucionales, etc. Cita el ejemplo de las notas de prensa: a pesar de que en muchos casos no existe referencia a la oficina de prensa, los comunicados de prensa se publican y a menudo en la página de inicio, lo que pone de manifiesto la relevancia de esta nueva profesión dentro de la comunicación científica.

Las secciones de noticias y calendarios de eventos para la promoción de actividades ponen de relieve el esfuerzo realizado por la mayoría de estos sitios por ofrecer un enfoque de información periodístico. Massoli cita el ejemplo del sitio finlandés MTT (Agrifood Research Finland) el cual ofrece, en su página principal, un producto periodístico novedoso: historias de vida en las que jóvenes investigadores describen no sólo sus actividades científicas, también su enfoque personal sobre la carrera científica, a fin de acercar la figura del investigador al gran público.

Las instituciones de investigación europeas tienden a utilizar Internet principalmente como una herramienta para transmitir información científica institucional. Para los usuarios es fácil llegar a los contenidos entorno a la entidad, sus proyectos y actividades. Sin embargo, los servicios relacionados con la promoción de la cultura científica para el público en general fueron deficientes. Las oportunidades de interacción y participación también fueron poco frecuentes y las que localizaron se dirigen más a los científicos que al público en general (Massoli, 2007). Tan solo centros de investigación de Estados Unidos y Reino Unido han invertido y experimentado en servicios interactivos dirigidos a estos usuarios.

Cody (2013) examinó en qué grado las webs de las instituciones de investigación biomédica de Europa, Estados Unidos y Canadá se utilizan para comunicar ciencia a un público general. El estudio apunta que los centros de Estados Unidos se esfuerzan en mayor grado en comunicarse con el público en general a través de la Web. Sin embargo, en general, la comunicación pública de la investigación en biomedicina no parece ser el objetivo principal de la comunicación online y en los que se produce esta comunicación el modelo de déficit predomina frente a los nuevos modelos más 
participativos. La no consideración del público en general en los contenidos se manifiesta en que las webs de las instituciones de investigación están pobladas de información con un lenguaje denso, altamente científico.

El mismo autor plantea una serie de consideraciones a tener en cuenta a la hora de realizar una comunicación online eficaz: dirigir el contenido de las webs a segmentos de audiencia particulares, proporcionar información en profundidad, pero con un lenguaje accesible para todos los públicos, adoptar un enfoque abierto con el fin de fomentar la confianza y mezclar distintos enfoques o modelos de comunicación.

A nivel español, Bellón Rodríguez y Sixto García (2011) analizaron el uso que hacen las entidades científicas de la Web 2.0 para la difusión de sus actividades e informaciones, utilizando como caso de estudio la Semana de la Ciencia 2009. A su juicio la comunicación científica debe realizarse actualmente teniendo en cuenta estas nuevas potencialidades digitales y las nuevas conductas de los usuarios. La interactividad ha aumentado, la personalización de los contenidos ha mejorado, la participación ha surgido y la propagación viral en la red social es el mejor ámbito de difusión que se conoce.

También López-Pérez y Olvera-Lobo (2015) estudiaron la comunicación científica realizada por los centros de investigaciçón universidades españolas y observaron que los blogs son la herramienta menos utilizada por estas entidades para divulgar los resultados de sus trabajos científicos, mientras que los canales de noticias científicas son los más usados.

El caso de España es paradógico. Aunque algunos gabinetes de comunicación llevan más de 50 años trabajando en centros de investigación de Estados Unidos y Europa, son algo relativamente nuevo en el ámbito hispanohablante (Frías y Rueda, 2014). En España, las universidades y centros de investigación más grandes empezaron a crear oficinas similares en los años 80 (Onieva, 2016).

En 2007, en el contexto del Año de la Ciencia en España, el gobierno español impulsó, a través de la Fundación Española para la Ciencia y la Tecnología (FECYT), la figura de las Unidades de Cultura Científica y de la Innovación (UCC+i). El objetivo fue crear oficinas de difusión de la cultura científica o fortalecer las ya existentes en los centros de investigación españoles, como elementos clave para mejorar la transmisión de los desarrollos científicos y tecnológicos a la sociedad. De esta forma, se trataba de paliar el desinterés por la ciencia de la población española detectado en las Encuestas de Percepción Social de la Ciencia y la Tecnología de FECYT. 
En el marco de esta misión, las UCC+i han trabajado en la organización de actividades de divulgación científica de diversa naturaleza como jornadas de puertas abiertas, exposiciones, acciones formativas, visitas guiadas a los centros de investigación o actividades para fomentar las vocaciones científicas entre los jóvenes, entre otras.

Asimismo, desde su concepción, las UCC+i han asumido el trabajo periodístico como una labor fundamental para acercar la ciencia al público en general y aumentar su cultura científica. Según recoge el Libro Blanco de las Unidades de Cultura Científica y de la Innovación (AA.VV., 2012), uno de los principales destinatarios de las acciones de estas unidades son los medios de comunicación. Dada la escasez de periodistas especializados en ciencia en las redacciones y el acceso privilegiado a las fuentes de información científica que tienen las UCC+i, "estas deberán trabajar para ofrecer contenidos rigurosos de actualidad, contactos con los investigadores y cualquier otro material que necesiten los profesionales de los medios, como imágenes, cortes de voz, fotografías, datos estadísticos, etc." (2012:16).

De este modo, mediar entre los científicos y los medios; convertirse en referente para la comunicación y la divulgación de los resultados de la ciencia, la tecnología y la innovación producida en los centros españoles; gestionar la participación de los investigadores en el análisis de temas de actualidad, contribuyendo así a generar una opinión crítica en la sociedad; dar una mayor visibilidad a los resultados del trabajo científico, y asegurar el rigor de la información de estas temáticas publicada en los medios de comunicación, constituyen el núcleo del trabajo periodístico de las UCC+i, tal y como refleja su Libro Blanco.

Hoy en día, según los últimos datos oficiales disponibles, más de 70 las UCC+i integradas no solo en centros de investigación y universidades, sino también en otras instituciones relacionadas con la ciencia repartidas por todo el territorio español (AA.VV., 2016). Estas unidades son paradógicas, respecto a las oficinas presentes en otros países, porque a los fines institucionales se suma un fin último social que cuenta con el respaldo, traducido en una cofinanciación, del Gobierno español.

\subsection{EL EMISOR TRADICIONAL: EL PERIODISTA ESPECIALIZADO EN CIENCIA}

Como se ha señalado, la figura que tradicionalmente ha sido canalizadora de la información científica desde la fuente hacia el público general es la del periodista científico. Algunos estudios han tratado de esbozar la figura del periodista científico 
"tipo", que difiere en función del país y del tipo de investigación llevada a cabo. Por ejemplo, mientras que Pilholster y O’Malley (2006) observaron que la mayoría de los más de 1.000 periodistas científicos suscritos a EurekAlert! tienen una experiencia en este campo de más de 10 años y casi el 70\% trabaja para medios escritos, impresos o digitales; Massarani et al. (2013) concluyeron que el profesional "tipo" de Brasil sería una mujer menor de 40 años con una experiencia menor a $10 \mathrm{y}$, de manera coincidente, que publica especialmente en medios escritos.

Otro trabajo que ha tratado de tomar una fotografía de estos profesionales es el Global Science Journalism Report firmado por Bauer et al. (2013). Esbozan un perfil de hombre, de entre 21 y 44 años, aunque en Canadá estados Unidos y Latinoamérica predominan las mujeres. Un $10 \%$ contaba con un doctorado y un $32 \%$ trabajaba como freelance en condiciones precarias. Entre sus resultados, los periodistas científicos trabajaban, de promedio, en 9 temas durante dos semanas.

Al margen de su perfil, esta figura se ha visto sacudida por importantes cambios motivados por Internet (Allan, 2009; Granado, 2011), algunos de ellos positivos para estos profesionales y, otros, no tanto. En el lado positivo, el número especial de la revista Journalism (2011) dedicado al periodismo científico en la era digital, se señala que este canal ofrece la oportunidad de participar de forma directa y transparente con las audiencias y mejora la comprensión de la ciencia. De este modo, los periodistas que cuentan con destrezas a la hora de crear historias online tienen el potencial de comunicar ciencia de forma mucho más poderosa que antes (Dunwoody, 2014).

Asimismo, blogs y redes sociales permiten a los periodistas científicos mantenerse en contacto con las fuentes y con sus pares, así como construir sus propias "marcas" personales para posicionarse en el sector (Dunwoody, 2014). La web permite a los periodistas científicos diseñar una estrategia de marketing personal con la que ganar visibilidad, credibilidad y, en último término, nuevos contratos. En este sentido, la precariedad laboral de los periodistas científicos hace que tengan que colaborar para diferentes medios, tradicionales y online, y al mismo tiempo, mantener su "marca" digital en las redes sociales (Brown, 2014). Esto origina, a su juicio del mismo autor, que la credibilidad de la información, que antes se atribuía al medio en que se publicaba, ahora pase a la firma del periodista que trabaja para distintos medios.

Pese a todo, algunos estudios evidencian una actitud generalmente positiva de los periodistas científicos hacia las nuevas tecnologías (Granado, 2011; Pont Sorribes et al., 2013). 
Gráfico 17. Grado de acuerdo sobre si Internet ha mejorado la calidad del trabajo del periodista científico

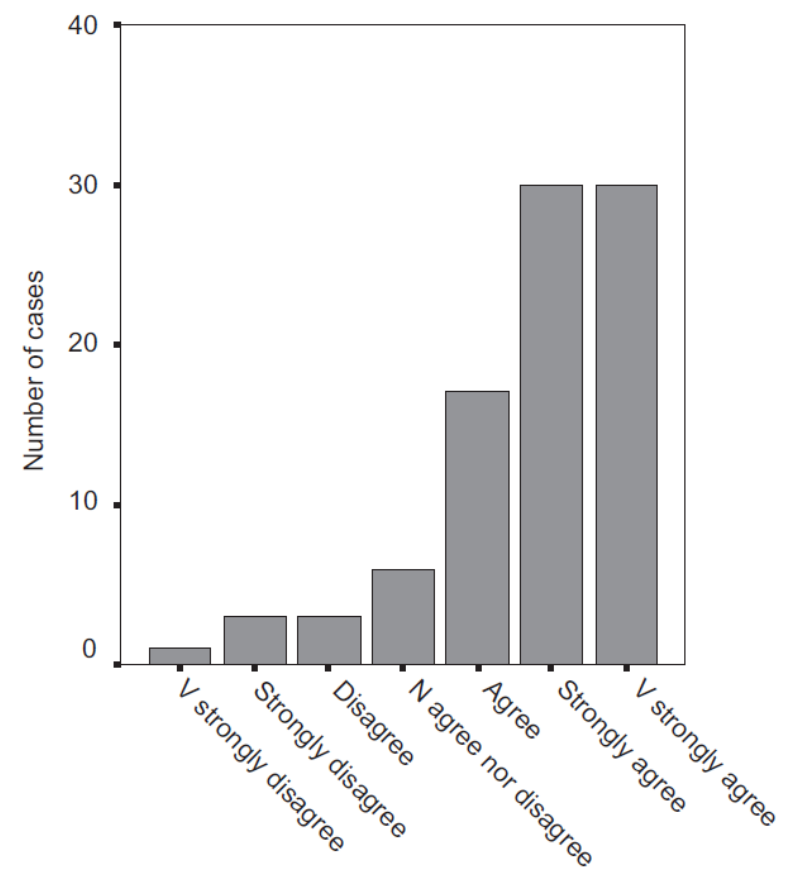

Fuente: Granado, 2011.

En el lado negativo, varios autores aluden a la sobrecarga laboral que ha traído Internet (Brumfiel, 2009; Murcott y Williams, 2013; Fernández de Lis, 2013). La actualización permanente que requieren los medios de comunicación digitales en los que trabajan en estos momentos muchos periodistas científicos (Dunwoody, 2014; Brown, 2014) supone la implantación de redacciones permanentes, activas las 24 horas del día durante los 365 días del año, que en muchas ocasiones no vienen acompañadas de un incremento en el número de profesionales en plantilla, sino de un aumento en la carga laboral de los periodistas ya presentes.

La actualización constante se relaciona también con la necesidad de publicar primero una información para adelantarse a la competencia. Para un periodista científico, esto supone que los temas se deben gestionar y elaborar con gran rapidez, lo que a veces conlleva a que las historias se cuenten con mayor brevedad, sin profundizar en las implicaciones que puede tener un hallazgo científico o sin incidir en el proceso, es decir, en la propia naturaleza de la ciencia (Dunwoody, 2014).

También se han evidenciado otras resistencias, como la incertidumbre en torno al modelo de negocio de los cibermedios (Pont Sorribes et al., 2013). Internet permite el consumo de contenidos de manera gratuita y es aquí donde los dos modelos de 
periodismo, el tradicional y el digital, entran en conflicto. Como concluyen los mismos autores, las nuevas tecnologías se han incorporado de forma natural en el día a día de los profesionales del periodismo Científico, sin que haya habido una planificación al respecto en las redacciones ni en los medios. Tanto los periodistas científicos que trabajan en medios de comunicación como los que forman parte de los gabinetes de comunicación han tenido que adaptarse a ellas y ampliar sus competencias de manera generalmente informal (Holliman, 2010).

Así, un aspecto destacado en la literatura es la polivalencia que deben tener los periodistas científicos que desempeñan su trabajo en entornos digitales. Estos profesionales tienen que alimentar cada vez más plataformas al mismo tiempo, adaptando el mensaje especialmente a las características de cada una de ellas (Allan, 2009; Brown, 2014) e incluso se han creado nuevos perfiles, como los profesionales que actúan como moderadores de foros y comentarios online o los community managers (Holliman, 2001). Según Brumfiel (2009), casi el $60 \%$ de los periodistas científicos había aumentado su número de tareas diarias en los últimos 5 años, elaborando contenidos para webs, redes sociales, blogs, podcast, etc.

Aunque cada vez más se requieren profesionales capaces de realizar varias tareas y desarrollar habilidades y competencias adicionales para el canal online (Holliman, 2011), los medios de comunicación han tenido la necesidad de reducir costes en equipamiento y personal para poder sobrevivir (Fernández de Lis, 2013). El panorama es incierto y se priorizan los periodistas generalistas, capaces de cubrir informaciones de cualquier área, frente a los periodistas especializados, y los periodistas eventuales en forma de freelance frente al personal indefinido (Allan, 2009; De Semir, 2010, Ribas, 2012; Murcott y Williams, 2013).

\subsubsection{ROLES CAMBIANTES DEL PERIODISTA CIENTÍFICO EN EL ENTORNO DIGITAL}

Pese a que los periodistas científicos fueron los primeros en utilizar las nuevas tecnologías de forma competente, mostrando su curiosidad por las mismas y su disposición a los nuevos desarrollos (Trench, 2009), y respondiendo así a la propia naturaleza de los temas que cubren (ciencia, tecnología e innovación), han tenido que "reciclarse" y sus funciones y roles se han diversificado (Horning Priest, 2009; Holliman, 2007).

En un estudio referente en esta línea, Fahy y Nisbet (2011) identifican siete prácticas y roles del periodista científico en el entorno digital: 
- El papel tradicional de conductor que explica o traduce la información científica desde la fuente experta al público en general sigue siendo la "piedra angular" del trabajo de los periodistas científicos.

- La evaluación de la gran cantidad de contenido informativo relacionado con la ciencia presente en la Web se ha convertido en una función cada vez más importante para los periodistas científicos.

- Otro rol es el de educador cívico que informa a un público no especializado de los métodos, objetivos, límites y riesgos del trabajo científico. Con Internet esta función se ha visto favorecida, ya que los periodistas gozan de mayor espacio y de recursos hipertextuales y multimedia que permiten enriquecer esta información.

- La función de intelectual público, en la que el periodista valora información compleja sobre la ciencia y sus implicaciones sociales y presenta esa información de forma distintiva e identificable a partir de su concepción del mundo.

- El establecimiento de la Agenda Setting de la ciencia: identificar y llamar la atención sobre las áreas de investigación más importantes, las últimas tendencias y los problemas que suscitan, realizar la cobertura y recoger en los medios la información.

- La función de watchdog (perro guardián), relacionada con la necesaria "vigilancia" no solo de las instituciones y de la comunidad científica, sino también de los individuos o grupos que hacen afirmaciones científicas falsas, del sector empresarial e industrial o de las organizaciones políticas.

- Finalmente, el papel de "conector" con capacidad de aglutinar a científicos y públicos no especialistas en diferentes herramientas digitales (como blogs 0 redes sociales) para discutir temas relacionados con la ciencia en público.

- Schäfer (2011) añadía la función de fact checker o verificador de hechos, centrado en la necesidad de comprobar la veracidad de las informaciones. En el entorno digital esta labor se ha visto favorecida porque muchos datos se pueden contrastar fácilmente con una búsqueda rápida en bases de datos de libre acceso. 


\subsubsection{LA FORMACIÓN DEL PERIODISTA CIENTÍFICO EN COMPETENCIAS DIGITALES}

En este panorama, se torna imprescindible explorar las mejores maneras para formar a los periodistas científicos. Aunque es vital que los nuevos profesionales conozcan las particularidades del entorno digital en la comunicación de la ciencia (Russell, 2009), existe una ausencia general de programas de Grado de Periodismo modernizados (Parin et al., 2014; Quiñónez Gómez, 2015).

Estos últimos autores investigaron la eficacia del entrenamiento online de periodistas en activo para mejorar la comunicación de riesgos, concretamente en temas de salud y medio ambiente. El objetivo fue observar las actitudes de estos periodistas hacia el entrenamiento y determinar si existe una brecha en la formación en estos temas que puede impactar en la comunicación de riesgos asociados. Pese a que el $41 \%$ había informado de asuntos relacionados con la salud y el medio ambiente en los tres meses anteriores, los autores evidenciaron una falta de formación en esta materia. El $83 \%$ no tenía ninguna formación en salud y menos del 50\% en medio ambiente, unido a una total ausencia de formación centrada en el contexto digital. El mismo trabajo reveló una preferencia de los periodistas a la instrucción online así como la eficacia del entrenamiento.

Parin et al. (2014) sugieren la necesidad de realizar una reforma en la enseñanza del periodismo y de innovar incorporando competencias como los comportamientos de búsqueda de noticias online por parte del público o la utilización de las tecnologías móviles para publicar contenidos periodísticos.

No obstante, Russell advierte que "es crucial que las anticuadas virtudes de una buena información periodística precisa, el uso de múltiples fuentes, la explicación del contexto sobre una controversia y la independencia editorial no se pierdan en el entusiasmo de comunicar el contenido de manera novedosa" (2009: 1491).

En el caso de España, Fernández de Lis (2013) alude también a una infraespecialización de los periodistas que trabajan actualmente en los medios generalistas. A su juicio, los periodistas científicos son demasiado caros de formar y mantener, razón por la cual la mayoría de grandes redacciones prescinde de ellos, con el problema de fondo de que la ciencia no forma parte de la agenda política y económica del país a la que se ciñen los grandes medios.

La formación del periodista científico en competencias digitales presenta un vacío investigador, por tanto, es sin duda uno de los asuntos que precisa un mayor interés 
por parte de la comunidad académica que centra sus estudios en la comunicación de la ciencia en Internet.

\subsubsection{LA DEPENDENCIA INFORMATIVA DE FUENTES ORGANIZADAS}

Como se ha esbozado en apartados precedentes, las nuevas tecnologías han facilitado en gran medida la labor diaria del periodista científico, y del periodista en general, ya que han reducido el tiempo dedicado a la búsqueda y gestión de los temas (Pont Sorribes et al., 2013). Esto significa que los periodistas ya no están obligados a realizar trabajo a pie de calle, es decir, a desplazarse a los laboratorios para conocer de primera mano el trabajo que realizan los científicos y del que se va a informar (Trench, 2009), lo que ha fomentado un periodismo "perezoso" (Cullen, 2013) con importantes implicaciones en la ética profesional (Trench, 2009).

A través, simplemente, del correo electrónico posible recibir propuestas de temas, contactar con la fuente, gestionar una entrevista, realizarla -aunque para algunos autores esto no es lo más adecuado desde el punto de vista de la práctica profesional, ya que no se establece un diálogo directo, no se pueden improvisar preguntas y no se puede registrar el lenguaje no verbal (Elías, 2008)- y enviar documentación adicional, fotografías, vídeos o enlaces para completar la información (Trumbo et al., 2001).

En cuanto a la recepción de propuestas de temas a través del correo electrónico, debido a la creciente carga de trabajo y a la consiguiente falta de tiempo, como ya se ha advertido, los periodistas científicos dependen cada vez más de la información que les envían los gabinetes de comunicación de las revistas científicas, las universidades y los centros de investigación (Trench, 2009; Calloni et al., 2009; Granado, 2011; Murcott y Williams, 2013; Olvera-Lobo y López-Pérez, 2015). Estas fuentes organizadas y, como señalan numerosos autores, también interesadas (De Pablos Coello, J. M., y Mateos Martín, C., 2004; Olvera-Lobo y López-Pérez, 2015), pueden estar contribuyendo a una homogeneización de los contenidos científicos que se publican en los medios de comunicación tradicionales y digitales.

Patricia Fernández de Lis, directora de Materia -un cibermedio de referencia en el periodismo científico encargado de la sección de ciencia de El País- ilustraba de forma concluyente la sobresaturación que están viviendo los periodistas científicos en España, lo que podría estar motivando esa dependencia informativa de fuentes organizadas:

"Recibimos toneladas de información de numerosas fuentes, como centros de investigación, empresas o universidades, y también comprobamos a diario los 
embargos de las publicaciones científicas en servicios como EurekAlert! o AlphaGalileo. La información también nos llega ahora a través de blogs y redes sociales, lo que significa que cada día hay decenas de historias que evaluar, comprender, escribir y editar. Sin embargo, tenemos un tiempo limitado para comprender la información, y un tiempo y un espacio limitado para hablar de ello. Además, necesitamos contrastar la información, es decir, hablar con otros investigadores aparte del que firma el artículo o la nota. $Y$ todo ello tratando de respetar el trabajo del científico en unas condiciones muy complejas, ya que las redacciones periodísticas no dejan de menguar: unos 4.000 periodistas se han quedado sin trabajo en el último año en España, según datos de la Federación de Asociaciones de Periodistas de España (FAPE)", (Fernández de Lis, 2013:17).

Pero esta situación no es exclusiva del ámbito español. Granado (2011) refería que los periodistas científicos pasan alrededor de 3,5 horas de su horario laboral buscando nuevos temas en Internet. Los sitios en los que estos periodistas encuentran temas confiables sobre los que publicar son reducidos, lo que ha propiciado, según el mismo autor, una concentración de profesionales en unos pocos sitios, fundamentalmente las webs de las revistas científicas y de las universidades y centros de investigación.

Tabla 14. Credibilidad de las fuentes de información científica online para los periodistas científicos europeos.

\begin{tabular}{llllll} 
& N & Minimum & Maximum & Mean & Std. Deviation \\
\hline Science journals' websites & 96 & 2 & 7 & 5.92 & 1.083 \\
University websites & 96 & 2 & 7 & 5.71 & 0.917 \\
International organizations & 96 & I & 7 & 5.24 & 1.254 \\
Big news organizations & 95 & 2 & 7 & 4.91 & 1.082 \\
Government websites & 95 & $\mathrm{I}$ & 7 & 4.24 & 1.397 \\
General interest portals & 94 & $\mathrm{I}$ & 6 & 3.59 & 1.273 \\
Industry websites & 95 & $\mathrm{I}$ & 6 & 3.11 & 1.162 \\
Political organizations & 96 & $\mathrm{I}$ & 7 & 3.04 & 1.313 \\
Corporate websites & 94 & $\mathrm{I}$ & 6 & 2.98 & 1.182 \\
Usenet newsgroups & 90 & $\mathrm{I}$ & 5 & 2.82 & 1.097 \\
Activists' websites & 96 & $\mathrm{I}$ & 7 & 2.77 & 1.294 \\
Chats and message boards & 92 & $\mathrm{I}$ & 4 & 1.71 & 0.778
\end{tabular}

Fuente: Granado, 2011.

De este modo, los periodistas científicos estarían atendiendo a las mismas historias, visitando y utilizando las mismas fuentes, independientemente del país en que se encuentren, de modo que los principales periódicos y agencias de noticias podrían 
estar publicando los mismos temas. Esta situación es quizás una de las consecuencias más importantes de la introducción de Internet en las salas de redacción y de la mayor carga de trabajo de los periodistas científicos (Brumfiel, 2009; Murcott y Williams, 2013; Cullen, 2013).

Además, Granado (2011) apunta que, lejos de dar voz a otro tipo de ciencia, la red está fomentando un predominio de la investigación publicada en las revistas revisadas por pares, especialmente de la que se realiza en los Estados Unidos, uns situación que han confirmado estudios posteriores (Pérez-Rodríguez, 2016). La ciencia que llevan a cabo los investigadores europeos o el proceso científico en los laboratorios es recogida raras veces en los medios de comunicación.

"Si los periodistas científicos se quedan dentro de sus redacciones y no visitan los laboratorios y conferencias, los lectores solo pueden estar en contacto con el producto final de la ciencia: el artículo científico publicado. Toda la práctica de la ciencia está quedando en el olvido y los periodistas se convierten en transmisores pasivos de información procedente de fuentes organizadas", (Granado, 2011: 810).

Las grandes editoriales científicas, apoyadas en Internet, están estableciendo la Agenda Setting de la ciencia (Peterson, 2001) y esta "colaboración" ha dado más control a los científicos sobre la información periodística (Granado, 2011: 812). Además, teniendo en cuenta que el acceso a Internet para localizar temas está relacionado con la edad de los periodistas, en el futuro, cuando la nueva generación de profesionales nativos digitales sea general, la homogeneización de la información científica se podrá ver incluso acentuada.

En paralelo a las revistas, los organismos de investigación, universidades y otro tipo de centros, han fomentado enormemente las relaciones públicas favorecidas por el contexto online. La frontera entre la comunicación corporativa y la información periodística es una línea muy fina y para el usuario es difícil diferenciar entre una y otra. Además, algunos cibermedios mermados de periodistas parecen estar aprovechando esa ambigüedad para abastecerse de contenidos científicos de forma gratuita, lo que presenta claras implicaciones éticas. “¿Qué pensarian los lectores si 'Le Point' mezclara en su sección de política artículos escritos por el Ministerio de Interior con los de sus redactores", (Allemand, 2013:75).

Así, esta situación de desequilibrio entre los periodistas científicos y sus fuentes afecta a un importante elemento democrático en el periodismo como es la independencia. Pero Internet, al mismo tiempo que está favoreciendo esta situación, 
puede ser la llave para resolverla o, al menos, para paliarla, ya que el mismo canal ofrece herramientas para elaborar críticas y denunciar los casos de falta de independencia (Trench, 2009).

Tal y como se ha expuesto a lo largo de esta revisión, la actual situación profesional de los periodistas científicos y el aumento de las relaciones públicas y la comunicación corporativa dentro de los centros de investigación parecen estar jugando un papel fundamental en cómo la información científica es construida y reflejada en los medios de comunicación. Pero todavía no se conoce a qué nivel ni qué aspectos concretos están mediando esta situación, por lo que parecen necesarios nuevos estudios que produndicen en este objeto que podría tener importantes implicaciones respecto a la ética profesional y a cómo las audiencias están recibiendo el mensaje científico. 


\section{DISCUSIÓN}

La revisión llevada a cabo permite poner sobre la mesa y discutir una serie de asuntos fundamentales en relación con el presente y el futuro de la comunicación de la ciencia en el contexto de Internet. Estos temas se confrontan desde el marco del periodismo científico, debatiendo las implicaciones que tienen para la profesión, los problemas y desafíos que acarrean, y cómo la figura del periodista científico, a partir de sus conocimientos, prácticas y valores, puede contribuir decisivamente a paliar los déficits de la información científica en la web.

\section{La red y las relaciones entre periodistas y científicos.}

El estudio de la comunicación pública de la ciencia en Internet desde la perspectiva del emisor de información tradicional -el periodista científico-, y desde el ángulo de uno de los principales emisores emergentes en la web -el propio científico-, así como de sus relaciones en la red, pone de manifiesto que, actualmente, ambos actores guardan distancias, tienen diferentes apreciaciones en relación a cómo debe articularse la comunicación, utilizan para ello sus propios medios y sus propios códigos, y compiten por las mismas audiencias.

En cuanto al periodista científico, se ha comprobado cómo el entorno digital ha traído algunos aspectos francamente positivos para su desempeño profesional, como las posibilidades de interacción con las audiencias o el enriquecimiento que suponen los elementos multimedia o el hipertexto para facilitar la comprensión y ampliar la cobertura de la información de carácter científico (Byrne et al, 2002; Hermida, 2007).

Al mismo tiempo, esto ha propiciado que los periodistas científicos tengan que ser cada vez más polivalentes, capaces de elaborar contenidos para diferentes soportes y plataformas, lo que no se ha visto acompañado de refuerzos en las redacciones ni de formación especializada (Brumfiel, 2009, Murcott y Williams, 2013; Cullen, 2013). Los mismos profesionales e incluso menos, porque muchos medios han recortado sus plantillas de periodistas especializados en los últimos años, deben cubrir temas para más plataformas -prensa impresa, digital, redes sociales, plataformas audiovisuales, blogs, etc.- y en menor tiempo, porque la actualización continua de la web apremia y la competencia es feroz.

Es decir, Internet puede ofrecer muchas posibilidades para el periodismo científico, pero en la práctica ha producido una sobrecarga laboral de los periodistas y unos contenidos poco trabajados y apegados a las facilidades que ofrecen las fuentes organizadas -básicamente, revistas de alto impacto y gabinetes de comunicación 
institucionales-, que facilitan la labor de estos profesionales en la vorágine del día a día.

Por otro lado, se pone de manifiesto cómo la red ha sido decisiva en la incorporación de los propios científicos a la comunicación pública de la ciencia, en la que también ha influido el descontento con la cobertura que realizan los periodistas, sacudidos por los problemas a los que se acaba de hacer referencia.

Finalmente, se hace patente que la histórica brecha entre ambas figuras, científicos y periodistas se mantiene también en la red, acentuada porque la web proporciona herramientas para la comunicación directa con el público, lo que permite a los investigadores esquivar al periodista como intermediario en su relación con la sociedad (González-Pedraz y Campos-Domínguez, 2015). Esto ha motivado que muchos científicos hayan adoptado una nueva función de comunicadores públicos, utilizado para ello nuevos medios, primero los blogs y posteriormente las redes sociales.

En esta línea, es significativo el hecho de que no se haya localizado ninguna referencia, en la extensa literatura consultada sobre la materia, en la que se refiera alguna experiencia de carácter colaborativo entre científicos y periodistas. Tan solo se han localizado algunos experimentos cercanos al periodismo ciudadano que se encuentran aún en fase temprana de desarrollo (Minol et al., 2007; Waldrop, 2008). Estas denominadas "formas de transición" parten de la idea de que los periodistas están dispuestos a adoptar nuevas maneras de conectarse con el público convencidos de que la calidad de sus productos se verá enriquecida (Allan, 2009b).

Sin embargo, no parece que exista convicción de que pueda producirse una mejora en la cobertura informativa a partir de la colaboración directa con la propia comunidad científica. Quizás motivados porque los científicos son vistos como fuente interesada, lo que entraría en disputa con la independencia periodística; o porque no se quiere compartir el histórico monopolio de la emisión informativa, los periodistas científicos prefieren mantenerse distanciados. Pero en el canal abierto de Internet se han esfumado los privilegios, y ambos actores parecen estar condenados a entenderse.

La adopción de herramientas online por parte de los periodistas y la emergencia de una cultura participativa pueden ayudar a disminuir la actitud de desconfianza de los científicos, quienes tienen la oportunidad de puntualizar o corregir la información a través, por ejemplo, de sus comentarios en las noticias o de las redes sociales (Luz, 2012). 
Asimismo, el hecho de que la mayor parte de la audiencia prefiera que sean los propios científicos quienes comuniquen directamente los resultados de sus investigaciones, invita a la reflexión de que algo se está haciendo de forma deficiente en la práctica periodística.

Muchos autores convienen que este nuevo escenario obliga a repensar la figura del periodista científico (Porto y Palacios, 2012), que debe adaptarse a los cambios en el entorno comunicativo, a los nuevos formatos de difusión y a las formas emergentes de intercambio de información online para no quedar atrás (Trench, 2007; Brossard, 2013; González-Pedraz y Campos-Domínguez, 2015).

\section{Multiplicidad de emisores y multiplicidad de intereses. Las dificultades para filtrar información científica en la red.}

Asociada a la multiplicidad de emisores y a la facilidad de acceso a todo tipo de contenidos en la red, la revisión ha reportado el importante problema para filtrar información científica fiable y de calidad por parte del usuario.

Cada uno de los emisores estudiados tiene sus propios intereses a la hora de seleccionar, elaborar y poner en circulación información de carácter científico en Internet, creando "un espacio lleno de gente, ruidoso, donde discernir información válida y contrastada se vuelve cada vez más difícil", (Trench, 2007:134). Igualmente, De Semir (2010) señala que así como los mensajes políticos se pueden convertir en "fragmentos" de desinformación, los hallazgos científicos también son vulnerables a las distorsiones y tergiversaciones, sobre todo cuando se ajustan a prejuicios ideológicos. Estas distorsiones se están volviendo muy comunes en el nuevo entorno de medios, ya que la web puede dar voz a cualquier emisor con un interés particular.

La denominada "mercantilización de las noticias" (Priest, 2013), en referencia al tratamiento de la información como una mercancía que se puede comprar y vender, ha adquirido un nuevo significado en la actualidad, con intereses publicitarios financiando buena parte de la información científica que circula en la web.

Otro caso es el de las universidades y centros de investigación, que emplean cada vez más personal de márketing, relaciones públicas y periodistas para poner en circulación información controlada en la red sobre los resultados científicos que obtienen, utilizando el formato de "noticia" aunque su propósito último sea, más allá del servicio público, mejorar la imagen y la reputación de la organización (Trench, 2007). Pero también otros intereses mueven a universidades y centros de investigación, como la captación de nuevos clientes o la búsqueda de financiación adicional (De 
Semir, 2010). De este modo, el usuario de Internet "se encuentra cara a cara con una pieza informativa, las intenciones no siempre están claras. La objetividad absoluta no existe en el periodismo, pero mucho menos en la comunicación institucional" (De Semir, 2010:62).

El objetivo de los gabinetes de comunicación de universidades y centros de investigación es que las notas de prensa que envían a los medios sean seleccionadas por los periodistas, de entre todas las informaciones a las que actualmente tienen acceso sin necesidad de salir de la redacción (Elías, 2008). Esto origina que uno de los principales méritos que son valorados por los gestores y directivos de los centros de investigación, respecto a los profesionales que trabajan en sus gabinetes de comunicación, sea el de la llamada "eficiencia mediática", o lo que es lo mismo "la huella de impacto de un comunicado en los medios de comunicación (...) considerando que cuanto más sale un hallazgo en los medios gracias al periodista del gabinete, mejor es ese periodista” (Elías, 2008:119). Pero, como reflexiona este autor, ¿merece la pena sacrificar rigor y seriedad para la obtención de una mayor publicidad?

Trench $(2007 ; 2009)$ advierte de los intereses de otros emisores de contenidos científicos muy activos en la red. Es el caso de las agencias de noticias especializadas, a las que considera un servicio comercial corporativo desarrollado expresamente para periodistas, lo que demuestra, a juicio del autor, el hecho de que algunas como la europea Alpha Galileo restrinjan su acceso a reporteros y corresponsales especializados en esta materia. También sociedades científicas, fundaciones, organismos gubernamentales y otras entidades relacionadas con la ciencia, la tecnología y la innovación pueden utilizar la web con fines promocionales, comerciales y/o partidistas. En este sentido, las organizaciones políticas pueden obedecer a cuestiones estratégicas en su comunicación de temas científicotecnológicos a través de Internet. Incluso los propios científicos, otros emisores favorecidos por la red, pueden responder a sus propios intereses y hacer un uso parcial de la comunicación.

Por otro lado, la web facilita la presencia de organizaciones defensoras de la ciencia y de la propia comunidad científica, como el Science Media Centre o el Sense about Science, originarios de Reino Unido y centrados en promover el enfoque científico de los problemas actuales que ellos consideran "correcto". La presencia en la red de estos grupos es una respuesta a la percepción de ciertas tendencias en los medios de comunicación y en la sociedad que ellos estiman contrarias a los intereses de la ciencia. También hay otras organizaciones que, del lado contrario, invitan al escepticismo sobre la ciencia contemporánea, como las estadounidenses Union of 
Concerned Scientist o el Center for Science in the Public Interest, que adoptan posiciones críticas sobre las responsabilidades sociales de la ciencia y que han ampliado su público con la presencia en Internet (Trench, 2009).

En definitiva, gracias a la red una gran cantidad de emisores ajenos al tradicional mediador periodista, están emitiendo mensajes científicos que son accesibles a cualquier persona con conexión a Internet. Estos emisores, generalmente organizaciones, tienen intereses concretos que difunden en una comunicación disfrazada de objetividad que es muy difícil de detectar por el ciudadano medio. Estas entidades tampoco tienen la obligación de informar equitativamente, de modo que el periodista científico, que sí la tiene, se convierte en una figura de gran valor en el contexto online. Esta situación no se está produciendo solo en el ámbito de la información científica, sino que es transversal a todo tipo de información. Por ello, se antoja necesaria la puesta en marcha de acciones de alfabetización mediática para orientar a los ciudadanos en la filtración de la información que encuentran en Internet.

El periodista científico, una figura esencial en la comunicación de la ciencia en Internet.

La situación que atraviesa en estos momentos el profesional del periodismo científico es compleja. En Internet, crear una página web, un blog o un perfil en redes sociales es fácil y la forma es la misma para cualquier interesado en emitir información científica, ya sea o no profesional. Así, la autoría de este tipo de contenidos se "desdibuja" y periodistas profesionales y aficionados comparten los mismos espacios. Pero el periodista tiene la posibilidad de ofrecer más y mejores contenidos que el usuario medio (Allemand, 2013). Dunwoody (2014) incide en la misma línea, al considerar que un ambiente dominado por Internet no significa necesariamente un patrón de "todo vale" en la búsqueda de información, como demuestra el éxito de audiencia de sitios que filtran información periodística como Yahoo! News, CNN, MSNBC, Google News o The New York Times. "Tenemos hambre de mantenernos al día sobre eventos actuales, pero continuamos dependiendo del periodismo para tomar decisiones razonadas y elaborar argumentos legibles" (Dunwoody, 2014:34).

Sin embargo, los medios de comunicación tradicionales han realizado importantes recortes en sus plantillas de periodistas científicos (Krumenaker, 2010; Priest, 2013) o, en el mejor de los casos, las han estancado (Fahy y Nisbet, 2011). Esta situación podría afectar, según recogía el editorial de la revista Nature 'Filling the void' (2009), a la comprensión pública de la ciencia, a la calidad de la cobertura de la ciencia en los medios -con una mayor utilización de información procedente de fuentes como los 
gabinetes de comunicación de los centros de investigación- y a la capacidad de los medios de desempeñar el rol de vigilancia (watchdogs) en el ámbito de la ciencia, desvelando fraudes $u$ otras malas conductas.

Dunwoody (2014) notaba que, pese a que los periodistas científicos son cada vez más necesarios, la profesión está en peligro en un panorama de medios digitales en el que los usuarios realizan su propia selección de información y las fuentes no siempre son fiables (De Semir, 2013; Priest, 2013). Los periodistas científicos están sujetos a éticas y códigos profesionales que otorgan a la información periodística una credibilidad fundamental (Trench, 2007; Elías, 2013).

No obstante, como se ha advertido previamente, el periodista científico tendrá que evolucionar en este nuevo contexto, en el que la tradicional función de mediadores entre científicos y público, transformando la ciencia en historias que todo el mundo puede entender, debe dar un paso más en Internet para no quedar atrás. Y puede ser la propia web la principal aliada de los periodistas científicos: gráficos interactivos, encuestas, comentarios abiertos, archivos multimedia o enlaces a diversas fuentes de información complementarias, pueden enriquecer en gran medida el mensaje periodístico y aportar un valor añadido, fundamentado en la experiencia de los periodistas como comunicadores públicos en un nuevo entorno repleto de competencia extra-periodística (González-Pedraz y Campos-Domínguez, 2015).

Por ello, el entorno digital pone en valor a los periodistas científicos (Moreno Castro, 2013; Elías, 2015), elementos clave, por ejemplo, para paliar el problema de la fiabilidad de los contenidos en Internet, donde cualquier usuario puede publicar informaciones no contrastadas, imprecisas, falsas o interesadas (Thomas, 2009; Montgomery, 2009; Oghton, 2010; Allemand, 2013). Esto cobra especial relevancia, por ejemplo, en el caso de la información científico-sanitaria, ya que muchas personas toman decisiones que afectan a su salud sobre la base de lo que leen, escuchan o ven en los medios de comunicación, por lo que es fundamental contar con profesionales capaces de proporcionar contenidos precisos y fiables (Cullen, 2013). La demanda de información especializada de calidad hace que la especialización del periodismo científico tenga un futuro brillante, según el mismo autor.

Para Gomes da Silva (2012) los periodistas deben producir contenidos más consistentes que valoricen la explicación del cómo y el porqué de los temas científicos reportados. Rogers (2000) también ofrece algunas pistas sobre cómo los periodistas pueden utilizar mejor Internet que cualquier otro emisor. En primer lugar, considera que deben ser más conscientes de las necesidades e intereses de una audiencia que 
ahora puede interactuar con los periodistas y los propios medios de comunicación, haciendo preguntas y comentarios que pueden proporcionar información muy valiosa. Por otro lado, opina que los periodistas deben ir más allá de lo básico y proporcionar una información más completa. Por último, la misma autora subraya que los periodistas tienen que incorporar a su trabajo el conocimiento académico que se tiene sobre cómo las personas procesan la información para dar sentido a sus ideas y para gestionar la incertidumbre.

A modo de conclusión sobre el potencial que ofrece Internet para la información científica y el papel del periodista en este contexto online de medios, es destacable una reflexión que, pese a realizarse a principios de siglo, está más vigente que nunca:

"Toda esta potencialidad no tendría ningún valor si se pierde lo fundamental: la calidad informativa. A diferencia de lo que auguran algunos teóricos, la misión del periodista en este entorno será cada vez más importante, tanto en su labor de selector de información como en la recogida, redacción, interrelación y contextualización de los contenidos, integración del multimedia, profundización selectiva y fomento de la reflexión y el debate por parte del lector" (Sanz-Pérez de Guzmán, 2002:184).

\section{El impacto de los gabinetes de comunicación de los centros de investigación en la comunicación online de la ciencia.}

Un asunto transversal que ha emergido en diversos varios capítulos de la revisión es el papel de las fuentes organizadas en el actual contexto de la comunicación de la ciencia online, las cuales han aprovechado eficazmente el potencial que les ofrece la web para ganar terreno.

Las revistas científicas han mantenido en el entorno online un dominio sobre la agenda de la ciencia que ya tenían en el contexto analógico (Corbett y Mori, 1999; Kiernan, 1997; Kiernan, 2003). Pero el caso de los gabinetes de comunicación de universidades y centros de investigación es paradigmático. Mientras hace dos décadas los profesionales de la comunicación corporativa eran excepciones, hoy son un fenómeno generalizado en los organismos públicos y privados de investigación (Trench, 2009; Gerber, 2014).

Este auge ha sido beneficiado precisamente por Internet, que permite a estas entidades científicas comunicarse efectivamente con dos tipos de públicos: por una parte, los medios de comunicación, con el fin de que éstos recojan sus informaciones y las difundan al público general; $y$, por otra parte, directamente con el propio público, sin la mediación de los periodistas. Esto es posible porque buena parte de los 
servicios ofrecidos por web de las instituciones científicas están dirigidos a periodistas y medios de comunicación pero también son accesibles para cualquier usuario (Trench, 2009; Granado, 2011).

Así, los gabinetes institucionales han visto en Internet la posibilidad de alcanzar directamente a las audiencias de manera sencilla y sin un elevado coste (Trench, 2009), la denominada "mediatización" de la ciencia de Peters (2013). Para ello, los gabinetes institucionales han adoptado el modelo de comunicación del periodismo en la distribución de información a los diferentes públicos. Los sitios web de estos centros cuentan con secciones de noticias o equivalentes en los que presentan información de ciencia con un estilo periodístico, adelantándose en cierta medida a la interpretación que realizan los periodistas que trabajan en medios de comunicación independientes (Trench, 2009). Como se ha apuntado, los profesionales de los gabinetes de comunicación han sido entrenados para difundir los resultados de investigación como una historia de éxito bien contada, contribuyendo en algunos casos a la formación de una imagen distorsionada de la realidad científica (Gerber, 2014).

Al mismo tiempo, diversos estudios sugieren que los periodistas científicos dependen cada vez más de la información que les envían los gabinetes de comunicación de las revistas científicas, las universidades y los centros de investigación (Trench, 2009; Calloni et al., 2009; Granado, 2011; Murcott y Williams, 2013; Shäfer, 2017). Una situación que acarrearía diversas objeciones éticas y profesionales. En unos medios de comunicación cuyo trabajo se realiza cada vez más deprisa, sobre todo en la prensa digital, dada la importancia de la actualización continua y de adelantarse a la nutrida competencia (Dunwoody, 2014), y con unas plantillas de periodistas científicos profesionales cada vez más pequeñas (Hermida, 2010; Priest, 2013), se tiende a publicar información directamente de estas fuentes, lo que puede contribuir a los intereses sesgados de las instituciones de investigación (Granado, 2011).

De este modo, ya sea directa o indirectamente, los gabinetes institucionales ejercen una gran influencia sobre lo que se publica en los medios y, en consecuencia, sobre lo que opina el público acerca del trabajo que realizan los centros de investigación (Brumfiel, 2009). Algunos autores, incluso, advierten de prácticas discursivas emergentes en los medios de comunicación que se pueden atribuir a un cambio de poder en la producción de noticias, desde los periodistas a las instituciones científicas (Zhang, 2018). 
Sin embargo, dada la escasez de trabajos localizados, se necesitan más estudios empíricos para confirmar esta situación (Brossard y Schefeule, 2013; Olvera-Lobo y López-Pérez, 2015), así como para estimar qué presencia real tiene el trabajo de estos gabinetes en los medios de comunicación y qué imagen de la ciencia y el conocimiento reflejan finalmente los medios digitales. 


\section{BLOQUE III \\ ESTUDIO DE CASO}

\section{ANÁLISIS DE LA COBERTURA DE LAS UNIVERSIDADES ESPAÑOLAS Y EL TRATAMIENTO DE LA INFORMACIÓN CIENTÍFICA EN CIBERMEDIOS}




\section{PRESENTACIÓN}

El aumento de las relaciones públicas y la comunicación corporativa dentro de los centros de investigación parecen estar jugando un papel fundamental en cómo la información científica es construida y reflejada en los medios de comunicación, favorecidos por el entorno online. Algunos trabajos apuntan a que algunos medios se estarían limitando a realizar una simple reescritura de notas de prensa procedentes de estos organismos (Davies, 2009), lo que derivaría en piezas cortas de rápida lectura que limitan la cobertura de la ciencia (Gross, 2008; Loose y De Lima, 2012; Martínez Valdés y Rodríguez Lara, 2014) y conducen a una disminución de la calidad del periodismo científico (Murcott y Williams, 2013; Moraes y aia, 2014; Shäfer, 2017). Recientemente, autores como Zhang (2018) sugieren incluso un cambio de poder en la producción de las noticias desde los periodistas científicos a los gabinetes de las instituciones científicas.

Para ahondar a qué nivel se está produciendo esta situación en el contexto online y qué elementos pueden estar mediando en la misma, se plantea la realización de un estudio empírico, en el que se toma como caso una muestra de organismos públicos de investigación y cibermedios españoles.

Se tiene en cuenta la muestra de universidades monitorizada en el proyecto Impacto de las UCC+i en la visibilidad pública de la Ciencia española: prensa digital y Twitter, cuyo fin último fue cuantificar la presencia de contenidos gestionados por estos gabinetes de comunicación en cibermedios españoles a lo largo de un periodo de tiempo representativo; describir el tratamiento periodístico y la imagen de la ciencia y el conocimiento reflejado en la prensa digital, y detectar posibles indicios de la dependencia informativa de este tipo de fuentes planteada en la literatura (Trench, 2009; Calloni et al., 2009; Brumfiel, 2009; Granado, 2011; Cullen, 2013; Murcott y Williams, 2013; Peters, 2013; Shäfer, 2017). Los resultados del trabajo apuntaron que los cibermedios con menores recursos podrían estar dependiendo informativamente de ellas.

Así, el estudio de caso que se desarrolla en los siguientes apartados parte y trata de comprobar esa premisa: el tamaño del cibermedio estaría asociado a una mayor o menor dependencia de la información científica procedente de centros de investigación.

Para probar dicha hipótesis principal, se plantea la realización de un estudio empírco comparativo de la información científica protagonizada por las universidades españolas en cibermedios de gran tamaño -alcance nacional- y de pequeño tamaño - 
alcance regional y local-. Se decide tener en cuenta solo a las universidades y no a otro tipo de organismos de investigación dada la desigual cantidad de unidades de análisis recuperadas en el trabajo previo, ${ }^{29}$ y con la intención de que los resultados obtenidos puedan ser más representativos y confrontarse con los reportados en otros estudios centrados precisamente en estas instituciones de educación superior.

Desde los años 80, se han realizado estudios de caso de diversa naturaleza en torno a la presencia en prensa y el tratamiento periodístico que reciben las universidades (Pérez Serrano, 1984; Gómez Hernández, 1996; Fernández y Molero de Cabeza, 2003; Quintanilla et al., 2004; Jianbin, 2006; Kim et al. 2007; Rowe y Brass, 2008; Hererro-Solana et al., 2014; Pérez-Rodríguez, 2016).

Sin embargo, apenas se han localizado trabajos que centren su análisis en el tamaño del medio de comunicación. Tan solo Repiso et al. (2016) apuntan a una presencia del sistema universitario en prensa fundamentalmente regional.

No obstante, no se han hallado estudios que comparen la cobertura y el tratamiento periodístico de la información científica protagonizada por las universidades en medios de diferente tamaño, poniendo el foco en aspectos como el tipo de información científica publicada, la autoría, el género o las fuentes.

\section{OBJETIVOS, PREGUNTAS DE INVESTIGACIÓN E HIPÓTESIS}

El objetivo general del presente trabajo es realizar un análisis comparativo de la información científica participada por las universidades españolas en prensa nacional, y regional y local, centrándonos en este caso en ediciones digitales de medios generalistas. Asimismo, se plantean cuatro fines específicos:

- Profundizar en el tratamiento periodístico de la información científica que llevan a cabo estos dos tipos de cibermedios.

- Determinar qué tipo de información científica que involucra a las universidades (investigación, eventos científicos, etc.) son las predominantes en cada caso.

- Conocer qué visión de la colaboración científica es reflejada en estos medios.

\footnotetext{
${ }^{29}$ En el análisis previo, cuyos resultados completos se presentan en González-Pedraz et al. (2018), se recupera una gran cantidad de piezas periodísticas relativas al CSIC, pero escasas piezas, ninguna en algunos casos, de otros centros de investigación periféricos. Por ello, se opta por tener en cuenta solo a las universidades en el análisis, cuya presencia es más uniforme.
} 
- Estimar las áreas de conocimiento que suscitan un mayor interés periodístico a escala nacional y a escala local.

- Conocer si el uso de las características del ciberperiodismo en la información científica es mayor o menor en función del tamaño del medio.

Se pretende así dar respuesta a las siguientes preguntas de investigación: ¿Existen diferencias significativas en el tratamiento periodístico de la información científica en función del tamaño del medio de comunicación? ¿Qué actividades científicas de las universidades tienen mayor presencia en los periódicos digitales nacionales y cuáles son más visibles en los periódicos locales? ¿Qué áreas de conocimiento son las que más interesan a los periódicos nacionales y cuáles reclaman la atención de los medios locales? ¿Aprovechan unos u otros el potencial de las características propias del ciberperiodismo?

Este estudio formula cuatro hipótesis:

- H1: se predice una dependencia de los gabinetes de comunicación de las universidades en la información científica que publican los cibermedios regionales y locales.

- H2: el tratamiento periodístico de la información científica en los cibermedios nacionales es más profundo y trabajado, ya que estos cuentan con mayores recursos tanto humanos como materiales, frente a los cibermedios de alcance local, más pequeños y con menores recursos. Esto se vería reflejado en aspectos como el género de las piezas periodísticas publicadas (más reportajes, entrevistas y artículos de opinión en los periódicos nacionales y más noticias y breves en los locales), en la autoría de las mismas (principalmente periodistas y expertos en los medios nacionales y más información de agencias y gabinetes en los locales) o en las fuentes (varias fuentes en los medios nacionales y piezas periodísticas de única fuente en los locales).

- H3: los medios nacionales dan una mayor visibilidad al desempeño investigador y al conocimiento aportado por los expertos de las universidades, mientras que los medios locales realizan una cobertura más amplia de eventos. También que, en general, no se refleja la ciencia como colaborativa.

- H4: se presupone que no existen diferencias apreciables en función del alcance del medio en relación a las temáticas que suscitan mayor interés. 
- H5: sí existe una diferencia notable en cuanto al uso de recursos ciberperiodísticos -como el hipertexto o los elementos multimedia- en función del tamaño de los medios, siendo mayor en los medios nacionales, que a priori contarían con plataformas informáticas más avanzadas y un personal más numeroso en las redacciones para elaborar piezas periodísticas más completas.

\section{METODOLOGÍA}

Para contrastar o refutar estas hipótesis se ha diseñado una metodología de análisis mixta, cuantitativa y cualitativa. Por un lado, se realiza un análisis de contenido cuantitativo de piezas periodísticas publicadas en cibermedios: 15 periódicos digitales, 2 de alcance nacional y 13 de alcance regional y/o local. Para localizar dichas piezas se han utilizado los sistemas de búsqueda de estos medios, en los que se han introducido cadenas de palabras clave -en línea con metodologías precedentes (Legerén Álvarez, 2014)- relativas a las denominaciones completas de 23 universidades españolas, en castellano y también en el segundo idioma oficial de la comunidad autónoma, según el caso (Anexo IV).

Los periódicos digitales incluidos en la muestra son aquellos que cuentan con mejores datos de difusión según la OJD (Oficina de Justificación de la Difusión). Respecto a los periódicos de alcance regional y/o local, se han seleccionado aquellos del entorno de las universidades analizadas que igualmente cuentan con mayor difusión, salvo en determinados casos. ${ }^{30}$

Para delimitar las búsquedas se filtraron las piezas periodísticas publicadas en un periodo de 9 meses, entre el 1 de enero y el 30 de septiembre de 2016. Un equipo de cuatro técnicos se encargó de buscar, seleccionar y descargar las unidades de análisis entre el 1 y el 10 de octubre de 2016.

Se elaboró un libro de códigos (Anexo V) y una ficha de análisis de contenido (Anexo VI) compuesta por una batería de variables y respuestas, teniendo en cuenta cuatro dimensiones -tratamiento periodístico, marco mediático, cobertura temática y tratamiento ciberperiodístico- alineadas con los cuatro objetivos específicos del presente estudio. En primer lugar, para ahondar en el tratamiento periodístico se

\footnotetext{
${ }^{30}$ La variabilidad en los sistemas de búsqueda de información de los distintos periódicos ha impedido incluir algunos de estos medios, en concreto los que no permitían realizar búsquedas con los criterios descritos en la metodología, por lo que se han reemplazado por los siguientes periódicos con mayor difusión según la OJD. Por ejemplo, se programó la búsqueda de información en el Diari de Tarragona y en el Diari de Girona pero, debido a las dificultades encontradas en sus buscadores, fueron sustituidos por La Vanguardia.
} 
incluyeron las variables sección, autor, género y fuentes, aplicadas en estudios previos relacionados (Fernández Muerza, 2005; Camacho Markina, 2009).

En segundo lugar, para determinar el marco mediático, se aplicó la Teoría del Frame (Scheufele, 1999; Bubela et al., 2009; Brossard, 2012; Koziner, 2013; ArdèvolAbreu, 2015) y se establecieron seis posibles ecnuadres: la presencia universitaria en el contexto de un estudio o proyecto de carácter científico, tecnológico o innovador desarrollado por la misma; en una actividad o evento científico organizado por la institución; una simple mención en una información científica en la que la universidad no es la protagonista, una valoración sobre algún asunto de actualidad a cargo de un experto de la institución; un artículo de opinión elaborado por expertos de la institución, así como una opción 'otros' para posibles encuadres no definidos. ${ }^{31}$ Además, cuando el encuadre fue un estudio o proyecto de investigación, se midió otra variable, en torno a si se describía o no algún tipo de colaboración, y el alcance de la misma (regional, nacional, europeo o internacional).

En tercer lugar, para definir la cobertura temática, es decir, los campos de conocimientos predominantes en la información científica, se utilizaron las 26 áreas delimitadas por la ANEP (Agencia Nacional de Evaluación y Prospectiva) como entidad de referencia estatal para la evaluación de la calidad de la investigación. ${ }^{32}$

En cuarto y último lugar, para profundizar en el tratamiento ciberperiodístico, se incluyeron variables relativas a los cuatro rasgos básicos del ciberperiodismo postulados por Díaz Noci y Salaverría (2003), multimedialidad -recursos multimedia incluidos en la pieza periodística-, hipertextualidad -posibilidades de macro y micronavegación-, actualización -hora de publicación-, e interactividad -número de comentarios recibidos-.

Posteriormente, se probó la utilidad del libro de códigos y la fiabilidad inter codificadores en una muestra aleatoria de 50 unidades de análisis. Este ensayo se

\footnotetext{
${ }^{31}$ Se eximen del análisis temas relacionados con la gestión económica y formativa de la institución (presupuestos, salarios, implantación y extinción de titulaciones, etc.), referencias a las mismas realizadas en el marco de biografías o currículos en informaciones no protagonizadas por la institución, asuntos políticos, elecciones y nombramientos, sucesos, procesos judiciales y actividades deportivas y de ocio, al entender que no forman parte de la actividad científica de las universidades.

${ }^{32}$ La ANEP comprende 26 áreas temáticas. La clasificación de las áreas refleja la situación de las actividades de I+D que se llevan a cabo en los centros de investigación y universidades españolas. En cada una se ha incluido un descriptor de su contenido (por ejemplo, Área de Ciencias Sociales-CS) que es el que se emplea en la presente codificación. Todas las áreas y descriptores utilizados se presentan a continuación y las áreas que engloban pueden consultarse en el siguiente enlace: http://ow.ly/Wkhv30kt8BN (consultado por última vez el 03/03/2018)
} 
llevó a cabo entre el 11 y el 15 de octubre de 2016. Se obtuvo un coeficiente de fiabilidad satisfactorio (93\%) según las estimaciones de Lombard et al. (2002) y, tras detectar algunas carencias, se actualizó el libro de códigos, formulando nuevas respuestas para algunas de las variables.

Asimismo, para recabar información complementaria se desarrolló una observación de carácter cualitativo. Con dicho estudio se trató de describir, en un diario de campo, información relevante respecto al objeto de estudio derivada de la observación indirecta y no estructurada, registrando datos de interés que, por sus características, no podían ser recogidos en el análisis cuantitativo. Esta parte del trabajo fue realizada igualmente entre el 1 de octubre y el 30 de noviembre de 2016 por los mismos codificadores, quienes registraron sus observaciones en un procesador de textos ( ${ }^{*}$.word) alojado en Google Drive.

Antes de detallar los resultados es preciso realizar una serie de consideraciones generales. Durante las búsquedas programadas se localizaron numerosas informaciones repetidas, todas ellas registradas en los periódicos de alcance regional o local, algunas con distinta fecha e incluso en diferente sección. En estos casos, se decidió seleccionar solo las piezas periodísticas que habían sido publicadas en primer lugar. Además, en el estudio cualitativo se reflejó que, por la hora de publicación de estas informaciones -generalmente las 00.00 o las 01.00 horas a.m.-, podría tratarse de piezas que se vuelcan desde la versión impresa a la versión digital del periódico de forma automatizada.

Por otro lado, el escaso número de piezas periodísticas localizadas en algunos periódicos, como La Vanguardia, sugiere que algunos motores de búsqueda no recuperan adecuadamente la información. También el hecho de que no se hayan seleccionado las piezas periodísticas procedentes de suplementos ha podido influir en el volumen total de resultados, sobre todo en las búsquedas realizadas en periódicos digitales que cuentan con suplementos específicos de la universidad, como Diario Córdoba y su suplemento 'UCOniversitas', tal y como se desprende del estudio cualitativo. En total, 3.137 piezas periodísticas cumplieron con los criterios establecidos y conformaron la muestra.

\section{RESULTADOS}

En líneas generales, la presencia de las universidades fue significativamente mayor en los periódicos de menos tamaño, los de alcance regional y local $(70,25 \%)$, en línea 
con estudios anteriores (Barroso Osuna, 2000; Kim et al., 2007; Herrero-Solana et al., 2014; Repiso et al., 2016).

\subsection{ANÁLISIS COMPARATIVO RESPECTO AL TRATAMIENTO PERIODÍSTICO}

Para responder a la pregunta de investigación relativa a si existen diferencias significativas en el tratamiento periodístico de la información científica en función del tamaño del medio de comunicación se midieron cuatro variables: sección, autor, género y fuentes.

En relación con la sección, no existen diferencias significativas en función del tamaño del periódico. La comparación de las frecuencias relativas indica, en línea con lo expuesto anteriormente, que las piezas periodísticas sobre las universidades se insertan mayoritariamente en la sección 'Local'. Esto sucede en más de un $40 \%$ de los casos tanto en los medios regionales y locales como en los nacionales. Este último dato llama especialmente la atención ya que, incluso los medios nacionales, le otorgan a la información universitaria una perspectiva netamente local.

Muy por detrás de la sección 'Local' se sitúan las secciones ‘Economía', 'Opinión' y 'Cultura' frente a las que, a priori, parecen más propicias como 'Ciencia', 'Salud' o 'Tecnología'.

Tabla 1. Sección donde se inserta la información científica relativa a las universidades.

\begin{tabular}{|ccccc|}
\hline & \multicolumn{2}{c}{ Prensa nacional } & \multicolumn{2}{c|}{ Prensa regional y local } \\
\hline Ciencia & 27 & $2,89 \%$ & 73 & $3,31 \%$ \\
\hline Salud & 32 & $3,43 \%$ & 45 & $2,04 \%$ \\
\hline Tecnología & 26 & $2,79 \%$ & 40 & $1,81 \%$ \\
\hline Sociedad & 43 & $4,61 \%$ & 119 & $5,40 \%$ \\
\hline Cultura & 61 & $6,54 \%$ & 113 & $5,13 \%$ \\
\hline Nacional & 16 & $1,71 \%$ & 41 & $1,86 \%$ \\
\hline Internacional & 12 & $1,29 \%$ & 18 & $0,82 \%$ \\
\hline Local & 390 & $41,80 \%$ & 983 & $44,60 \%$ \\
\hline Política & 14 & $1,50 \%$ & 22 & $1,00 \%$ \\
\hline Economía & 77 & $8,25 \%$ & 148 & $6,72 \%$ \\
\hline Opinión & 59 & $6,32 \%$ & 151 & $6,85 \%$ \\
\hline Otras & 176 & $18,86 \%$ & 451 & $20,46 \%$ \\
\hline Total & 933 & $100,00 \%$ & 2204 & $100,00 \%$ \\
\hline
\end{tabular}




\section{Fuente: elaboración propia}

En cuanto a la autoría, sí se han obtenido diferencias significativas en función del tamaño del medio. Aunque las informaciones firmadas por periodistas son las más frecuentes en ambos casos (un $65,49 \%$ del total en la prensa digital nacional y un $49,32 \%$ en la regional y local), los cibermedios regionales y locales hay una mayor proporción de piezas periodísticas firmadas como 'agencias' $(21,55 \%)$ o 'redacción' $(25,23 \%)$, frente a la prensa nacional, con un $7,61 \%$ y un $7,29 \%$ respectivamente, resultados que difieren en parte a los obtenidos en otros trabajos (Sancha, 2005; Loose y De Lima, 2012; Martín y Ponce, 2012; Ruiz Jiménez et al., 2014). Asimismo, la presencia de artículos de opinión firmados por columnistas es muy escasa en los medios regionales y locales $(3,45 \%)$, mientras que en los nacionales se sitúa en el $19,61 \%$. 
Gráfico 1. Autoría de la información científica relativa a las universidades.

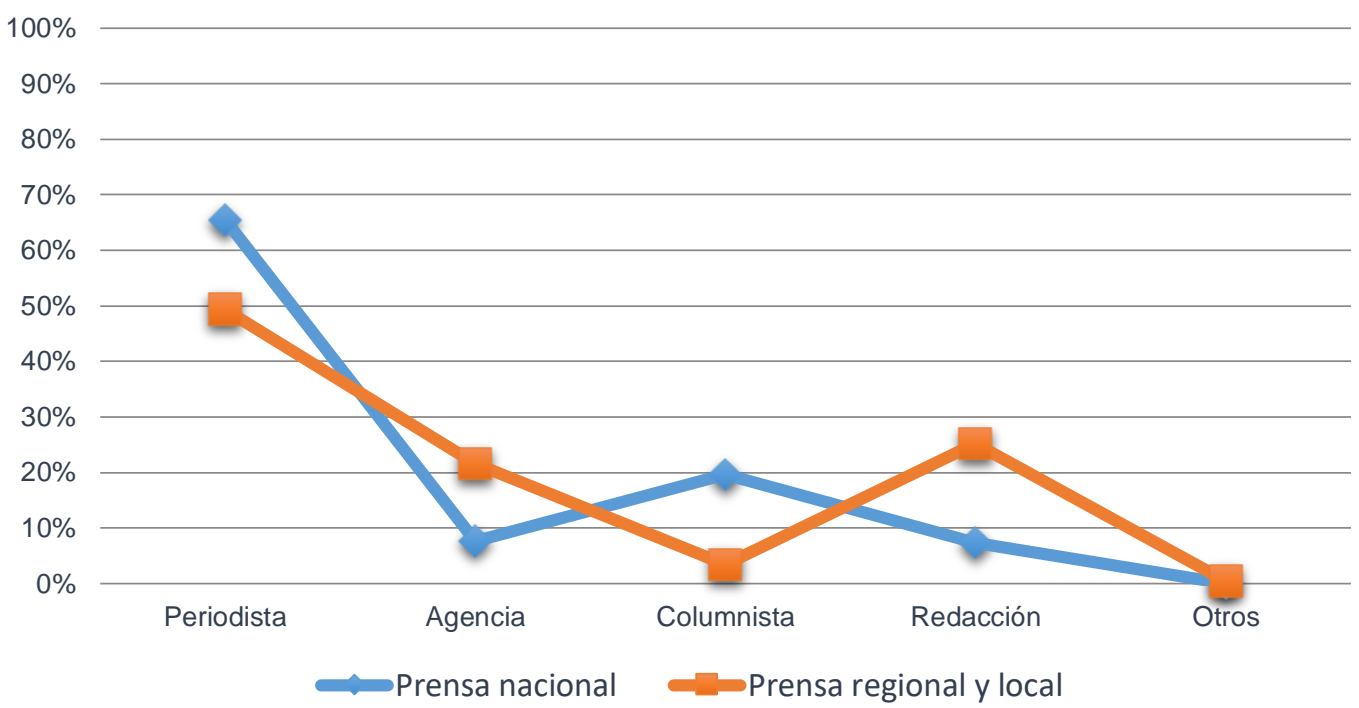

Fuente: elaboración propia

También se han registrado diferencias significativas en el género periodístico. Mientras que casi la mitad de las piezas periodísticas localizadas en la prensa nacional son reportajes $(47,7 \%)$, el género predominante en la prensa regional y local es la noticia $(64,56 \%)$, al igual que refieren otros trabajos (Torres et al., 2014; De Moraes y Maia, 2014).

Asimismo, no se han localizado breves en los medios de alcance nacional, mientras que en los de alcance regional y local el porcentaje si sitúa en el 10,48\%. El estudio cualitativo apunta que en Las provincias se publican frecuentemente breves sobre temas de investigación pese a que, por la complejidad de los mismos, no parece el mejor formato. También en El Diario de Jaén se han localizado numerosas informaciones breves que, para su ampliación, remiten a la edición impresa del periódico, quizás a modo de reclamo de la misma.

En consonancia con los datos relativos a la autoría, tan solo el 3,81\% de los artículos de la prensa regional y local son de opinión, frente al 20,47\% de la prensa nacional. Otro dato reseñable es la escasez de entrevistas registradas en ambos tipos de medios (un $2,14 \%$ y un $3,86 \%$ respectivamente). 
Gráfico 2. Género de la información científica relativa a las universidades.

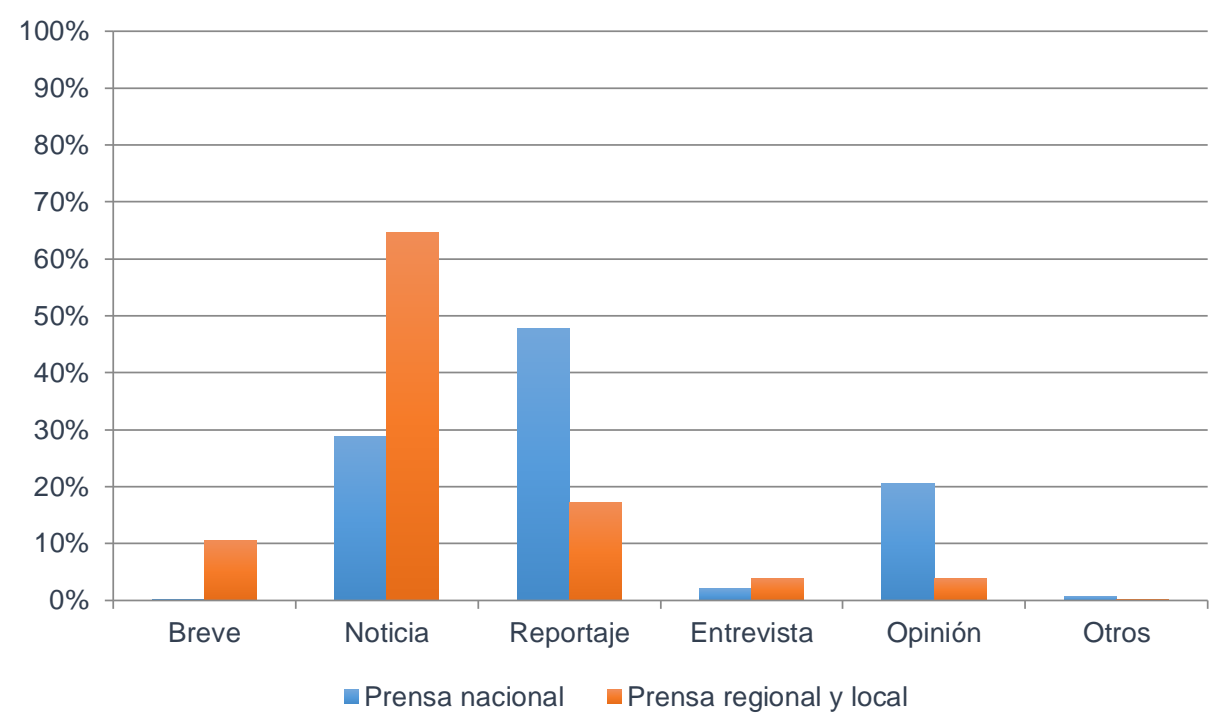

Fuente: elaboración propia

Igualmente, el análisis comparativo de las fuentes muestra grandes diferencias. En los cibermedios nacionales lo más frecuente es citar varias fuentes de información $(52,2 \%)$. Solo en el $28 \%$ de los casos se citó una única fuente. En el caso de los artículos de opinión, la variable se codificó como "no procede" $(18,44 \%)$.

Por el contrario, el periodismo de única fuente es claro y notorio en la prensa regional y local $(54,63 \%)$, pese a ser una práctica periodísticamente desaconsejada (Loose y De Lima, 2012; Taylor et al. 2015). También resalta el hecho de que en el $21,19 \%$ de las piezas periodísticas no se cite ninguna fuente. El estudio cualitativo refleja que, en gran parte de estos casos, se puede deducir que se trata de notas de prensa institucionales publicadas por el medio. 
Gráfico 3. Fuentes de la información científica relativa a las universidades.

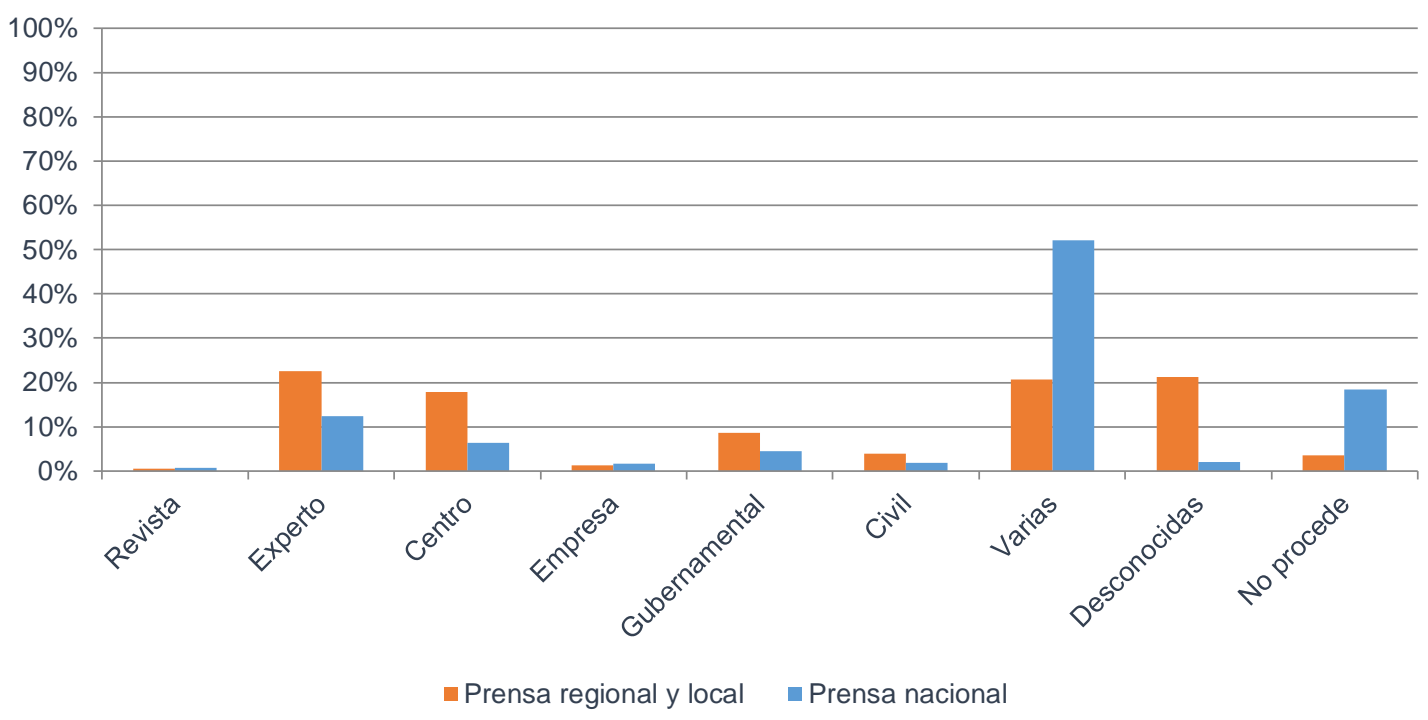

Fuente: elaboración propia

En ambos tipos de medios, los expertos, los centros de investigación, los organismos gubernamentales, las entidades pertenecientes a la sociedad civil, las empresas y las revistas académicas son, por este orden, las fuentes más comunes cuando solo se cita una única fuente.

\subsection{ANÁLISIS COMPARATIVO RESPECTO AL MARCO MEDIÁTICO}

En el caso de los cibermedios nacionales, el marco mediático de las universidades son mayoritariamente las valoraciones de expertos $(38,26 \%)$, quienes aplican sus conocimientos para opinar sobre asuntos de actualidad; mientras que, en el segundo, la principal categoría son los eventos organizados por las universidades $(31,9 \%)$.

Por otro lado, la presencia universitaria en el marco de un artículo de opinión fue, de nuevo, netamente superior en el caso de la prensa nacional (16,83\%). Por el contrario, las frecuencias relativas fueron similares en cuanto a la presencia universitaria en el contexto de un estudio o proyecto de carácter científico, tecnológico o innovador desarrollado por la misma, incluso ligeramente superior en el caso de los medios locales y regionales $(17,68 \%$ frente a $24,18 \%)$. 
Gráfico 4. Marcos de la información científica relativa a las universidades.

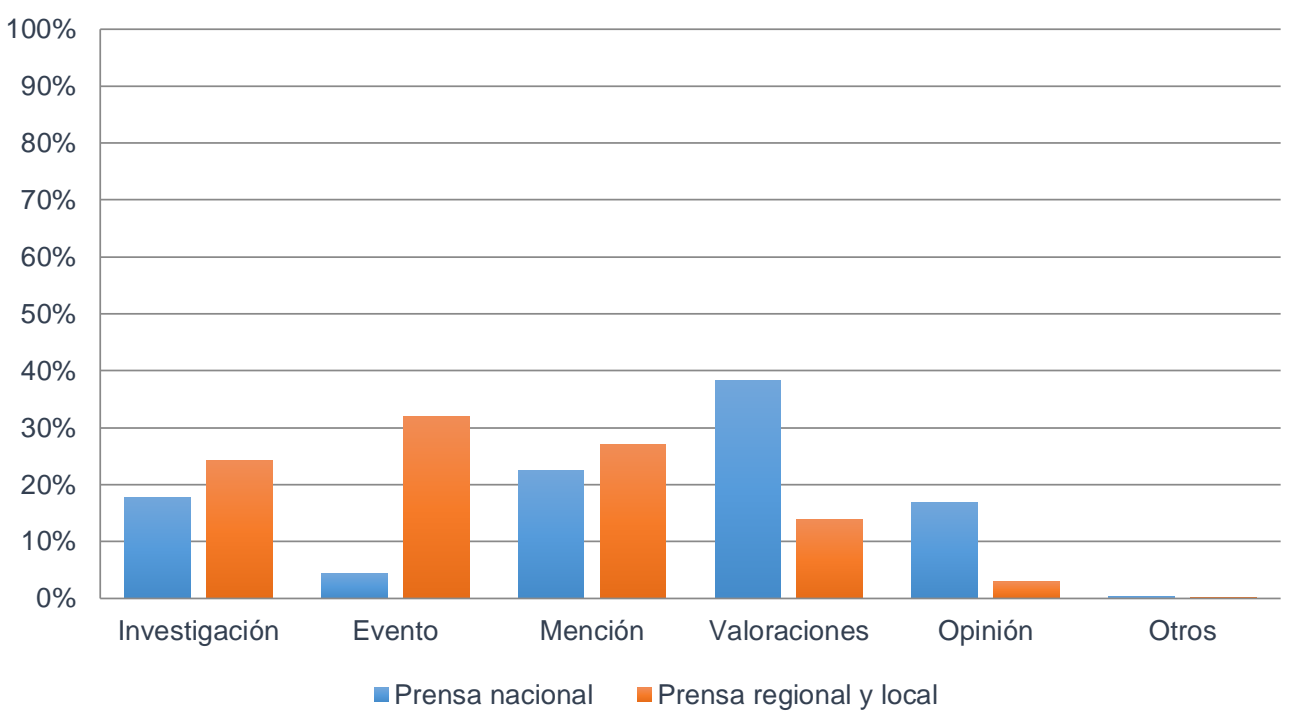

Fuente: elaboración propia

Cuando se recogió este último encuadre, se codificó además una variable relativa a si se nombraba o no algún tipo de colaboración científica, y el alcance de la misma. Las universidades aparecen como actores únicos en el proceso científico en cerca del $40 \%$ de las piezas periodísticas, igualmente, en ambos tipos de periódicos.

En los artículos en los que se menciona algún tipo de colaboración científica sí se han registrado diferencias. En la prensa nacional, en un $32,32 \%$ de los casos la colaboración se establece con entidades nacionales y en un $25,61 \%$ con entidades internacionales ajenas a la UE, en línea con estudios que apuntan al interés de los medios por la ciencia extranjera, fundamentalmente la norteamericana (Banda, 2003; Adam, 2012; Loose y De Lima, 2012; Martín y Ponce, 2012; Pérez-Rodríguez, 2016). En solo un $1,22 \%$ se hace referencia a una colaboración de ámbito europeo, lo que llama la atención teniendo en cuenta que España capta el 9,7\% de la financiación del programa de investigación Horizonte 2020, tal y como recoge el Informe COTEC (2016). 
Gráfico 5. Colaboración científica mencionada en la información científica relativa a las universidades.

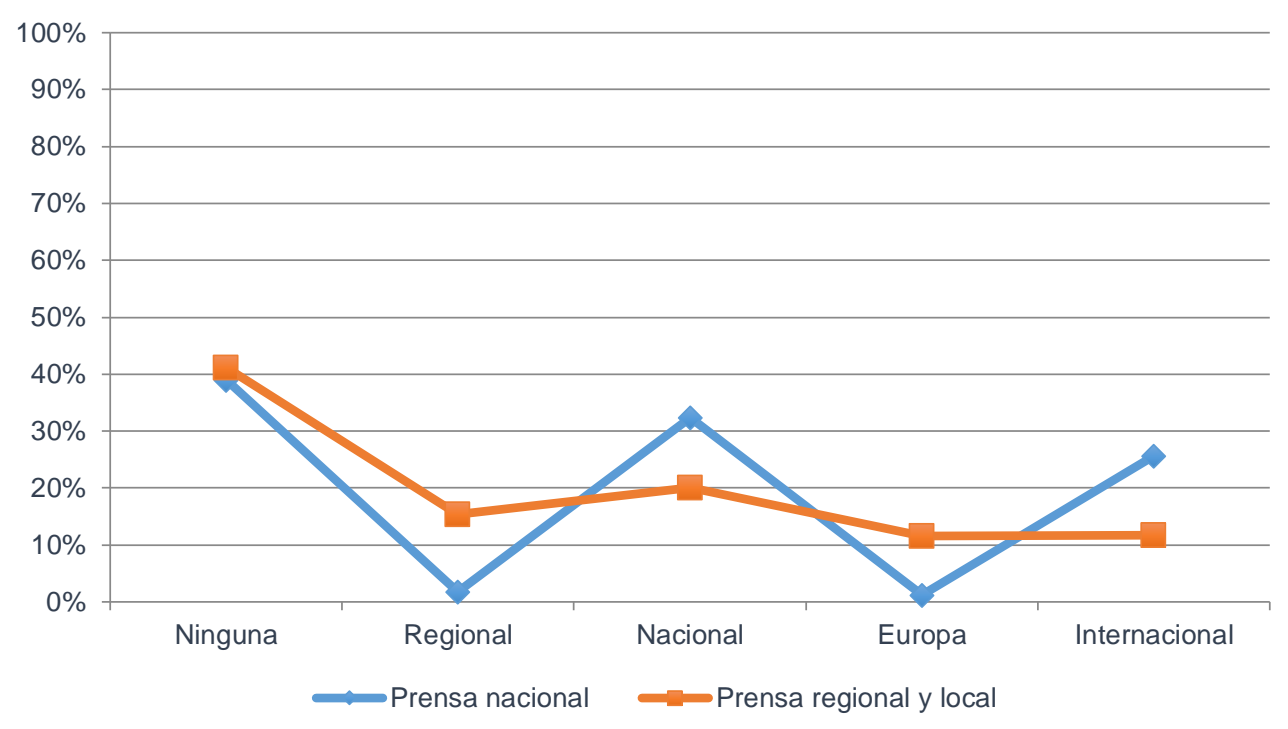

Fuente: elaboración propia

En la prensa regional y local, los porcentajes relativos al alcance de la colaboración indicada son bastante equilibrados, siendo la nacional $(20,11 \%)$ la más frecuente, seguida de la regional $(15,37 \%)$, en congruencia con el criterio noticioso de proximidad geográfica.

\subsection{ANÁLISIS COMPARATIVO RESPECTO A LA COBERTURA TEMÁTICA}

En cuanto a la tercera pregunta de investigación, sobre qué áreas de conocimiento son las que más interesan a los periódicos nacionales y cuáles reclaman la atención de los medios locales, los resultados indican que, en el caso de los primeros, son las Ciencias Sociales $(21,86 \%)$-en las que se engloban disciplinas como las Ciencias políticas y de la Administración, la Comunicación o la Sociología-, Historia y Arte $(10,83 \%)$ y Economía $(10,4 \%)$. Estos resultados podrían relacionarse con el marco principal en el que se inscribe la presencia universitaria en la prensa nacional, las valoraciones de expertos acerca de asuntos de actualidad política, social y económica, tal y como sugiere el estudio cualitativo. 
Gráfico 6. Área temática de la información científica relativa a las universidades.

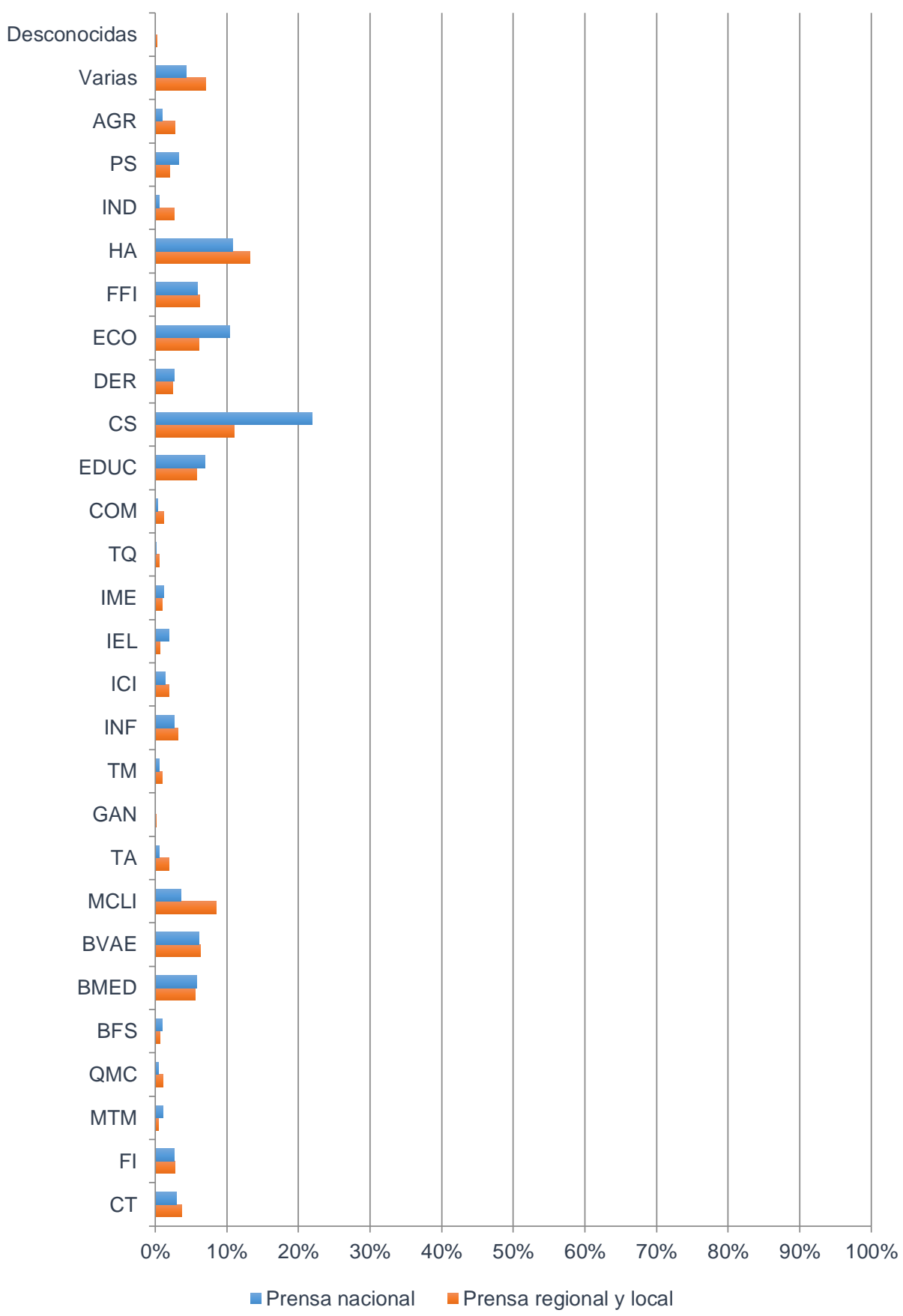

Fuente: elaboración propia

Aunque en el orden inverso, los temas más presentes en la cobertura universitaria a nivel regional y local son de nuevo Historia y Arte $(13,25 \%)$ y Ciencias Sociales $(11,03 \%)$. Después, los porcentajes se equilibran, si bien las temáticas relacionadas con la Salud -Medicina Clínica (8,48\%), Biomedicina (5,54\%) y Biología Fundamental y de Sistemas $(0,96 \%)$ - son las que suscitan un mayor interés (juntas sumarían cerca 
del 15\%), al igual que sugieren otros estudios (Martín y Ponce, 2012; Ruiz Jiménez et al., 2014). La naturaleza del propio tema, de interés general, podría explicar que llame la atención mediática y sea uno de los preferentes (Tian y Stewart, 2005; Cullen, 2013). Es destacable en ambos casos el buen dato registrado por el área Historia y Arte.

El estudio cualitativo recoge algunas puntualizaciones en relación con temáticas concretas, como Matemáticas. El porcentaje de artículos relativos a esta área es mayor en la prensa nacional debido a la presencia de secciones permanentes como 'Café y Teoremas' en El País.

\subsection{ANÁLISIS COMPARATIVO RESPECTO AL TRATAMIENTO CIBERPERIODÍSTICO}

Por último, se ha tratado de responder a la pregunta de si los medios digitales estudiados aprovechan el potencial de las características propias del ciberperiodismo. En relación con el uso de recursos y narrativas multimedia, los resultados muestran una muy limitada utilización de los mismos. Al igual que en la prensa impresa tradicional, los periódicos digitales utilizan mayoritariamente como único recurso la fotografía, lo que indica que, pese al potencial de los cibermedios en este ámbito, ni los periódicos con mayores recursos han apostado aún por enriquecer sus piezas periodísticas con estos elementos, al igual que ponen de manifiesto otros estudios (Martín y Ponce, 2012). Tampoco las galerías fotográficas, como contenedores de varias fotografías sobre un mismo asunto, obtienen datos considerables. 
Gráfico 7. Uso de recursos multimedia en la información científica relativa a las universidades.

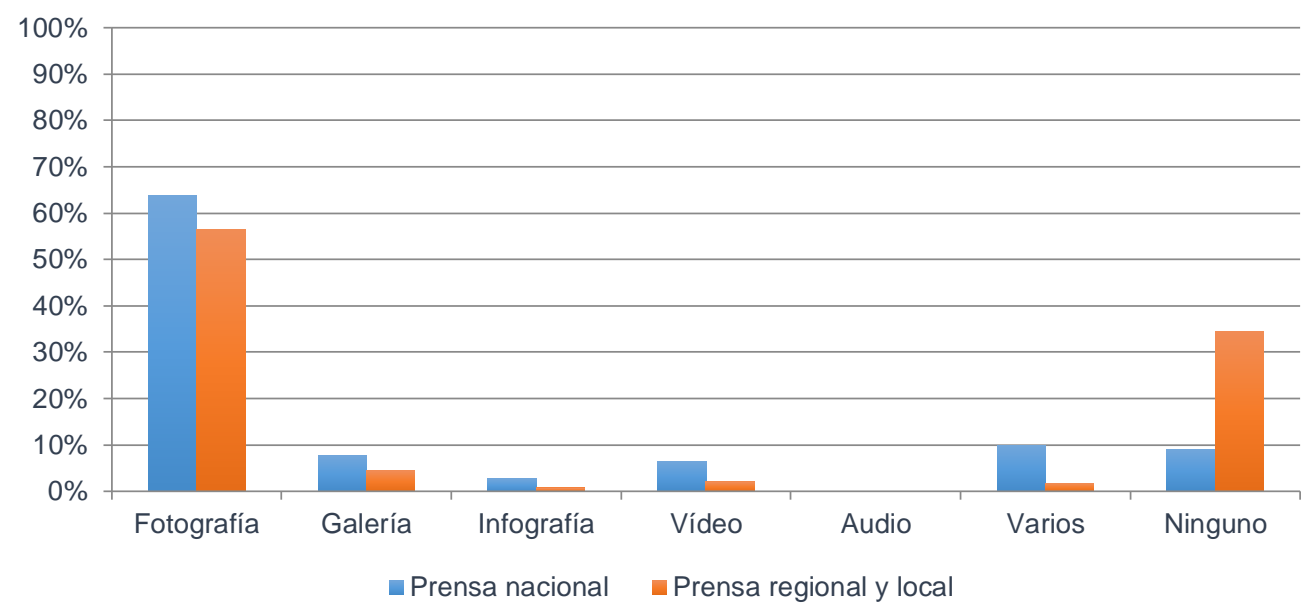

Fuente: elaboración propia.

Aunque la situación es similar en ambos tipos de medios, en los de alcance nacional sí parecen existir algunos atisbos, aunque tímidos, por incorporar otro tipo de elementos ajenos a la imagen fija. Un $9,97 \%$ de las piezas periodísticas de estos periódicos incorpora ya varios recursos (multimedialidad), un porcentaje que se reduce al $1,77 \%$ en el caso de los medios regionales y locales. En estos últimos, es destacable que el $34,53 \%$ de los artículos periodísticos analizados no va acompañado por ningún elemento, que en general la infografía se utilice de forma prácticamente residual y que no se haya localizado ningún audio, lo que sugiere una notable infrautilización del potencial digital, pese a constituir este uno de los principales valores de los cibermedios en relación con la información científica (Byrne et al., 2002; Rodrigues Pereira et al., 2014).

En relación con la característica de hipertextualidad, las diferencias sí son sustanciales en función del alcance del medio. En una de cada cuatro piezas periodísticas de los periódicos nacionales existe posibilidad de macronavegación enlazar a otras páginas web ajenas al medio- y de micronavegación -enlazar a páginas del mismo medio- (Díaz Noci y Salaverría, 2003) de forma paralela. En los artículos en los que solo es posible uno u otro tipo de navegación, predomina la micronavegación $(26,26 \%)$ frente a la macronavegación $(11,04 \%)$.

No obstante, en una proporción elevada de artículos $(37,19 \%)$ no se incluye ningún tipo de enlace, lo que indica que los avances en este sentido son aún exiguos. Este porcentaje se eleva hasta el $90,11 \%$ en los periódicos regionales y locales, un dato 
que revela el total retardo de los medios más pequeños en cuanto a las posibilidades de lectura hipertextual, en consonancia con otros estudios (Bell, 2012; Martín y Ponce, 2012). Según el estudio cualitativo esto puede deberse a que se trata de informaciones publicadas en la edición impresa que se suben a la web de forma automática sin añadir este elemento, como sugiere el hecho de que la hora de publicación que figura en buena parte de ellas, de madrugada, sea coincidente.

Gráfico 8. Uso de hipertexto según el alcance de medio.

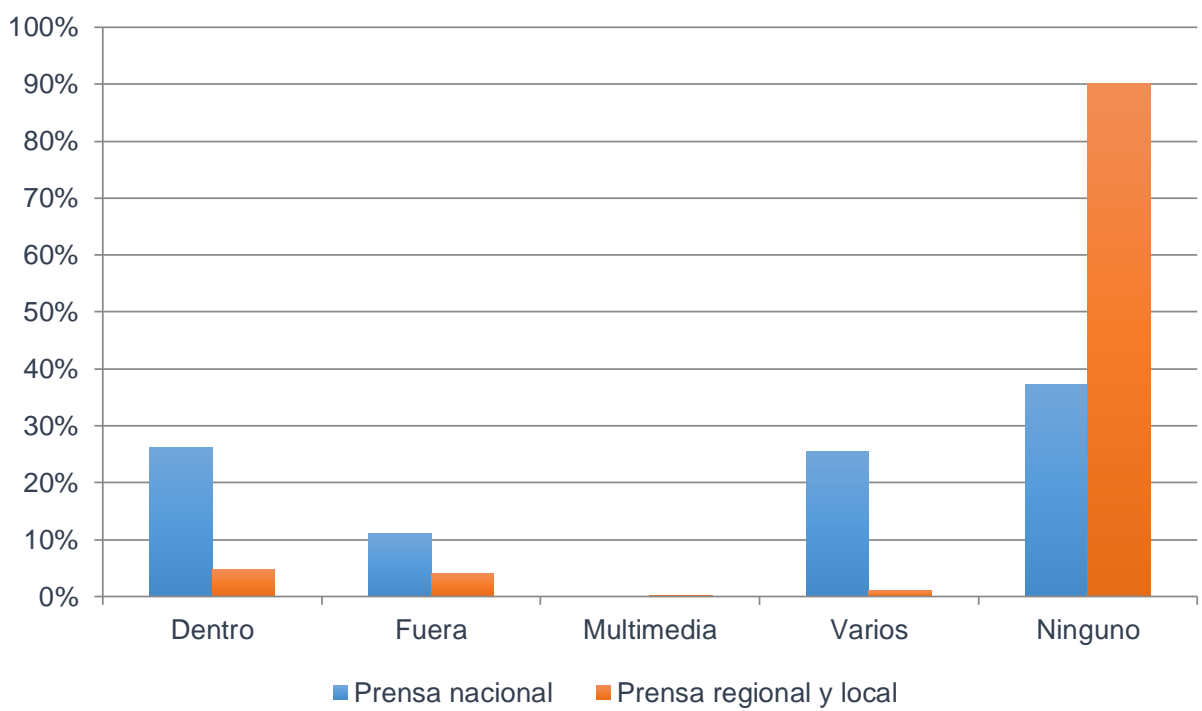

Fuente: elaboración propia.

La actualización permanente es otro de los rasgos fundamentales de los cibermedios. Esto ha supuesto la implantación de redacciones permanentes, activas las 24 horas del día, y la necesidad de publicar primero una información para adelantarse a la competencia (Dunwoody, 2014). Los resultados obtenidos muestran claramente esta tendencia. La información se actualiza a lo largo de todo el día, equilibradamente, en todos los medios independientemente de su tamaño, tal y como muestra la escasa dispersión de las líneas del siguiente gráfico. 
Gráfico 9. Actualización de las piezas periodísticas según el alcance del medio.

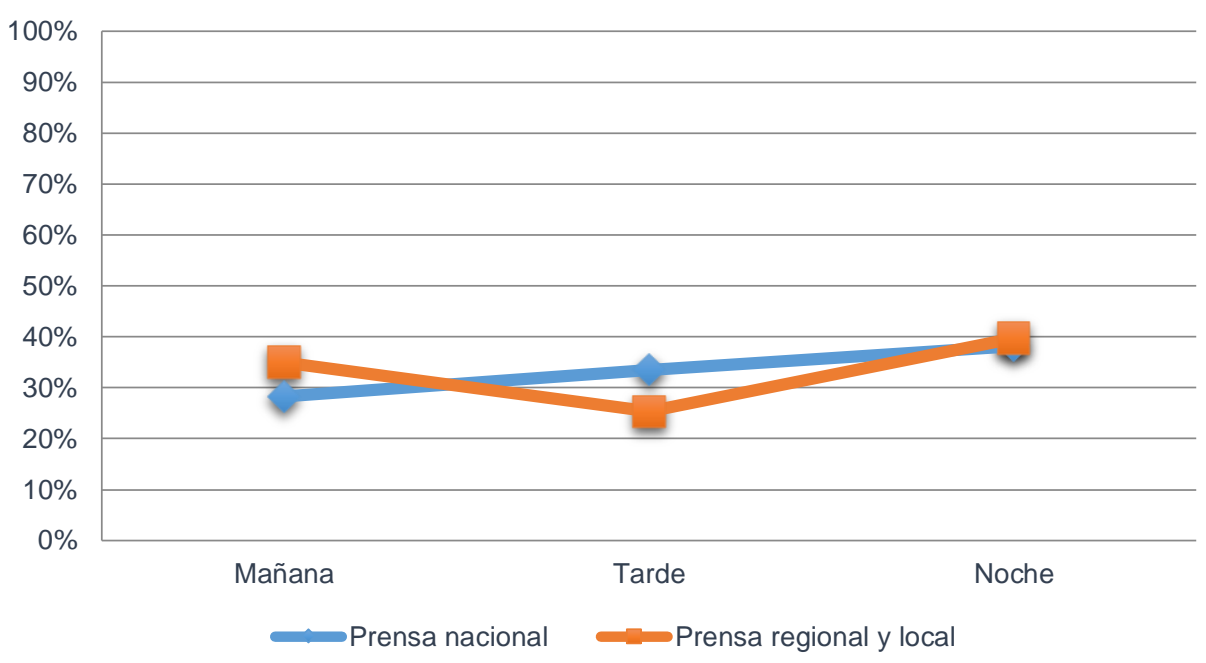

Fuente: elaboración propia.

El estudio cualitativo recoge que en algunas piezas periodísticas y en el total de los artículos tomados de El Diario de Jaén y de El Periódico de Aragón no aparece indicada la hora de publicación, lo que supone que en el $33,26 \%$ de las informaciones de los periódicos regionales y locales se desconoce el momento de actualización.

Para estudiar el rasgo de la interactividad se contabilizó, concretamente, el número de comentarios recibidos en cada artículo periodístico. Se seleccionó esta forma de interacción como una de las herramientas que contribuyen a crear un ambiente participativo y dialógico en el entorno online, haciendo del lector más que un simple consumidor de información científica (Montgomery, 2009; Luzón, 2013) y contribuyendo a salvar la tradicional desconexión percibida entre científicos y legos (Thorsen, 2013).

Las diferencias son palpables en los periódicos analizados. Mientras que los de alcance nacional contabilizaron un total de 33.073 comentarios (una media de 35,44 comentarios por artículo), los de alcance regional y local registraron 1.142 (una media de 0,51 comentarios por artículo). Esto puede ser debido a la lógica de que un mayor número de lectores realiza un mayor número de comentarios. Sin embargo, es llamativo que los periódicos de alcance regional y local, los que publican asuntos del entorno más cercano y, por tanto, que pueden implicar directamente a sus lectores, no registren ni siquiera un comentario por artículo. Es decir, pese a las posibilidades de participación de los lectores en la información universitaria relativa a su entorno 
cercano, esta posibilidad apenas registra interés y en la práctica no se está produciendo.

Además, en el 0,43\% de los artículos tomados de la prensa nacional y en el 3,94\% de los de la prensa regional y local no existe posibilidad de realizar comentarios. La observación cualitativa apunta que, en el caso de los periódicos nacionales, el porcentaje se relaciona con algunas piezas periodísticas publicadas en El País, principalmente en la sección de opinión.

\section{CONCLUSIONES Y DISCUSIÓN}

El estudio de caso realizado sugiere que la dependencia informativa de fuentes organizadas -concretamente, de los gabinetes de comunicación de las universidadesen el periodismo científico online está directamente relacionada con el tamaño del medio de comunicación, evidenciando la tesis propuesta en la $\mathbf{H 1}$.

Además, el tamaño del medio es un factor clave en el tratamiento periodístico de la información científica y en el tipo de cobertura mediática que reciben las universidades $y$, por tanto, en la imagen de estas que recibe la sociedad. Es decir, en función del tipo de medio que se consuma, los lectores reciben una u otra imagen de la ciencia y de las instituciones de educación superior. Los desiguales recursos humanos y materiales de los que disponen unos y otros cibermedios se observan claramente en el análisis realizado e inciden directamente en el tratamiento periodístico de la información científica, tal y como predecía la $\mathbf{H} \mathbf{2}$.

En los medios de alcance nacional, con mayores recursos, la cobertura es más profunda y profesional como demuestra que el $85 \%$ de las informaciones sean firmadas por periodistas o columnistas, que el género predominante sea el reportaje, que una de cada 5 piezas periodísticas sea un artículo de opinión o que lo habitual sea citar varias fuentes de información.

Por el contrario, los medios de alcance regional y local, que cuentan con menores recursos, realizan una cobertura científica más amplia en cuanto a cantidad, pero más superficial y dependiente de las notas de prensa y las convocatorias emitidas por los gabinetes de prensa de las universidades. Lo evidencia el hecho de que la proporción de piezas firmadas por periodistas (49\%) sea prácticamente igual a la suma de informaciones firmadas por agencias o por la redacción (47\%), el uso de los formatos más reducidos, como noticias y breves, el predominio del periodismo de única fuente o que el principal encuadre de la información universitaria sea el de los eventos que estas instituciones organizan. 
Los resultados sugieren que los gabinetes de comunicación universitarios están dirigiendo, consciente o inconscientemente, la cobertura de la ciencia que lleva a cabo la prensa digital de su entorno cercano. Por el contrario, las posibilidades de control institucional en la prensa digital nacional se tornan muy escasas, ya que en estos medios los periodistas parecen seguir realizando las funciones tradicionales del periodismo científico -selección de información, búsqueda de diversos puntos de vista, vigilancia, contraste de fuentes, etc. (Hayes et al., 2007)-, de modo que la presencia de la información científica se relaciona mayormente con la consulta que los periodistas realizan a los académicos como fuentes expertas (55\%).

En relación a la H3 se confirma solo en parte, ya que se ha comprobado que los cibermedios regionales y locales sí realizan una cobertura más amplia de eventos y que los cibermedios nacionales otorgan una mayor visibilidad al conocimiento aportado por los expertos, pero en ningún caso la investigación universitaria tiene un lugar predominante en la prensa nacional. Incluso, los cibermedios regionales y locales registran una cobertura ligeramente mayor de este tipo de asuntos frente a los nacionales.

En esta misma línea, es posible concluir que ambos tipos de medios ofrecen una imagen de la investigación universitaria un tanto atomizada, poco colaborativa y escasamente internacionalizada. Pese a ello, la Estrategia para la Internacionalización de las Universidades Españolas 20015-2020 no recoge entre sus objetivos operativos la importancia estratégica de la comunicación.

La H4, que presupone la inexistencia de diferencias apreciables en relación a las temáticas que suscitan mayor interés en ambos tipos de medios, ha sido confirmada en este trabajo empírico. Las temáticas políticas, económicas y sociales son las más frecuentes en la cobertura universitaria y, más allá, las áreas de Historia y Arte y las relacionadas con la Salud son las que más llaman la atención en ambos tipos de periódicos. Es destacable el caso de Historia y Arte, que no se ha reportado en otros estudios. No parece existir una explicación aparente al respecto, por lo que serían necesarias nuevas investigaciones para aclarar este hecho.

Finalmente, la H5 prevé diferencias notables en cuanto al uso de recursos ciberperiodísticos en función del tamaño de los medios. También esta hipótesis ha podido confirmarse casi en su totalidad, ya que, en los periódicos nacionales, con mayores medios técnicos y humanos, se han registrado avances significativos en relación a los rasgos básicos del ciberperiodismo: hipertextualidad, actualización e 
interactividad. En cambio, en los periódicos regionales y locales solo la característica relativa a la actualización permanente ha obtenido unos resultados considerables.

En relación con la multimedialidad, se puede concluir que es la asignatura pendiente en ambos tipos de medios. Este rasgo básico del ciberperiodismo presenta escasos avances y constituye sin duda un reto de futuro sobre todo para la cobertura de la información científica. Pese a que la Web posibilita la realización de un tratamiento multimedia de los contenidos, conjugando texto, imágenes, gráficos, vídeo y audio para facilitar la comprensión por parte del público y tener una visión más contextualizada y multidimensional de este tipo de mensaje periodístico especializado, aún no se ha producido una evolución y la cobertura sigue siendo equivalente a la de la prensa impresa tradicional, con el predominio de la fotografía fija.

En resumen, pese a las limitaciones del trabajo, ${ }^{33}$ este análisis comparativo ha permitido evidenciar que el tamaño del cibermedio está mediando en la dependencia de la información científica de fuentes organizadas, como son los gabinetes de comunicación universitarios, unas oficinas en auge gracias a las facilidades que les brinda Internet. Tambien que el tamaño del medio tiene influye en el tratamiento de la información, en los marcos mediáticos y en el tratamiento ciberperiodístico de la ciencia.

En cuanto a la dependencia informativa que se ha observado en los cibermedios más pequeños, la situación tiene importantes implicaciones respecto a la profesión periodística y a la ética profesional. En unos medios con plantillas reducidas de periodistas que, con probabilidad, no son especializados, parece que efectivamente la elaboración de información científica se está "externalizando" a la comunicación institucional, tal y como sugerían algunos autores (Moraes y Maia, 2014; Zhang, 2018). En los cibermedios pequeños, la reescritura de notas de prensa o churnalism (Murcott y Williams, 2013; Shäfer, 2017) es frecuente en el ámbito de la información científica, lo que es contraproducente en relación al papel del periodismo como contrapoder de la ciencia. Para paliar esta situación, es fundamental que los cibermedios pequeños encuentren un modelo de negocio que les permita no solo sobrevivir, sino poder desempeñar su actividad periodística de manera profesional, con garantías de libertad e independencia.

\footnotetext{
${ }^{33}$ Las limitaciones de la tesis se presentan en el bloque IV apartado 1, agrupadas por cada parte del estudio.
} 


\section{BLOQUE IV}

CONSIDERACIONES FINALES 


\section{REFLEXIONES FINALES}

Como se planteaba al inicio, el fin último de esta tesis doctoral ha sido ahondar en la comunicación de la ciencia en Internet como objeto de investigación, bajo la premisa de que Internet ha originado una revolución en la forma en que se comunica la ciencia $y$, en concreto, en el periodismo científico. Para ello, se ha llevado a cabo una revisión que ha permitido recopilar, organizar y evaluar las aportaciones académicas realizadas hasta el momento en esta línea, que se encontraban dispersas y sin un hilo conductor claro, para ponerlas a disposición de la comunidad científica (González-Pedraz y Campos-Domínguez, 2015; González-Pedraz y Campos-Domínguez, 2017). También se ha tratado de contribuir a un mayor conocimiento y comprensión del fenómeno mediante la realización de un estudio de caso en torno a un objeto clave detectado en dicho trabajo de revisión, la dependencia informativa de fuentes organizadas referida en la literatura (González-Pedraz et al., 2017). Fruto de este trabajo se pueden aportar una serie de reflexiones finales en torno a algunos asuntos específicos reportados en estas páginas.

\section{Las dificultades para filtrar información científica veraz y de calidad en} Internet: algunas aportaciones.

Sin duda, las dificultades que están encontrando los usuarios para localizar información científica, o de cualquier otro tipo, fiable y veraz en la Web, es uno de los mayores problemas a los que se enfrenta la actual sociedad digital. En el caso concreto de la información científica, del tradicional esquema comunicativo de mediación-monopolización periodística se ha pasado a otro de desintermediacióndemocratización basado en la multiplicidad de agentes presentes online. Sin obviar que el primer esquema no estaba exento de problemas y dificultades que se han reportado históricamente en la literatura -desde el paternalismo que impregna la filosofía del modelo de déficit al tradicional cruce de críticas entre la fuente científica y los periodistas-, el nuevo esquema, pese a lo democrático, ha traído nuevas complicaciones.

Si bien es cierto que, en la actualidad, los usuarios tienen acceso a más información científica que nunca en la historia, la multiplicidad de agentes emisores en el nuevo panorama comunicativo está obstaculizando enormemente el acceso a información científica contrastada y de calidad.

Todos estos agentes que, tradicionalmente, habían sido fuentes informativas para los periodistas científicos -universidades y centros de investigación, científicos, revistas científicas, agencias, empresas, organizaciones políticas, organizaciones 
prociencia, organizaciones contra la ciencia, etc.- hoy pueden comunicar sus mensajes interesados directamente con la audiencia sin necesidad de pasar por el filtro periodístico, gracias a las facilidades de publicación y acceso que ha traído Internet y sus herramientas asociadas -redes sociales, blogs, APPs, etc.-. De este modo, Internet ha transformado radicalmente el proceso de comunicación pública de la ciencia, pasando de una estructura lineal, en el que el canal representa un elemento más de esa línea, a un proceso integrado en el que el canal ejerce un papel protagonista, aglutinando y posibilitando a todos los elementos. 
Figura 1. Representación del proceso tradicional de transmisión de información científica vs proceso online.

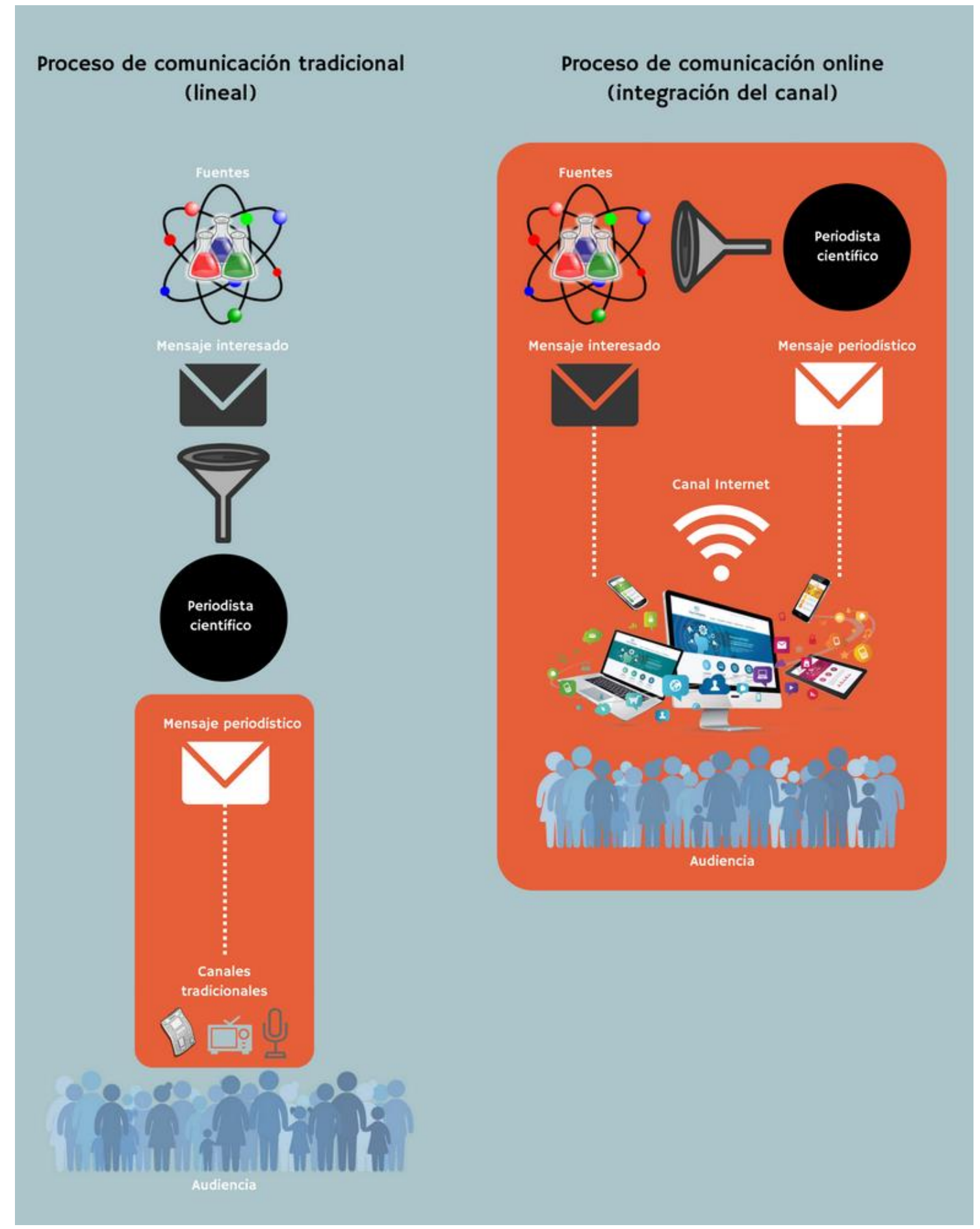

Fuente: elaboración propia

Todos estos contenidos interesados, "disfrazados" de noticia, son muchas veces difíciles de detectar incluso para los propios profesionales del periodismo. Por ello, se proponen algunas medidas que pueden ayudar a mitigar este importante problema. En 
primer lugar, se plantea la creación de un sello para distinguir a aquellos portales y entidades que proporcionan información y contenidos científicos online de calidad en España. Este sello, que sería emitido por la autoridad competente -en este caso, quizás, el Ministerio de Economía y Competitividad a través de la Fundación Española para la Ciencia y la Tecnología (FECYT)-, podría basarse en el cumplimiento de una serie de indicadores de calidad, tal y como ya se hace en la evaluación de las revistas científicas españolas a través del proyecto ARCE. ${ }^{34}$ Aunque sería necesario un estudio en profundidad, estos indicadores deberían evaluar criterios relacionados con la transparencia editorial, la independencia informativa, las prácticas relativas a la recogida y elaboración de los contenidos, el rigor y veracidad de los mismos, las posibilidades de participación por parte de los usuarios, la actualización de los contenidos, el acceso abierto o el almacenamiento de la información y sus posibilidades de recuperación posterior.

Además de ayudar a mejorar los problemas de fiabilidad de la información científica en Internet, el disponer de portales de calidad contrastada contribuiría a otros ejes de actuación importantes que guían cualquier práctica relacionada con la comunicación pública de la ciencia, incluidas las periodísticas: el fomento de la cultura científica y la divulgación, el apoyo a la I+D+i como elemento clave para el progreso de los pueblos, el incremento de la participación social en la ciencia o el fomento de las vocaciones científicas y tecnológicas entre los más jóvenes, sobre todo entre las niñas.

Una iniciativa reciente muy interesante en esta línea es el Observatorio PerCientEx de periodismo científico, un proyecto que cuenta con la colaboración de la Obra Social 'La Caixa', promovido por la Associación Catalana de Comunicación Científica (ACCC), cuyo fin es recopilar ejemplos de periodismo de calidad impreso y digital en el ámbito iberoamericano. La iniciativa continúa la línea del Proyecto PerCientEx: Excelencia e Innovación en el Periodismo Científico en España, impulsado por estas entidades con la colaboración de la Fundación Española para la Ciencia y la Tecnología (FECYT). El objetivo es recopilar aquellos artículos de periodismo científico que destaquen por su innovación, trabajo investigativo, por el uso de nuevas narrativas o periodismo de datos en temas de ciencia y difundirlos a través de Internet. ${ }^{35}$

\footnotetext{
34 Más información sobre el proyecto ARCE de apoyo a la profesionalización e internacionalización de las revistas científicas: http://ow.ly/u1BO30kagll (última consulta 08/03/2018)

${ }^{35}$ Más información sobre el Observatorio PerCientEx: http://ow.ly/nnRA30kqgla (última consulta 08/03/2018)
} 
Una mayor colaboración entre periodistas y científicos en Internet, clave para mejorar la calidad de la información. Apuesta por un mejor conocimiento mutuo apoyado en la formación.

De la instantánea tomada en este trabajo también se puede concluir que periodistas y científicos deben aprovechar mejor sus potencialidades en pro de la mejora de la comunicación pública de la ciencia, un factor clave en una sociedad cada vez más influenciada por la ciencia y la tecnología, y en la que existe la necesidad de que los ciudadanos conozcan mejor la influencia de estos avances en sus vidas, para que tomen decisiones o adopten posiciones informadas (Cazaux, 2016).

Ambos, periodistas y científicos, cuentan con puntos fuertes, conocimientos y habilidades que, aglutinadas, permitirían un salto cualitativo en cómo se está seleccionando, produciendo y difundiendo actualmente la información científica en Internet. Por un lado, el científico dispone del conocimiento experto y de la experiencia en las dinámicas del trabajo investigador y de la publicación académica, lo que posibilitaría mejorar algunas de las tareas más complicadas para el periodista científico, como son la selección y el filtrado de la investigación que llega a las redacciones, su valoración, el enfoque y el tratamiento más adecuado, o la descripción de conceptos complejos. Por otro lado, el periodista puede aportar sus conocimientos sobre cómo debe ser la redacción de un texto dirigido a un público general, la explotación de recursos multimedia para una mejor comprensión de los conceptos científicos, su conocimiento sobre la audiencia y los canales de difusión, o la ética y los códigos profesionales que otorgan a la información periodística una credibilidad fundamental -como son el contraste de la información o el papel de watchdog desenmascarando intereses ocultos, malas praxis, riesgos, etc.-

Para llegar a esta suma de esfuerzos entre científicos y periodistas se debería partir de un mayor conocimiento mutuo: que los científicos se interesen más en conocer el funcionamiento de los medios de comunicación, los entresijos del trabajo de los periodistas y el porqué de algunas de las prácticas que rebaten, y que los periodistas conozcan de cerca el trabajo diario de la investigación, para evitar la "mitificación" de los resultados y mostrar la ciencia como el proceso que es.

La formación es fundamental en este sentido. Por un lado, que las titulaciones universitarias, independientemente de la rama de conocimiento a la que se adscriban, pongan a disposición de los alumnos una asignatura u otro tipo de formación complementaria sobre comunicación, tanto formal -teniendo en cuenta que buena parte de cualquier carrera profesional depende de lo bien que se comunique en congresos, artículos académicos, proyectos de investigación y de innovación, etc.-, como informal. Al mismo tiempo, es conveniente que los periodistas conozcan de 
primera mano la investigación, desarrollando sus propios trabajos, como ya se está produciendo con los nuevos grados, y ampliando su formación de posgrado y doctorado.

\section{La figura del periodista científico, más importante en el actual contexto de la información científica en Internet.}

Al inicio de este trabajo se plantearon diversos interrogantes en relación con el periodismo científico y la profesión periodística que se han ido desarrollando a lo largo de los capítulos, entre ellas: ¿Cuál es la situación del periodista científico en el nuevo entorno online? ¿Qué papel desempeña en este nuevo panorama? ¿Están otros actores desplazando al periodista en su papel de "mediador" entre la ciencia y el público? ¿Sigue siendo necesaria la figura del profesional periodista? ¿Qué valor añadido aporta en el actual contexto de la comunicación de la ciencia online?

Como se ha señalado, en Internet crear una página web, un blog o un perfil en redes sociales es libre y la forma es la misma para cualquier interesado en emitir información científica, ya sea o no un periodista profesional. Así, la autoría de este tipo de contenidos se diluye y tanto periodistas profesionales como el resto de los actores online comparten los mismos espacios y compiten por las mismas audiencias. Pero el periodista tiene la posibilidad de ofrecer más y mejores contenidos que buena parte de estos emisores.

Tal y como sugiere el estudio de caso realizado, cuando un medio de comunicación tiene una estructura y unos recursos suficientes, es decir, cuando cuenta con una plantilla importante de periodistas y con periodistas especializados en materias como ciencia, éstos siguen llevando a cabo las tradicionales funciones de selección de información, búsqueda de diversos puntos de vista, vigilancia o contraste de fuentes. En estos casos, como apunta el trabajo de campo, la influencia de los gabinetes de comunicación institucionales es exigua y los contenidos científicos difundidos gozan de una calidad más que aceptable.

Así, la búsqueda de un modelo de negocio viable para la prensa digital más modesta parece fundamental para contar con más periodistas y con periodistas especializados y, con ello, generar información científica de mayor calidad, ajena a las notas de prensa y convocatorias que emiten las organizaciones y que llegan en masa a las redacciones de todos los medios. El hallazgo de este modelo de negocio es especialmente relevante para que los medios locales y regionales puedan elaborar información independiente sobre la $\mathrm{I}+\mathrm{D}+\mathrm{i}$ que se genera en su entorno, que ahora llega a sus numerosos lectores modulada. 
Por ello, se considera que el periodista científico, lejos de ser un profesional "en extinción", como apuntan muchos estudios, debe enfrentar el futuro con optimismo, ya que, con los recursos suficientes, su papel puede ser fundamental en este entorno online donde es difícil distinguir el "grano" de la "paja".

Aunque se pone en valor la figura del periodista científico, también es importante que este profesional sea consciente de los retos a los que se enfrenta, que han sido desgranados a lo largo del presente trabajo, y del valor añadido que puede y debe aportar. Ahora más que nunca, es fundamental que el periodista científico se esfuerce en visibilizar que está sujeto a unas normas éticas y a un código deontológico profesional que le diferencia y le sitúa una posición privilegiada en cuanto a fiabilidad, veracidad e independencia frente al resto de emisores de contenidos científicos en Internet.

El periodista científico también debería hacer un mayor esfuerzo en reciclarse y en formarse continuamente para no quedarse atrás en la evolución de la narrativa digital. También en el aprovechamiento de las oportunidades que ofrece la web, la posibilidad de diversificar fuentes, ampliar el contexto y perspectiva de los temas, acercarse al día a día de los laboratorios y "humanizar" la ciencia, el potencial creativo que la web ofrece en relación a la creación y difusión de contenidos científicos multimedia o la aproximación a las nuevas tendencias del ciberperiodismo. 


\section{LIMITACIONES DE LA INVESTIGACIÓN}

Este trabajo trata de contribuir a la investigación de la comunicación de la ciencia en Internet y de las implicaciones que este nuevo contexto está teniendo en el periodista científico. Los resultados obtenidos no son definitivos, sino que suponen una aportación más a este campo en el que, como hemos apuntado a lo largo del trabajo, se requiere mucha más investigación.

El trabajo de revisión sistematizada planteado en esta tesis doctoral presenta ciertas limitaciones que han podido influir, de algún modo, en los resultados y en las conclusiones obtenidas. En referencia a la búsqueda y selección de los artículos que han compuesto la muestra final, el rastreo se ha acotado a siete bases de datos de referencia, no obstante, existen otras muchas bases de datos de publicaciones científicas que también podrían haberse utilizado. Del mismo modo, el sistema de búsqueda empleado, una lista de descriptores básicos en tres idiomas referentes a la comunicación de la ciencia en Internet, no garantiza que se haya localizado la totalidad de referencias sobre nuestro objeto de estudio. La selección y restricción idiomática al inglés, castellano y portugués, pese a la importancia de estos idiomas, es otra salvedad clara ya que se relegan los artículos publicados en otros idiomas. Por otro lado, es importante aclarar que la revisión sistematizada es un estudio de carácter descriptivo y comparativo, no un trabajo deductivo y representativo estadísticamente.

Asimismo, la falta de trabajos similares en otros campos de la comunicación imposibilita la realización de comparativas que permitan conocer si los resultados obtenidos son propios de la investigación de comunicación de la ciencia en Internet o si son extrapolables a otras líneas.

Por otro lado, algunas limitaciones han podido producir algún sesgo en los resultados del estudio de caso. En cuanto a la selección de las entidades objeto de análisis, se incluyeron en la muestra final solo las universidades que dieron su consentimiento a ser monitorizadas dentro del proyecto FCT-15-10271, lo que ha podido influir en el volumen de información científica recuperada y en su posterior análisis.

Una de las barreras más importantes enfrentadas en este trabajo ha sido la variabilidad y la limitación de los sistemas de búsqueda y recuperación de información que incorporan los periódicos digitales. Estos sistemas son tan numerosos y diversos como medios se han analizado, lo que dificulta garantizar que se haya recuperado el total de la información y que las piezas periodísticas incluidas en la muestra sean las originales, ya que los medios pueden reeditar la información una vez se ha publicado, en cualquier momento, sin que aparentemente quede ningún rastro. 
También respecto al estudio de caso, el enfoque ciberperiodístico adoptado no tiene en cuenta las nuevas tendencias (periodismo algorítmico, de datos, robot, inmersivo, etc.) que no han sido consideradas en el estudio y que también podrían haber aportado información de interés. Se ha optado por un enfoque más básico y clásico bajo la premisa de que los cibermedios estudiados son versiones digitales de periódicos clásicos, en los que estas tedencias son aún minoritarias. De hecho, ni el enfoque ciberperiodístico básico se ha cumplido en gran medida en los periódicos analizados, lo que ha permitido indagar y señalar retos inmediatos para el periodismo científico. 


\section{LÍNEAS DE INVESTIGACIÓN FUTURAS}

Aunque a lo largo de los capítulos se han ido introduciendo líneas de investigación de interés para abordar en un futuro, el presente capítulo aglutina otras complementarias respecto a la comunicación de la ciencia en Internet, en general, y al periodismo científico, en particular.

Según lo reflejado en la revisión sistemática, la investigación sobre comunicación de la ciencia en Internet es en gran medida transversal a múltiples áreas de conocimiento ajenas a las ciencias sociales y, en particular, a la comunicación. Este "intrusismo" a nivel investigador, como paradójicamente sucede también a nivel profesional, pone sobre la mesa una nueva pregunta de investigación y es si esta situación es característica de la comunicación de la ciencia, es común a otras especialidades de la comunicación o si sucede en alguna otra área. Serán necesarios más estudios de metanálisis en otros campos para confirmar esta hipótesis.

También se necesitan más investigaciones para corroborar si ese déficit de calidad detectado en los estudios en castellano y portugués es común a otras disciplinas de la comunicación, a las ciencias sociales en general y a otras ciencias.

Uno de los aspectos evidenciados en el metanálisis es el uso frecuente de las redes sociales académicas por parte de la comunidad científica estudiada. El metanálisis sugiere que estas herramientas se utilizarían, de algún modo, para sortear las restricciones de difusión de las publicaciones de pago, no obstante, es un aspecto que convendría analizar con mayor profundidad.

El metanálisis y la posterior revisión dejan abiertas otras tantas posibles líneas de investigación centradas en la comunicación de la ciencia online y algunas extrapolables a la comunicación digital en general. Entre las necesidades de investigación que se extraen de los resultados obtenidos destacan el análisis de la actual formación universitaria de los periodistas en competencias digitales, la comunicación de la ciencia a través de dispositivos móviles, la jerarquización de los contenidos científicos y los criterios de noticiabilidad en Internet, la interactividad y la participación en contenidos científicos online en España, o las características de la comunicación realizada desde el mundo empresarial, para conocer si dentro de sus estrategias de responsabilidad social corporativa se está desarrollando algún tipo de actividad de comunicación científica y tecnológica online. También el hecho de que una de las principales comunidades de blogs de ciencia, como fue ScienceBlogs, y que uno de los principales agregadores, como ResearchBlogging, hayan cesado su 
actividad en los últimos meses, apunta a la hipótesis de un posible declive en el uso de los blogs como herramientas para la comunicación de la ciencia.

Finalmente, en referencia al estudio de caso, el análisis presentado supone solo un primer paso en la apertura de una línea de investigación más amplia en torno al impacto que tienen los gabinetes de comunicación de las universidades en los medios de comunicación, especialmente en el actual escenario online. Sería interesante ampliar el trabajo a otras universidades y a otros cibermedios internacionales, con el objetivo de conocer si los datos obtenidos en el presente estudio de caso son extrapolables a otros contextos.

En cuanto al análisis comparativo, sería oportuno extender tanto el número de universidades como el de periódicos analizados en el futuro, con el fin de obtener unos resultados más concluyentes y monitorizar la evolución del objeto de estudio. También sería interesante trasladar este enfoque comparativo a los medios audiovisuales, para contrastar si los resultados obtenidos en cuanto a la presencia y el tratamiento de la información científica es extrapolable a las televisiones y radios nacionales y regionales/locales. Esto permitiría conocer si estos medios están realizando una cobertura independiente o no de la información científica y qué imagen de la ciencia recibe el público en función del canal o la emisora que sintonice.

Respecto al tratamiento ciberperiodístico, sería interesante estudiar en qué grado la información científica está atendiendo a las nuevas tendencias, como el periodismo algorítmico, de datos o el clikbait. 


\section{BIBLIOGRAFÍA}




\section{A}

AA.VV. (2012). Libro Blanco de las Unidades de Cultura Científica y de la Innovación UCC+i. Madrid: Fundación Española para la Ciencia y la Tecnología (FECYT). Disponible en: http://ow.ly/hWq130iJ2Ft (última consulta: 02/03/2018)

AA.VV. (2016). UCC+i Origen y evolución (2007 - 2014). Madrid: Fundación Española para la Ciencia y la Tecnología (FECYT). Disponible en: http://ow.ly/LXr930iJ2Ih (última consulta: 02/03/2018)

Adam, L. B. (2012). "The significance of EU topics in national media. Has there been an europeanization of reporting in the national media?". Bruges Political Research Papers, (27). Disponible en: http://ow.ly/nq1u30iJ2NZ (última consulta: 02/03/2018 )

Albuquerque, A., y Esperança, J. P. (2010). "El valor económico del portugués: lengua de conocimiento con influencia global". Documentos de Trabajo (Real Instituto Elcano de Estudios Internacionales y Estratégicos), (26), 1. Disponible en: http://ow.ly/VPyV30iJ2Vr (última consulta: 02/03/2018)

Aleixandre-Benavent, R., Alonso-Arroyo, A., González de Dios, J., Sempere, Á. P., Castelló Cogollos, L., Bolaños Pizarro, M., y Valderrama Zurián, J. C. (2013). "Coautoría y redes de colaboración en la investigación española sobre esclerosis múltiple (1996-2010)". Rev Neurol, 57, 157-66. Disponible en: http://ow.ly/Gyhl30iJ32K (última consulta: 02/03/2018)

Alonso-Arroyo, A., Navarro-Molina, C., López-Gil, J. M., de Dios, J. G., y AleixandreBenavent, R. (2015). "Comunicación científica (XXVIII). Nuevas formas de difusión de contenidos: streaming, webcasting y podcasting”. Acta Pediátrica Española, 73(10), 278. Disponible en: http://ow.ly/iQks30iJ38m (última consulta: 02/03/2018)

Amsen, E. (2006). “Who Benefits From Science Blogging?”. Hypothesis, 4 (2), $10-$ 14. Disponible en: http://ow.ly/q4Po30iJ3cB (última consulta: 02/03/2018) 
Alcíbar, M. (2015). "Comunicación pública de la ciencia y la tecnología: una aproximación crítica a su historia conceptual". Arbor, 191 (773): a242. Disponible en: http://ow.ly/dWYH30iJ3fU (última consulta: 02/03/2018)

Albornoz, L. A. (2006). "Los principales diarios on line en español: el empleo de recursos audiovisuales y multimedia, e hipervínculos". Telos: Cuadernos de comunicación e innovación, (66), 23-30. Disponible en: http://ow.ly/dyJD30iJ3kt (última consulta: 02/03/2018)

Allan, S. (2009). "The future of science journalism". Journalism, 10 (3).

Allan, S. (2009). "Making science newsworthy: Exploring the conventions of science journalism". En: Holliman, R., Whitelegg, L., Scanlon, E., Smidt, S., y Thomas, J. (Eds.). Investigating science communication in the information age: Implications for public engagement and popular media. Oxford University Press. 149-165.

Allan, S. (2011). "Introduction: Science journalism in a digital age. Journalism: Theory, Practice and Criticism". Journalism, 12 (7). Disponible en: http://ow.ly/ZIUu30iJ3vi (última consulta: 02/03/2018)

Allemand, L. (2013). “¿Internet matará o salvará a la prensa científica? La experiencia de la revista francesa 'La Recherche'". Mètode: Revista de difusión de la Investigación, (80), 71-77. Disponible en: http://ow.ly/K5Fw30iJ3B2 (última consulta: 02/03/2018)

Allgaier, J., Dunwoody, S., Brossard, D., Lo, Y. Y., y Peters, H. P. (2013). "Journalism and social media as means of observing the contexts of science". BioScience, 63(4), 284-287. Disponible en: http://ow.ly/mF8I30iJ3Fw (última consulta: 02/03/2018)

Alonso, J., y Martínez, L. (2003). "Medios interactivos: caracterización y contenidos". En Manual de redacción ciberperiodística. Barcelona: Ariel.

Alvarado, E. A. (2013). "La investigación y divulgación científica en la era digital". Población, 8, 5. 
Alves Baubier, A. S. M., De Souza, R. F., y Ribeiro Pinheiro, L. V. (2014). "Classificação e representação do conhecimento em CT\&I no contexto da divulgação científica em fontes de informação digitais". En: Encontro Nacional de Pesquisa em Ciência da Informação. Belo Horizonte, Brasil, 27-31 octubre. Disponible en: http://ow.ly/gGOh30iJvQc (última consulta: 02/03/2018)

Ammon, U. (Ed.). (2001). The dominance of English as a language of science: Effects on other languages and language communities (Vol. 84). Berlín; Nueva York: Walter de Gruyter.

Anderson, C. (2004). "The Long Tail". Wired. Disponible en: http://ow.ly/zKqT30iJvU3 (última consulta: 02/03/2018)

Anderson, A. A., Brossard, D., y Scheufele, D. A. (2010). "The changing information environment for nanotechnology: online audiences and content". Journal of Nanoparticle Research, 12 (4), 1083-1094. Disponible en: http://ow.ly/sxPC30iJvZ0 (última consulta: 02/03/2018)

Anderson, A. A., Brossard, D., y Scheufele, D. A. (2012). "News coverage of controversial emerging technologies: Evidence for the issue attention cycle in print and online media". Politics and the Life Sciences, 31(1), 87-96.

Anderson, A. A., Brossard, D., Scheufele, D. A., Xenos, M. A., y Ladwig, P. (2013). "The "nasty effect:" online incivility and risk perceptions of emerging technologies". Journal of Computer Mediated Communication. Disponible en: http://ow.ly/Wp8030iJw2a (última consulta: 02/03/2018)

Antelman, K. (2004). "Do open-access articles have a greater research impact?". College \& research libraries, 65(5), 372-382. Disponible en: http://ow.ly/QjuQ30iJw31 (última consulta: 02/03/2018)

Ardèvol-Abreu, A. (2015): "Framing o teoría del encuadre en comunicación. Orígenes, desarrollo y panorama actual en España". Revista Latina de Comunicación Social, 70, pp. 423 a 450. Disponible en: http://ow.ly/WRqE30iJw4f (última consulta: 02/03/2018) 
Area Moreira, M. (2008). "Las redes sociales en Internet como espacios para la formación del profesorado". Razón y palabra, (63), 4. Disponible en: http://ow.ly/g8ZC30iJw5a (última consulta: 02/03/2018)

Arias Valencia, M. M. (2000). "La triangulación metodológica: sus principios, alcances y limitaciones". Investigación y educación en enfermería, 18(1), 13-26. Disponible en: http://ow.ly/JeNI30iJw7H (última consulta: 02/03/2018)

Arias, R. D. (2009). "El vídeo en el ciberespacio: usos y lenguaje". Comunicar: Revista científica iberoamericana de comunicación y educación, (33), 63-71. Disponible en: http://ow.ly/nxWb30iJw8x (última consulta: 02/03/2018)

Asensi, F. (2013). "Comunicación digital e investigación científica". Quaderns de la Fundació Dr. Antoni Esteve, (28), 53-61. Disponible en: http://ow.ly/fCjl30iJw90 (última consulta: 02/03/2018)

Ashlin, A., y Ladle, R. J. (2006). "Environmental science adrift in the blogosphere". Science, 312, 201. Disponible en: http://ow.ly/u6Rp30iJwdC (última consulta: 02/03/2018)

Ávila-Toscano, J. H., Marenco-Escuderos, A., y Madariaga Orozco, C. (2014). "Indicadores bibliométricos, redes de coautorías y colaboración institucional en revistas colombianas de psicología”. Avances en Psicología Latinoamericana, 32(1), 167-182. Disponible en: http://ow.ly/xSPX30iJwhj (última consulta: 02/03/2018)

Avveduto, Sveva. (2011). "Science and the Internet: be fruitful and multiply?". JCOM, 10 (2). Disponible en: http://ow.ly/VW3B30iJwip (última consulta: 02/03/2018)

Axelrod, L. (2010). "Brad L. Graham, coined the term 'blogosphere,' dies at 41". Disponible en el blog Al.com: http://ow.ly/8he830iJwlA (última consulta: 02/03/2018) 


\section{B}

Baker, L., Wagner, T. H., Singer, S., y Bundorf, M. K. (2003). "Use of the Internet and e-mail for health care information: results from a national survey". Jama, 289(18), 2400-2406. Disponible en: http://ow.ly/ttmY30iJwnb (última consulta: 02/03/2018)

Banda, E. (2003). "Science communication in Europe". European Science Foundation Policy Briefing. Disponible en: http://ow.ly/aTP030iJwtG (última consulta: 02/03/2018)

Baram-Tsabari, A., y Segev, E. (2009). "Just Google it! Exploring New Web-based Tools for Identifying Public Interest in Science and Pseudoscience". En: Eshet-Alkalai, Y., Caspi, A., Eden, S., Geri, N., y Yair, Y (eds). Proceeding of Chais Conference on Instructional Technologies Research. 20-28. Raanana: The Open University of Israel. Disponible en: http://ow.ly/w8vp30iJwuw (última consulta: 02/03/2018)

Baram-Tsabari, A., y Segev, E. (2009). "Exploring new web-based tools to identify public interest in science". Public Understanding of Science. Disponible en: http://ow.ly/r19730iJwwL (última consulta: 02/03/2018)

Barberá Forcadell, S. (2014). "El tratamiento periodístico de la ciencia en las agencias de noticias especializadas. El caso de SINC". Trabajo Fin de Master de Especialización en Periodismo Digital y Multimedia. Universidad Jaume I.

Barrionuevo Almuzara, L., Estupinyà Pinyol, E., Martín Marichal, M. C., Martín Rodero, H., Mezquita Acosta, J. et al. (2014). Manual de buenas prácticas en redes sociales. CRUE-REBIUN (Red de Bibliotecas Universitarias). Disponible en: http://ow.ly/HoTw30iJwz4 (última consulta: 02/03/2018)

Barroso Osuna, J. M. (2000). "Los medios de comunicación como creadores de imagen social: la imagen de la universidad en la prensa". Revista de Enseñanza Universitaria, 16. Disponible en: http://ow.ly/haZI30iJwBI (última consulta: 02/03/2018) 
Batts, S. A., Anthis, N. J., y Smith, T. C. (2008). "Advancing science through conversations: Bridging the gap between blogs and the academy". PLoS biology, 6 (9), e240, 1837-1841. Disponible en: http://ow.ly/59zP30iJwCy (última consulta: $02 / 03 / 2018)$

Bauer, M. W., Howard, S., Ramos, R., Jessica, Y., Massarani, L., y Amorim, L. (2013). Global science journalism report: working conditions \& practices, professional ethos and future expectations. Science and Development Network. Disponible en: http://ow.ly/R4c030krNXi (última consulta: 02/03/2018)

Benchimol, J. L., Cerqueira, R. C., y Papi, C. (2014). "Desafios aos editores da área de humanidades no periodismo científico e nas redes sociais: reflexões e experiencias". Educ. Pesqui, 40(2), 347-364. Disponible en: http://ow.ly/uxKt30iJwE3 (última consulta: 02/03/2018)

Belinchón Carmona, B., Muñoz, L. B., De Andrés, E. G., Biggi, J. F., y De La Paz, M. P. (2010). "Evolución de los estudios sobre autismo en España: publicaciones y redes de coautoría entre 1974 y 2007". Psicothema, 22(2), 242-249. Disponible en: http://ow.ly/N7Gr30iJwGt (última consulta: 02/03/2018)

Bell, A. (2012). "Has blogging changed science writting?". JCOM, 11 (1). Disponible en: http://ow.ly/WkX730iJwHd (última consulta: 02/03/2018)

Bellón Rodríguez, A., y Sixto García, J. (2011). "Aplicación y uso de la web 2.0 y de las redes sociales en la comunicación científica especializada: del marketing viral al usuario activo". Anagramas, 9 (18), 61-70. Disponible en: http://ow.ly/RNv030iJwlE (última consulta: 02/03/2018)

Bellón Rodríguez, A. (2014). "Dos programas y un portal para comunicar la I+D+i en Galicia: Efervesciencia, Soño con Ciencia y GCiencia”. Revista de la Asociación Española de Investigadores en Comunicación, 1(2), 58-64. Disponible en: http://ow.ly/Gizo30iJUrY (última consulta: 02/03/2018)

Bellón-Rodriguez, A. (2017). "La labor en soporte papel y online de suplementos y revistas en la divulgación de la I+ D+ i en España. Dos casos de estudio: Tercer Milenio y Quo". Razón y Palabra, 20(4_95), 439-461. Disponible en: (última consulta: 02/03/2018) 
Berland, G. K., Elliott, M. N., Morales, L. S., Algazy, J. I., Kravitz, R. L., Broder, M. S., ... y McGlynn, E. A. (2001). "Health information on the Internet: accessibility, quality, and readability in English and Spanish". Jama, 285(20), 2612-2621. Disponible en: http://ow.ly/uKgM30iJUt (última consulta: 02/03/2018)

Biermann, J. S., Golladay, G. J., Greenfield, M. L. V., \& Baker, L. H. (1999). "Evaluation of cancer information on the Internet". Cancer, 86 (3), 381-390. Disponible en: http://ow.ly/levL30iJUvx (última consulta: 02/03/2018)

Bik, H. M., y Goldstein, M. C. (2013). "An introduction to social media for scientists". PLoS biology, 11(4). Disponible en: http://ow.ly/RBB630iJUAe (última consulta: 04/03/2018)

Birch, H. (2011). "The social web in science communication”. En: Bennett, D. J., y Jennings, R. C (eds.). Successful Science Communication. Cambridge University Press.

Birch, H., y Weitkamp, E. (2010). "Podologues: conversations created by science podcasts". New Media \& Society, 12(6), 889-909. Disponible en: http://ow.ly/5WoD30iJUzb (última consulta: 04/03/2018)

Blanchard, A. (2011). "Science Blogs in Research and Popularization of Science: Why, how and for whom?". En: Cockell, J. B., Darbellay, F., y Waldvogel, F. (eds.). Common knowledge: The challenge of transdisciplinarity. 219-231. World Knowledge Dialogue Foundation Disponible en: http://ow.ly/hTtE30iJUAV (última consulta: 04/03/2018)

Bohlin, G., y Höst, G. E. (2014). "Evolutionary Explanations for Antibiotic Resistance in Daily Press, Online Websites and Biology Textbooks in Sweden". International Journal of Science Education, 1-20.

Bolet, F. J. "Difusión y divulgación de la ciencia: orígeneshistóricos y rasgos discursivos diferenciadores". (2015). Bitácora-e Revista Electrónica Latinoamericana de Estudios Sociales, Históricos y Culturales de la Ciencia y la Tecnología, 1. Disponible en: http://ow.ly/2oib30iJUEj (última consulta: 04/03/2018) 
Bonetta, L. (2007). "Scientist enter the blogosphere". Cell, 129. Disponible en: http://ow.ly/UUap30iJUFi (última consulta: 04/03/2018)

Bonetta, L. (2009). "Should you be tweeting?". Cell, 139(3), 452-453. Disponible en: http://ow.ly/bxkT30iJUFX (última consulta: 04/03/2018)

Bordons, M. (1999). "Evaluación de la actividad científica a través de indicadores bibliométricos". Revista Española de Cardiología, 52(10), 790-800. Disponible en: http://ow.ly/p1Bx30iJUGm (última consulta: 04/03/2018)

Bortoliero, S. T., y León, B. (2017). "El rigor científico en el vídeo online. La percepción de los expertos sobre los vídeos de contaminación del aire en Youtube". Observatorio (OBS*), 11(3), 106/page-119. Disponible en: http://ow.ly/71zf30krEJa (última consulta: 02/03/2018)

Broersma, M., y Graham, T. (2012). "Social media as beat: Tweets as a news source during the 2010 British and Dutch elections". Journalism Practice, 6(3), 403-419. Disponible en: http://ow.ly/4ISj30jYrfi (última consulta: 04/03/2018)

Brown Jarreau, P. (2014). An explosion of alternatives. EMBO reports, e201439130. Disponible en: http://ow.ly/MY9p30iJUGX (última consulta: 04/03/2018)

Brown Jarreau, P. (2015). "Science bloggers' self-perceived communication roles". JCOM, 14(04), A02-2. Disponible en: http://ow.ly/Hdux30iJUHo (última consulta: 04/03/2018)

Brossard, D. (2012). "A (Brave) New World? Challenges and Opportunities for Communication about Biotechnology in New Information Environments". En: Weitze, D., y Pühler, A. Biotechnologie-Kommunikation (pp. 427-445). Springer Berlin Heidelberg.

Brossard, D. (2013). "New media landscapes and the science information consumer". Proceedings of the National Academy of Sciences - PNAS, 110 (Supplement 3), 14096-14101. Disponible en: http://ow.ly/RK1J30iJUlr (última consulta: 04/03/2018) 
Brossard, D., y Scheufele, D. A. (2013). "Science, new media, and the public". Science, 339 (6115), 40-41. Disponible en: http://ow.ly/88IT30iJUJE (última consulta: 04/03/2018)

Brossard, D. (2013). "Ciencia, público y nuevos medios Reflexión sobre el presente y el futuro de la divulgación científica". Mètode: Revista de difusión de la Investigación, (80), 78-83. Disponible en: http://ow.ly/B20t30iJUKa (última consulta: 04/03/2018)

Brown D. D. (2009). "Science blogging: The future of science communication and why you should be a part of it". Blog Biochemical Soul.

Brumfiel, G. (2009). "Science journalism: Supplanting the old media?". Nature, 458 (7236), 274-277. Disponible en: http://ow.ly/Q07u30iJUQ4 (última consulta: 04/03/2018)

Brumfiel, G. (2009). "Science journalism: breaking the convention?". Nature, 2009, 459, 1050-1051. Disponible en: http://ow.ly/Ckl030iJUQN (última consulta: 04/03/2018)

Bubela, T., Nisbet, M. C., Borchelt, R., Brunger, F., Critchley, C., Einsiedel, E., ... y Caulfield, T. (2009). "Science communication reconsidered". Nature Biotechnology, 27(6), 514-518. Disponible en: http://ow.ly/AOf930iJURN (última consulta: 04/03/2018)

Bucchi, M. (2008). "Of deficits, deviations and dialogues: Theories of public communication of science". Handbook of public communication of science and technology, 57-76. Disponible en: http://ow.ly/HCGk30iJUTm (última consulta: 04/03/2018)

Bucchi, M., y Trench, B. (2014). "Science communication research, themes and challenges". En: Bucchi, M., y Trench, B. (Eds.). Routledge Handbook of Public Communication of Science and Technology. Routledge. 2-11.

Büchi, M. (2017). "Microblogging as an extension of science reporting". Public Understanding of Science, 26(8), 953-968.

Burke, P. y Briggs, A. (2002). De Gutenberg a Internet:una historia social de los medios de comunicación. Madrid: Taurus 
Burns, T. W., O'Connor, D. J., y Stocklmayer, S. M. (2003). "Science communication: a contemporary definition". Public understanding of science, 12(2), 183-202. Disponible en: http://ow.ly/qQ7A30iJUZr (última consulta: 04/03/2018)

Butler, D. (2005). "Science in the web age: Joint efforts". Nature, 438(7068), 548549. Disponible en: http://ow.ly/fLT430iJV25 (última consulta: 04/03/2018)

Byrne, P. F., Namuth, D. M., Harrington, J., Ward, S. M., Lee, D. J., y Hain, P. (2002). "Increasing public understanding of transgenic crops through the World Wide Web". Public Understanding of Science,11(3), 293-304. Disponible en: http://ow.ly/cKQi30iJV33 (última consulta: 04/03/2018)

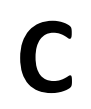

Cacciatore, M. A., Anderson, A. A., Choi, D. H., Brossard, D., Scheufele, D. A., Liang, X., ... y Dudo, A. (2012). "Coverage of emerging technologies: A comparison between print and online media". New Media \& Society, 14 (6), 1039-1059. Disponible en: http://ow.ly/RxwT30iKB2y (última consulta: 05/03/2018)

Calloni, M., Felt, U., Gorski, A., Grunwald, A., Markus, E., Rip, A., ... y Wyatt, S. (2009). "Science Communication". En: Challenging Futures of Science in Society. Emerging Trends and cutting-edge issues. 50-64. Bruselas: European Commission. Disponible en: http://ow.ly/46fo30iKB3A (última consulta: 05/03/2018)

Calvo Hernando, M. (1997). Manual de periodismo científico. Barcelona: Bosh.

Camacho Markina, I. (2009). "La 'gripe A', en la prensa española”. Revista Latina de Comunicación Social, 64, 827-843. Disponible en: http://ow.ly/P6Aw30iKB5P (última consulta: 05/03/2018)

Cambronero, A. (2011) “¿Cuántos blogs hay en el mundo?”. Disponible en el blog Blogpocket: http://ow.ly/x9LD30iKB7h (última consulta: 05/03/2018) 
Campbell, V. (2017). "The Importance of Citizenship: Theoretical Issues in Studying Citizen Journalism in International Context”. En: Jingrong, T. y Shih-Hung, L. (eds.) Digital Technology and Journalism. Palgrave Macmillan, Cham.

Canavilhas, J. (2009). "Contenidos informativos para móviles: estudio de aplicaciones para iPhone". Revista Textual \& Visual Media, 2, 61-80. Disponible en: http://ow.ly/8by730iKB9P (última consulta: 05/03/2018)

Canavilhas, J. (2013). "Modelos informativos para aparatos móviles: información hipermultimediática y personalizada". En: AA.VV. Hacia el periodismo móvil. Colección Mundo Digital. Santiago de Chile. Disponible en: http://ow.ly/EtSI30iKBaX (última consulta: 05/03/2018)

Canavilhas, J. (2018). “Journalism in the Twenty-First Century". En: Rampazzo Gambarato, R. y Alzamora, G. C. (eds.): Exploring Transmedia Journalism in the Digital Age. IGI Global.

Carmona Jiménez, J. (2006). "Algunas notas sobre periodismo científico y saber arqueológico". RE-Presentaciones Periodismo, Comunicación y Sociedad, 1(1). Dsponible en: http://ow.ly/foZ530iKBc3 (última consulta: 05/03/2018)

Carracedo Verde, J. D. (2006). "Prácticas y discursos sobre brechas digitales y sus estratificaciones". En: Casado Ortiz, R. (coord.). Claves de la alfabetización digital. Madrid. Fundación Telefónica.

Carrington, D. (2008). How to set up a science blog. Disponible en: http://ow.ly/RQyB30iKBdb (última consulta: 05/03/2018)

Carroll, S. (2007). "Blogging for physics". Physics World, 14. Disponible en: http://ow.ly/frno30iKBeE (última consulta: 05/03/2018)

Cascais, A. F. (2003). "Divulgação científica: a mitologia dos resultados". A Comunicação Pública da ciência. Taubaté: Cabral, 65-77. Disponible en: http://ow.ly/t1Y230iKBjt (última consulta: 05/03/2018)

Casino, G. (2014). 13. "Conflictos y complicidades entre científicos y periodistas. Una visión crítica con propuestas de mejora". Quaderns de la Fundació Dr. Antoni 
Esteve, (28), 97-103. Disponible en: http://ow.ly/Jprq30iKBI0 (última consulta: 05/03/2018)

Casterá, V. T., Sanz Valero, J., Juan-Quilis, V., Wanden-Berghe, C., Culebras, J. M., y García de Lorenzo y Mateos, A. (2008). "Estudio bibliométrico de la revista Nutrición Hospitalaria en el periodo 2001 a 2005: parte 2, análisis de consumo; las referencias bibliográficas". Nutrición Hospitalaria, 23(6), 541-546. Disponible en: http://ow.ly/VruK30iKBmq (última consulta: 05/03/2018)

Castillo, A. y Carretón, M. (2010) "Investigación en Comunicación. Estudio bibliométrico de las Revistas de Comunicación en España”. Comunicación y Sociedad, vol. XXIII, n. 2, pp.289-327 Disponible en: http://ow.ly/6VM030iKBnU (última consulta: 05/03/2018)

Castillo-Esparcia, A., Rubio-Moraga, Á., y Almansa-Martínez, A. (2012). "La investigación en Comunicación. Análisis bibliométrico de las revistas de mayor impacto del ISI". Revista Latina de Comunicación Social, (67), 248. Disponible en: http://ow.ly/X49j30iKBpc (última consulta: 05/03/2018)

Cazaux, D. (2016). "La comunicación pública de la Ciencia y la tecnología en la 'Sociedad del Conocimiento'. Razón y Palabra, 65. Disponible en: https://goo.gl/8uSnHm (última consulta: 05/03/2018)

Chakraborty, A., Paranjape, B., Kakarla, S., y Ganguly, N. (2016). "Stop clickbait: Detecting and preventing clickbaits in online news media". En: Advances in Social Networks Analysis and Mining (ASONAM), 2016 IEEE/ACM International Conference. Disponible en: http://ow.ly/xqAB30jYp0v (última consulta: 05/03/2018)

Chalmers, M. (2009). "Communicating physics in the information age". En: Holliman, R., Thomas, J., Smidt, S., Scanlon, E., y Whitelegg, L. (Eds.). Practising science communication in the information age: Theorising professional practices. Oxford University Press. 67-80.

Clarke, M. (2009). "Ethics of science communication on the web". Ethics in Science and Environmental Politics, 9(1), 9-12. Disponible en: http://ow.ly/fGYj30iKBrr (última consulta: 05/03/2018) 
Claussen, J. E., Cooney, P. B., Defilippi, J. M., Fox, S. G., Glaser, S. M., Hawkes, E., ... y Steward, C. (2013). "Science Communication in a Digital Age: Social Media and the American Fisheries Society". Fisheries, 38(8), 359-362. Disponible en: http://ow.ly/eWJw30iKBw3 (última consulta: 05/03/2018)

Cline, R. J., y Haynes, K. M. (2001). "Consumer health information seeking on the Internet: the state of the art". Health education research, 16 (6), 671-692. Disponible en: http://ow.ly/9tPu30iKBy9 (última consulta: 05/03/2018)

Cobos, J. S. (2004). "Google, DSI y la sindicación de contenidos mediante RDF/RSS". El profesional de la información, 13(1), 67-70. Disponible en: http://ow.ly/WJYk30iKBzc (última consulta: 05/03/2018)

Cody, L. (2010). "Engaging with Online Audiences. A cross-country analysis of use of the Web for communicating biomedical science to public audiences". Trabajo Fin de Master en Comunicación de la Ciencia. Dublin City University. Disponible en: http://ow.ly/PELI30iKBA4 (última consulta: 05/03/2018)

Cohen, B. (1963). The press and foreign policy. Princeton: Princeton University Press

Collins, L., y Nerlich, B. (2015). "Examining User Comments for Deliberative Democracy: A Corpus-driven Analysis of the Climate Change Debate Online". Environmental Communication, 1-19. Disponible en: http://ow.ly/bAND30iKBC0 (última consulta: 05/03/2018)

Colson, V. (2011). "Science blogs as competing channels for the dissemination of science news". Journalism, 12 (7). Disponible en: http://ow.ly/8Txh30iKBDJ (última consulta: 05/03/2018)

Corbett, J. B., y Mori, M. (1999). "Medicine, media, and celebrities: News coverage of breast cancer, 1960-1995". Journalism \& Mass Communication Quarterly, 76(2), 229-249.

Cortassa, C. G. (2010). "Del déficit al diálogo,¿ y después?: Una reconstrucción crítica de los estudios de comprensión pública de la ciencia". Revista iberoamericana 
de ciencia tecnología y sociedad, 5(15), 47-72. Disponible en: http://ow.ly/jZCd30iKBHW (última consulta: 05/03/2018)

Costa Sánchez, C. (2008). "Medicina y salud en la prensa. Las noticias de salud en los principales diarios de Galicia". Revista Latina de Comunicación Social, 63, 15-21. Disponible en: http://ow.ly/nJYe30iKBJ6 (última consulta: 05/03/2018)

Costa Sánchez, C. (2012). "Ciberperiodismo en el smartphone. Estudio de la multimedialidad, usabilidad, hipertextualidad e interactividad de las aplicaciones de medios nativos digitales para smartphone". Estudios sobre el mensaje periodístico, 18, 243-251. Disponible en: http://ow.ly/yBoA30iKBN0 (última consulta: 05/03/2018)

Coturnix. (2010). "Science blogs and public engagement with science". Disponible en $A$ blog around the clock: http://ow.ly/SRwZ30iKBOE (última consulta: 05/03/2018)

Culebras, J. M., y García de Lorenzo, A. (2009). "Formato Uniforme para declaración de conflicto de intereses en manuscritos remitidos a revistas científicas". Nutrición Hospitalaria, 24(6), 627-628. Disponible en: http://ow.ly/VAec30iKBRd (última consulta: 05/03/2018)

Cullen, T. A. (2013). "Online health information: shortcomings and challenges". Australia and New Zealand Communication Association (ANZCA) Conference. Disponible en: http://ow.ly/AuFa30iKBSq (última consulta: 05/03/2018)

Cullen, T. A. (2013), "Exploring ways to improve online health news stories". eJournalist - a referred media journal, 13 (2), 59-72. Disponible en: http://ow.ly/TL5r30iKBTS (última consulta: 05/03/2018)

Cummings, J. N., y Kiesler, S. (2005). "Collaborative research across disciplinary and organizational boundaries". Social studies of science, 35(5), 703-722. Disponible en: http://ow.ly/SYYr30iKBX3 (última consulta: 05/03/2018) 


\section{D}

Darling, E. S., Shiffman, D., Côté, I. M., y Drew, J. A. (2013). "The role of Twitter in the life cycle of a scientific publication". PeerJ PrePrints. Disponible en: http://ow.ly/Wdg030iKEhB (última consulta: 05/03/2018)

Dash, A. (2010). "Remembering Brad L. Graham". Disponible en el blog A blog about making culture: http://ow.ly/Z43t30iKEjA (última consulta: 05/03/2018)

David, P. A. (2004). 'Understanding the emergence of 'open science' institutions: functionalist economics in historical context". Industrial and Corporate Change, 13(4), 571-589.

Davies, N. (2009). Flat Earth News. London: Vintage Books.

Davies, B. J., y Glasser, N. F. (2014). "Analysis of www.AntarcticGlaciers.org as a tool for online science communication". Journal of Glaciology, 60 (220), 399-406. Disponibe en: http://ow.ly/VpVc30iKEot (última consulta: 05/03/2018)

Decálogo del comunicador de la ciencia en redes (2013). En: Ciencia en redes. Asociación Española de Comunicación Científica (AECC). Disponible en: http://ow.ly/vY7W30iKErO (última consulta: 05/03/2018)

De Campos Bernardi, A. C., Fragalle, C. V. P., Fragalle, E. P., da Silva, J. C., y Inamsu, R. Y. (2015). "Estratégias de comunicação em agricultura de precisão". Perspectivas em Ciência da Informação, 20(1), 189-200. Disponible en: http://ow.ly/fknW30iKEsS (última consulta: 05/03/2018)

De Moraes, T. P. B., y Maia, S. P. A. (2014). "Jornalismo na web e clonagem biológica: Um estudo sobre o tema clonagem nos cadernos de ciência online dos jornais O Estado de São Paulo e Folha de São Paulo". Aurora. Revista de Arte, Mídia e Política, 7(19), 71-96. Disponible en: http://ow.ly/l77030iKEuN (última consulta: 05/03/2018)

De Pablos Coello, J. M., y Mateos Martín, C. (2004). "Estrategias informativas para acceder a un periodismo de calidad en prensa y TV". Ámbitos: Revista internacional de 
comunicación, (11), 19. Disponible en: http://ow.ly/ngTb30iKEwz (última consulta: 05/03/2018)

De Semir, V. (2010). Science Communication \& Science Journalism. Media for Science Forum, Madrid. Disponible en: http://ow.ly/uUaE30iKEAd (última consulta: 05/03/2018)

De Semir, V. (2010). "El «mutatis mutandis» de la comunicación científica en la era de Internet”. ArtefaCToS, 3(1), 49-79. Disponible en: http://ow.ly/wW9q30iKEEr (última consulta: 05/03/2018)

De Semir, M. (2013). "La comunicación científica corporativa. Integrando conceptos comunicativos en el ADN de los investigadores". Quaderns de la Fundació Dr. Antoni Esteve, (28), 79-84. Disponible en: http://ow.ly/zLoU30iKEGD (última consulta: 05/03/2018)

De Solla Price, D. J. (2002). "The pattern of bibliographic references indicates the nature of the scientific research front". Social Networks: Critical Concepts in Sociology, 4, 328.

Declaración de Berlín sobre acceso abierto. (2003).Geotrópico, 1 (2), 152-154. Sociedad Max Planck. Disponible en: http://ow.ly/E07V30iKENC (última consulta: 05/03/2018)

Delfanti, A. (2008). "Collaborative Web between open and closed science". JCOM, 7(2). Disponible en: http://ow.ly/sNOC30iKERO (última consulta: 05/03/2018)

Delfanti, A. (2009). "Too much power to the networks". JCOM, 8, 4. Disponible en: http://ow.ly/LfYK30iKETK (última consulta: 05/03/2018)

Delgado López-Cózar, E., Ruiz-Pérez, R., y Jiménez-Contreras, E. (2006). "Criterios MEDLINE para la selección de revistas científicas. Metodología e indicadores: Aplicación a las revistas médicas españolas con especial atención a las de salud pública". Revista Española de Salud Pública, 80(5), 521-551. Disponible en: http://ow.ly/UNcz30iKEXh (última consulta: 05/03/2018) 
Dembe, A. E., Partridge, J. S., y Geist, L. C. (2011). "Statistical software applications used in health services research: analysis of published studies in the US". BMC health services research, 11(1), 252. Disponible en: http://ow.ly/eKyp30iKF0U (última consulta: 05/03/2018)

Devi, B. M (2013). "Scientific communication through social networking sites". Science Communicator, (4), 12-34.

Di Pietro, N. C., Whiteley, L., Mizgalewicz, A., y Illes, J. (2013). "Treatments for neurodevelopmental disorders: evidence, advocacy, and the Internet". Journal of autism and developmental disorders, 43(1), 122-133. Disponible en: http://ow.ly/ZMZI30iKF9i (última consulta: 05/03/2018)

Díaz Noci, J. (2002). "Revistas científicas en Internet: luces y sombras de la divulgación en el ciberespacio". Revista Internacional de Estudios Vascos, 47, 2, 429445. Disponible en: http://ow.ly/Embc30iKFdD (última consulta: 05/03/2018)

Díaz Noci, J., y Salaverría, R. (2003). Manual de redacción ciberperiodística. Barcelona: Ariel.

Díaz-Noci, J. (2018). "Hipertexto en periodismo: realidad e investigaciones de futuro". Anuario ThinkEPI, 12, 230-235. Disponible en: http://ow.ly/hgaR30jVZFI (última consulta: 05/03/2018)

Domínguez Gutiérrez, S. (2014). "Consumo mediático de información científica entre estudiantes de educación superior". Comunicación y sociedad, (21), 43-69. Disponible en: http://ow.ly/uGis30iKFgS (última consulta: 05/03/2018)

Duffy, M. E. (1987). "Methodological triangulation: a vehicle for merging quantitative and qualitative research methods". Journal of Nursing Scholarship, 19(3), 130-133.

Dunwoody, S. (2014). "Science journalism: prospects in the digital age". En: Bucchi, M., y Trench, B. (Eds.). Routledge Handbook of Public Communication of Science and Technology. Routledge. 27-39. Disponible en: http://ow.ly/kb3130iKFuf (última consulta: 05/03/2018) 


\section{$\mathbf{E}$}

Eastin, M. S. (2001). "Credibility assessments of online health information: The effects of source expertise and knowledge of content". Journal of Computer Mediated Communication, 6 (4). Disponible en: http://ow.ly/pDXG30iKFKH (última consulta: 05/03/2018)

Eisend, M. (2002). "The internet as a new medium for the sciences? The effects of internet use on traditional scientific communication media among social scientists in Germany". Online information review, 26(5), 307-317.

Eisenstein, E. L. (1980). The printing press as an agent of change (Vol. 1). Cambridge University Press.

Elías, C. (2008). Fundamentos de periodismo científico y divulgación mediática. Alianza Editorial.

Elías, C. (2009). "La «cultura convergente» y la filosofía Web 2.0 en la reformulación de la comunicación científica en la era del ciberperiodismo". Arbor, 185(737), 623-634. Disponible en: http://ow.ly/Rzlg30iLB9W (última consulta: 05/03/2018)

Elías, C. (2013). "Contraconocimiento y pandemias de credulidad en la Sociedad Red: el papel del periodismo en la búsqueda de la verdad en los entornos digitales". Estudios sobre el Mensaje Periodístico, 19(2), 667-681. Disponible en: http://ow.ly/qVKz30iLBeQ (última consulta: 05/03/2018)

Elías Pérez, C. (2015). "Google y Wikipedia como fuentes 2.0 en información sanitaria: de los algoritmos de jerarquización al oficio periodístico de búsqueda de la verdad". Panace@, 16 (42), 206-216. Disponible en: http://ow.ly/RTOG30iLBiz (última consulta: 05/03/2018)

Enrique Hamel, R. (2007). "The dominance of English in the international scientific periodical literature and the future of language use in science". Aila Review, 20(1), 5371. Disponible en: http://ow.ly/BISI30iLBn7 (última consulta: 05/03/2018) 
Escribà, E. y Cortiñas, S. (2013). "La internacionalización y las coautorías en las principales revistas científicas de Comunicación en España”. Comunicar, 21(41), 3544. Disponible en: http://ow.ly/ZAk530iLBrt (última consulta: 05/03/2018)

Esteban, M., y Rodrigo, J. G. (2014). "Botánica 2.0”. El/O botânico: Revista de la AIMJB, (8), 77-81.

Eveland, W. P., y Dunwoody, S. (1998). "Users and navigation patterns of a science World Wide Web site for the public". Public Understanding of Science, 7(4), 285-311. Disponible en: http://ow.ly/ifq230iLBzu (última consulta: 05/03/2018)

\section{$\mathbf{F}$}

Fahy, D., y Nisbet, M. C. (2011). "The science journalist online: Shifting roles and emerging practices". Journalism, 12 (7). Disponible en: http://ow.ly/i5V830iLBDg (última consulta: 05/03/2018)

Falagas, M. E., Kouranos, V. D., Arencibia-Jorge, R., y Karageorgopoulos, D. E. (2008). "Comparison of SCImago journal rank indicator with journal impact factor". The FASEB journal, 22(8), 2623-2628. Disponible en: http://ow.ly/xW8B30iLBTc (última consulta: 05/03/2018)

Fallows, D. (2005). "Search engine users". Pew Internet \& American Life Project website. Disponible en: http://ow.ly/2fn930iLBJj (última consulta: 05/03/2018)

Fausto, S., Machado, F. A., Bento, L. F. J., lamarino, A., Nahas, T. R., y Munger, D. S. (2012). "Research blogging: Indexing and registering the change in science 2.0". PloS one, 7 (12), 1-10. Disponible en: http://ow.ly/qSSu30iLBW8 (última consulta: 05/03/2018)

Fernández, S., y Molero de Cabeza, L. (2003). "Construcción lingüística de la imagen de la Universidad del Zulia en Panorama”. Opción, 19(41), 58-84. Disponible en: http://ow.ly/3WZX30iLC2w (última consulta: 05/03/2018) 
Fernández, L., Hernández, E. L., y Jovell, A. J. (2004). "Observatory of woman and health”. En: 8o Congreso Internacional sobre Comunicación Pública de la Ciencia y la Tecnología (PCST). Barcelona, 3-6 junio. Disponible en: http://ow.ly/nMxn30iLC60 (última consulta: 05/03/2018)

Fernández, L. (2007). "Los 'blogs' cumplen 10 años". El País. Disponible en: http://ow.ly/te4G30iLChN (última consulta: 05/03/2018)

Fernández de Lis, P. (2013). "Ciencia y periodismo en la red". Quaderns de la Fundació Dr. Antoni Esteve, (28), 15-19. Disponible en: http://ow.ly/WoDt30iLC8F (última consulta: 05/03/2018)

Fernández-Muerza, A. (2005). "Periodismo Científico On-line: Internet y las Nuevas Oportunidades para la Ciencia y Tecnología". Razón y Palabra, 10, 43. Disponible en: http://ow.ly/Uhdm30iLCmx (última consulta: 05/03/2018)

Fernández Muerza, Á. (2005). "La información científica en la prensa de referencia: el caso español a partir de un análisis comparativo". Zer-Revista de Estudios de Comunicación, 10(19). Disponible en: http://ow.ly/cnR430iLCpc (última consulta: 05/03/2018)

Fernández Vítores, D.(2016). “El español: una lengua viva”. Informe 2016. Instituto Cervantes. Disponible en: http://ow.ly/dp5030iLCri (última consulta: 05/03/2018)

Ferrer, A., y León, G. (2008). "Cultura Científica y Comunicación de la ciencia". Razón y palabra, 13(65). Disponible en: http://ow.ly/7vmV30iLCxD (última consulta: 05/03/2018)

Fleischman, J., y Szalinski, C. (2014). "So you want to be a science writer". Molecular biology of the cell, 25(13), 1938-1941. Disponible en: http://ow.ly/e4Y030iLCAk (última consulta: 05/03/2018)

Figueiredo Castro, R. C. (2006). Impacto da Internet no fluxo da comunicação científica em saúde. Revista de Saúde Pública, 40(spe), 57-63. Disponible en: http://ow.ly/wMwT30iLCFs (última consulta: 05/03/2018) 
Flores, N. M., y Gomes, I. M. A. M. (2013). "Blogs no campo científico: subjetivaçâo e profanaçâo". Intexto, 29, 199-215. Disponible en: http://ow.ly/PuO630iLCXU (última consulta: 05/03/2018)

Fondevila Gascón, J. F. (2013). "Periodismo ciudadano y" cloud journalism": un flujo necesario en la sociedad de la banda ancha". Comunicación y hombre: revista interdisciplinar de ciencias de la comunicación y humanidades, (9), 25-41. Disponible en: http://ow.ly/iuGc30iLD7Y (última consulta: 05/03/2018)

Formenti, C. (2012). "Web 2.0: netizen empowerment vs. unpaid labor". JCOM, 11 (1). Disponible en: http://ow.ly/zvsi30iLDaQ (última consulta: 05/03/2018)

Fourez, G. (1997). Alfabetización científica y tecnológica: acerca de las finalidades de la enseñanza de las ciencias. Ediciones Colihue SRL.

Franklin, J. (1998). "El fin del periodismo científico". Quark, (11), 53. Disponible en: http://ow.ly/bwdL30iLDkz (última consulta: 05/03/2018)

Freitas, G. (2014). "Principales plataformas para blogs". Disponible en el blog Quiero crear un blog: http://ow.ly/1HMQ30iLDtv (última consulta: 05/03/2018)

Frías, G. y Rueda, A. (2014). "Las oficinas de comunicación de la ciencia en la UNAM". Revista Digital Universitaria, 15(3). Disponible en: http://ow.ly/aqSh30iLDwi (última consulta: 05/03/2018)

\section{$\mathbf{G}$}

Galligan, F., y Dyas-Correia, S. (2013). "Altmetrics: Rethinking the way we measure". Serials Review, 39(1), 56-61. Disponible en: http://ow.ly/cnjD30iLEnX (última consulta: 05/03/2018)

García Álvarez de Toledo, J., y Fernández Sánchez, R. (2011). Difusión y divulgación científica en internet. Gobierno del Principado de Asturias. Disponible en: http://ow.ly//4xx30iLEkf (última consulta: 05/03/2018) 
García-Hernández, M. L., Martínez-Rodrigo, E., y Victoria Mas, J. S. (2017). "Retórica y divulgación científica. Una propuesta para la web de empresas biotecnológicas". Athenea Digital. Revista de pensamiento e investigación social, 17(1). Disponible en: http://ow.ly/aNn530krFsK (última consulta: 05/03/2018)

García Orosa, B., Gallur Santorun, S, y López García, X. (2017). "El uso del clickbait en cibermedios de los 28 países de la Unión Europea". Revista Latina de Comunicación Social, 72, 1.261-1.277. Disponible en: http://ow.ly/78ON30jYoTE (última consulta: 05/03/2018)

Gerber, A. (2012). "Online trends from the first German trend study on science communication”. En: Tokar, A., Beurskens, M., Keuneke, S., Mahrt, M., Peters, I., Van Treeck, T., y Weller, K. (eds.). Science and the Internet, 13-18. Düsseldorf: Düsseldorf University Press. Disponible en: http://ow.ly/BNf030iLErF (última consulta: 05/03/2018)

Gerber, A. (2014). "Science Caught Flat-Footed: How Academia Struggles with Open Science Communication". En: Bartling, S., y Friesike, S. Opening Science. Springer International Publishing. Págs 73-80. Disponible en: http://ow.ly/s6p130iLEtx (última consulta: 05/03/2018)

Gil, D., y Vilches, A. (2001). "Una alfabetización científica para el siglo XXI: obstáculos y propuestas de actuación". Revista Investigación en la Escuela, (43), 2737. Disponible en: http://ow.ly/E4L330iLExQ (última consulta: 05/03/2018)

Gil de Zúñiga, H., Diehl, T., y Ardèvol-Abreu, A. (2018). "When citizens and journalists interact on Twitter: Expectations of journalists' performance on social media and perceptions of media bias". Journalism Studies, 19(2), 227-246.

Goldstein, A. M. (2009). "Blogging evolution". Evolution: Education and Outreach, 2 (3), 548-559. Disponible en: http://ow.ly//4rS30iLEzo (última consulta: 05/03/2018)

Gomes, I. M. A. M., Flores, N. M. (2012). “Um olhar bakhtiniano sobre os blogs de ciência". Macabea - Revista Electrônica do Netlli, 1 (2), 391-407. Disponible en: http://ow.ly/FcFa30iLEC7 (última consulta: 05/03/2018)

Gómez Hernández, J. A. (1996). "Presencia e imagen de la Biblioteca Universitaria en los medios de comunicación escrita. El caso de la biblioteca universitaria de 
Murcia". Anales de Pedagogía, № 14, 1996. Disponible en: http://ow.ly/HgNb30iLEH4 (última consulta: 05/03/2018)

Gómez Núñez, A. J. (2015). Una aproximación multimetodológica para la clasificación de las revistas de Scimago Journal \& Country Rank (SJR). Tesis Doctoral, Universidad de Granada. Disponible en: http://ow.ly/WiTj30iLEMU (última consulta: 05/03/2018)

González Alcaide, G., Valderrama Zurián, J., Aleixandre Benavent, R., Alonso Arroyo, A., De Granda Orive, J. I., y Villanueva Serrano, S. (2006). "Redes de coautoría y colaboración de las instituciones españolas en la producción científica sobre drogodependencias en biomedicina 1999-2004". Trastornos adictivos, 8(2), 78114. Disponible en: http://ow.ly/Qcia30iLESv (última consulta: 05/03/2018)

González-Alcaide, G., Alonso-Arroyo, A., González de Dios, J., Sempere, A. P., Valderrama-Zurián, J. C., y Aleixandre-Benavent, R. (2008). "Redes de coautoría y colaboración institucional en Revista de Neurología". Rev Neurol, 46(11), 642-51. Disponible en: http://ow.ly/CzUj30iLEZv (última consulta: 05/03/2018)

González Alcaide, G., Calatayud, V., Valderrama Zurián, J., y Aleixandre Benavent, R. (2009). "Participación de la mujer y redes de coautoría en las revistas españolas de Sociología". Revista Española de Investigaciones Sociológicas, 126(1), 153-166.

Disponible en: http://ow.ly/3WWC30iLF5G (última consulta: 05/03/2018)

González Díaz, C., Iglesias García, M., y Codina Bonilla, L. (2015). "Presencia de las universidades españolas en las redes sociales digitales científicas: caso de los estudios de comunicación". El profesional de la información, 24(5), 640-647. Disponible en: http://ow.ly/CVGF30iRPko (última consulta: 05/03/2018)

González-Pedraz, C. (2013). Ciberperiodismo Científico. El descubrimiento del Bosón de Higgs en 'El Mundo' y 'elmundo.es'. Trabajo Fin de Master. Universidad de Valladolid.

González-Pedraz, C. (2014a). "Ciberperiodismo Científico. El caso del descubrimiento del bosón de Higgs". En: Congreso Mundial de Comunicación Iberoamericana (Confibercom). Braga (Portugal), 13-16 abril. 
González-Pedraz, C. (2014b). "Ciberperiodismo Científico: prácticas, retos y oportunidades". En: XX Congreso Internacional de la Sociedad Española de Periodística (SEP). Barcelona, 13 y 14 junio.

González-Pedraz, C. y Campos-Domínguez, E. (2015). "El periodista científico en la blogosfera de Ciencia: un actor privilegiado en un entorno digital abierto". Panace@: Revista de Medicina, Lenguaje y Traducción, 16(42), 158-164. Disponible en: http://ow.ly/LbEi30iKWuu (última consulta 05/03/2018)

González-Pedraz, C., y Campos-Domínguez, E. (2017). "Práctica profesional del periodista científico: revisión bibliográfica de las disfunciones derivadas del entorno digital". Revista Mediterránea de Comunicación, 8(2), 225-240. Disponible en: http://ow.ly/Cyi830iKX2x (última consulta 05/03/2018)

González-Pedraz, C., Pérez-Rodríguez, A. V., Campos-Domínguez, E., y Quintanilla Fisac, M. Á. (2017). "Análisis comparativo de la presencia de las universidades españolas en prensa digital nacional y local". Revista Latina de Comunicación Social, (72), 861-882. Disponible en: http://ow.ly/VAE130iKWH7 (última consulta 05/03/2018)

González-Pedraz, C., Pérez-Rodríguez, A. V., Campos-Domínguez, E., y Quintanilla Fisac, M. Á. (2018). "Estudio de caso sobre las Unidades de Cultura Científica (UCC+i) españolas en la prensa digital”. Doxa Comunicación: revista interdisciplinar de estudios de comunicación y ciencias sociales (in press)

Gouvela, F. C., y Kurtenbach, E. (2004). "Content and link network analysis of five science communication websites in latin america". En: 8 Congreso Internacional sobre Comunicación Pública de la Ciencia y la Tecnología (PCST). Barcelona, 3-6 junio. Disponible en: http://ow.ly/LRRk30iMA86 (última consulta 05/03/2018)

Gramling, C. (2008). Science bloggers question their role. Geotimes, 53 (6), 47. Disponible en: http://ow.ly/NUPb30iMAar (última consulta 05/03/2018)

Granado, A. (2011). "Slaves to journals, serfs to the web: The use of the internet in newsgathering among European science journalists". Journalism, 12 (7), 794-813. Disponible en: http://ow.ly/C9T830iMAgd (última consulta 05/03/2018) 
Gregory, J. (2009). "Scientists communicating”. En: Holliman, R., Thomas, J., Smidt, S., Scanlon, E., y Whitelegg, L. (Eds.). Practising science communication in the information age: Theorising professional practices. Oxford University Press. 3-18.

Griffiths, M. (2007). "Talking physics in the social web”. Physics world, 29 (1), 24-28. Disponible en: http://ow.ly/YCwd30iMAny (última consulta 05/03/2018)

Gross, M. (2008). "Is science reporting turning into fast food?". Ethics in Science and Environmental Politics. 1-3. Disponible en: http://ow.ly/3Q3A30iMAr9 (última consulta 05/03/2018)

Guallar, J., Rovira, C., y Ruiz, S. (2010). "Multimedialidad en la prensa digital. Elementos multimedia y sistemas de recuperación en los principales diarios digitales españoles". El profesional de la información, 19(6), 620-631. Disponible en: http://ow.ly/NHFH30iMAtg (última consulta 05/03/2018)

Guenther, L., Bischoff, J., Löwe, A., Marzinkowski, H., y Voigt, M. (2017). "Scientific Evidence and Science Journalism: Analysing the representation of (un) certainty in German print and online media”. Journalism Studies, 1-20.

Gutiérrez Lozano, J. F. (2002). "La divulgación científica en la programación de las televisiones generalistas". Comunicar, 19, 43-48. Disponible en: http://ow.ly/i21T30iMAyT (última consulta 05/03/2018)

Gutiérrez, S. D. (2014). "Internet: medio preferido entre los jóvenes en la obtención de información científica". En: Memorias: Encuentro Nacional San Luis Potosí 2014. México. Disponible en: http://ow.ly/Fs7230iMACH (última consulta 05/03/2018)

\section{H}

Hansen, A. (2009). "Science, communication and media". En: Holliman, R., Whitelegg, L., Scanlon, E., Smidt, S., y Thomas, J. (Eds.). Investigating science communication in the information age: Implications for public engagement and popular media. Oxford University Press. 105-127. 
Harnad, S., y Brody, T. (2004). "Comparing the impact of open access (OA) vs. nonOA articles in the same journals". D-lib Magazine, 10(6). Disponible en: http://ow.ly/mTap30iMAGj (última consulta 05/03/2018)

Hart, P. S., y Leiserowitz, A. A. (2009). "Finding the teachable moment: An analysis of information-seeking behavior on global warming related websites during the release of The Day After Tomorrow". Environmental Communication, 3(3), 355-366.

Hayes, A. S., Singer, J. B., y Ceppos, J. (2007). "Shifting roles, enduring values: The credible journalist in a digital age". Journal of Mass Media Ethics, 22(4), 262-279. Disponible en: http://ow.ly/XVQj30iMAQh (última consulta 05/03/2018)

Hermida, A. (2007). "Reimagining Science Journalism". Future directions in Science Journalism conference. Disponible en: http://ow.ly/gJyr30iMASF (última consulta 05/03/2018)

Hermida, A. (2010). "Revitalizing science journalism for a digital age". En: Kennedy, D., y Overholser, G. Science and the Media. Cambridge, MA: American Academy of Arts and sciences. Págs. 80-87. Disponible en: http://ow.ly/nSLU30iMAWJ (última consulta 05/03/2018)

Herrero-Solana, V.; Arboledas, L. y Legerén-Álvarez, E. (2014). “Universidades y Google News: visibilidad internacional a través de los medios de comunicación online". Revista Española de Documentación Científica, 37 (3): e052. Disponible en: http://ow.ly/D4TL30iMB1b (última consulta 05/03/2018)

Hetland, P. (2015). "Popularizing the Internet". Nordicom Review, 36(2), 157-171. Disponible en: http://ow.ly/rC9H30iMB39 (última consulta 05/03/2018)

Holding, C. (2007). "What makes science news?". The Write Stuff, 16 (3), 108-110

Holliman, R. (2007). "Reporting environmental news: newspapers in the digital age". Frontiers in Ecology and the Environment, 5(5), 277-278.

Holliman, R., Whitelegg, L., Scanlon, E., Smidt, S., y Thomas, J. (2009). Investigating science communication in the information age: Implications for public engagement and popular media. Oxford University Press. 
Holliman, R. (2010). "From analogue to digital scholarship: implications for science communication researchers". JCOM, 9 (3). Disponible en: http://ow.ly/c3UN30iMBna (última consulta 05/03/2018)

Holliman. R. (2011a). "Telling science stories in an evolving digital media ecosystem: from communication to conversation and confrontation". JCOM, 10 (4). Disponible en: http://ow.ly/SGHj30iMBtc (última consulta 05/03/2018)

Holliman, R. (2011b). "Advocacy in the tail: Exploring the implications of 'climategate'for science journalism and public debate in the digital age". Journalism, 12 (7), 832-846. Disponible en: http://ow.ly/XR8t30iMBLc (última consulta 05/03/2018)

Horning Priest, S. (2009). "Reinterpreting the audiences for media messages about science". En: Holliman, R., Whitelegg, L., Scanlon, E., Smidt, S., y Thomas, J. (Eds.). Investigating science communication in the information age: Implications for public engagement and popular media. Oxford University Press. 223-236.

Horrigan, J. B. (2006). "The Internet as a Resource for News and Information Science". Pew Internet \& American Life Project. Disponible en: http://ow.ly/haTY30iMBRS (última consulta 05/03/2018)

Hudson, D. L. (2009). Blogging. New York: Infobase Publishing.

Humanes, M. L. (2007). "La investigación sobre la profesión periodística en España". Sphera publica, 1, 173-194. Disponible en: http://ow.ly/V9b130iMBYH (última consulta 05/03/2018)

Illingworth, S. (2015). "A brief history of science communication". Disponible en el blog GeoLog: http://ow.ly/Omj230iMC6U (última consulta 05/03/2018) 
Islas-Carmona, J. O. (2008). "El prosumidor. El actor comunicativo de la sociedad de la ubicuidad". Palabra Clave, 11, 1, 29-39. Disponible en: http://ow.ly/zrhd30iMC8Z (última consulta 05/03/2018)

Irwin, A. (2009). "Moving forwards or in circles? Science communication and scientific governance in an age of innovation”. En: Holliman, R., Whitelegg, L., Scanlon, E., Smidt, S., y Thomas, J. (Eds.). Investigating science communication in the information age: Implications for public engagement and popular media. Oxford University Press. 3-17.

Jaafar, Z., y Giam, X. (2012). "Misinformation and omission in science journalism". Tropical Conservation Science, 5(2), 142-149. Disponible en: http://ow.ly/Fbp430iMCbL (última consulta 05/03/2018)

Jackson, J. G. (2004). "The interaction collaboration: The role of the World Wide Web in global physics communication". En: 8o Congreso Internacional sobre Comunicación Pública de la Ciencia y la Tecnología (PCST). Barcelona, 3-6 junio. Disponible en: http://ow.ly/4Pc830iMCe9 (última consulta 05/03/2018)

Jang, S. M. (2013). "Seeking congruency or incongruency online? Examining selective exposure to four controversial science issues". Science Communication. Disponible en: http://ow.ly/67iP30iMCkF (última consulta 05/03/2018)

Jaskowska, M. (2004). "What are doing polish science institutions for Internet science communication with the different groups of the public?". En: $8^{\circ}$ Congreso Internacional sobre Comunicación Pública de la Ciencia y la Tecnología (PCST). Barcelona, 3-6 junio. Disponible en: http://ow.ly/4Pc830iMCe9 (última consulta 05/03/2018)

Jaspal, R., Nerlich, B., y Koteyko, N. (2012). "Contesting science by appealing to its norms: readers discuss climate science in The Daily Mail". Science Communication. Disponible en: http://ow.ly/aWHc30iMCqL (última consulta 05/03/2018) 
Jáuregui, P. (2013). "Periodismo científico: el desafío de compartir «información asombrosa»". Quaderns de la Fundació Dr. Antoni Esteve, (28), 9-14. Disponible en: http://ow.ly/TIlk30iMCuK (última consulta 05/03/2018)

Jensen, J. D., Pokharel, M., Scherr, C. L., King, A. J., Brown, N., y Jones, C. (2017). "Communicating uncertain science to the public: How amount and source of uncertainty impact fatalism, backlash, and overload". Risk Analysis, 37(1), 40-51.

Jianbin, J. I. N. (2006). "Presented image of universities in mass media". Journal of International Communication, 2, 004.

Jiménez, A., Fuentes, M. A. y González, A. (2003). "Los archivos audiovisuales en los medios de comunicación digital”. Scire: Representación y organización del conocimiento, 9(2), 99-110. Disponible en: http://ow.ly/ZGDw30iMCEe (última consulta 05/03/2018)

Jiménez Hidalgo, S., y Salvador Bruna, J. (2007). "Evaluación formal de los blogs con contenidos académicos y de investigación en el área de documentación". El profesional de la documentación. Disponible en: http://ow.ly/Mijk30iMCGZ (última consulta 05/03/2018)

Jiménez, M. (2011). “El fenómeno Twitter engancha a las compañías”. Cinco Días. Disponible en: http://ow.ly/ycvx30iMCKh (última consulta 05/03/2018)

John, W. S., y Johnson, P. (2000). "The pros and cons of data analysis software for qualitative research". Journal of Nursing Scholarship, 32(4), 393-397.

Jones, A., Issroff, K., Scanlon, E., Clough, G., McAndrew, P., y Blake, C. (2006). "Using mobile devices for learning in informal settings: is it motivating?". En: IADIS International Conference on Mobile Learning, 14-16 Julio, Dublin, IADIS,. 251-255 Disponible en: http://ow.ly/afbx30k9UaZ (última consulta 05/03/2018)

\section{K}

Kahle, K., Sharon, A. J., y Baram-Tsabari, A. (2016). "Footprints of Fascination: Digital Traces of Public Engagement with Particle Physics on CERN's Social Media 
Platforms". PloS one, 11(5), e0156409. Disponible en: http://ow.ly/dMW630iMCPJ (última consulta 05/03/2018)

Kandachi, K. (2001). Traditional and online media: how the Internet has changed the reporting of medical news. Tesis de Master. Escuela de Periodismo, Universidad de Maryland. Disponible en: http://ow.ly/c7mZ30iMCXL (última consulta 05/03/2018)

Kiernan, V. (1997). "Ingelfinger, embargoes, and other controls on the dissemination of science news". Science Communication, 18(4), 297-319.

Kiernan, V. (2003). "Embargoes and science news". Journalism \& Mass Communication Quarterly, 80(4), 903-920.

Kim, S. H., Carvalho, J.P. y Cooksey, C.E. (2007). "Exploring the effects of negative publicity: News coverage and public perceptions of a university". Public Relations Review, 33 (2), 233-235.

Kjellberg, S. (2010). "I am a blogging researcher: Motivations for blogging in a scholarly context". First Monday, 15 (8). Disponible en: http://ow.ly/6zdZ30iMDd9 (última consulta 05/03/2018)

Koolstra, C. M., Bos, M. J., y Vermeulen, I. E. (2006). "Through which medium should science information professionals communicate with the public: television or the internet". JCOM, 5 (3), A01. Disponible en: http://ow.ly/NGry30iMDkf (última consulta 05/03/2018)

Koteyko, N., Jaspal, R., y Nerlich, B. (2013). "Climate change and 'climategate'in online reader comments: a mixed methods study". The Geographical Journal, 179(1), 74-86. Disponible en: http://ow.ly/LJif30iMDnb (última consulta 05/03/2018)

Kouper, I. (2010). "Science blogs and public engagement with science: practice, challenges and opportunities". JCOM, 9 (1). Disponible en: http://ow.ly/sgzv30iMDto (última consulta 05/03/2018)

Kovic, I., Lulic, I., y Brumini, G. (2008). "Examining the medical blogosphere: an online survey of medical bloggers". Journal of Medical Internet Research, 10 (3). Disponible en: http://ow.ly/tsLZ30iMDBD (última consulta 06/03/2018) 
Koziner, N. S. (2013). "Antecedentes y fundamentos de la teoría del framing en comunicación". Austral Comunicación, 2(1), 01-25. Disponible en: http://ow.ly/yxFV30iMDHK (última consulta 06/03/2018)

Krakow, M., Crossley, K., Christy, K., Jensen, J. D., y Ratcliff, C. L. (2018). "News Coverage of Cancer Research: Does Disclosure of Scientific Uncertainty Enhance Credibility?". En: Risk and Health Communication in an Evolving Media Environment, 178-197. Focal Press. Disponible en: http://ow.ly/qTz930krReM (última consulta 06/03/2018)

Krumenaker L (2010). "Recession Causes NASW Members to Leave". Science Writers, 59, 3, 25.

Labarre, S. (2013). "Why we're shutting off our comments". Popular Science. Disponible en: http://ow.ly/YXaw30iMDOM (última consulta 06/03/2018)

Ladwig, P., Anderson, A. A., Brossard, D., Scheufele, D. A., y Shaw, B. (2010). "Narrowing the nano discourse?". Materials Today, 13(5), 52-54. Disponible en: http://ow.ly/4cVm30iMDSa (última consulta 06/03/2018)

Lagu, T., Kaufman, E. J., Asch, D. A., y Armstrong, K. (2008). "Content of weblogs written by health professionals". Journal of General Internal Medicine, 23 (10), 16421646. Disponible en: http://ow.ly/pxZw30iMDWb (última consulta 06/03/2018)

Laslo, E., Baram-Tsabari, A., y Lewenstein, B. (2011). "A growth medium for the message: Online science journalism affordances for exploring public discourse of science and ethics". Journalism, 12 (7). Disponible en: http://ow.ly/gKKa30iME0N (última consulta 06/03/2018)

Lasswell, H. D. (1985). Estructura y función de la comunicación en la sociedad. Sociología de la Comunicación de masas. II Estructura, funciones y efectos. 
Barcelona. Gustavo Gili, 50-68. Disponible en: http://ow.ly/Jgf130iME5w (última consulta 06/03/2018)

Lederbogen, U., y Trebbe, J. (2003). "Promoting Science on the Web Public Relations for Scientific Organizations-results of a Content Analysis". Science Communication, 24(3), 333-352. Disponible en: http://ow.ly/zcbL30iOcPz (última consulta 06/03/2018)

Lederbogen, U. (2004). "When Science goes public on the web: An analysis of the online PR strategies of German Universities and Research Organizations". Scientific Knowledge and Cultural Diversity, 267-275. Disponible en: http://ow.ly/807930iOcEM (última consulta 07/03/2018)

Lee, C. J., y Scheufele, D. A. (2006). "The influence of knowledge and deference toward scientific authority: A media effects model for public attitudes toward nanotechnology". Journalism \& Mass Communication Quarterly, 83(4), 819-834. Disponible en: http://ow.ly/2yM430iOd5B (última consulta 07/03/2018)

Legerén-Álvarez, E. (2014). "Visibilidad de las universidades andaluzas en los medios de comunicación on-line a través de Google News". Tesis Doctoral. Universidad de Granada. Disponible en: http://ow.ly/ptPP30iOd9b (última consulta 07/03/2018)

Len-Ríos, M. E., Bhandari, M., y Medvedeva, Y. S. (2014). "Deliberation of the Scientific Evidence for Breastfeeding Online Comments as Social Representations". Science Communication, 36(6), 778-801.

Lemos, A. (2009). "Nova esfera conversacional". En: Künsch, D. et al. Esfera pública, redes e jornalismo. Rio de Janeiro: E-Papers, 9-30.

León, B. (2002). "Divulgar la ciencia en televisión: problemas y oportunidades". A divulgação científica nos media-contributo. Ediçoes Cine-clube de Avanca, 73-79. Disponible en: http://ow.ly/HVW030iOdsW (última consulta 07/03/2018)

Levina, M. (2010). "Googling your genes: personal genomics and the discourse of citizen bioscience in the network age". JCOM, 9 (1), 1-8. Disponible en: http://ow.ly/QukR30iOdvK (última consulta 07/03/2018) 
Lewenstein, B. (1992). "Introduction". En: When science meets the public. Lewenstein, B. Washington, DC: American Association for the Advancement of Science. Disponible en: http://ow.ly/2IFW30iOdz3 (última consulta 07/03/2018)

Lewenstein, B. (2003). "Models of Public Communication of Science \& Technology". Manuscrito no publicado. Disponible en: http://ow.ly/vKoZ30iOdDx (última consulta 07/03/2018)

Lewenstein, B. V. (2009). "Where do books fit in the information age?". En: Holliman, R., Thomas, J., Smidt, S., Scanlon, E., y Whitelegg, L. (Eds.). Practising science communication in the information age: Theorising professional practices. Oxford University Press. 151-165.

Li, N., Anderson, A. A., Brossard, D., y Scheufele, D. A. (2013). "Channeling Science Information Seekers' Attention? A Content Analysis of Top-Ranked vs. Lower-Ranked Sites in Google". Journal of Computer Mediated Communication. Disponible en: http://ow.ly/YRdu30iOdlt (última consulta 07/03/2018)

Li, N., Akin, H., Su, L. Y. F., Brossard, D., Xenos, M., y Scheufele, D. A. (2016). "Tweeting disaster: an analysis of online discourse about nuclear power in the wake of the Fukushima Daiichi nuclear accident”. JCOM, 15(05), A02-2. Disponible en: http://ow.ly/rt8C30iOdOZ (última consulta 07/03/2018)

Liang, X., Anderson, A. A., Scheufele, D. A., Brossard, D., y Xenos, M. A. (2012). "Information snapshots: What Google searches really tell us about emerging technologies". Nano Today,7(2), 72-75. Disponible en: http://ow.ly/63F530iOdY7 (última consulta 07/03/2018)

Liang, X., Su, L. Y. F., Yeo, S. K., Scheufele, D. A., Brossard, D., Xenos, M., ... y Corley, E. A. (2014). "Building Buzz (Scientists) Communicating Science in New Media Environments". Journalism \& Mass Communication Quarterly. Disponible en: http://ow.ly/jEz730iOe4J (última consulta 07/03/2018)

Lippmann, W. (1946). Public opinion. Transaction Publishers. Disponible en: http://ow.ly/1iHS30iOeaQ (última consulta 07/03/2018) 
Lombard, M., Snyder-Duch, J., y Bracken, C. C. (2002). "Content analysis in mass communication: Assessment and reporting of intercoder reliability". Human communication research, 28(4), 587-604. Disponible en: http://ow.ly/hmMk30iOefC (última consulta 07/03/2018)

Loose, E. B., y de Lima, M. R. D. V. (2013). "A ciência nos portais de notícias: notas para pensar a popularização científica a partir do jornalismo online.Animus". Revista Interamericana de Comunicação Midiática, 12 (23), 85-102.

López, S. (2009). "AlphaGalileo, servicio de noticias de investigación líder en Europa". En: Foro Iberoamericano de Comunicación y Divulgación Científica, Campinas, Brasil, 25-29 de noviembre. Disponible en: http://ow.ly/3E1T30iOenX (última consulta 07/03/2018)

López-Goñil, I., y Angulo, M. S. (2013). "Un paseo microbiano por la web". SEM@foro, 56, 38-39. Disponible en: http://ow.ly/ej7l30iOesj (última consulta 07/03/2018)

López Pérez, L. (2015). Comunicación de la ciencia 2.0 en españa: El papel de los centros públicos de investigación y de las ediciones digitales de los periódicos de mayor audiencia. Tesis Doctoral. Universidad de Granada. Disponible en: http://ow.ly/LwCb30iOeyO (última consulta 07/03/2018)

López-Pérez, L. y Olvera-Lobo, M.D. (2015). "De la alfabetización científica a la comunicación pública de la ciencia en España”. En: López Ornelas, M.; Mateos Martín, C. (coords.). La comunicación científica: Una perspectiva universitaria. La Laguna (Tenerife): Sociedad Latina de Comunicación Social, 2015. (Cuadernos Artesanos de Comunicación; 93). pp. 185-213. Disponible en: http://ow.ly/9l5f30iOeDK (última consulta 07/03/2018)

López-Pérez, L., y Olvera Lobo, M. D. (2015). "El tratamiento de la información científica en las ediciones digitales de los periódicos españoles". El Profesional de la Información, 24, 6, 766-777. Disponible en: http://ow.ly/cjKB30iOel0 (última consulta 07/03/2018)

López-Pérez, L., y Olvera-Lobo, M. D. (2015). "Comunicación de la ciencia 2.0 en España: El papel de los centros públicos de investigación y de medios digitales". 
Revista Mediterránea de Comunicación/Mediterranean Journal of Communication, 6(2), 165-179. Disponible en: http://ow.ly/Tdl530iOeTO (última consulta 07/03/2018)

Lovato, C. D. S. (2014). "A homogeneidade discursiva em notícias de popularização da ciência nas revistas Ciência hoje online e Galileu". Tesis Doctoral, Programa de Posgraduado en Letras. Universidade Federal de Santa Maria. Disponible en: http://ow.ly/UqiQ30iOf3Q (última consulta 07/03/2018)

Luz, I. C. (2012). "Ciência 2.0: Comunicar ciência na era digital - da experiência à reflexão". Trabajo Fin de Grado en Ciencias de la Comunicación (Rama de Cultura, Patrimonio y Ciencia). Universidade do Porto. Disponible en: http://ow.ly/kbch30iOf7X (última consulta 07/03/2018)

Luzón, M. J. (2013). "Public Communication of Science in Blogs Recontextualizing Scientific Discourse for a Diversified Audience". Written Communication, 30 (4), 428457.

\section{M}

Macedo-Rouet, M. (2002). "Revistas de divulgação científica: do texto ao hipertexto". Ciência e público: Caminhos da divulgação científica no Brasil, 185-202. Disponible en: http://ow.ly/G33S30iOfhA (última consulta 07/03/2018)

Macedo-Rouet, M., Rouet, J. F., Epstein, I., y Fayard, P. (2003). "Effects of online reading on popular science comprehension". Science Communication, 25 (2). Disponible en: http://ow.ly/mA0730iOfnW (última consulta 07/03/2018)

Mahrt, M., y Puschmann, C. (2014). "Science blogging: an exploratory study of motives, styles, and audience reactions". JCOM, 13 (3). Disponible en: http://ow.ly/UfpP30iOfx0 (última consulta 07/03/2018)

Mandavilli, A. (2011). "Trial by twitter. Nature", 469 (7330), 20. Disponible en: http://ow.ly/AeqC30iOfAM (última consulta 07/03/2018) 
Marín Martínez, F., Sánchez Meca, J., y López López, J. (2009). “El metaanálisis en el ámbito de las Ciencias de la Salud: una metodología imprescindible para la eficiente acumulación del conocimiento". Fisioterapia, 31(3), 107-114. Disponible en: http://ow.ly/5jYv30iOfFW (última consulta 07/03/2018)

Marín-Murillo, F., y Armentia-Vizuete, J. I. (2002). "El periodismo científico en los diarios digitales del Estado español". Mediatika: cuadernos de medios de comunicación, (8), 157-178. Disponible en: http://ow.ly/VPER30iOfMx (última consulta 07/03/2018)

Martín, M. B., y Ponce, V. M. (2012). "Los periódicos digitales de San Luis y su papel en la divulgación de la ciencia. Análisis comparativo de algunos casos particulares". Fundamentos en Humanidades, 13(26), 147-158. Disponible en: http://ow.ly/IK3230iOfSz (última consulta 07/03/2018)

Martín Sempere, M. J., y Rey Rocha, J. (2007). El papel de los científicos en la comunicación de la ciencia y la tecnología a la sociedad: actitudes, aptitudes e implicación. Comunidad de Madrid, Consejería de Educación, Dirección General de Universidades e Investigación. Disponible en: http://ow.ly/McF130iOfYR (última consulta 07/03/2018)

Martínez Albertos, J. L. (1998). "La Tesis del" perro-guardián": revisión de una teoría clásica". Periodística, 99-110. Disponible en: http://ow.ly/fTpX30iOg9V (última consulta 07/03/2018)

Martínez-Badía, A., y Robinson-García, N. (2007). "Recursos en Internet para el periodista científico". Revista española de documentación científica, 30 (4), 565-578. Disponible en: http://ow.ly/ZQL030iOgjD (última consulta 07/03/2018)

Martínez Mendoza, S. (2011). "La difusión y la divulgación de la ciencia en Chiapas". Razón y Palabra, 16(78). Disponible en: http://ow.ly/zNZK30iOgnH (última consulta 07/03/2018)

Martínez Nicolás, M., y Saperas Lapiedra, E (2011). "La investigación sobre Comunicación en España (1998-2007). Análisis de los artículos publicados en revistas científicas". Revista latina de comunicación social, (66), 101. Disponible en: http://ow.ly/xszs30iOgt8 (última consulta 07/03/2018) 
Martínez Valdés, V., y Rodríguez Luna, E. ( 2004). "La Divulgación en la Era Tecnológica, el Caso de la Percepción del Mundo Natural”. XIII Congreso Nacional de Divulgación de la Ciencia y la Técnica. Disponible en: http://ow.ly/ecHI30iOgzf (última consulta 07/03/2018)

Massarani, L., Bauer, M. W., y Amorim, L. (2013). “Um raio X dos jornalistas de ciência: há uma nova 'onda'no jornalismo científico no Brasil?". Comunicação \& Sociedade, 35(1), 111-129. Disponible en: http://ow.ly/TFXv30iOgHm (última consulta 07/03/2018)

Massoli, L. (2007). "Science on the net: An analysis of the websites of the European public research institutions". JCOM, 6, 3, 1-16. Disponible en: http://ow.ly/26Es30iOgLr (última consulta 07/03/2018)

Mauranen, A. (2013). "Research blogging?". Documento online disponible en: http://ow.ly/YJ1U30iOgPy (última consulta 07/03/2018)

Mauranen, A. (2013). "Hybridism, Edutainment, and doubt: Science blogging finding its feet". Nordic Journal of English Studies, 13(1), 7-36. Disponible en: http://ow.ly/n4kj30iOgZ6 (última consulta 07/03/2018)

Mayoral Sánchez, J., Abejón Mendoza, P. y Morata Santos, M. (2016). "El vídeo en la prensa digital española: 2010-2015". Revista Latina de Comunicación Social, 71, pp. 775 a 799. Disponible en: http://ow.ly/Yg9T30iOh5J (última consulta 07/03/2018)

Mazzaro, C. (2010). "Comunicar la ciencia. Perspectivas, problemas y propuestas. PSIENCIA". Revista Latinoamericana de Ciencia Psicológica, 2(2). Disponible en: http://ow.ly/4jx430iOheq (última consulta 07/03/2018)

McCombs, M. E., y Shaw, D. L. (1972). "The agenda-setting function of mass media". Public opinion quarterly, 176-187. Disponible en: http://ow.ly/B9XA30iOhoL (última consulta 07/03/2018)

McCombs, M. (1996). "Influencia de las noticias sobre nuestras imágenes del mundo". En: Bryant, J. y Zillmann, D. (coords.). Los efectos de los medios de 
comunicación: investigaciones y teorías. 13-34. Grupo Planeta (GBS). Disponible en: http://ow.ly/YvO930iOhxF (última consulta 07/03/2018)

McCombs, M. (1997). "Building consensus: The news media's agenda-setting roles". Political Communication, 14(4), 433-443. Disponible en: http://ow.ly/ztdd30iOhC2 (última consulta 07/03/2018)

McFedries, P. (2012). "Measuring the impact of altmetrics [Technically Speaking]". IEEE Spectrum, 8(49), 28.

Meishar-Tal, H., y Pieterse, E. (2018). "Academics' Use of Academic Social Networking Sites: The Case of ResearchGate and Academia. Edu". European Journal of Open, Distance and E-learning, 21(1). Disponible en: http://ow.ly/GFUN30kT2kN (última consulta 07/03/2018)

Membiela Iglesia, P. (2002). Enseñanza de las ciencias desde la perspectiva ciencia-tecnología-sociedad: formación científica para la ciudadanía (Vol. 89). Narcea Ediciones.

Mendoza, S., y Paravic, T. (2006). "Origen, clasificación y desafíos de las revistas científicas". Investigación y postgrado, 21(1). Disponible en: http://ow.ly/iDfq30iOhQv (última consulta 07/03/2018)

Melo, L. B. (2017). "Títulos em notícias de divulgação científica: estratégias discursivas e funcionalidades na interface do Facebook". Linguagem em (Dis) curso, 17(1), 51-66. Disponible en: http://ow.ly/dHtx30krHU1 (última consulta 07/03/2018)

Meso-Ayerdi, K., y Díaz-Noci, J. (2002). Periodismo científico en el ciberespacio: la información académica al encuentro de la tecnología digital. Mediatika: cuadernos de medios de comunicación, (8), 605-629. Disponible en: http://ow.ly/PV8u30iOhUS (última consulta 07/03/2018)

Meso Ayerdi, K. (2005). "Periodismo ciudadano: voces paralelas a la profesión periodística". Chasqui. Revista Latinoamericana de Comunicación, (90), 4-13. Disponible en: http://ow.ly/Dski30iOi8e (última consulta 07/03/2018) 
Michael, G. (2013). "Opening up the conversation: an exploratory study of science Bloggers". Trabajo Fin de Master de Artes. University of Maryland. Disponible en: http://ow.ly/o0Xh30iOic7 (última consulta 07/03/2018)

Miller, J. D. (2001). "Who is using the web for science and health information?" Science Communication, 22(3), 256-273.

Miller, J. D. (2010). "Civic scientific literacy: The role of the media in the electronic era". En: Kennedy, D., y Overholser, G. (Eds.). Science and the Media. American Academy of Arts and Sciences, 44-63. Disponible en: http://ow.ly/Q83y30iOikj (última consulta 07/03/2018)

Miller, C. C. (2011). "Another try by Google to take on Facebook". The New York Times. Disponible en: http://ow.ly/YZNv30iOioU (última consulta 07/03/2018)

Minol, K., Spelsberg, G., Schulte, E., y Morris, N. (2007). "Portals, blogs and co.: the role of the Internet as a medium of science communication". Biotechnology journal, 2(9), 1129-1140. Disponible en: http://ow.ly/goA830iOiEm (última consulta 07/03/2018)

Mol, L. (2011). "The Potential Role for Infographics in Science Communication". Trabajo Fin de Master de Especialización en Comunicación. Vrije Universiteit Amsterdam. Disponible en: http://ow.ly/O4QR30iOiU2 (última consulta 07/03/2018)

Molek-Kozakowska, K. (2014). "Hybrid styles in popular reporting on science: A study of New Scientist's headlines". En: Electronic Proceedings, Hybrid forms of journalism in the $21^{\text {st }}$ century. Bruselas, Bélgica. Disponible en: http://ow.ly/wU4L30iOj4k (última consulta 07/03/2018)

Montgomery, S. L. (2009). "Science and the online world: realities and issues for discussion". En: Holliman, R., Thomas, J., Smidt, S., Scanlon, E., y Whitelegg, L. (Eds.). Practising science communication in the information age: Theorising professional practices. Oxford University Press. 83-97.

Montenegro, V., y Escudero, H. (2013). "Las redes sociales y la difusión de la tecnología y la innovación”. En: III Congreso Internacional de Comunicación Pública de la Ciencia, Santa Fe, Argentina. 
Mooney, C. (2009). "Science writers and science bloggers". Disponible en el blog Science Progress: http://ow.ly/1WGm30iOjsv (última consulta 07/03/2018)

Moreno Castro, C. (2003). "La investigación universitaria en periodismo científico". Ámbitos, (10). Disponible en: http://ow.ly/ocKp30iOjHS (última consulta 07/03/2018)

Moreno-Castro, C. (2013). "Estudio de la percepción social de la ciencia en Internet". En: Percepción social de la Ciencia y la Tecnología 2012. Fundación Española para la Ciencia y la Tecnología (FECYT). 125-158. Disponible en: http://ow.ly/6Ro230iOk8n (última consulta 07/03/2018)

Moreno-Espinosa, M. (2010). "Periodismo biomédico, nuevos contenidos mediáticos". Estudios sobre el Mensaje Periodístico, 16, 319-330. Disponible en: http://ow.ly/UquK30iOki0 (última consulta 07/03/2018)

Morton, C. C. (1996). "In how many ways do science writers love the Internet". ScienceWriters, 44, 21-26.

Morse, J. M. (1991). "Approaches to qualitative-quantitative methodological triangulation". Nursing research, 40(2), 120-123. Disponible en: http://ow.ly/GUGt30iOkuZ

Munive Suárez, P. (2010). "Videoconferencias interactivas, Internet, webcasting, Internet 2 y museos de ciencia en un proyecto de divulgación de la ciencia. Experiencias y propuestas de Universum". En: Virtual Educa Barcelona 2004.

Munzlinger, A., Ranzan, E. M. y Dandolini, G. A. (2014). "O impacto das TICs na disseminação do conhecimento: a divulgação científica pela revista da FAPESP". En: Confibercom, Braga, Portugal, 13-16 abril. Disponible en: http://ow.ly/bzVo30iOkXG (última consulta 07/03/2018)

Muñoz, E. (2002). "La cultura científica, la percepción pública y el caso de la biotecnología". Seminario La cultura científica en la Sociedad de la Información. Universidad de Oviedo. Disponible en: http://ow.ly/Gu6V30iOl3E (última consulta 07/03/2018) 
Murcott, T. H., y Williams, A. (2013). "The challenges for science journalism in the UK". Progress in Physical Geography, 37 (2), 152-160. 


\section{$\mathbf{N}$}

Nafría, I. (2007). Web 2.0: El usuario, el nuevo rey de Internet. Barcelona: Gestión 2000. Disponible en: http://ow.ly/fApT30iOnSN (última consulta 07/03/2018)

Nature. (2009). "It's good to blog". Editorial. 457, 1058. Disponible en: http://ow.ly/9cwh30iOo5I (última consulta 07/03/2018)

Nature. (2009). "Filling the void". Editorial. 458, 260. Disponible en: http://ow.ly/xZQk30iOo9f (última consulta 07/03/2018)

Nature Chemistry. (2013). "All you can tweet". Editorial, 5, 247. Disponible en: http://ow.ly/yBH130iOocL (última consulta 07/03/2018)

Nature Methods. (2009). "Lines of Communications". Editorial. 6 (3), 181. Disponible en: http://ow.ly/YILb30iOofd (última consulta 07/03/2018)

Navarro, I., y Revuelta, G. (2011). "Cómo hacer un vídeo científico: manual paso a paso". Colección comunicar es fácil. Observatorio de la Comunicación Científica Universidad Pompeu Fabra.

Nelkin, D. Selling science. How the press covers science and technology. Rev. ed. New York: Freeman.

Nentwich, M., y König, R. (2014). "Academia Goes Facebook? The Potential of Social Network Sites in the Scholarly Realm”. En: Bartling, S., y Friesike, S. Opening Science (pp. 107-124). Springer International Publishing. Disponible en: http://ow.ly/ldP830iOowN (última consulta 07/03/2018)

Neuman, L. W. (2011). Social research methods: Qualitative and quantitative approaches. Edimburgo, Reino Unido: Pearson Education Limited.

Newman, M. E. (2001). "The structure of scientific collaboration networks". Proceedings of the National Academy of Sciences, 98(2), 404-409. Disponible en: http://ow.ly/XQi430iOoDC (última consulta 07/03/2018) 
Newman, M. E. (2004). "Coauthorship networks and patterns of scientific collaboration". Proceedings of the National Academy of Sciences, 101(suppl 1), 52005205. Disponible en: http://ow.ly/BiSe30iOoHY (última consulta 07/03/2018)

Nieda, J., y Macedo, B. (1998). "Importancia de la enseñanza de las ciencias en la sociedad actual". Un currículo científico para jóvenes de 11 a 14 años, 19-24. Disponible en: http://ow.ly/qyD330iOoKY (última consulta 07/03/2018)

Nielsen, M. (2009). "Is scientific Publishing about to be disrupted?". Disponible en el blog: http://ow.ly/G05I30iOoPz (última consulta 07/03/2018)

Nielsen, M. (2009). "Doing science online”. Disponible en el blog Michael Nielsen: http://ow.ly/Bo7X30iOoSd (última consulta 07/03/2018)

Nisbet, M. C., Scheufele, D. A., Shanahan, J., Moy, P., Brossard, D., y Lewenstein, B. V. (2002). "Knowledge, reservations, or promise? A media effects model for public perceptions of science and technology". Communication Research, 29(5), 584-608. Disponible en: http://ow.ly/iSXI30iOoXC (última consulta 07/03/2018)

Norris, P. (2001). Digital divide: Civic engagement, information poverty, and the Internet worldwide. Cambridge University Press.

Novin, A., y Meyers, E. (2017). "Making sense of conflicting science information: Exploring bias in the search engine result page". En: Proceedings of the 2017 Conference on Conference Human Information Interaction and Retrieval, Oslo,7-11 marzo, 175-184. Disponible en: http://ow.ly/tTUM30krJLY (última consulta 07/03/2018)

Nozal Cantarero, T., y González Neira, A. (2012). "La interactividad en las aplicaciones periodísticas para iPad italianas y españolas". Estudios sobre el mensaje periodístico, 18, 639-648. Disponible en: http://ow.Iy//Z6h30iOp0n (última consulta 07/03/2018) 


\section{0}

O'Connor, C., y Joffe, H. (2014). "Gender on the brain: a case study of science communication in the new media environment". PLoS One, 9(10), e110830. Disponible en: http://ow.ly/8BbS30iOlzK (última consulta 07/03/2018)

Ogden, L. E. (2013). "Tags, blogs, tweets: social media as science tool?". BioScience, 63(2), 148. Disponible en: http://ow.ly/EVtK30iOIN2 (última consulta 07/03/2018)

Oliveira Fagundes, V. (2014). "Science blogs: communication, participation and public engagement". En: $13^{\circ}$ Congreso Internacional sobre Comunicación Pública de la Ciencia y la Tecnología (PCST). Salvador, Brasil, 5-8 mayo. Disponible en: http://ow.ly/rKql30iOIUZ (última consulta 07/03/2018)

Oltra, C., Delicado, A., Prades, A., Pereira, S., y Schmidt, L. (2014). "The Holy Grail of energy? A content and thematic analysis of the presentation of nuclear fusion on the Internet". JCOM, 13. Disponible en: http://ow.ly/qsPM30iOmhE (última consulta 07/03/2018)

Olvera-Lobo, M. D. y López-Pérez, L. (2015). "Periodismo científico: la homogeneización de la información del papel a internet”. JCOM 14 (03), Y01_es. Disponible en: http://ow.ly/Na0N30iOmnZ (última consulta 07/03/2018)

Onieva, J. E. S. (2016). Gabinetes de comunicación universitarios y redes sociales: Estudio del uso de las redes sociales por las Universidades Públicas andaluzas. Tesis Doctoral. Universidad de Almería.

Orihuela, J. L. (2007). "Los 'weblogs' cumplen diez años de agitación”. El País. Disponible en: http://ow.ly/Fcb730iOmle (última consulta 07/03/2018)

Osset Hernández, M. (2014). Responsible Research and Innovation (RRI): the next frontier in R+ D. Revista Lasallista de Investigación, 11(1), 51-55. Disponible en: http://ow.ly/rk6L30iOmUm (última consulta 07/03/2018) 
Osterrieder, A. (2013). "The value and use of social media as communication tool in the plant sciences". Plant methods, 9(1), 26. Disponible en: http://ow.ly/uCiG30iOn3l (última consulta 07/03/2018)

Oughton, J. (2010). "Science communication and the age of the Internet". Communicating science online- A crash course in Internet marketing. Disponible en: http://ow.ly/6lk330iOnyZ (última consulta 07/03/2018)

Owen, R., Macnaghten, P., y Stilgoe, J. (2012). "Responsible research and innovation: From science in society to science for society, with society". Science and public policy, 39(6), 751-760. Disponible en: http://ow.ly/ke2530iOnGz (última consulta 07/03/2018)

\section{$\mathbf{P}$}

Page, L., Brin, S., Motwani, R., y Winograd, T. (1999). The PageRank citation ranking: Bringing order to the web. Stanford InfoLab. Disponible en: http://ow.ly/bkMF30iOp3K (última consulta 07/03/2018)

Papworth, S. K., Nghiem, T. P. L., Chimalakonda, D., Posa, M. R. C., Wijedasa, L. S., Bickford, D., y Carrasco, L. R. (2015). "Quantifying the role of online news in linking conservation research to Facebook and Twitter". Conservation Biology, 29(3), 825-833. Disponible en: http://ow.ly/mCjq30iOpas (última consulta 07/03/2018)

Parin, M. L., Yancey, E., Beidler, C., y Haynes, E. N. (2014). "Efficacy of Environmental Health E-Training for Journalists". Studies in Media and Communication, 2 (1), 71-80. Disponible en: http://ow.ly/nZdn30iOpff (última consulta 07/03/2018)

Parra Castillo, S. (2013). "Col- laboració 2.0: El futur de la divulgació científica". Mètode Science Studies, 77, 36-41. Disponible en: http://ow.ly/NIR930iOpnd (última consulta 07/03/2018)

Parra Valcarce, D., y Álvarez Marcos, J. (2004). Ciberperiodismo. Madrid: Síntesis. 
Pearce, W., Brown, B., Nerlich, B., y Koteyko, N. (2015). "Communicating climate change: conduits, content, and consensus". Wiley Interdisciplinary Reviews: Climate Change, 6(6), 613-626. Disponible en: http://ow.ly/AOjm30iOpuF (última consulta 07/03/2018)

Pereira Cavalcanti, D., y Cavalcanti, C. C. B. (2009). "New languages for the spreading of scientific knowledge: broadening the dialog between science and society". JCOM, 8 (1). Disponible en: http://ow.ly/b0ly30iOpxl (última consulta 07/03/2018)

Pérez, V. (2010). "Parte de la comunidad científica cuestiona el anuncio de la NASA". ABC. Disponible en: http://ow.ly/3ABm30iOpAj (última consulta 07/03/2018)

Pérez Martínez, A. (2011). "La comunicación sobre la salud en medios digitales cubanos", Revista Cubana de Salud Pública, 37 (3), 288-305. Disponible en: http://ow.ly/xtMb30iOpEI (última consulta 07/03/2018)

Pérez Martínez, A. (2012). "Acercamiento a la divulgación de salud en Webs periodísticas nacionales cubanas". ACIMED, 23(1), 2-18. Disponible en: http://ow.ly/vDtF30iOpl1 (última consulta 07/03/2018)

Pérez-Rodríguez, A.V. (2016). Imagen visible de la ciencia en la prensa digital generalista: Actores y Procesos (España 2002-2011). Tesis Doctoral. Universidad de Salamanca. Disponible en: http://ow.ly/VEYX30iOpLf (última consulta 07/03/2018)

Pérez-Rodríguez, A. V., González-Pedraz, C., y Berrocal, J. L. A. (2018). "Twitter como herramienta de comunicación científica en España: principales agentes y redes de comunicación". Communication Papers, 7(13), 95. Disponible en: http://ow.ly/1CpC30k8ECZ (última consulta 23/05/2018)

Pérez Serrano, M. G. (1984). Un análisis de contenido de la prensa: la imagen de la Universidad a Distancia. Universidad Nacional de Educación a Distancia, UNED.

Peters, H. P. (2013). "Gap between science and media revisited: Scientists as public communicators". Proceedings of the National Academy of Sciences, 110(Supplement 3), 14102-14109. Disponible en: http://ow.ly/uSY830iOpQl (última consulta 07/03/2018) 
Peters, H. P., Dunwoody, S., Allgaier, J., Lo, Y. Y., y Brossard, D. (2014). "Public communication of science 2.0". EMBO reports, 15(7). Disponible en: http://ow.ly/AhMm30iOpXq (última consulta 07/03/2018)

Peterson, I. (2001). "Touring the scientific web". Science Communication, 22(3), 246-255.

Picardi, I., y Regina, S. (2008). "Sience via podcast". JCOM, 7 (2). Disponible en: http://ow.ly/7ELt30iOq2P (última consulta 07/03/2018)

Picó Garcés, M. J. (2014). "La divulgación del medio ambiente a través del relato periodístico digital". Nuevos retos en la comunicación de la complejidad ambiental. Prisma Social, (12). Disponible en: http://ow.ly/MuTi30iOq7w (última consulta 07/03/2018)

Pinholster, G., y O’Malley, C. (2006). "EurekAlert! survey confirms challenges for science communicators in the post-print era". JCOM, 5 (03), 1-12. Disponible en: http://ow.ly/RvNI30iOabJ (última consulta 07/03/2018)

Pinholster, G., y Ham, B. "Science Communication Requires Time, Trust, and Twitter". Science. 342, 1464. Disponible en: http://ow.ly/Hlj330iOgfo (última consulta 07/03/2018)

Pinto Cejas, T. (2013). “La información científica en la Red". Revista Española de Física, 27(3), 16-19.

Pitrelli, N. (2011). "Science journalism and digital storytelling". JCOM, 10 (4). Disponible en: http://ow.ly/lcZ630iOqwK (última consulta 07/03/2018)

Pjesivac, I., Geidner, N., y Cameron, J. (2018). "Social credibility online: The role of online comments in assessing news article credibility". Newspaper Research Journal, $39,1,18-31$.

Pont Sorribes, C., Cortiñas Rovira, S., y Di Bonito, I. (2013). "Challenges and opportunities for science journalists in adopting new technologies: the case of Spain”. JCOM, 12 (03). Disponible en: http://ow.ly/uTh630iOqB6 (última consulta 07/03/2018) 
Porto, C. (2007). "O Jornalismo Científico on-line e sua função política moderadora: estudo no site Comciencia". Diálogos \& Ciência, 10, 1-15. Disponible en: http://ow.ly/ihqQ30iOqEu (última consulta 07/03/2018)

Porto, C., y Almeida, D. (2009). "Divulgação científica independente na Internet como fomentadora de uma cultura científica no Brasil: estudo inicial em alguns Blogs que tratam de ciência”. En: Magalhães, C. (Editora). Difusão e cultura científica: alguns recortes. SciELO-EDUFBA (Editoria da Universidade Federal da Bahia). Disponible en: http://ow.ly/TX5M30iOgK3 (última consulta 07/03/2018)

Porto, C. (2009). "A internet e a cultura científica no Brasil: difusão de ciência”. En: Magalhães, C. (Editora). Difusão e cultura científica: alguns recortes. SciELO-EDUFBA (Editoria da Universidade Federal da Bahia). Disponible en: http://ow.ly/BmyA30iOqMS (última consulta 07/03/2018)

Porto, C., y Palacios, M. S. (2012). "O lugar eo peso da autopublicação na internet ea cultura científica no Brasil”. Revista Educação e Cultura Contemporânea, 9 (18), 53-74. Disponible en: http://ow.ly/Ln1b30iOgRW (última consulta 07/03/2018)

Priest, S. (2013). "Un panorama cambiante para los medios de comunicación: ciencia, público y prensa: el caso del cambio climático". Mètode: Revista de difusión de la Investigación, (80), 84-92. Disponible en: http://ow.ly/XRqh30iOqWr (última consulta 07/03/2018)

Puschmann, C., y Mahrt, M. (2012). "Scholarly blogging: A new form of publishing or science journalism 2.0". En: Tokar, A., Beurskens, M., Keuneke, S., Mahrt, M., Peters, I., et al. (eds.). Science and the Internet, 171-181. Düsseldorf: Düsseldorf University Press. Disponible en: http://ow.ly/qhSe30iOrOH (última consulta 07/03/2018)

Puschmann, C. (2014). "(Micro) Blogging Science? Notes on Potentials and Constraints of New Forms of Scholarly Communication”. En: Friesike, S., y Bartling, S. (eds.). Opening Science. 89-106. New York, NY: Springer International Publishing. Disponible en: http://ow.ly/Dofs30iOr2X (última consulta 07/03/2018) 


\section{Q}

Quintanilla, M. A., Sabbatini, M., Cerro, S., Palacio Mateos, E., y Gómez López, P. (2004). "Novatores: an integral project for science communication". En: $8^{\circ}$ Congreso Internacional sobre Comunicación Pública de la Ciencia y la Tecnología (PCST). Barcelona, 3-6 junio. Disponible en: http://ow.ly/iWQ130iOr5D (última consulta 07/03/2018)

Quintanilla, M. Á., Montero Becerra, A., Ochoa Henao, M., Orellana McBride, A. E., y Sabbatini, M. (2004). Análisis del impacto de la actividad científica y tecnológica de las universidades españolas en los medios de comunicación. Informe de resultados. Disponible en: http://ow.ly/pQjh30iOraQ (última consulta 07/03/2018)

Quintanilla, M. Á. (2011). "La ciencia y la cultura científica”. ArtefaCToS, 3, 1, 31 -48. Disponible en: http://ow.ly/Lp1p30iOrio (última consulta 07/03/2018)

Quintas-Froufe, N. (2016). "La emergencia de las redes sociales académicas: su impacto académico". Opción: Revista de Ciencias Humanas y Sociales, (10), 517-528. Disponible en: http://ow.ly/iFUh30kT1VN (última consulta 07/03/2018)

Quiñónez Gómez, H. (2015). “Enseñanza de la escritura digital: aspectos formativos para el periodismo científico". Educere, 19(63). Disponible: http://ow.ly/CxsZ30iOroU (última consulta 07/03/2018)

Quiñónez Gómez, H., y Sánchez Colmenares, M. (2016). "Uso de Twitter en el periodismo científico. Los casos de los diarios El Nacional y El Universal en Venezuela". Questión, 1. Disponible en: http://ow.ly/Pxbf30iOrx4 (última consulta 07/03/2018)

\section{$\mathbf{R}$}

Ramalho, M., Massarani, L., Castrillón, T. A., Polino, C., Vara, A. M., Crúz-Mena, J., ... y de Castro Moreira, I. (2012). "Ciência em telejornais: uma proposta de ferramenta para análise de conteúdo de notícias científicas". En: Ramalho, M. y Massarani, L. (Eds.). Monitoramento e capacitação em jornalismo científico: a experiência de uma rede ibero-americana. Centro Internacional de Estudios Superiores de Comunicación 
para América Latina (Ciespal). Disponible en: http://ow.ly/HTIk30iOrBa (última consulta 07/03/2018)

Ranger, M., y Bultitude, K. (2016). 'The kind of mildly curious sort of science interested person like me': Science bloggers' practices relating to audience recruitment. Public Understanding of Science, 25(3), 361-378. Disponible en: http://ow.ly/4ouv30iOrEy (última consulta 07/03/2018)

Regan, Á., Shan, L., McConnon, Á., Marcu, A., Raats, M., Wall, P., y Barnett, J. (2014). "Strategies for dismissing dietary risks: insights from user-generated comments online". Health, risk \& society, 16(4), 308-322. Disponible en: http://ow.ly/y5ye30iOrlW (última consulta 07/03/2018)

Redfern, M. (2009). "Speaking to the world: radio and other audio". En: Holliman, R., Thomas, J., Smidt, S., Scanlon, E., y Whitelegg, L. (Eds.). Practising science communication in the information age: Theorising professional practices. Oxford University Press. 178-192.

Repiso, R., Merino-Arribas, A., y Chaparro-Domínguez, M. Á. (2016). "Agrupación de las universidades españolas en la prensa impresa nacional". Revista Española de Documentación Científica, 39(2), 131. Disponible en: http://ow.ly/FyFw30iOrU9 (última consulta 07/03/2018)

Revuelta, G. (1999). "Relaciones entre científicos y periodistas". Alambique: Didáctica de las Ciencias Experimentales, 6(21), 27-34.

Revuelta, G., y Corchero García, C. (2010). "Búsqueda activa y recepción pasiva de información sobre ciencia y tecnología". En: Percepción social de la ciencia y la tecnología 2010. Fundación Española para la Ciencia y la Tecnología (FECYT). 183202. Disponible en: http://ow.ly/UKOq30iOs58 (última consulta 07/03/2018)

Ribeiro, F. M. (2010). "Weblogues como meio privilegiado para o exercício do ombudsman em Jornalismo de ciencia". Revista Prisma, (3), 274-288. Disponible en: http://ow.ly/nNFA30iOsa3 (última consulta 07/03/2018)

Riesch, H. (2011). "Changing news: re-adjusting science studies to online newspapers". Public Understanding of Science, 20 (6), 771-777. Disponible en: http://ow.ly/m1x730iOsdP (última consulta 07/03/2018) 
Ribas, C. (2012). "La divulgación y la comunicación de la ciencia, en la encrucijada". SEBBM, 173, 10-12. Disponible en: http://ow.ly/J7v030iOsgm (última consulta 07/03/2018)

Rocha, P. M., y Zauith, G. (2016). Análise bibliométrica das produções acadêmicas brasileiras sobre jornalismo científico e difusão científica durante o período de 2007 a 2013. Conexão-Comunicação e Cultura, 15(29). Disponible en: http://ow.ly/BjAe30krHny (última consulta 07/03/2018)

Robbins, M. (2010). "This is a news website article about a scientific paper". Disponible en el blog The Lay Scientist: http://ow.ly/Ygbr30iOsiL (última consulta 07/03/2018)

Rodrigues Pereira, F., Oliveira, L. y Zamith, F. (2014). "A perspetiva dos editores sobre a criação e utilização de infográficos de ciência e tecnologia nas ediçcoe dos jornais on-line". En: Confibercom, Braga, Portugal, 13-16 abril. Disponible en: http://ow.ly/6cNt30iOsmG (última consulta 07/03/2018)

Rodríguez-Polo, X. R. (2011). "Los efectos de la comunicación de masas de Joseph T. Klapper”. Razón y palabra, (75), 28. Disponible en: http://ow.ly/fLm930iOspQ (última consulta 07/03/2018)

Rodríguez Ruiz, Ó. (2005). "La triangulación como estrategia de investigación en ciencias sociales". Revista Madri+d, 31. Disponible en: http://ow.ly/l0Bo30iOsvk (última consulta 07/03/2018)

Rogers, R. y Marres, N. (2000). "Landscaping climate change: a mapping technique for understanding science and technology debates on the World Wide Web". Public Understanding of Science, 9, 1-23. Disponible en: http://ow.ly/K5ha30iQTsg (última consulta 09/03/2018)

Rogers, C. L. (2000). "Making the audience a key participant in the science communication process". Science and engineering ethics, 6(4), 553-557.

Rowan, C. (2011). "How blogs, Twitter and other social media tools are changing conversations about scientific research". Earth Magazine. Disponible online en: http://ow.ly/45tz30iQTJh (última consulta 09/03/2018) 
Rowe, D. y Brass, K. (2008). "The uses of academic knowledge: the university in the media". Media, Culture \& Society, 30 (5), pp. 677-698.

Ruiz Jiménez, I., Barragán, M. J. R., y Moral, M. V. N. (2014). “Difusión Social de la Ciencia en los Medios de Comunicación Extremeños". Cuadernos de Documentación Multimedia, 25, 101-117. Disponible en: http://ow.ly/iNPE30iQTVO (última consulta 09/03/2018)

Ruiz-Pérez, R., Delgado López-Cózar, E., y Jiménez-Contreras, E. (2006). "Criterios del Institute for Scientific Information para la selección de revistas científicas. Su aplicación a las revistas españolas: metodología e indicadores". International journal of clinical and health psychology, 6(2). Disponible en: http://ow.ly/Uwx030iQU3p (última consulta 09/03/2018)

Runge, K. K., Yeo, S. K., Cacciatore, M., Scheufele, D. A., Brossard, D., Xenos, M., ... y Su, L. Y. F. (2013). "Tweeting nano: How public discourses about nanotechnology develop in social media environments". Journal of nanoparticle research, 15(1), 1-11. Disponible en: http://ow.ly/Whp330iQU5J (última consulta 09/03/2018)

Russell, J. M., Ainsworth, S., del Río, J. A., Narváez-Berthelemot, N., y Cortés, H. D. (2007). "Colaboración científica entre países de la región latinoamericana". Revista Española de Documentación Científica, 30(2), 180-198. Disponible en: http://ow.ly/PvOs30iQU8p (última consulta 09/03/2018)

Russell, J. M., Madera Jaramillo, M., y Ainsworth, S. (2009). "El análisis de redes en el estudio de la colaboración científica". Redes: revista hispana para el análisis de redes sociales, 17, 039-47. Disponible en: http://ow.ly/zfDK30iQUaP (última consulta 09/03/2018)

Russell, C. (2009). "Science journalism goes global". Science, 324 (5934), 14911491. Disponible en: http://ow.ly/s5CE30iQUdW (última consulta 09/03/2018)

Russell, N. (2010). Communicating science: Professional, popular, literary. Cambridge University Press. 
Rzepa, H. (1999). "The Internet as a medium for science communication.Communicating science". Reader, 1, 141-149. Disponible en: http://ow.ly/HU0a30iQUgL (última consulta 09/03/2018)

Sádaba, T. (2001). "Origen, aplicación y límites de la "teoría del encuadre" (framing) en comunicación". Communication \& Society 14(2), 143-175. Disponible en: http://ow.ly/akDq30iRjfh (última consulta 09/03/2018)

Sabbatini, M., Maciel, B., Coll, I., López, P. J. G., Pérez-Rodríguez, A.V., ... y Quintanilla, M. Á. (2004). "Dicyt: a proposal for regional science communication”. En: 8ํㅡㄹ Congreso Internacional sobre Comunicación Pública de la Ciencia y la Tecnología (PCST). Barcelona, 3-6 junio. Disponible en: http://ow.ly/CPTD30iRjhZ (última consulta 09/03/2018)

Sabbatini, M. y Maciel, B. (2005). "Suporte teórico e aplicação prática das infografías multimedia como suporte ao jornalismo científico online: um estudo exploratório". En: III Encontro Nacional de Pesquisadores em Jornalismo, Florianópolis, 27-29 noviembre. Disponible en: http://ow.ly/ZG4I30iRjof (última consulta 09/03/2018)

Sagan, C. (1989). "Why we need to understand science". Parade Magazine, 10. Disponible en: http://ow.ly/yFWF30iRjwg (última consulta 09/03/2018)

Salaverría, R. (2005). Cibermedios: el impacto de Internet en los medios de comunicación en España (Vol. 15). Sevilla: Comunicación Social Ediciones y Publicaciones.

Salaverría, R. (2016). Ciberperiodismo en Iberoamérica. Ariel y Fundación Telefónica. Disponible en: http://ow.ly/t5JV30jW0iv (última consulta 09/03/2018)

Sancha, D. (2005). "El uso de la información de agencia en las ediciones electrónicas de diarios en España: estudio comparativo de las páginas web de 'El Periódico','El Mundo’y 'La Vanguardia'”. Athenea digital: revista de pensamiento e 
investigación social, (8), 234-267. Disponible en: http://ow.ly/Jvur30iRizF (última consulta 09/03/2018)

Sancho, R., Morillo, F., De Filippo, D., Gómez, I., y Fernández, M. T. (2006). "Indicadores de colaboración científica inter-centros en los países de América Latina". Interciencia, 31(4), 284-292. Disponible en: http://ow.ly/V2qV30iRjCB (última consulta 09/03/2018)

Sanz-Pérez de Guzmán, E. (2002). “Ciencia digit@ I: ciencia para todos en Internet”. Mediatika: cuadernos de medios de comunicación, (8), 179-184. Disponible en: http://ow.ly/xFdE30iRjEE (última consulta 09/03/2018)

Sánchez Ramos, M. E., y Barradas Bribiesca, I. (2014). "Divulgación de la ciencia a través de los dispositivos móviles. Alternativa Educativa en México". Revista Iberoamericana para la Investigación y el Desarrollo Educativo, (12). Disponible en: http://ow.ly/TtPE30iRjJQ (última consulta 09/03/2018)

Sarmento, M. F., Foresti, M. C. P. P., y Vidotti, S. A. B. G. (2004). "Arquitetura da Informação em web site de periódico científico". Educação Temática Digital, 5(2), 87. Disponible en: http://ow.ly/WRKi30iRjMB (última consulta 09/03/2018)

Segado-Boj, F., Chaparro, M. A., y Berlanga, I. (2014). "La divulgación en los blogs científicos hispanoparlantes. Funciones, fuentes, lenguaje y estrategias retóricas". Prisma Social, (12), 143-172. Disponible en: http://ow.ly/HGfn30iRjPf (última consulta 09/03/2018)

Scanlon, E., Jones, A., y Waycott, J. (2005). "Mobile technologies: prospects for their use in learning in informal science settings". Journal of Interactive Media in Education, 2005(2). Disponible en: http://ow.ly/Xtnf30k9Uhl (última consulta 09/03/2018)

Schummer, J. (2009). "Science communication across disciplines". En: Holliman, R., Thomas, J., Smidt, S., Scanlon, E., y Whitelegg, L. (Eds.). Practising science communication in the information age: Theorising professional practices. Oxford University Press. 53-66. 
Seabra, D. F. D. S. (2012). "O envolvimento dos jovens em conteúdos de ciência online". Trabajo Fin de Grado en Ciencias de la Comunicación (Rama de Cultura, Patrimonio y Ciencia). Universidade do Porto. Disponible en: http://ow.ly/1udA30iRjua (última consulta 09/03/2018)

Secko, D. M., Tlalka, S., Dunlop, M., Kingdon, A., y Amend, E. (2011). "The unfinished science story: Journalist-audience interactions from the Globe and Mail's online health and science sections". Journalism, 12(7), 814-831.

Segev, E., y Baram-Tsabari, A. (2012). "Seeking science information online: Data mining Google to better understand the roles of the media and the education system". Public Understanding of Science,21(7), 813-829. Disponible en: http://ow.ly/Ar6e30iRk2R (última consulta 09/03/2018)

Segev, E., y Sharon, A. J. (2017). "Temporal patterns of scientific informationseeking on Google and Wikipedia". Public Understanding of Science, 26(8), 969-985.

Shäfer, M. (2011). "Science journalism and fact checking”. JCOM, 10 (4). Disponible en: http://ow.ly/AXDw30iRk4g (última consulta 09/03/2018)

Schäfer, M. (2012). "Taking stock: A meta-analysis of studies on the media's coverage of science". Public Understanding of Science, 21(6), 650-663.

Schäfer, M. S. (2017). "How changing media structures are affecting science news coverage". En: Jamieson. K. H., Kahan, D. y Scheufele, D. A. The Oxford Handbook of the Science of Science Communication, 51-60.

Shanahan, M. C. (2010). "Changing the meaning of peer-to-peer? Exploring online comment spaces as sites of negotiated expertise". JCOM, 9 (1). Disponible en: http://ow.ly/9KHT30iRk5D (última consulta 09/03/2018)

Shanahan, M. C. (2011). "Science blogs as boundary layers: Creating and understanding new writer and reader interactions through science blogging". Journalism, 12 (7), 903-919. 
Sharma, O. P. (2014). "Science communication through mobile devices". En: Communicating Science to the Public (pp. 247-260). Springer Netherlands. Disponible en: http://ow.ly/mPVQ30iRk90 (última consulta 09/03/2018)

Sharman, A. (2014). "Mapping the climate sceptical blogosphere". Global Environmental Change, 26, 159-170. Disponible en: http://ow.ly/jR|x30iRkbW (última consulta 09/03/2018)

Scheufele, D. A. (1999). "Framing as a theory of media effects". Journal of communication, 49(1), 103-122. Disponible en: http://ow.ly/iqNP30iRkdY (última consulta 09/03/2018)

Shema, H., Bar-llan, J., y Thelwall, M. (2012). "Self-citation of bloggers in the science blogosphere". En: Tokar, A., Beurskens, M., Keuneke, S., Mahrt, M., Peters, I., Van Treeck, T., y Weller, K. (eds.). Science and the Internet, 183-192. Düsseldorf: Düsseldorf University Press. Disponible en: http://ow.ly/A2eT30iRkhe (última consulta 09/03/2018)

Shema, H., Bar-llan, J., y Thelwall, M. (2012). Research blogs and the discussion of scholarly information. PloS one, 7(5), e35869. Disponible en: http://ow.ly/sZ2j30iRkiO (última consulta 09/03/2018)

Shema, H., Bar-llan, J., y Thelwall, M. (2015). "How is research blogged? A content analysis approach". Journal of the Association for Information Science and Technology, 66(6), 1136-1149. Disponible en: http://ow.ly/wq1x30iRkmk (última consulta 09/03/2018)

Shiffman, D. S. (2012). "Twitter as a tool for conservation education and outreach: what scientific conferences can do to promote live-tweeting". Journal of Environmental Studies and Sciences, 2 (3), 257-262. Disponible en: http://ow.ly/Qp1Z30iRkol (última consulta 09/03/2018)

Smith, R. (1998). "Beyond conflict of interest: transparency is the key". BMJ: British Medical Journal, 317(7154), 291. Disponible en: http://ow.ly/foyU30iRkuU (última consulta 09/03/2018) 
Smith, C. (2011). "The power of the podcast: the Naked Scientists' story". En: Bennett, D. J., y Jennings, R. C. (Eds.). Successful science communication. 268-279

Smith, B., Baron, N., English, C., Galindo, H., Goldman, E., McLeod, K., ... y Neeley, E. (2013). "COMPASS: navigating the rules of scientific engagement". PLoS biology, 11(4), e1001552. Disponible en: http://ow.ly/c6m030iRkCZ (última consulta 09/03/2018)

Smith, L. F., Arcand, K. K., Smith, J. K., Smith, R. K., Bookbinder, J., y Watzke, M. (2014). "Examining perceptions of astronomy images across mobile platforms". JCOM. Disponible en: http://ow.ly/hY1l30iRkF0 (última consulta 09/03/2018)

Soler-Tovar, D. (2014). "Redes sociales y divulgación científica". Revista de Medicina Veterinaria, (27), 9-10. Disponible en: http://ow.ly/NZ7a30iRkTa (última consulta 09/03/2018)

Stahl, B. C. (2013). "Responsible research and innovation: The role of privacy in an emerging framework". Science and Public Policy, 40(6), 708-716. Disponible en: http://ow.ly/Jljo30iRkQj (última consulta 09/03/2018)

Stocking, S. H. (1999). "How journalists deal with scientific uncertainty. Communicating uncertainty: Media coverage of new and controversial science", 23-42. Disponible en: http://ow.ly/gYcS30iRkWI (última consulta 09/03/2018)

\section{$\mathbf{T}$}

Taddicken, M. (2013). "Climate change from the user's perspective". Journal of Media Psychology. 25, 39-52.

Taylor, J. W., Long, M., Ashley, E., Denning, A., Gout, B., Hansen, K., ... y Wojtowicz, A. (2015). "When medical news comes from press releases-A case study of pancreatic cancer and processed meat". PloS one, 10(6), e0127848. Disponible en: http://ow.ly/Ny6i30iRP7M (última consulta 09/03/2018) 
Thomas, J. (2009). "Controversy and consensus". En: Holliman, R., Thomas, J., Smidt, S., Scanlon, E., y Whitelegg, L. (Eds.). Practising science communication in the information age: Theorising professional practices. Oxford University Press. 130-148.

Thorsen, E. (2013). "Blogging on the ice: Connecting audiences with climate-change sciences". International Journal of Media \& Cultural Politics, 9(1), 87-101. Disponible en: http://ow.ly/sjqh30iRP8y (última consulta 09/03/2018)

Tian, Y., y Stewart, C. M. (2005). "Framing the SARS crisis: A computer-assisted text analysis of CNN and BBC online news reports of SARS". Asian Journal of Communication, 15(3), 289-301.

Tola, E. (2008). "To blog or not to blog, not a real choice there...". JCOM, 7 (2), 1-3. Disponible en: http://ow.ly/5Mgp30iRPa1 (última consulta 09/03/2018)

Torres, M., Patrón, E., Posadas, J. y Juárez, S. (2014). "Catálogo de medios impresos en México, que difunden contenidos científicos y tecnológicos a través de sus ediciones online". En: Congreso Iberoamericano de Ciencia, Tecnología, Innovación y Educación. Buenos Aires, Argentina, 12-14 de noviembre. Disponible en: http://ow.ly/XtFt30iRPb3 (última consulta 09/03/2018)

Torres-Salinas, D., y Cabezas-Clavijo, Á. (2008). "Los blogs como nuevo medio de comunicación científica". III Encuentro Ibérico de Docentes e Investigadores en Información y Documentación. Disponible en: http://ow.ly/l2N630iRPbq (última consulta 09/03/2018)

Tous, M. G., y Mattar, S. (2012). "Las claves de las palabras clave en los artículos científicos". Revista MVZ Córdoba, 17(2), 2955-2956. Disponible en: http://ow.ly/QyDp30iRPcv (última consulta 09/03/2018)

Treise, D., Walsh-Childers, K., Weigold, M. F., y Friedman, M. (2003). "Cultivating the science internet audience impact of brand and domain on source credibility for science information". Science Communication, 24 (3), 309-332. Disponible en: http://ow.ly/ondj30iRPcY (última consulta 09/03/2018) 
Tremayne, M., y Dunwoody, S. (2001). "Interactivity, information processing, and learning on the World Wide Web". Science Communication, 23(2), 111-134. Disponible en: http://ow.ly/OFlp30iRPdH (última consulta 09/03/2018)

Trench, B. (2006) Science communication and citizen science: how dead is the deficit model?, Comunicación Presentada en el Congreso PCST9, Seúl, 17-19 Mayo. Disponible en: http://ow.ly/LRmm30iRPes (última consulta 09/03/2018)

Trench, B. (2007). "How the Internet changed science journalism". Journalism, Science and Society: Science Communication Between News and Public Relations, 7, 133-139. Disponible en: http://ow.ly/gmkx30iRPeL (última consulta 09/03/2018)

Trench, B. (2008), "Internet: turning science communication inside-out?" En: Bucchi, M., y Trench, B. (eds.). Handbook of Public Communication of Science and Technology. Routledge, London and New York. Disponible en: http://ow.ly/ucjA30iRPfx (última consulta 09/03/2018)

Trench, B. (2009). "Science reporting in the electronic embrace of the Internet". En: Holliman, R., Whitelegg, L., Scanlon, E., Smidt, S., y Thomas, J. (Eds.). Investigating science communication in the information age: Implications for public engagement and popular media. Oxford University Press. 166-180.

Trench, B., y Bucchi, M. (2010). "Science communication, an emerging discipline". JCOM, 9(3), C03. Disponible en: http://ow.ly/hE7630iRPfY (última consulta 09/03/2018)

Trench, B. (2012). "Scientists' blogs: Glimpses behind the scenes". En: Rödder, S., Franzen, M., y Weingart, P. The Sciences' Media Connection-Public Communication and Its Repercussions. 273-289. Dordrecht, Springer Netherlands. Disponible en: http://ow.ly/JhXs30iRPgl (última consulta 09/03/2018)

Trumbo, C. W., Sprecker, K. J., Dumlao, R. J., YUN, G. W., y Duke, S. (2001). “Use of e-mail and the web by science writers". Science Communication, 22 (4). 
Van Alstyne, M., y Brynjolfsson, E. (1996). "Could the Internet balkanize science?". Science, 274 (5292), 1479-1480. Disponible en: http://ow.ly/kDHp30iRm0W (última consulta 09/03/2018)

Véiliverronen, E. (1993). "Science and the media: changing relations". Science studies, 6(2), 23-34. Disponible en: http://ow.ly/78kB30iRIYS (última consulta 09/03/2018)

Veltri, G. A. (2013). "Microblogging and nanotweets: Nanotechnology on Twitter". Public Understanding of Science, 22(7), 832-849. Disponible en: http://ow.ly/PFzC30iRITR (última consulta 09/03/2018)

Vera Carrasco, O. (2009). Cómo escribir artículos de revisión. Revista Médica La Paz, 15(1), 63-69. Disponible en: http://ow.ly/piZD30iRIQ4 (última consulta 09/03/2018)

Villagrán, A. y Harris, P. R. (2009). "Algunas claves para escribir correctamente un artículo científico". Revista Chilena de Pediatría, 80(1), 70-78. Disponible en: http://ow.ly/GWOn30iRIM3 (última consulta 09/03/2018)

\section{W}

Wagner, L., Paquin, R., y Persky, S. (2012). "Genetics blogs as a public health tool: assessing credibility and influence". Public health genomics, 15(3-4), 218-225. Disponible en: http://ow.ly/WAcM30iRIJP (última consulta 09/03/2018)

Waldrop, M. M. (2008). "Science 2.0: Great New Tool, or Great Risk? Wikis, blogs and other collaborative web technologies could usher in a new era of science. Or not". Scientific American. Disponible en: http://ow.ly/Dehq30iRIGQ (última consulta 09/03/2018)

Walejko, G., y Ksiazek, T. (2010). "Blogging from the niches: The sourcing practices of science bloggers". Journalism Studies, 11(3), 412-427.

Walsh, L. (2015). "The Double-Edged Sword of Popularization: The Role of Science Communication Research in the Popsci. com Comment Shutoff". Science Communication, 37(5), 658-669. 
Wang, X., Jiang, T., y Ma, F. (2010). "Blog-supported scientific communication: An exploratory analysis based on social hyperlinks in a Chinese blog community". Journal of Information Science, 36(6), 690-704.

Warden, R. (2010). "The Internet and science communication: blurring the boundaries". Ecancer rmedical science, 4, 1-8. Disponible en: http://ow.ly/UXun30iRlxm (última consulta 09/03/2018)

Weber, R., Dinc, S., y Williams, M. (2016). “Americans' Support for NASA's James Webb Space Telescope: Effects of Traditional Texts Compared to Interactive Media". Science Communication, 38(5), 601-625.

Weigold, M. F., y Treise, D. (2004). "Attracting teen surfers to science Web sites". Public Understanding of Science,13(3), 229-248. Disponible en: http://ow.ly/3Fml30iRltG (última consulta 09/03/2018)

Wilcox, C. (2012). "Guest editorial: It's time to e-volve: Taking responsibility for science communication in a digital age". The Biological Bulletin, 222(2), 85-87. Disponible en: http://ow.ly/mJuJ30iRIrV (última consulta 09/03/2018)

Wilkins, J. S. (2008). "The roles, reasons and restrictions of science blogs". Trends in ecology \& evolution, 23(8), 411-413.

Winter, S., y Krämer, N. C. (2012). "Selecting science information in Web 2.0: How source cues, message sidedness, and need for cognition influence users' exposure to blog posts". Journal of Computer-Mediated Communication, 18 (1), 80-96. Disponible en: http://ow.ly/PiJ030iRlng (última consulta 09/03/2018)

Winter, S., y Krämer, N. C. (2016). "Who's right: The author or the audience? Effects of user comments and ratings on the perception of online science articles". The European Journal of Communication Research, 41, 3. Disponible en: http://ow.ly/wlZK30iRIlt (última consulta 09/03/2018) 
Xenos, M. A., Becker, A. B., Anderson, A. A., Brossard, D., y Scheufele, D. A. (2011). "Stimulating upstream engagement: an experimental study of nanotechnology information seeking". Social Science Quarterly, 92(5), 1191-1214. Disponible en: http://ow.ly/sXCH30iRlj4 (última consulta 09/03/2018)

Yaros, R. A. (2011). "Effects of text and hypertext structures on user interest and understanding of science and technology". Science Communication, 33 (3). Disponible en: http://ow.ly/RKml30iRlgA (última consulta 09/03/2018)

Yong, E. (2011). "Are science blogs stuck in an echo chamber? Chamber? Chamber?". Disponible en el blog Rocket Science: http://ow.ly/4YeQ30iRlcS (última consulta 09/03/2018)

\section{Z}

Zhang, Y., Machin, D., y Song, T. (2015). "Visual forms of address in social media discourse: the case of a science communication website". Journal of Multicultural Discourses, 10(2), 236-252.

Zhang, Y. (2018). "Retailing science: genre hybridization in online science news stories". Text \& Talk, 38(2), 243-265.

Zhao, L. (2013). "Science Communication Language in Chinese New Media: Evolution, Characteristics and Trend". International Journal of Social Science and Humanity, 3(5), 434. Disponible en: http://ow.ly/Eeqr30iRl6J (última consulta 09/03/2018)

Ziman, J. (1979). “Conhecimento público”. Belo Horizonte: Editora Itatiaia. 
Ziman, J. (2003). "Ciencia y sociedad civil". Revista iberoamericana de ciencia tecnología y sociedad, 1(1), 177-188. Disponible en: http://ow.ly/rtSc30iRl1J (última consulta 09/03/2018)

Zimmer, C. (2009). "Disappearing the science news". Disponible en el blog The Loom: http://ow.ly/qh1630iRkZD (última consulta 09/03/2018) 
ANEXOS 


\section{ANEXO I}

\section{FICHA DE ANÁLISIS \\ ANÁLISIS DE LA INVESTIGACIÓN SOBRE COMUNICACIÓN DE LA CIENCIA EN INTERNET}

\begin{tabular}{|c|c|c|}
\hline \multicolumn{2}{|c|}{ Variable } & \multirow{2}{*}{$\begin{array}{l}\text { Tipo de respuesta } \\
1,2,3 \ldots\end{array}$} \\
\hline 0 & $\begin{array}{l}\text { Número identificador de la unidad de } \\
\text { análisis (ID) }\end{array}$ & \\
\hline \multicolumn{3}{|c|}{ 1. Datos generales } \\
\hline 1.1. & Año de publicación & \\
\hline 1.2. & Título & \\
\hline 1.3 & Idioma del texto & $\begin{array}{ll}0 & =\text { Inglés } \\
1 & =\text { Castellano } \\
2 & =\text { Portugués }\end{array}$ \\
\hline 1.4. & Acceso al artículo & $\begin{array}{ll}0 & =\text { Abierto } \\
1 & =\text { De pago }\end{array}$ \\
\hline 1.5. & Posibilidad de acceso abierto indirecto & $\begin{array}{ll}0 & =\mathrm{No} \\
1 & =\mathrm{Si}\end{array}$ \\
\hline \multicolumn{3}{|c|}{ 2. Autoría del artículo } \\
\hline 2.1 & ¿Es un autor o varios? & $\begin{array}{ll}0 & =\text { Uno } \\
1 & =\text { Dos o tres } \\
2 & =\text { Más de tres }\end{array}$ \\
\hline 2.2. & Perfil de los autores & $\begin{array}{l}0=\text { No aplica } \\
1=\text { Todos son investigadores } \\
\text { académicos } \\
2=\text { Alguno de los autores es } \\
\text { periodista en activo } \\
3=\text { Alguno de los autores es } \\
\text { divulgador científico-no periodista } \\
4=\text { Alguno de los autores procede } \\
\text { del mundo de la empresa }\end{array}$ \\
\hline
\end{tabular}

2.3. Nombre del autor

2.4. Sexo del autor principal $0=$ Hombre

1 = Mujer

2.5. Mujeres en coautoría $0=$ No

$1=\mathrm{Si}$

2.6. ¿La proporción de mujeres y hombres es $0=$ No equilibrada? $1=\mathrm{Si}$

2.7. País de procedencia del autor principal

2.8. ¿Se trata de una investigación $0=$ No plurinacional?

$1=\mathrm{Si}$

2.9. Países de procedencia del/los autor/es secundario/s 


\begin{tabular}{lll}
\hline 2.10. Tipo de colaboración & $\begin{array}{l}0=\text { Ninguna } \\
1=\text { Regional } \\
2=\text { Nacional } \\
3=\text { Internacional }\end{array}$ \\
& & \\
\hline 2.11. & Afiliación del autor principal & \\
\hline 2.12. & Afiliación del/los autor/es secundario/s. \\
\hline 2.13. & Área de conocimiento del autor principal \\
\hline 2.14. & Si la respuesta anterior es Ciencias & \\
& Sociales, indicar subárea & \\
\hline 2.15. & ¿Se trata de una investigación & $0=\mathrm{No}$ \\
& pluridisciplinar? & $1=\mathrm{Si}$ \\
\hline
\end{tabular}

2.16. Área/s de conocimiento de los autor/es secundario/s.

3. Estructura y contenido del artículo

3.1. Campo de estudio

$$
\begin{array}{ll}
0 & =\text { No aplica } \\
1 & =\text { Emisor } \\
2 & =\text { Mensaje } \\
3 & =\text { Receptor } \\
4 & =\text { Canal } \\
5 & =\text { Efectos }
\end{array}
$$

\begin{tabular}{|c|c|c|c|}
\hline 3.2. & $\begin{array}{l}\text { Si se abordan casos relativos a una } \\
\text { temática científica específica, indicar cuál }\end{array}$ & & \\
\hline 3.3. & $\begin{array}{l}\text { ¿El trabajo habla sobre comunicación de } \\
\text { riesgos? }\end{array}$ & $\begin{array}{l}0 \\
1\end{array}$ & $\begin{array}{l}=\mathrm{No} \\
=\mathrm{Si}\end{array}$ \\
\hline 3.4. & Tipo de investigación & $\begin{array}{l}0 \\
1 \\
2\end{array}$ & $\begin{array}{l}=\text { Teórica } \\
=\text { Empírica } \\
=\text { Mixta }\end{array}$ \\
\hline 3.5. & ¿Existe abstract? & $\begin{array}{l}0 \\
1\end{array}$ & $\begin{array}{l}=\mathrm{No} \\
=\mathrm{Si}\end{array}$ \\
\hline 3.6. & $\begin{array}{l}\text { Si el artículo está en castellano o } \\
\text { portugués, ¿el abstract también se } \\
\text { presenta en inglés? }\end{array}$ & $\begin{array}{l}0 \\
1\end{array}$ & $\begin{array}{l}=\mathrm{No} \\
=\mathrm{Si}\end{array}$ \\
\hline 3.7. & ¿Y el título? & & $\begin{array}{l}=\mathrm{No} \\
=\mathrm{Si}\end{array}$ \\
\hline 3.8. & ¿Se especifican palabras clave? & & $\begin{array}{l}=\mathrm{No} \\
=\mathrm{Si}\end{array}$ \\
\hline 3.9. & $\begin{array}{l}\text { Si las palabras clave están en castellano } \\
\text { o portugués, ¿también se incluyen en } \\
\text { inglés? }\end{array}$ & & $\begin{array}{l}=\mathrm{No} \\
=\mathrm{Si}\end{array}$ \\
\hline 3.10. & $\begin{array}{l}\text { Si se especifican palabras clave, indicar } \\
\text { cuáles }\end{array}$ & & \\
\hline 3.11. & ¿Existe capítulo metodológico? & $\begin{array}{l}0 \\
1 \\
\mathrm{me} \\
2 \\
3\end{array}$ & $\begin{array}{l}=\text { No } \\
=\text { No, pero aparece alguna } \\
\text { nción en otros apartados } \\
=\mathrm{Si} \text {, informativo } \\
=\mathrm{Si} \text {, detallado }\end{array}$ \\
\hline 3.12. & ¿Cuál es la perspectiva dominante? & 0 & = No hay información suficiente \\
\hline
\end{tabular}




\begin{tabular}{|c|c|}
\hline & $\begin{array}{ll}1 & =\text { Cuantitativa } \\
2 & =\text { Cualitativa } \\
3 & =\text { Métodos mixtos }\end{array}$ \\
\hline 3.13. ¿Se sigue el modelo IMRyD? & $\begin{array}{l}0=\mathrm{No} \\
1=\mathrm{Si}\end{array}$ \\
\hline 3.14. Apoyo bibliográfico & $\begin{array}{l}0=\text { No se incluyen referencias } \\
1 \text { = Se incluyen escasas } \\
\text { referencias } \\
2=\text { Se realiza un rastreo } \\
\text { bibliográfico sin referencia a otras } \\
\text { investigaciones que emplean esta } \\
\text { metodología } \\
3=\text { Se realiza un rastreo } \\
\text { bibliográfico completo con } \\
\text { referencia a otras investigaciones } \\
\text { que emplean esta metodología }\end{array}$ \\
\hline 3.15. ¿Se utilizan recursos informáticos? & $\begin{array}{l}0=\text { No existen referencias } \\
1=\text { Se emplea programa } \\
\text { informático }\end{array}$ \\
\hline
\end{tabular}

3.16. Si la respuesta es sí, indicar cuál

\begin{tabular}{|c|c|c|c|}
\hline 3.17. & ¿Existen autocitas? & $\begin{array}{l}0 \\
1\end{array}$ & $\begin{array}{l}=\mathrm{No} \\
=\mathrm{Si}\end{array}$ \\
\hline 3.18. & $\begin{array}{l}\text { ¿Se indica que se trata de una } \\
\text { investigación financiada? }\end{array}$ & $\begin{array}{l}0 \\
1\end{array}$ & $\begin{array}{l}=\mathrm{No} \\
=\mathrm{Si}\end{array}$ \\
\hline \multirow[t]{3}{*}{3.19} & $\begin{array}{l}\text { ¿Existe declaración de conflictos de } \\
\text { interés? }\end{array}$ & $\begin{array}{l}0 \\
1\end{array}$ & $\begin{array}{l}=\mathrm{No} \\
=\mathrm{Si}\end{array}$ \\
\hline & Citas relevantes (entrecomillados) & & \\
\hline & Reflexión/valoraciones sobre el texto & & \\
\hline \multicolumn{4}{|c|}{ 4. Datos sobre la revista } \\
\hline 4.1. & Nombre de la revista & & \\
\hline 4.2. & País de origen de la revista & & \\
\hline 4.3. & Factor de impacto SJR & & \\
\hline 4.4. & Cuartil según SJR & $\begin{array}{l}0 \\
1 \\
2 \\
3 \\
4\end{array}$ & $\begin{array}{l}=\text { No aplica } \\
=\text { Primero } \\
=\text { Segundo } \\
=\text { Tercero } \\
=\text { Cuarto }\end{array}$ \\
\hline
\end{tabular}

4.5. Área de conocimiento a la que pertenece

4.6. Si pertenece al Área de Ciencias Sociales, indicar subárea 


\section{ANEXO II}

\section{LIBRO DE CÓDIGOS ANÁLISIS DE LA INVESTIGACIÓN SOBRE COMUNICACIÓN DE LA CIENCIA EN INTERNET}

0. Número identificador de la unidad de análisis -ID- (número asignado al artículo de investigación analizado)

\section{Datos generales.}

1.1. Año de publicación. Se indica siempre el que aparece en la fecha de publicación final, obviando la fecha de recepción y aceptación del artículo.

1.2. Título. En el caso de los artículos con dos títulos, uno en inglés y otro en el idioma de origen de la revista o de sus autores, se especifica solo el primero.

1.3. Idioma del texto.

$$
\begin{aligned}
& 0=\text { Inglés } \\
& 1=\text { Castellano } \\
& 2=\text { Portugués }
\end{aligned}
$$

1.4. Acceso al artículo. Son artículos de pago aquellos que, al pulsar su hipervínculo, enlazan a una plataforma de pago editorial.

$$
\begin{aligned}
& 0=\text { Abierto } \\
& 1=\text { De pago }
\end{aligned}
$$

1.5. Posibilidad de acceso abierto indirecto. Se consideran artículos de acceso abierto indirecto aquellos que pueden requerirse al autor a través de redes socials académicas como Researchgate o Academia.Edu.

$$
\begin{aligned}
& 0=\mathrm{No} \\
& 1=\mathrm{Si}
\end{aligned}
$$

\section{Autoría del artículo.}

2.1. ¿Es un autor o varios?

$$
\begin{array}{ll}
0 & =\text { Uno } \\
1 & =\text { Dos o tres } \\
2 & =\text { Más de tres }
\end{array}
$$

2.2. Perfil de los autores

$$
\begin{array}{ll}
0 & =\text { No aplica } \\
1 & =\text { Investigadores académicos } \\
2 & =\text { Alguno de los autores es periodista en activo } \\
3 & =\text { Alguno de los autores es divulgador científico-no periodista } \\
4 & =\text { Alguno de los autores procede del mundo de la empresa }
\end{array}
$$

2.3. Nombre del autor principal. Recoger nombre y apellido.

2.4. Sexo del autor principal.

$$
\begin{aligned}
& 0=\text { Hombre } \\
& 1=\text { Mujer }
\end{aligned}
$$


2.5. Mujeres en coautoría. Solo se codifica cuando el artículo tiene más de un autor.

$$
\begin{aligned}
& 0=\mathrm{No} \\
& 1=\mathrm{Si}
\end{aligned}
$$

2.6. ¿La proporción de mujeres y hombres es equilibrada? Solo se codifica cuando el artículo tiene más de un autor y los coautores pertenecen a ambos sexos.

$$
\begin{aligned}
& 0=\mathrm{No} \\
& 1=\mathrm{Si}
\end{aligned}
$$

2.7. País de procedencia del autor principal.

2.8. ¿Se trata de una investigación plurinacional? Solo se codifica para artículos en coautoría.

$$
\begin{aligned}
& 0=\text { No } \\
& 1=\mathrm{Si}
\end{aligned}
$$

2.9. Países de procedencia del/los autor/es secundario/s. Solo se codifica para artículos en coautoría. Recoger en forma de lista para después hacer recuento.

2.10. Tipo de colaboración. Solo se codifica para los artículos en coautoría.

$$
\begin{aligned}
& 0=\text { Ninguna } \\
& 1=\text { Regional } \\
& 2=\text { Nacional } \\
& 3=\text { Internacional }
\end{aligned}
$$

2.11. Afiliación del autor principal. Se recoge la afiliación referida en el artículo. En el caso de que el autor principal tenga más de una afiliación oficial, se recogerán todas. Solo se recoge la institución de procedencia, no el departamento (Ej. Universidad de Washington). Recoger en forma de lista para después hacer recuento.

2.12. Afiliación del/los autor/es secundario/s. Solo se codifica para artículos en coautoría. Se recoge la afiliación referida en el artículo. En el caso de que el/los autor/es secundario/s tenga/n más de una afiliación oficial, se recogerán todas. Igualmente solo se recoge la institución de procedencia. Se codifica como no procede cuando el autor sea periodista en activo o divulgador científico.

2.13. Área de conocimiento del autor principal. Se tomarán como áreas de referencia las de la ANEP y sus descriptores oficiales para codificar la variable. Se codifica como no procede cuando el autor sea periodista en activo o divulgador científico.

2.14. Si la respuesta anterior es Ciencias Sociales, indicar subárea. Se tomarán como subáreas de referencia las desglosadas por la ANEP para Ciencias Sociales y los descriptores de elaboración propia para codificar la variable.

2.15. ¿Se trata de una investigación pluridisciplinar? Solo se codifica para artículos en coautoría. Se considera investigación pluridisciplinar aquella cuyos autores pertenecen a diferentes áreas o departamentos dentro de una misma o distinta institución.

$$
\begin{aligned}
& 0=\mathrm{No} \\
& 1=\mathrm{Si}
\end{aligned}
$$


2.16. Área/s de conocimiento de los autor/es secundario/s. Solo se codifica para artículos en coautoría. Se tomarán como áreas de referencia las de la ANEP y sus descriptores oficiales para codificar la variable.

\section{Estructura y contenido del artículo.}

3.1. Campo de estudio. Se indicará el campo de estudio predominante en el caso de que los artículos se relacionen con más de uno.

$$
\begin{array}{ll}
0 & =\text { No aplica } \\
1 & =\text { Emisor } \\
2 & =\text { Mensaje } \\
3 & =\text { Receptor } \\
4 & =\text { Canal } \\
5 & =\text { Efectos }
\end{array}
$$

3.2. Si se abordan casos relativos a una temática científica específica, indicar cuál. Se tomarán como temáticas de referencia las incluidas en las áreas de la ANEP y sus descriptores oficiales para codificar la variable.

3.3. ¿El trabajo habla sobre comunicación de riesgos? Solo se codificará 1 cuando el estudio de la comunicación de riesgos sea uno de los objetivos principales del trabajo, entendiendo que debe referenciarse en el título, resumen y/o palabras clave.

$$
\begin{aligned}
& 0=\mathrm{No} \\
& 1=\mathrm{Si}
\end{aligned}
$$

3.4. Tipo de investigación. Se considera investigación teórica aquella que carece de enfoque y metodología empírica. Codifica como mixta aquella que presenta un estado de la cuestión/estado del arte/revisión lo suficientemente significativa que deriva a un estudio empírico. Las revisiones y metanálisis sistematizados metodológicamente se codifican como investigación empírica.

$$
\begin{array}{ll}
0 & =\text { Teórica } \\
1 & =\text { Empírica } \\
2 & =\text { Mixta }
\end{array}
$$

3.5. ¿Existe abstract?

$$
\begin{aligned}
& 0=\text { No } \\
& 1=\mathrm{Si}
\end{aligned}
$$

3.6. Si el artículo está en castellano o portugués, ¿el abstract también se presenta en inglés?

$$
\begin{aligned}
& 0=\mathrm{No} \\
& 1=\mathrm{Si}
\end{aligned}
$$

3.7. ¿Y el título?

$$
\begin{aligned}
& 0=\mathrm{No} \\
& 1=\mathrm{Si}
\end{aligned}
$$

3.8. ¿Se especifican palabras clave?

$$
\begin{aligned}
& 0=\mathrm{No} \\
& 1=\mathrm{Si}
\end{aligned}
$$

3.9. Si las palabras clave están en castellano o portugués, ¿también se incluyen en inglés?

$$
0=\text { No }
$$




$$
1=\mathrm{Si}
$$

3.10. Si se especifican palabras clave, indicar cuáles. Solo la primera en mayúscula, también en el caso de los lexemas, para evitar palabras iguales duplicadas a la hora de elaborar el tesauro.

3.11. ¿Existe capítulo metodológico? Se codifica como informativo aquel capítulo metodológico que describe, de forma sucinta, la metodología aplicada. Se codifica como detallado aquel capítulo metodológico que profundiza de tal forma que la investigación podría replicarse.

$$
\begin{array}{ll}
0 & =\text { No } \\
1 & =\mathrm{No}, \text { pero aparece alguna mención en otros apartados } \\
2 & =\mathrm{Si} \text {, informativo } \\
3 & =\mathrm{Si} \text {, detallado }
\end{array}
$$

3.12. ¿Cuál es la perspectiva dominante? Codifica como cuantitativa aquella investigación que aplica métodos cuantitativos (análisis de contenido, encuesta, etc.); que codifica como cualitativa aquel estudio que emplea métodos cualitativos (entrevistas en profundidad, observación, grupos de enfoque, etc.); codifica como mixto el estudio que aplica, al menos, un método cuantitativo y un método cualitativo.

$$
\begin{aligned}
& 0=\text { No hay información suficiente } \\
& 1=\text { Cuantitativa } \\
& 2 \text { = Cualitativa } \\
& 3 \text { = Métodos mixtos }
\end{aligned}
$$

3.13. ¿Se sigue el modelo IMRyD? Se registra 1 cuando el artículo presenta claramente la estructura Introducción, Métodos, Resultados y Discusión.

$$
\begin{aligned}
& 0=\mathrm{No} \\
& 1=\mathrm{Si}
\end{aligned}
$$

3.14. Apoyo bibliográfico. Se consideran escasas referencias menos de 15 registros, el promedio referido por De Solla Price (2002) para artículos académicos. Se codifica 2 o 3 en función de si la metodología referencia ptras investigaciones que aplican el mismo enfoque, recogiendo así una posible replicación metodológica.

$0=$ No se incluyen referencias

1 = Se incluyen escasas referencias

2 = Se realiza un rastreo bibliográfico sin referencia a otras investigaciones que emplean esta metodología

3 = Se realiza un rastreo bibliográfico completo con referencia a otras investigaciones que emplean esta metodología

3.15. ¿Se utilizan recursos informáticos? Se codifica 1 solo si se realiza una mención expresa a la utilización de software para la recogida y procesamiento de los datos del estudio.

$$
\begin{aligned}
& 0=\text { No existen referencias } \\
& 1=\text { Se emplea programa informático }
\end{aligned}
$$

3.16. Si la respuesta es sí, indicar cuál autoría

3.17. ¿El autor se autocita? Se codifica 1 si existe una o más autocitas en y/o coautoría.

$$
\begin{aligned}
& 0=\mathrm{No} \\
& 1=\mathrm{Si}
\end{aligned}
$$


3. 18. ¿Se indica que se trata de una investigación financiada? Se codifica 1 solo cuando exista mención expresa a financiación total o parcial para la realización del estudio.

$$
\begin{array}{ll}
0 & =\mathrm{No} \\
1 & =\mathrm{Si}
\end{array}
$$

3.19. ¿Existe declaración de conflictos de interés? Codifica 1 si los autores de la investigación incluyen, en alguna parte de la publicación, la existencia de algún conflicto de interés.

$0=$ No

$1=\mathrm{Si}$

Citas relevantes

Reflexión/valoraciones sobre el texto

\section{Datos sobre la revista.}

4.1. Nombre de la revista. Se especifica el nombre oficial en el idioma de origen de la misma.

\subsection{País de origen}

4.3. Factor de impacto. Factor de impacto según los últimos datos disponibles en el SJR (2015).

4.4. Cuartil. Cuartil en el que se encuentra la revista según los últimos datos disponibles en el SJR (2015).

$$
\begin{array}{ll}
0 & =\text { No aplica } \\
1 & =\text { Primero } \\
2 & =\text { Segundo } \\
3 & =\text { Tercero } \\
4 & =\text { Cuarto }
\end{array}
$$

4.5. Área de conocimiento a la que pertenece. Se tomará como referencia el área principal indicada para la revista en el SJR (según los últimos datos disponibles de 2015) y se codificará con los descriptores oficiales de la ANEP.

4.6. Si pertenece al Área de Ciencias Sociales, indicar subárea. Se tomarán como subáreas de referencia las desglosadas por la ANEP para Ciencias Sociales y los descriptores de elaboración propia para codificar la variable. 


\section{ANEXO III}

Tesauro sobre comunicación de la ciencia e Internet. Cadenas de palabras clave en inglés, castellano y portugués y frecuencia.

\begin{tabular}{|c|c|}
\hline Palabras clave (Inglés) & Frecuencia \\
\hline Science communication & 19 \\
\hline Internet & 16 \\
\hline Science journalism & 15 \\
\hline Social Media & 9 \\
\hline Blogs & 9 \\
\hline Nanotechnology & 8 \\
\hline Google & 6 \\
\hline Science & 6 \\
\hline Journalism & 6 \\
\hline Social networks & 5 \\
\hline Content analysis & 4 \\
\hline Scientific journalism & 4 \\
\hline Twitter & 4 \\
\hline Climate change & 4 \\
\hline Public understanding of science & 4 \\
\hline New media & 4 \\
\hline Science blogging & 3 \\
\hline Citizen journalism & 3 \\
\hline Scientific communication & 3 \\
\hline Web 2.0 & 3 \\
\hline Media and science & 3 \\
\hline Online comments & 3 \\
\hline Science news & 3 \\
\hline Online journalism & 3 \\
\hline Digital media & 3 \\
\hline Communication & 3 \\
\hline Blog & 3 \\
\hline Blogging & 3 \\
\hline Science and Media & 3 \\
\hline World Wide Web & 3 \\
\hline Weblog & 2 \\
\hline Risk perceptions & 2 \\
\hline Public understanding & 2 \\
\hline Climate scepticism & 2 \\
\hline Selective exposure & 2 \\
\hline Communication assesment & 2 \\
\hline Public interest in science & 2 \\
\hline
\end{tabular}




\begin{tabular}{|c|c|}
\hline Corpus linguistics & 2 \\
\hline Reporting science & 2 \\
\hline Digital journalism & 2 \\
\hline Science magazines & 2 \\
\hline Digital newspapers & 2 \\
\hline Societal implications & 2 \\
\hline Electronic publications & 2 \\
\hline Participatory journalism & 2 \\
\hline Electronic publishing & 2 \\
\hline Public opinion & 2 \\
\hline Environment & 2 \\
\hline Publishing & 2 \\
\hline Evolution & 2 \\
\hline Rhetorical strategies & 2 \\
\hline Framing & 2 \\
\hline Science and technology & 2 \\
\hline Informetrics & 2 \\
\hline Science writing & 2 \\
\hline $\mathrm{BBC}$ & 2 \\
\hline Social representation & 2 \\
\hline Mass media & 2 \\
\hline Sources & 2 \\
\hline Multimedia & 2 \\
\hline Online & 2 \\
\hline Tweets & 1 \\
\hline Science imagery & 1 \\
\hline Counterknowledge & 1 \\
\hline CNN & 1 \\
\hline Social communication & 1 \\
\hline Autism & 1 \\
\hline Print media & 1 \\
\hline Cognitive load & 1 \\
\hline San Luis & 1 \\
\hline Digital press & 1 \\
\hline Scientific dissemination & 1 \\
\hline Digital publishing & 1 \\
\hline Specialized cyber-media & 1 \\
\hline Digital science reporting & 1 \\
\hline Podcasting & 1 \\
\hline Discourse analysis & 1 \\
\hline Public health & 1 \\
\hline Domain credibility & 1 \\
\hline Research & 1 \\
\hline
\end{tabular}




\begin{tabular}{|c|c|}
\hline Editorial management of journals & 1 \\
\hline Data mining & 1 \\
\hline Elaboration likelihood model & 1 \\
\hline Science writers & 1 \\
\hline Elecgtronic scientific jorunal & 1 \\
\hline Scientific publishing & 1 \\
\hline Collaborative tools & 1 \\
\hline Social psychology & 1 \\
\hline Comments & 1 \\
\hline Syndrome disorder & 1 \\
\hline ELSI & 1 \\
\hline Digital content & 1 \\
\hline E-mail & 1 \\
\hline Popularization of science & 1 \\
\hline Emerging technology & 1 \\
\hline Public communication & 1 \\
\hline Enunciation & 1 \\
\hline Public perception of science and technology & 1 \\
\hline Audiences & 1 \\
\hline Recontextualization & 1 \\
\hline Environmental communication & 1 \\
\hline Risk amplification & 1 \\
\hline Environmental health reporting & 1 \\
\hline Attitudes & 1 \\
\hline Environmental reporting training & 1 \\
\hline Science blogs & 1 \\
\hline Ethics & 1 \\
\hline Science journalism online & 1 \\
\hline Europe & 1 \\
\hline Scientific citizenship & 1 \\
\hline Climategate & 1 \\
\hline Scientific literacy & 1 \\
\hline Evolutionary biology & 1 \\
\hline Search queries & 1 \\
\hline Expert-Novice Differences & 1 \\
\hline Social network & 1 \\
\hline Facebook & 1 \\
\hline Digital & 1 \\
\hline Fetal alcohol & 1 \\
\hline Subjetivatio & 1 \\
\hline Formal quality assesment & 1 \\
\hline Theory and models & 1 \\
\hline Forms and address & 1 \\
\hline
\end{tabular}




\begin{tabular}{|c|c|}
\hline User-generated content & 1 \\
\hline Fourth estate & 1 \\
\hline Periodicals & 1 \\
\hline Communication media & 1 \\
\hline Popular science & 1 \\
\hline Framing analysis & 1 \\
\hline Press release & 1 \\
\hline France & 1 \\
\hline Pro-innovation bias & 1 \\
\hline Fusion energy & 1 \\
\hline $\begin{array}{l}\text { Public communication of science and } \\
\text { technology }\end{array}$ & 1 \\
\hline Genetically modified organism & 1 \\
\hline convergence culture & 1 \\
\hline Global media & 1 \\
\hline Cloning & 1 \\
\hline Bakhtin & 1 \\
\hline Questionnaires & 1 \\
\hline Google analytics & 1 \\
\hline Credibility & 1 \\
\hline Hashtag & 1 \\
\hline Critical discourse analysis & 1 \\
\hline Health & 1 \\
\hline Roles of science journalists & 1 \\
\hline Health communication & 1 \\
\hline Schema incongruency & 1 \\
\hline Health promotion & 1 \\
\hline Science and popular culture & 1 \\
\hline Health specialized journalism & 1 \\
\hline Science attitudes and perceptions & 1 \\
\hline Health-specialized journalism & 1 \\
\hline Science communication in China & 1 \\
\hline Higher education students & 1 \\
\hline Animal experimentation & 1 \\
\hline Hipertext & 1 \\
\hline Breastfeeding & 1 \\
\hline Homeophaty & 1 \\
\hline Sciences & 1 \\
\hline Hyperlinks & 1 \\
\hline Scientific culture & 1 \\
\hline Impact journals & 1 \\
\hline Chilean archaeology & 1 \\
\hline Impartiality & 1 \\
\hline
\end{tabular}




\begin{tabular}{|c|c|}
\hline Scientific outreach & 1 \\
\hline Incivility & 1 \\
\hline Scientist attitudes & 1 \\
\hline Informal communication & 1 \\
\hline Serial publications & 1 \\
\hline Information acquisition & 1 \\
\hline Social interation & 1 \\
\hline Information architecture & 1 \\
\hline Social networking & 1 \\
\hline Information dissemination & 1 \\
\hline Social software & 1 \\
\hline Information science & 1 \\
\hline Digital age news media & 1 \\
\hline Information seeking & 1 \\
\hline Streaming & 1 \\
\hline Information sources & 1 \\
\hline Survey data collection & 1 \\
\hline Comprehension & 1 \\
\hline Technology & 1 \\
\hline Interaction experts/publics & 1 \\
\hline Treatments & 1 \\
\hline Interactivity & 1 \\
\hline University & 1 \\
\hline International comparisons & 1 \\
\hline Web site & 1 \\
\hline Internationalization & 1 \\
\hline Perceptions & 1 \\
\hline Altmetrics & 1 \\
\hline Podcast & 1 \\
\hline Internet advocacy & 1 \\
\hline Podcasts & 1 \\
\hline Internet communications & 1 \\
\hline Popularization & 1 \\
\hline Internet credibility & 1 \\
\hline Praise & 1 \\
\hline Internet use & 1 \\
\hline Press websites & 1 \\
\hline Interviews & 1 \\
\hline Professionalism & 1 \\
\hline Invisible college & 1 \\
\hline Pseudoscience & 1 \\
\hline Issue attention cycles & 1 \\
\hline Public communication of Science & 1 \\
\hline
\end{tabular}




\begin{tabular}{|c|c|}
\hline Conference outreach & 1 \\
\hline Public engagement with science & 1 \\
\hline Journalism and science & 1 \\
\hline Controversy & 1 \\
\hline Journalism continuing education & 1 \\
\hline Public percepcion of science and technology & 1 \\
\hline Journalism sources & 1 \\
\hline Public perceptions & 1 \\
\hline Journalist training & 1 \\
\hline Blog community & 1 \\
\hline Journalists & 1 \\
\hline Qualitative interviews & 1 \\
\hline Knowledge & 1 \\
\hline Reader comments & 1 \\
\hline Knowledge society & 1 \\
\hline Reporting accuracy & 1 \\
\hline Language features & 1 \\
\hline Representations of science and technology & 1 \\
\hline Latent semantic analysis & 1 \\
\hline Rhetoric of science & 1 \\
\hline Legibility & 1 \\
\hline Risk & 1 \\
\hline Liberation of Emission Polo & 1 \\
\hline cyberjournalism & 1 \\
\hline Magazines & 1 \\
\hline Routines & 1 \\
\hline Consensus and controversy & 1 \\
\hline SARS & 1 \\
\hline Mass media use & 1 \\
\hline Scholary communication & 1 \\
\hline Mass-media & 1 \\
\hline Academic blogs & 1 \\
\hline Media & 1 \\
\hline science and society & 1 \\
\hline Biomedical expertise & 1 \\
\hline Science and technology communication & 1 \\
\hline Media consumption & 1 \\
\hline Boundaries & 1 \\
\hline Media coverage & 1 \\
\hline Altmetrics and impact & 1 \\
\hline Media effects & 1 \\
\hline Science education & 1 \\
\hline Media-scientists communication & 1 \\
\hline
\end{tabular}




\begin{tabular}{|c|c|}
\hline Science in society & 1 \\
\hline Mediator & 1 \\
\hline Science Journalism & 1 \\
\hline Medical & 1 \\
\hline Deliberation & 1 \\
\hline Medican Journalism & 1 \\
\hline Science popularization & 1 \\
\hline Medicine & 1 \\
\hline Design & 1 \\
\hline Message sidedness & 1 \\
\hline Scientific blogs & 1 \\
\hline Mobile Technology & 1 \\
\hline Cerebral palsy & 1 \\
\hline Conservation outreach & 1 \\
\hline Scientific diffusion & 1 \\
\hline Multimodal doscourse analysis & 1 \\
\hline Scientific governance & 1 \\
\hline Youtube & 1 \\
\hline Scientific journalism in human science & 1 \\
\hline 2.0 environment & 1 \\
\hline Scientific organizations & 1 \\
\hline Wikipedia & 1 \\
\hline Scientific popularization & 1 \\
\hline Argument quality & 1 \\
\hline Scientific search & 1 \\
\hline Neuroethics & 1 \\
\hline Search engine & 1 \\
\hline Neuroscience & 1 \\
\hline Dialogism & 1 \\
\hline Biosafety research & 1 \\
\hline Skepticism & 1 \\
\hline News & 1 \\
\hline Social hyperlink & 1 \\
\hline News media & 1 \\
\hline Antibiotic resistance & 1 \\
\hline News web & 1 \\
\hline Social network analysis & 1 \\
\hline Newsgathering & 1 \\
\hline Churnalism & 1 \\
\hline Newspapers & 1 \\
\hline Dietary health & 1 \\
\hline Webcasting & 1 \\
\hline Social web & 1 \\
\hline
\end{tabular}




\begin{tabular}{|c|c|}
\hline Authorship & 1 \\
\hline Source cues & 1 \\
\hline Audience interaction & 1 \\
\hline Sourcing & 1 \\
\hline Online communication & 1 \\
\hline spreading & 1 \\
\hline Online content analysis & 1 \\
\hline students, blogs, scientific journalism & 1 \\
\hline Online forums & 1 \\
\hline Survey & 1 \\
\hline Art and literatura & 1 \\
\hline Swine flu & 1 \\
\hline On-line journalism & 1 \\
\hline Technological transfer & 1 \\
\hline Online media & 1 \\
\hline Textbook analysis & 1 \\
\hline Online news & 1 \\
\hline Traditional media & 1 \\
\hline Online reader comments & 1 \\
\hline Trends & 1 \\
\hline Online search results & 1 \\
\hline Ciber journalism & 1 \\
\hline Online training & 1 \\
\hline User comments & 1 \\
\hline Openness and transarency & 1 \\
\hline Audience commentary & 1 \\
\hline Opinion mining & 1 \\
\hline Web-based content & 1 \\
\hline Controversial science & 1 \\
\hline Peer review & 1 \\
\hline Whale shark & 1 \\
\hline Online audiences & 1 \\
\hline Blame & 1 \\
\hline Network & 1 \\
\hline Network society & 1 \\
\hline Narrative analysis & 1 \\
\hline Total & 496 \\
\hline
\end{tabular}

\begin{tabular}{|lc|}
\hline Palabras clave (Portugués) & Frecuencia \\
\hline Internet & 5 \\
\hline Blogs & 2 \\
\hline Jornalismo científico & 1 \\
\hline
\end{tabular}




\begin{tabular}{|ll|}
\hline Bakhtin & 1 \\
\hline Moderador & 1 \\
\hline Popularização científica & 1 \\
\hline Subjetivação & 1 \\
\hline Arquitetura de informação & 1 \\
\hline Blogs de ciência & 1 \\
\hline Jornalismo online & 1 \\
\hline Ciência & 1 \\
\hline Periódico científicvo eletrônico & 1 \\
\hline Ciência da informação & 1 \\
\hline Redes sociais & 1 \\
\hline Clonagem & 1 \\
\hline web site & 1 \\
\hline Comunicação & 1 \\
\hline Jornalismo & 1 \\
\hline Comunicação científica & 1 \\
\hline Jornalismo e ciência & 1 \\
\hline Dialogismo & 1 \\
\hline Liberação do polo de emissão & 1 \\
\hline Divulgação científica & 1 \\
\hline Periodicals & 1 \\
\hline Electronic publications & 1 \\
\hline Periodismo científico nas ciências humanas & 1 \\
\hline Enunciação & 1 \\
\hline Publishing & 1 \\
\hline Gestão editorial de periódicos & 1 \\
\hline Scientific communication and diffusion & 1 \\
\hline Google analytics & 1 \\
\hline Transferência de tecnologia & 1 \\
\hline Interação social & 1 \\
\hline Youtube & 1 \\
\hline Internacionalização & 1 \\
\hline Altimetrias e impacto & 1 \\
\hline Total & 1 \\
\hline
\end{tabular}

\begin{tabular}{|lc|}
\hline Palabras clave (Castellano) & Frecuencia \\
\hline Periodismo científico & 12 \\
\hline Divulgación científica & 8 \\
\hline Internet & 6 \\
\hline Redes sociales & 5 \\
\hline Divulgación & 4 \\
\hline Periodismo digital & 4 \\
\hline
\end{tabular}




\begin{tabular}{|c|c|}
\hline Ciencia & 3 \\
\hline Comunicación científica & 3 \\
\hline Multimedia & 2 \\
\hline Informetría & 2 \\
\hline Medios digitales & 2 \\
\hline Ciberperiodismo & 2 \\
\hline Nuevos medios de comunicación & 2 \\
\hline Periodismo ciudadano & 2 \\
\hline Periodismo especializado en salud & 2 \\
\hline Evaluación de la comunicación & 2 \\
\hline Blogs & 2 \\
\hline Publicaciones electrónicas & 2 \\
\hline Google & 2 \\
\hline Web periodísticas & 2 \\
\hline Publicaciones seriadas & 1 \\
\hline Periodismo científico electrónico & 1 \\
\hline Twitter & 1 \\
\hline Comunicación social & 1 \\
\hline Precisión en reportajes & 1 \\
\hline Consumo mediático & 1 \\
\hline Sociedad red & 1 \\
\hline Contenido digital & 1 \\
\hline Ciencia en sociedad & 1 \\
\hline Contraconocimiento & 1 \\
\hline Comunicación & 1 \\
\hline Cultura convergente & 1 \\
\hline Promoción de la salud & 1 \\
\hline Diario Hoy & 1 \\
\hline Salud pública & 1 \\
\hline Difusión de la información & 1 \\
\hline Tecnología & 1 \\
\hline Digital & 1 \\
\hline Medios tradicionales de comunicación & 1 \\
\hline Cambio climático & 1 \\
\hline Periódico digital & 1 \\
\hline Divulgación & 1 \\
\hline Ciencia y sociedad & 1 \\
\hline Archivos digitales & 1 \\
\hline Periodismo y ciencia & 1 \\
\hline Educación & 1 \\
\hline Prensa especializada & 1 \\
\hline El Periódico de Extremadura & 1 \\
\hline Publicaciones en línea & 1 \\
\hline
\end{tabular}




\begin{tabular}{|c|c|}
\hline Entorno 2.0 & 1 \\
\hline Comunicación on-line & 1 \\
\hline Especializado & 1 \\
\hline Sanidad & 1 \\
\hline Estrategias retóricas & 1 \\
\hline Streaming & 1 \\
\hline Estudiantes & 1 \\
\hline Tecnología digital & 1 \\
\hline Estudiantes de educación superior & 1 \\
\hline Medios electrónicos & 1 \\
\hline Evaluación de la calidad formal & 1 \\
\hline Blogs científicos & 1 \\
\hline Ciberbitácoras & 1 \\
\hline Percepción pública de la ciencia & 1 \\
\hline Fuentes & 1 \\
\hline Arqueología chilena & 1 \\
\hline Fuentes periodísticas & 1 \\
\hline Ciencia y redes sociales & 1 \\
\hline Gadgets & 1 \\
\hline Periodismo electrónico & 1 \\
\hline Galicia & 1 \\
\hline Periodismo sanitario & 1 \\
\hline Ciberespacio & 1 \\
\hline Podcasting & 1 \\
\hline Gripe A & 1 \\
\hline Prensa digital & 1 \\
\hline Herramientas colaborativas & 1 \\
\hline Programas & 1 \\
\hline Hipertexto & 1 \\
\hline Búsquedas científicas & 1 \\
\hline Homeopatía & 1 \\
\hline Publicaciones periódicas & 1 \\
\hline Cibermedios especializados & 1 \\
\hline Red 2.0 & 1 \\
\hline Web 2.0 & 1 \\
\hline Revista & 1 \\
\hline Webcasting & 1 \\
\hline San Luis & 1 \\
\hline Biomédico & 1 \\
\hline Sociedad del conocimiento & 1 \\
\hline Mass media & 1 \\
\hline Software social & 1 \\
\hline Medio ambiente & 1 \\
\hline
\end{tabular}




\begin{tabular}{|lc|}
\hline Subjetivación & 1 \\
\hline Medios de comunicación & 1 \\
\hline Tecnología & 1 \\
\hline Medios de comunicación & 1 \\
\hline Tiburón ballena & 1 \\
\hline Medios de comunicación digitales & 1 \\
\hline $\begin{array}{l}\text { Comunicación pública de la ciencia y la } \\
\text { tecnología }\end{array}$ & 1 \\
\hline Blogs académicos & 1 \\
\hline Interactividad & 1 \\
\hline Wikipedia & 1 \\
\hline Alfabetización científica crítica & 1 \\
\hline Investigación & 1 \\
\hline Total & 153 \\
\hline
\end{tabular}




\section{ANEXO IV}

Tabla de búsquedas aplicadas. Periódico digital, enlace y cadenas de palabras buscadas.

\begin{tabular}{|c|c|}
\hline $\begin{array}{l}\text { El País } \\
\text { http://elpais.com }\end{array}$ & $\begin{array}{l}\text { "Universidad+de+Córdoba" } \\
\text { "Universitat+Rovira+i+Virgili" } \\
\text { "Universidad+Rovira+i+Virgili" } \\
\text { "Universidad+Complutense+de+Madrid" } \\
\text { "Universidad+de+Málaga" } \\
\text { "Universidad+de+Sevilla" } \\
\text { "Universidad+Internacional+de+La+Rioja" } \\
\text { "Universitat+de+Girona" } \\
\text { "Universidad+de+Gerona" } \\
\text { "Universidad+de+Extremadura" } \\
\text { "Universitat+de+València" } \\
\text { "Universidad+de+Valencia" } \\
\text { "Universidad+de+Zaragoza" } \\
\text { "Universidad+Carlos+III+de+Madrid" } \\
\text { "Universidad+de+Burgos" } \\
\text { "Universidad+Politécnica+de+Madrid" } \\
\text { "Universidad+de+Alcalá" } \\
\text { "Universidad+Rey+Juan+Carlos" } \\
\text { "Universidad+de+Granada" } \\
\text { "Universidad+de+Oviedo" } \\
\text { "Universidad+de+Cádiz" } \\
\text { "Universidad+de+Jaén" } \\
\text { "Universitat+Oberta+de+Catalunya" } \\
\text { "Univiversidad+Abierta+de+Cataluña" } \\
\text { "Universidad+Autónoma+de+Madrid" } \\
\text { "Unt+Pompeu+Fabra" }\end{array}$ \\
\hline $\begin{array}{l}\text { El Mundo } \\
\text { http://www.elmundo.e } \\
\underline{\mathbf{s}}\end{array}$ & $\begin{array}{l}\text { "Universidad+de+Córdoba" } \\
\text { "Universitat+Rovira+i+Virgili" } \\
\text { "Universidad+Rovira+i+Virgili" }\end{array}$ \\
\hline
\end{tabular}




\begin{tabular}{|c|c|}
\hline & $\begin{array}{l}\text { "Universidad+Complutense+de+Madrid" } \\
\text { "Universidad+de+Málaga" } \\
\text { "Universidad+de+Sevilla" } \\
\text { "Universidad+de+La+Rioja" } \\
\text { "Universitat+de+Girona" } \\
\text { "Universidad+de+Gerona" } \\
\text { "Universidad+de+Extremadura" } \\
\text { "Universitat+de+València" } \\
\text { "Universidad+de+Valencia" } \\
\text { "Universidad+de+Zaragoza" } \\
\text { "Universidad+Carlos+IIl+de+Madrid" } \\
\text { "Universidad+de+Burgos" } \\
\text { "Universidad+Politécnica+de+Madrid" } \\
\text { "Universidad+de+Alcalá" } \\
\text { "Universidad+Rey+Juan+Carlos" } \\
\text { "Universidad+de+Granada" } \\
\text { "Universidad+de+Oviedo" } \\
\text { "Universidad+de+Cádiz" } \\
\text { "Universidad+de+Jaén" } \\
\text { "Universitat+Oberta+de+Catalunya" } \\
\text { "Universidad+Abierta+de+Cataluña" } \\
\text { "Universitat+de+Barcelona" } \\
\text { "Universidad+de+Barcelona" } \\
\text { "Universidad+Autónoma+de+Madrid" } \\
\text { "Unidad+Pompeu+Fabra" }\end{array}$ \\
\hline $\begin{array}{l}\text { Diario Córdoba } \\
\text { www.diariocordoba.c } \\
\text { om }\end{array}$ & "Universidad+de+Córdoba" \\
\hline $\begin{array}{l}\overline{\text { Diario Sur }} \\
\text { www.diariosur.es/ }\end{array}$ & "Universidad+de+Málaga" \\
\hline $\begin{array}{l}\mathrm{ABC} \text { de Sevilla } \\
\text { sevilla.abc.es/ }\end{array}$ & "Universidad+de+Sevilla" \\
\hline $\begin{array}{l}\text { Diario La Rioja } \\
\text { http://www.larioja.com } \\
\end{array}$ & "Universidad+de+La+Rioja" \\
\hline $\begin{array}{l}\text { La Vanguardia } \\
\text { www.lavanguardia.co } \\
\underline{\mathrm{m} /}\end{array}$ & $\begin{array}{l}\text { "Universitat+Oberta+de+Catalunya" } \\
\text { "Universidad+Abierta+de+Cataluña" } \\
\text { "Universitat+de+Girona" } \\
\text { "Universidad+de+Gerona" }\end{array}$ \\
\hline
\end{tabular}




\begin{tabular}{|c|c|}
\hline & $\begin{array}{l}\text { "Universitat+Rovira+i+Virgili" } \\
\text { "Universidad+Rovira+i+Virgili" }\end{array}$ \\
\hline $\begin{array}{l}\text { Hoy } \\
\text { www.hoy.es/ }\end{array}$ & "Universidad+de+Extremadura" \\
\hline $\begin{array}{l}\text { Las Provincias } \\
\text { http://www.lasprovinci } \\
\text { as.es// }\end{array}$ & $\begin{array}{l}\text { "Universitat+de+València" } \\
\text { "Universidad+de+Valencia" }\end{array}$ \\
\hline $\begin{array}{l}\text { El Periódico de } \\
\text { Aragón } \\
\text { http://www.elperiodico } \\
\text { dearagon.com/ }\end{array}$ & "Universidad+de+Zaragoza" \\
\hline $\begin{array}{l}\text { El Correo de Burgos } \\
\text { www.elcorreodeburgo } \\
\text { s.com/ }\end{array}$ & "Universidad+de+Burgos" \\
\hline $\begin{array}{l}\mathrm{ABC}^{36} \\
\text { www.abc.es }\end{array}$ & $\begin{array}{l}\text { "Universidad+de+Alcalá" } \\
\text { "Universidad+Rey+Juan+Carlos" } \\
\text { "Universidad+Politécnica+de+Madrid" }\end{array}$ \\
\hline $\begin{array}{l}\text { El Comercio } \\
\text { www.elcomercio.es/ }\end{array}$ & "Universidad+de+Oviedo" \\
\hline $\begin{array}{l}\text { El Ideal } \\
\text { www.ideal.es/ }\end{array}$ & "Universidad+de+Granada" \\
\hline $\begin{array}{l}\text { La Voz de Cádiz } \\
\text { http://www.lavozdigita } \\
\text { l.es/ }\end{array}$ & "Universidad+de+Cádiz" \\
\hline $\begin{array}{l}\text { Diario Jaén } \\
\text { www.diariojaen.es/ }\end{array}$ & "Universidad+de+Jaén" \\
\hline
\end{tabular}

${ }^{36}$ Se tiene en cuenta el segundo periódico más leído en Madrid, al estar el primero, El País, en el análisis general de alcance nacional. El periódico $A B C$ y $A B C$ de Sevilla se cuenta como un solo medio en el análisis, ya que se web matriz es la misma. 


\section{ANEXO V}

\section{LIBRO DE CÓDIGOS ANÁLISIS DE LA INVESTIGACIÓN SOBRE COMUNICACIÓN DE LA CIENCIA EN INTERNET}

0. Número identificador de la unidad de análisis -ID- (número asignado al artículo de investigación analizado)

\section{Datos generales.}

1.1. Fecha de la pieza. Insertar en formato DD/MM/AAA

1.2. Enlace a la pieza. Insertar URL en formato: http://xxxx.xx

1.3. Periódico.

1.4. Universidad. Marcar con una $x$ la casilla de la/s universidad/es nombrada/s

\subsection{Alcance.}

\section{Tratamiento periodístico.}

2.1. Sección. Codificar la sección principal, en el caso de que haya subsecciones. Codificar 'otras' cuando la sección no se ajuste a las categorías establecidas.

2.2. Autor. Codificar 'periodista' cuando el autor de la información se pueda identificar claramente, con nombre y apellido/s. Cuando el autor no sea identificable o se especifique 'redacción', se codifica 'redacción'.

2.3. Género. Se codifica como 'breve' las piezas periodísticas de 1 o 2 párrafos, 'noticia' entre 2 y 6 párrafos y 'reportaje' más de 6 párafos. Para codificar 'artículo de opinión' este debe identificarse como tal en la caja de la pieza periodística o en la sección 'Opinión'.

2.4. Fuentes. Cuando se especifica una sola fuente, codificar la naturaleza de la misma. Cuando haya más de una fuente, codificar como 'varias'. Los artículos de opinión se codifican como 'no procede'.

\section{Marco mediático.}

3.1. Tipo de encuadre. Codifica 'investigación' cuando el artículo aborde un estudio o proyecto científico, así como investigaciones recogidas en papers; 'evento' cuando se trate de congresos, reuniones y otros eventos netamente científicos; 'mención' cuando se mencione a una universidad, de pasada, en una información científica más amplia; 'valoraciones' cuando la participación de la universidad en la información se centre en las declaraciones expertas de un miembro de la institución.

3.2. Trabajos en colaboración. Solo codifica cuando en la variable 3.1. se responda 'investigación'. Si no se menciona ninguna colaboración se codifica 'única'; para colaboraciones de instituciones que se encuentren en 
el mismo entorno local o regional se marca 'regional'. Cuando la colaboración sea con centros de países ajenos a la Unión Europea se codifica 'internacional'.

\section{Cobertura temática.}

4.1. Temática predominante. Si hay dudas sobre la temática del texto o se puede estimar más de una temática se tiene en cuenta solo la que se considere predominante en cada caso, según las áreas establecidas por la ANEP.

\section{Tratamiento ciberperiodístico}

5.1. Multimedialidad. Se codifica 'galería' si se observan más de dos fotografías en formato galería. Cuando haya más de dos tipos de recursos multimedia de los estimados codifica 'varios'.

5.2. Hiptertextualidad. Codifica 'multimedia' cuando el enlace lleve a recursos multimedia (galerías de imágenes, vídeo, audio). Cuando haya enlaces tanto dentro como fuera del cibermedio se marca 'varios'.

5.3. Actualización. Se tiene en cuenta si la actualización se hace de mañana, antes de las 12 h,; por la tarde, entre las 12 y las 19 h; o por la noche, desde las 19 horas.

5.4. Interactividad. Número total de comentarios. 


\section{ANEXO VI}

\section{FICHA DE ANÁLISIS}

\begin{tabular}{|c|c|c|}
\hline \multicolumn{2}{|c|}{ Variable } & \multirow{2}{*}{$\begin{array}{l}\text { Tipo de respuesta } \\
1,2,3 \ldots\end{array}$} \\
\hline 0 & $\begin{array}{l}\text { Número identificador de la } \\
\text { unidad de análisis (ID) }\end{array}$ & \\
\hline \multicolumn{3}{|c|}{ 1. Datos generales } \\
\hline 1.1. & Fecha de la pieza & $D D / M M / A A A A$ \\
\hline 1.2. & Enlace a la pieza & $U R L$ \\
\hline 1.3 & Periódico & $\begin{array}{l}\text { El Mundo = mundo } \\
\text { El País = país } \\
\text { Diario Córdoba = córdoba } \\
\text { Diario Sur = sur } \\
\text { ABC de Sevilla = abc } \\
\text { Diario La Rioja = rioja } \\
\text { Hoy = hoy } \\
\text { Las provincias = provincias } \\
\text { El Periódico de Aragón = aragón } \\
\text { El Correo de Burgos = burgos } \\
\text { ABC = abc } \\
\text { El Comercio = comercio } \\
\text { El ldeal = ideal } \\
\text { La Voz = voz } \\
\text { Diario Jaén = jaén } \\
\text { La Vanguardia = vanguardia }\end{array}$ \\
\hline 1.4. & Universidad & $\begin{array}{l}\text { Marcar con " } X \text { " la/s universidad/es nombradas } \\
\text { en la pieza periodística }\end{array}$ \\
\hline 1.5. & Alcance & $\begin{array}{l}\text { Nacional }=\text { nacional } \\
\text { Local o regional }=\text { local }\end{array}$ \\
\hline \multicolumn{3}{|c|}{ 2. Tratamiento periodístico } \\
\hline 2.1 & Sección & $\begin{array}{l}\text { Ciencia = ciencia } \\
\text { Salud = salud } \\
\text { Tecnología = tecnología } \\
\text { Sociedad = sociedad } \\
\text { Cultura = cultura } \\
\text { Nacional = nacional } \\
\text { Internacional = internacional } \\
\text { Autonómica y/o local = local } \\
\text { Política = política } \\
\text { Economía = economía } \\
\text { Opinión = opinión } \\
\text { Otras = otras }\end{array}$ \\
\hline 2.2. & Autor & $\begin{array}{l}\text { Periodista = periodista } \\
\text { Agencia = agencia } \\
\text { Columnista = columnista }\end{array}$ \\
\hline
\end{tabular}




\begin{tabular}{|c|c|c|}
\hline & & $\begin{array}{l}\text { No indentificado = redacción } \\
\text { Otros = otros }\end{array}$ \\
\hline 2.3. & Género & $\begin{array}{l}\text { Breve }=\text { breve } \\
\text { Noticia }=\text { noticia } \\
\text { Reportaje }=\text { reportaje } \\
\text { Entrevista }=\text { entrevista } \\
\text { Artículo de opinión = opinión } \\
\text { No indentificado/Otros= otros }\end{array}$ \\
\hline 2.4 & Fuentes & $\begin{array}{l}\text { Revista científica = revista } \\
\text { Investigador/experto = experto } \\
\text { Universidad/centro de investigación = centro } \\
\text { Empresa = empresa } \\
\text { Gubernamental = gubernamental } \\
\text { Sociedad civil/Entidades no lucrativas/ONGs } \\
=\text { civil } \\
\text { Varias = varias } \\
\text { Desconocidas/no citadas = desconocidas } \\
\text { No procede = no procede }\end{array}$ \\
\hline \multicolumn{3}{|c|}{ 3. Marco mediático } \\
\hline 3.1. & Tipo de encuadre & $\begin{array}{l}\text { Un estudio/proyecto científico desarrollado en } \\
\text { la institución es el protagonista de la pieza= } \\
\text { investigación } \\
\text { Se hace referencia a alguna actividad/evento } \\
\text { desarrollado en la institución = evento } \\
\text { La institución no es la protagonista de la } \\
\text { pieza, solo se menciona de pasada = } \\
\text { mención } \\
\text { Expertos de la institución realizan } \\
\text { valoraciones sobre algún asunto = } \\
\text { valoraciones } \\
\text { Artículo de opinión elaborado por expertos de } \\
\text { la institución = opinión } \\
\text { Otros = otros }\end{array}$ \\
\hline 3.2. & Trabajos en colaboración & $\begin{array}{l}\text { Única entidad = única } \\
\text { Colaboración regional = regional } \\
\text { Colaboración nacional = nacional } \\
\text { Colaboración europea }=\text { europa } \\
\text { Colaboración internacional = internacional }\end{array}$ \\
\hline \multicolumn{3}{|c|}{ 4. Cobertura temática } \\
\hline 4.1. & Temática predominante ${ }^{37}$ & $\begin{array}{l}\text { Área Ciencias de la Tierra = CT } \\
\text { Área Física y Ciencias del Espacio = FI } \\
\text { Área Matemáticas = MTM } \\
\text { Área Química = QMC } \\
\text { Área Biología Fundamental y de Sistemas = } \\
\text { BFS } \\
\text { Área de Biomedicina = BMED } \\
\text { Área Biología Vegetal y Animal, Ecología = } \\
\text { BVAE } \\
\text { Área de Medicina Clínica y Epidemiología = } \\
\text { MCLI }\end{array}$ \\
\hline
\end{tabular}

${ }^{37}$ Según las áreas de la ANEP: http://ow.ly/ouii30kuuss (última consulta 03/03/2018) 


\begin{tabular}{|c|c|c|}
\hline & & $\begin{array}{l}\text { Área Agricultura = AGR } \\
\text { Área Ciencia y Tecnología de Alimentos = TA } \\
\text { Área Ganadería y pesca = GAN } \\
\text { Área de ciencia y tecnología de materiales = } \\
\text { TM } \\
\text { Área Ciencias de la Computación y } \\
\text { Tecnología Informática = INF } \\
\text { Área Ingeniería Civil y Arquitectura = ICI } \\
\text { Área Ingeniería Eléctrica, Electrónica y } \\
\text { Automática = IEL } \\
\text { Área Ingeniería Mecánica, Naval y } \\
\text { Aeronáutica = IME } \\
\text { Área Tecnología Química = TQ } \\
\text { Área Tecnología electrónica y de las } \\
\text { comunicaciones = COM } \\
\text { Área Ciencias de la Educación = EDUC } \\
\text { Área Ciencias Sociales = CS } \\
\text { Área Derecho = DER } \\
\text { Área Economía = ECO } \\
\text { Área Filología y Filosofía = FFI } \\
\text { Área Historia y Arte = HA } \\
\text { Área Psicología = PS } \\
\text { Área de Transferencia de Tecnología = IND } \\
\text { Varias = varias } \\
\text { Desconocidas = desconocidas }\end{array}$ \\
\hline \multicolumn{3}{|c|}{ 5. Tratamiento ciberperiodístico } \\
\hline 5.1. & Multimedialidad & $\begin{array}{l}\text { Fotografía = fotografía } \\
\text { Galerías de imágenes (más de dos } \\
\text { fotografías) = galería } \\
\text { Infografía = infografía } \\
\text { Vídeo = vídeo } \\
\text { Audio = audio } \\
\text { Varios = varios } \\
\text { Ninguno = ninguno }\end{array}$ \\
\hline 5.2. & Hipertextualidad & $\begin{array}{l}\text { Micronavegación = dentro } \\
\text { Macronavegación = fuera } \\
\text { A multimedia = multimedia } \\
\text { Varios = varios } \\
\text { Ninguno = ninguno }\end{array}$ \\
\hline 5.2. & Actualización & $\begin{array}{l}\text { Antes de las } 12 \mathrm{~h}=\text { mañana } \\
\text { Entre las } 12 \text { y las } 19 \mathrm{~h}=\text { tarde } \\
\text { Desde las } 19 \mathrm{~h}=\text { noche } \\
\text { Desconocida = desconocida }\end{array}$ \\
\hline 5.3. & Interactividad & № comentarios $(n)$ \\
\hline
\end{tabular}

